UNIVERSIDADE DE SÃO PAULO

ESCOLA DE ENGENHARIA DE SÃO CARLOS

DEPARTAMENTO DE TRANSPORTES

\title{
UMA AVALIAÇÃO COMPARATIVA DE ALGUNS SISTEMAS DE INFORMAÇÃO GEOGRÁFICA APLICADOS AOS TRANSPORTES
}

\author{
Eng $^{\mathrm{a}}$ ADRIANA ROSE \\ Orientador: Prof. Associado Antônio Nélson Rodrigues da Silva
}

Dissertação apresentada à Escola de Engenharia de São Carlos da Universidade de São Paulo, como parte dos requisitos para a obtenção do título de Mestre em Engenharia Civil - Área de Concentração: Transportes.

SÃO CARLOS 
Ficha catalográfica preparada pela Seção de Tratamento da Informaçăo do Serviço de Biblioteca - EESC/USP

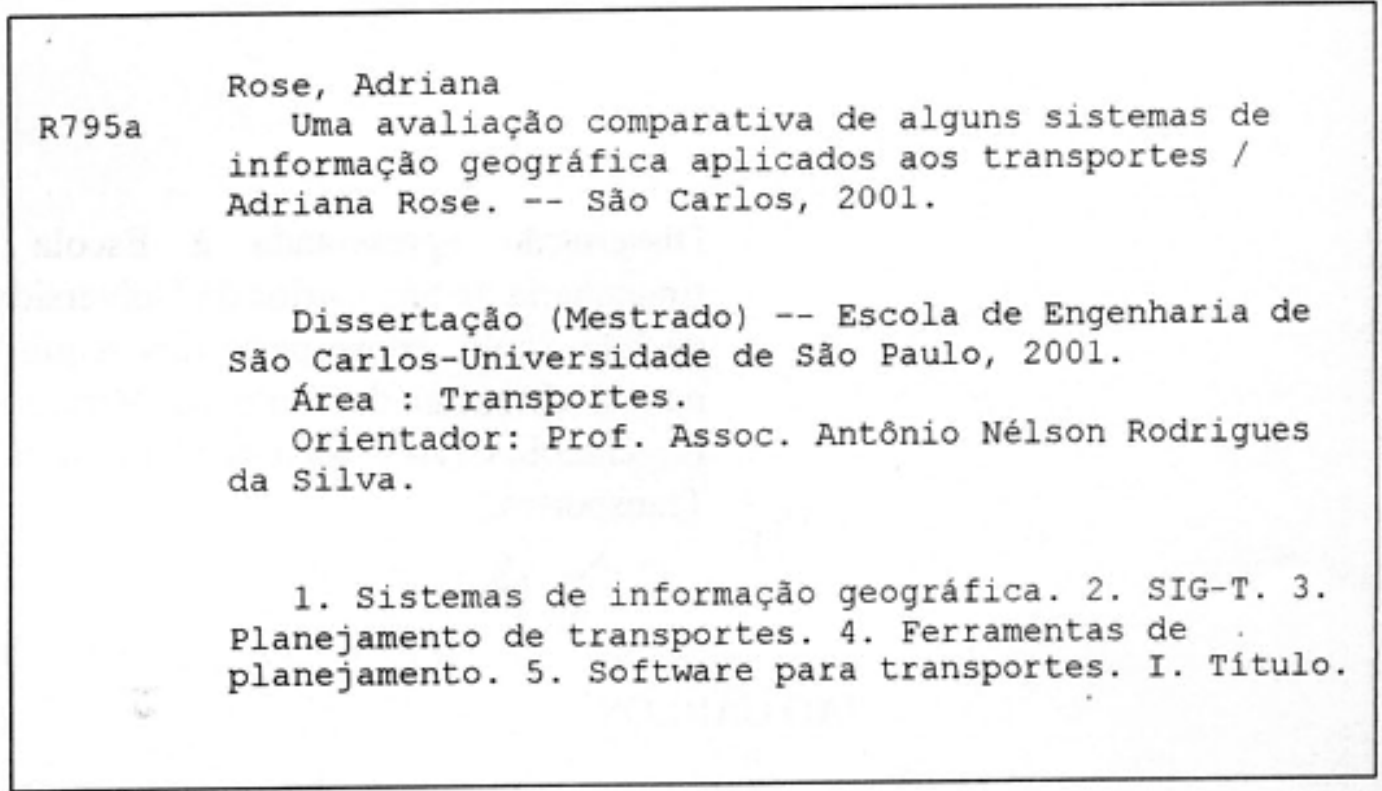


Dedicatória

À mamãe Ruth e papai Altevir, a quem devo tudo que sou $\mathrm{e}$ conquistei na vida. 


\section{Agradecimentos}

- Ao meu orientador e, principalmente, amigo Antônio Nélson Rodrigues da Silva, pela paciência, dedicação e confiança em mim depositada.

- Ao meu marido Ricardo, pelo constante incentivo, paciência, compreensão e por abraçar todas as minhas causas como se fossem suas.

- À minha filha Ana Vitória, por sua existência.

- Ao meu irmão Rodrigo e à vovó Jacy, por abdicarem de seus lares e dedicarem boa parte de seu tempo em minha companhia; à minha irmã Fernanda pelas horas ao telefone e pelas palavras de consolo e incentivo.

- À Tia Regina, pelo tempo dedicado e carinho nos cuidados à pequena Ana Vitória.

- Às amigas Cíntia e Ana Paula, por terem me acolhido na temporada em que passei longe de casa.

- Aos amigos, Ricardo (americano), Waléria, Andréa, Marcelo, Michelle, Delfin, Cláudia, Carim, Cíntia, Elaine, Roberto, Guaraci, Mônica, mestre Armando, Selma, Márcio, Cibele, que sempre tiveram uma frase de incentivo para dizer.

- Aos amigos, e que por acaso também são meus chefes ou melhor, colegas de trabalho, Jaqueline e Waldir, pelo incentivo, compreensão dos meus momentos de ausência e pelos ensinamentos que me tornaram uma profissional mais competente.

- Ao amigo Djalma, que sempre me apoiou e ajudou pessoal e profissionalmente.

- Aos amigos e professores Joel Kruger e Ricardo Bertin, que me impulsionaram a galgar esta etapa da vida.

- Às pessoas que, embora eu não conheça, estavam sempre dispostas a ajudar, Robert S. Tung, Marcelo Rosado, Massa Goto, Daniel Souto Rodrigues.

- Aos funcionários do Departamento de Transportes da EESC-USP, sempre prontos para resolver nossos problemas burocráticos.

- À CAPES, pelo apoio financeiro sem o qual esse trabalho não teria sido desenvolvido.

- A todos aqueles que colaboraram direta e indiretamente para a conclusão deste trabalho e não foram mencionados.

- À Deus, por todas as minhas conquistas e por me dar forças para continuar lutando. 


\section{Sumário}

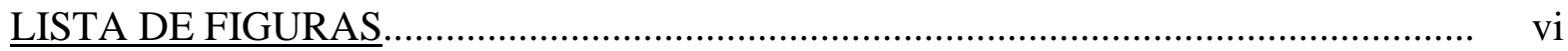

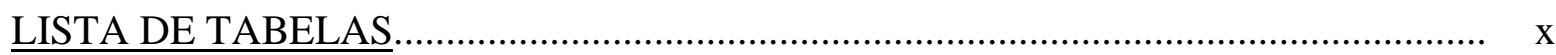

RESUMO

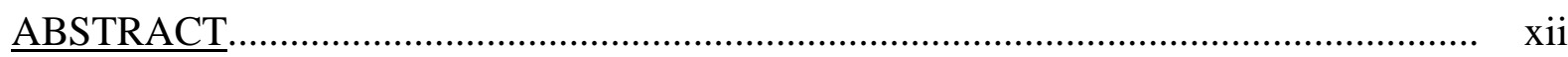

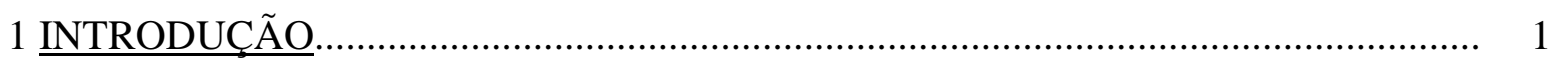

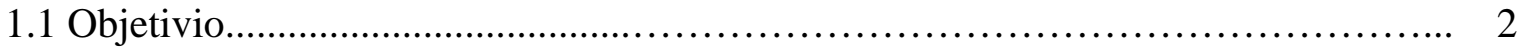

1.2 Estrutura do Texto...................................................................... 2

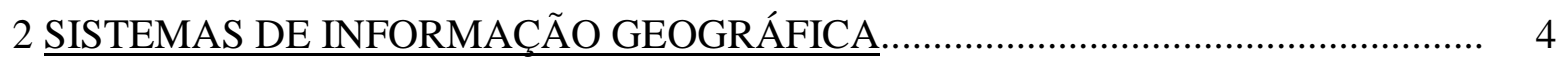

2.1 Histórico................................................................................ 4

2.2 Definição e Conceitos Básicos................................................. 4

2.3 Aplicações e Vantagens do Uso dos SIGs.......................................... 6

2.4 Programas Estudados................................................................... 8

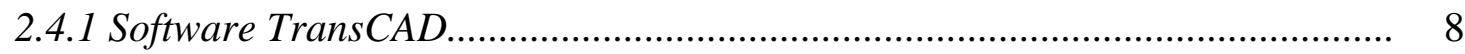

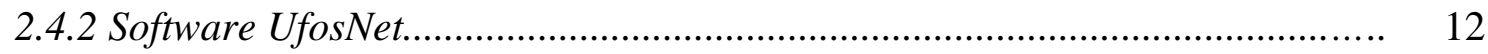

2.4.3 Software ArcView.................................................................................. 15

2.5 Considerações Finais.......................................................................... 17

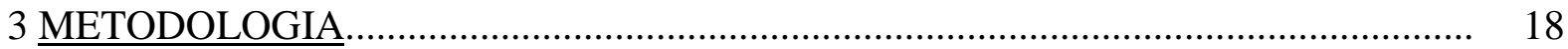

3.1 Parâmetros de Comparação....................................................... 19 
3.1.1 Características Funcionais Básicas de SIG

3.1.2 Características Operacionais Básicas de SIG ................................................ 20

3.1.3 Rotinas Avançadas de SIG....................................................................... 22

3.1.4 Rotinas Específicas de Transportes......................................................... 23

3.2 Uma Avaliação Específicas de um Problema de Transportes.................................. 23

3.3 Atividades Desenvolvidas.................................................... 24

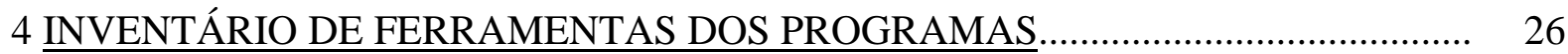

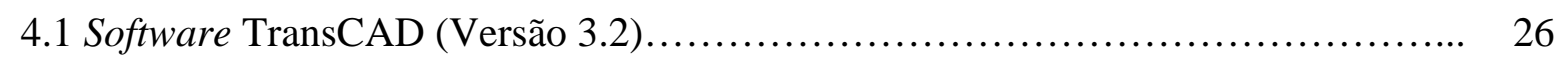

4.1.1 Comandos Básicos e Rotinas Avançadas de SIG......................................... 26

4.1.2 Rotinas Específicas de Transportes............................................................. 49

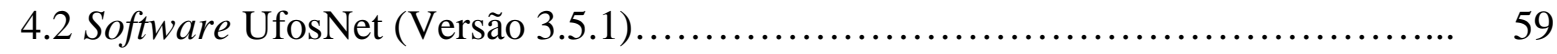

4.2.1 Comandos Básicos e Rotinas Avançadas de SIG............................................ $\quad 59$

4.2.2 Rotinas Específicas de Transportes.......................................................... 87

4.3 Software ArcView (Versão 3.1) ....................................... 93

4.3.1 Comandos Básicos e Rotinas Avançadas de SIG.......................................... 93

4.3.2 Spatial Analyst e Network Analyst.............................................................. 110

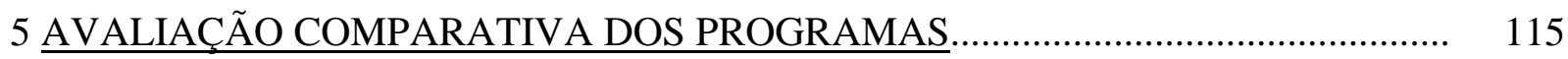

5.1 Características Básicas de SIG........................................... 115

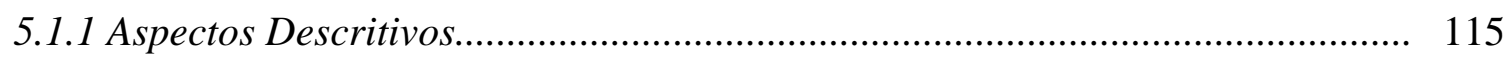

5.1.2 Características Operacionais................................................................ 117

5.2 Rotinas Avançadas de SIG...................................................... 119

5.3 Rotinas Específicas de Transportes...................................................................... 121

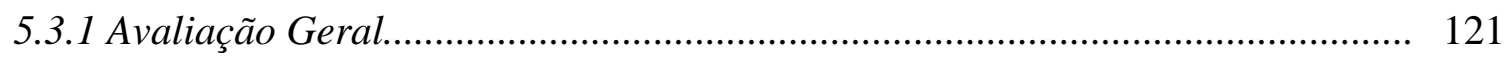

5.3.2 Avaliação de Recursos Básicos de Transportes............................................. 121 
5.3.2.1 Considerações Gerais.

5.3.2.2 Cálculo da Medida de Acessibilidade no Software TransCAD. 122

5.3.2.3 Cálculo da Medida de Acessibilidade no Software UfosNet. 123

5.3.2.3 Cálculo da Medida de Acessibilidade no Software ArcView. 125

5.4 Síntese da Comparação das Características dos Programas. 127

6 CONCLUSÃO 134

7 REFERÊNCIAS BIBLIOGRÁFICAS 136 


\section{Lista de Figuras}

Figura 4.1 - Opção File do menu principal do TransCAD .............................................. 26

Figura 4.2 - Opção Edit do menu principal do TransCAD ................................................ 28

Figura 4.3 - Opção Map do menu principal do TransCAD............................................. 29

Figura 4.4 - Opção Dataview do menu principal do TransCAD..................................... 31

Figura 4.5 - Opção Matrix do menu principal do TransCAD.......................................... 32

Figura 4.6 - Opção Layout do menu principal do TransCAD......................................... 35

Figura 4.7 - Opção Tools do menu principal do TransCAD............................................ 35

Figura 4.8 - Caixa de ferramentas do TransCAD....................................................... 36

Figura 4.9 - Caixa de diálogos ativada pela opção SELECTION....................................... 37

Figura 4.10 - Edição de pontos do mapa....................................................................... 37

Figura 4.11 - Edição de áreas do mapa....................................................................... 37

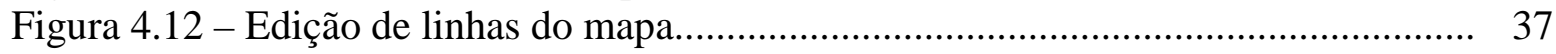

Figura 4.13 - Caixa de diálogos ativada pela opção IMAGERY ........................................ 38

Figura 4.14 - Caixa de ferramentas TINs Toolbox.......................................................... 39

Figura 4.15 - Opção Procedures do menu principal do TransCAD................................. 42

Figura 4.16 - Opção Networks/Paths do menu principal do TransCAD.......................... 42

Figura 4.17 - Caixa de ferramentas Turn Penalty Editor.................................................. 43

Figura 4.18 - Caixa de ferramentas Shortest Path Toolbox ........................................... 44

Figura 4.19 - Opção Statistics do menu principal do TransCAD..................................... 45

Figura 4.20 - Opção Window do menu principal do TransCAD ........................................ 46

Figura 4.21 - Ícones disponíveis na barra de menu do TransCAD quando a janela de mapa está ativa e uma camada de pontos selecionada.............................. 47

Figura 4.22 - Ícones disponíveis na barra de menu do TransCAD quando a janela de mapa está ativa e uma camada de linhas selecionada............................... 47

Figura 4.23 - Ícones disponíveis na barra de menu do TransCAD quando a janela de mapa está ativa e uma camada de áreas selecionada................................ 47

Figura 4.24 - Ícones disponíveis na barra de menu do TransCAD quando a janela de banco de dados de uma camada de pontos está ativa............................... 48

Figura 4.25 - Ícones disponíveis na barra de menu do TransCAD quando a janela de banco de dados de uma camada de linhas está ativa.................................. 48

Figura 4.26 - Ícones disponíveis na barra de menu do TransCAD quando a janela de banco de dados de uma camada de áreas está ativa.................................. 48

Figura 4.27 - Ícones disponíveis na barra de menu do TransCAD quando a janela de uma matriz está ativa. 
Figura 4.28 - Ícones disponíveis na barra de menu do TransCAD quando a janela de um leiaute está ativa.

Figura 4.29 - Opção Route Systems do menu principal do TransCAD.

Figura 4.30 - Opção EDITING TOOLBOX do menu Route Systems do menu principal do TransCAD.

Figura 4.31 - Opção RouTE QUERY TOOLBOX

Figura 4.32 - Opção TRIP PRODUCTIONS do menu Planning menu principal do TransCAD.

Figura 4.33 - Opções TRIP ATtRactions, BALANCE e Quick RESPONSE METHOD do menu Planning do menu principal do TransCAD.

Figura 4.34 - Opção TRIP DISTRIBUTION do menu Planning do menu principal do TransCAD.

Figura 4.35 - Opção Mode SPLIT do menu Planning do menu principal do TransCAD... 53

Figura 4.36 - Opção ADVANCED ASSignMENT do menu Planning do menu principal do TransCAD.

Figura 4.37 - Opção PLANNING UTILITIES do menu Planning do menu principal do TransCAD.

Figura 4.38 - Opção CENSUS UTILITIES do menu Planning do menu principal do TransCAD.

Figura 4.39 - Opção UTILITIES do menu Planning do menu principal do TransCAD....... 56

Figura 4.40 - Menu Transit do menu principal do TransCAD ......................................... 57

Figura 4.41 - Opções Cost MATRIX e Vehicle Routing do menu Routing/Logistics do menu principal do TransCAD.

Figura 4.42 - Opção ARC/STREet Routing do menu Routing/Logistics do menu principal do TransCAD.

Figura 4.43 - Opção File do menu principal do UfosNet.

Figura 4.44 - Opção LOAD do menu File do menu principal do UfosNet....

Figura 4.45 - Opção SAVE do menu File do menu principal do UfosNet.

Figura 4.46 - Opção Edit do menu principal do UfosNet.

Figura 4.47 - Caixa de ferramentas Network.

Figura 4.48 - Caixa de ferramentas Boundary.... 63

Figura 4.49 - Caixa de ferramentas Annotation. 64

Figura 4.50 - Opção DATA SHEET do menu Edit do menu principal do UfosNet............... 65

Figura 4.51 - Opção Plot do menu principal do UfosNet.................................................. 66

Figura 4.52 - Opção All OBJECTS do menu Plot do menu principal do UfosNet............. 66

Figura 4.53 - Opção QUERY OBJECTS do menu Plot do menu principal do UfosNet......... 68

Figura 4.54 - Opção Define Default Style do menu Plot do menu principal do UfosNet..

Figura 4.55 - Opção CleAR PlOT BUfFER do menu Plot do menu principal do UfosNet.. 70

Figura 4.56 - Opção View do menu principal do UfosNet................................................ 70

Figura 4.57 - Opção Matrix do menu principal do UfosNet............................................. 71

Figura 4.58 - Opção Calc do menu principal do UfosNet................................................. 75

Figura 4.59 - Opção REGRESSION do menu Calc do menu principal do UfosNet.............. 75

Figura 4.60 - Opção Histogram do menu Calc do menu principal do UfosNet............... 76

Figura 4.61 - Opção Tools do menu principal do UfosNet.............................................. 77

Figura 4.62 - Opção BUFFER REGION do menu Tools do menu principal do UfosNet....... 79

Figura 4.63 - Opção Porting do menu principal do UfosNet............................................ 80

Figura 4.64 - Opção OTHER Models do menu Porting do menu principal do UfosNet.... 80 
Figura 4.65 - Opção TIGER/Line FILE do menu Porting do menu principal do UfosNet. 81 Figura 4.66 - Opção IMPORT DBF do menu Porting do menu principal do UfosNet......... 81 Figura 4.67 - Opção Export DBF do menu Porting do menu principal do UfosNet.......... 82 Figura 4.68 - Opção EXPORT ASCII TEXT do menu Porting do menu principal do UfosNet......

Figura 4.69 - Opção Export Image do menu Porting do menu principal do UfosNet....... 83

Figura 4.70 - Opção ARCVIEW do menu Porting do menu principal do UfosNet.............. 83

Figura 4.71 - Opção OTHER GIS do menu Porting do menu principal do UfosNet.......... 84

Figura 4.72 - Opção Report do menu principal do UfosNet......................................... 84

Figura 4.73 - Opção Options do menu principal do UfosNet........................................... 85

Figura 4.74 - Opção Window do menu principal do UfosNet........................................... 85

Figura 4.75 - Ícones disponíveis na barra de menu do UfosNet..................................... 86

Figura 4.76 - Primeira linha de ícones disponíveis na barra de menu do UfosNet............ 86

Figura 4.77 - Segunda linha de ícones disponíveis na barra de menu do UfosNet............ 86

Figura 4.78 - Opção ToOlBOX - TRANSIT do menu Edit do menu principal do UfosNet.. 87

Figura 4.79 - Opção ToOlBoX - TRANSIT do menu Edit do menu principal do UfosNet.. 87

Figura 4.80 - Opção TRIP GENERATION do menu Models do menu principal do UfosNet. 88

Figura 4.81 - Opção TRIP DISTRIBUTION do menu Models do menu principal do UfosNet......

Figura 4.82 - Opção MODAL CHOICE do menu Models do menu principal do UfosNet.... 90

Figura 4.83 - Opção TRIP AssignMENT do menu Models do menu principal do UfosNet. 90

Figura 4.84 - Opção LOS ANALYSIS do menu Models do menu principal do UfosNet.... 91

Figura 4.85 - Opção TRANSIT PATH do menu Tools do menu principal do UfosNet........ 92

Figura 4.86 - Menu inicial e janela do projeto do ArcView............................................ 93

Figura 4.87 - Opção File do menu inicial do ArcView................................................... 93

Figura 4.88 - Opção Project do menu inicial do ArcView............................................. 94

Figura 4.89 - Opção Window do menu inicial do ArcView............................................ 95

Figura 4.90 - Menu de vistas do ArcView....................................................................... 95

Figura 4.91 - Opção File do menu de vistas do ArcView............................................... 95

Figura 4.92 - Opção Edit do menu de vistas do ArcView................................................. 96

Figura 4.93 - Ícones utilizados para inserir textos e desenhos ao mapa............................ 97

Figura 4.94 - Opção View do menu de vistas do ArcView............................................... 97

Figura 4.95 - Opção Theme do menu de vistas do ArcView............................................... 99

Figura 4.96 - Opção Graphics do menu de vistas do ArcView........................................ 101

Figura 4.97 - Menu de tabelas do ArcView................................................................. 101

Figura 4.98 - Opção File do menu de tabelas do ArcView........................................... 102

Figura 4.99 - Opção Edit do menu de tabelas do ArcView.............................................. 102

Figura 4.100 - Opção Table do menu de tabelas do ArcView.......................................... 103

Figura 4.101 - Opção Field do menu de tabelas do ArcView.......................................... 103

Figura 4.102 - Menu de gráficos do ArcView................................................................. 104

Figura 4.103 - Opção File do menu de gráficos do ArcView........................................... 104

Figura 4.104 - Opção Edit do menu de gráficos do ArcView............................................ 104

Figura 4.105 - Opção Gallery do menu de gráficos do ArcView...................................... 105

Figura 4.106 - Opção Chart do menu de gráficos do ArcView......................................... 105

Figura 4.107 - Menu de leiautes do ArcView................................................................. 105

Figura 4.108 - Opção File do menu de leiautes do ArcView.......................................... 106

Figura 4.109 - Opção Edit do menu de leiautes do ArcView........................................... 106

Figura 4.110 - Opção Layout do menu de leiautes do ArcView....................................... 106 
Figura 4.111 - Opção Graphics do menu de leiautes do ArcView................................... 107

Figura 4.112 - Ícones utilizados para inserir objetos à vista............................................ 107

Figura 4.113 - Ícones disponíveis na barra de menu da janela de vistas do ArcView........ 108

Figura 4.114 - Primeira linha de ícones disponíveis na barra de menu da janela de vistas do ArcView......................................................................................... 108

Figura 4.115 - Segunda linha de ícones disponíveis na barra de menu da janela de vistas do ArcView..................................................................................... 108

Figura 4.116 - Ícones disponíveis na barra de menu da janela de tabelas do ArcView...... 108

Figura 4.117 - Primeira linha de ícones disponíveis na barra de menu da janela de tabelas do ArcView.

Figura 4.118 - Segunda linha de ícones disponíveis na barra de menu da janela de tabelas do ArcView.

Figura 4.119 - Ícones disponíveis na barra de menu da janela de gráficos do ArcView... 109

Figura 4.120 - Primeira linha de ícones disponíveis na barra de menu da janela de gráficos do ArcView.

Figura 4.121 - Segunda linha de ícones disponíveis na barra de menu da janela de gráficos do ArcView...

Figura 4.122 - Ícones disponíveis na barra de menu da janela de leiautes do ArcView.... 109

Figura 4.123 - Primeira linha de ícones disponíveis na barra de menu da janela de leiautes do ArcView.

Figura 4.124 - Segunda linha de ícones disponíveis na barra de menu da janela de leiautes do ArcView.

Figura 4.125 - Menu inicial de vistas do ArcView com os módulos adicionais Spatial Analyst e Network Analyst......

Figura 4.126 - Opção Analysis, pertencente ao módulo Spatial Analyst, do menu de vistas do ArcView

Figura 4.127 - Opção Surface, pertencente ao módulo Spatial Analyst, do menu de vistas do ArcView

Figura 4.128 - Opção Network, pertencente ao módulo Network Analyst, do menu de vistas do ArcView

Figura 4.129 - Opção File do menu inicial de vistas do ArcView com os módulos adicionais Spatial Analyst e Network Analyst.

Figura 4.130 - Ícones adicionais disponíveis na barra de menu da janela de vistas do ArcView com os módulos Spatial Analyst e Network Analyst......

Figura 5.1 - Mapa Temático de Acessibilidade no TransCAD.

Figura 5.2 - Mapa Temático de Acessibilidade no UfosNet.

Figura 5.3 - Mapa Temático de Acessibilidade no ArcView 


\section{Lista de Tabelas}

Tabela 5.1 - Características Operacionais Básicas de SIG quanto à modelagem dos dados

Tabela 5.2 - Características Operacionais Básicas de SIG quanto à linguagem de consulta.

Tabela 5.3 - Características Operacionais Básicas de SIG quanto à geração de relatórios, importação e exportação de arquivos

Tabela 5.4 - Características Operacionais Básicas de SIG quanto à entrada de dados 118

Tabela 5.5 - Características Operacionais Básicas de SIG quanto à edição de dados 118

Tabela 5.6 - Rotinas Avançadas de SIG.

Tabela 5.7 - Rotinas Específicas de Transportes - Avaliação Geral

Tabela 5.8 - Avaliação quantitativa das características operacionais básicas de SIG disponíveis e não disponíveis nos programas avaliados.

Tabela 5.9 - Avaliação quantitativa das rotinas avançadas de SIG e específicas de transportes disponíveis e não disponíveis nos programas avaliados

Tabela 5.10 - Avaliação de dificuldades e facilidades na solução de um problema proposto.

Tabela 5.11 - Alterações conceituais importantes introduzidas na versão mais recente do software ArcView. 


\section{Resumo}

O sucesso de um projeto depende, em grande parte, da escolha e uso de ferramentas adequadas para o seu desenvolvimento. Como no caso de qualquer outra ferramenta, é de suma importância o conhecimento das características, funções e do desempenho dos programas de computador que se pretende empregar na solução de problemas de qualquer natureza. Tendo por base esta constatação e voltando-se apenas para uma área específica, o objetivo deste trabalho de pesquisa é comparar três software de SIG (Sistemas de Informação Geográfica) aplicados ao planejamento de transportes quanto às suas características funcionais e desempenho. Os software UfosNet, TransCAD e ArcView foram comparados quanto a alguns aspectos descritivos, tais como: tempo de aprendizado e possibilidades de customização, entre outros; características operacionais básicas de SIG; rotinas avançadas de SIG e rotinas específicas de transportes. Para uma análise mais efetiva do potencial dos mesmos como ferramentas de planejamento de transportes foi proposta a solução de um problema envolvendo o cálculo de uma medida de acessibilidade. Através dos resultados encontrados com as diversas avaliações realizadas foi possível concluir que os três sistemas atendem perfeitamente à configuração mínima desejada para um software SIG, mas que apenas o TransCAD e o UfosNet enquadram-se de fato na categoria de SIG-T, uma vez que o ArcView praticamente não fornecia as principais ferramentas necessárias à solução de problemas de transportes específicos. Embora os resultados deste trabalho possam ajudar diretamente aos usuários na escolha do software mais adequado à aplicações específicas na área de transportes, a sua maior contribuição está na metodologia de avaliação em si. Isto se deve à evolução extremamente rápida dos programas de computador, que torna qualquer resultado de uma análise comparativa efêmero e não conclusivo. Neste sentido, a metodologia de avaliação pode ser útil tanto para grandes empresas que desejam aplicar soluções de geoprocessamento, como para usuários individuais ou autônomos, pois em ambos os casos pode contribuir para um máximo aproveitamento do SIG como uma ferramenta auxiliar na solução de problemas de transportes. 
The success degree of any project is largely determined by the use of adequate tools to its development. Like any other tool, it is of utmost importance the knowledge of characteristics, functions and performance of the computer program one intends to use to solve any particular problem. Bearing it in mind and turning towards an specific area, the objective of this research work is to compare three GIS (Geographic Information Systems) software applied to transportation planning, concerning its functional and performance characteristics. The computer packages UfosNet, TransCAD, and ArcView were compared regarding some descriptive aspects, such as: learning time and customization possibilities, among others; basic GIS operating characteristics, advanced GIS routines and transportation routines. In order to conduct a more effective analysis of their potential as a transportation planning tool they were all applied for finding a solution of a problem involving the calculation of an accessibility measure. The results found suggest that all three systems comply with the minimum configuration desired for a GIS software. However, only TransCAD and UfosNet fit in the GIS-T category, since ArcView did not supply the main necessary tools to solve the specific transportation problems proposed. Although the results of this work may directly help users in their choice of more adequate software, its biggest contribution lies in the evaluation methodology itself. It is so due to the extremely fast evolution of computer programs that makes any result of a comparative analysis ephemeral and non-conclusive. In this sense, the evaluation methodology might be useful to big companies seeking GIS solutions as well as to individual users, since in both cases it can contribute to the maximum use of GIS as a supporting tool for solving transportation problems. 


\section{Introdução}

O crescimento populacional e conseqüente aumento da demanda por transportes tem exigido, por parte de governantes e planejadores, decisões mais eficazes no aspecto operacional e, principalmente, financeiro. Isto sem deixar de atender aos anseios diretos dos usuários, que buscam aumentar a sua satisfação ao utilizar os serviços de transportes, exigindo níveis de qualidade cada vez maiores. Os objetivos, de certa forma conflitantes, de reduzir custos, por um lado, e de melhorar a qualidade do serviço prestado, por outro, exigem um nível crescente de capacitação dos técnicos em transportes e melhores ferramentas para auxiliar o processo de planejamento. Esta necessidade de se utilizar ferramentas que auxiliem os tomadores de decisão atuantes nas áreas de planejamento urbano e de transportes tem levado a uma procura cada vez maior pelos Sistemas de Informação Geográfica (SIG).

Embora ainda relativamente pouco utilizados, os software de Sistemas de Informação Geográfica aplicados aos transportes (SIG-T) estão no mercado em larga escala, disponíveis com vários tipos de configurações e funcionalidades. Devido a essa variedade, há a necessidade de um maior conhecimento por parte do usuário no momento da aquisição do programa. Normalmente ocorre que, em função do desconhecimento das reais potencialidades dos programas, leigos e até mesmo profissionais adquirem produtos que nem sempre satisfazem integralmente às suas necessidades.

Como uma forma de enfrentar este problema propõs-se o desenvolvimento deste trabalho de pesquisa, através do qual são avaliados, com relação à sua capacidade e desempenho, três software que se apresentam no mercado como SIG-T: UfosNet, TransCAD e ArcView. A escolha desses três programas foi baseada no fato de que todos apresentam ferramentas específicas para soluções de problemas de transportes, além de não exigirem configurações de hardware muito robustas.

A justificativa principal para a avaliação detalhada aqui proposta é o fato de que a escolha de um SIG para atender às necessidades de um projeto ou aplicação não pode ser feita baseada apenas num exame superficial das características do software, nem pode ser realizada por impulso ou influência de outro usuário. Além disso, para o sucesso na implantação do sistema não basta apenas a implantação do software, é importante a existência de pessoal qualificado, interação com outras áreas dentro da organização e principalmente um objetivo no seu uso.

Por tudo isso, apesar de toda a contribuição que esta metodologia de avaliação possa significar, é importante lembrar que, sem uma análise criteriosa das necessidades e objetivos dos projetos para os quais se destina a ferramenta, é difícil escolher o software mais 
adequado. Para que este projeto seja realmente útil, o usuário deve estar ciente das análises que irá efetuar com o auxílio do programa, do tipo de dados que serão trabalhados e de qual o resultado final esperado. Assim, este trabalho proporcionará aos interessados uma base para a escolha do software mais apropriado às funções requeridas, evitando que a ferramenta de geoprocessamento seja deixada em segundo plano por falta de esclarecimentos. É comum software adquiridos erroneamente não serem aproveitados ou até substituídos por aplicativos com potencialidades muito inferiores às dos SIG-T.

\subsection{Objetivo}

Este trabalho tem por objetivo avaliar comparativamente três software de Sistemas de Informação Geográfica, com relação ao seu desempenho e funções disponíveis, visando especificamente aplicações no planejamento do transportes.

\subsection{Estrutura do Texto}

O presente documento é dividido em sete capítulos, incluindo esta introdução. No capítulo 2 é apresentada uma visão geral do tema SIG a partir de uma revisão da literatura específica, abordando os itens: Histórico, Definição e Conceitos Básicos e Aplicações e Vantagens do Uso dos SIG's. Neste mesmo capítulo é apresentada uma abordagem geral dos software estudados, TransCAD, UfosNet e ArcView. Esta primeira descrição dos programas é feita a partir de documentos de divulgação e apresentação dos mesmos, bem como material de informação constante na Internet, com o objetivo de identificar, de uma forma preliminar e geral, as características e funcionalidades de cada um.

O terceiro capítulo consiste da apresentação da metodologia a ser seguida para o desenvolvimento deste trabalho. Faz parte deste capítulo o levantamento dos parâmetros de comparação a serem observados quando da análise dos software em questão, os quais estão divididos em características funcionais básicas de SIG, características operacionais básicas de SIG, rotinas avançadas de SIG e rotinas específicas de transportes. Ainda neste capítulo é apresentado um problema de transportes, cuja solução envolve a manipulação de redes e matrizes, conceitos largamente utilizados na solução de problemas de transportes e básicos em qualquer programa concebido para tratá-los. Por fim é apresentada uma listagem das atividades a serem desenvolvidas para atingir o objetivo do trabalho.

O capítulo 4 traz um inventário das ferramentas dos programas, com uma apresentação e descrição detalhada dos comandos disponíveis nas barras de menu de cada um deles. São mostradas, através de figuras, as opções disponíveis em cada item do menu principal, bem como as telas e comandos ativados por cada uma delas. O levantamento das ferramentas divide-se em dois tópicos gerais: comandos básicos e rotinas avançadas de SIG e rotinas específicas de transportes.

O capítulo 5 apresenta uma avaliação comparativa dos programas. São analisadas as características básicas de SIG, o que envolve aspectos descritivos (tais como versões, material de apoio, etc.), e as características operacionais, levantadas no capítulo 3. Também são analisadas, em forma de tabelas, as rotinas avançadas de SIG e as rotinas específicas de transportes, sendo que este último ponto divide-se em uma avaliação geral e uma avaliação de recursos básicos de transportes. O último item citado consiste da solução do problema 
também apresentado no capítulo 3, que envolve a utilização de redes e matrizes para o cálculo de uma medida de acessibilidade. São apresentadas as seqüências de comandos utilizados em cada software e avaliação do tempo de processamento e resultados obtidos. O último item deste capítulo consiste da síntese da comparação das características dos programas apresentadas.

Os dois últimos capítulos contêm as conclusões deste trabalho e as referências bibliográficas citadas neste documento, respectivamente. 


\section{Sistemas de Informação Geográfica}

O SIG é atualmente a melhor ferramenta para solucionar problemas de organização de dados em modelos espaciais. Vários órgãos governamentais e empresas privadas baseiam hoje suas decisões de planejamento em SIG, utilizando suas potencialidades com relação a ferramentas de gerenciamento, bancos de dados e processamento de dados. O SIG também tem sido elemento chave para aprimorar o gerenciamento dos sistemas de transportes existentes.

\subsection{Histórico}

O primeiro SIG teve origem no Canadá em 1962, sendo denominado CGIS (Canada Geographic Information Systems). Seu objetivo era a realização de inventários de terras em âmbito nacional, envolvendo vários aspectos sócio-econômicos e ambientais. Pacotes de SIG comerciais passaram a ser desenvolvidos nos anos 70, principalmente nos EUA, e experimentaram rápido crescimento nos anos 80 , sendo utilizados inicialmente por empresas do governo. No Brasil as principais aplicações foram nos setores de energia e ambiental. O mercado dos anos 90 é caracterizado pela ampla aplicação no setor privado (Nazário, 1998).

\subsection{Definição e Conceitos Básicos}

Essencialmente, o SIG é um sistema de gerenciamento de banco de dados computacional para capturar, armazenar, recuperar, analisar e visualizar dados espaciais (Lewis, 1990). A empresa norte-americana Environmental Systems Research Institute Inc. ESRI (1996) define SIG como sendo uma coleção de hardware, software, dados geográficos e pessoal, com o propósito de capturar, armazenar, atualizar, manipular, analisar e visualizar eficientemente todas as formas de informação geograficamente referenciadas. Levine e Landis (1989) apud Heikkila (1998) afirmam que todo SIG integra uma função de mapeamento com um gerenciador de banco de dados. A marca de um verdadeiro SIG é a sua inteligência geográfica, ou topologia, que facilita procuras baseadas em localizações no mapa, e não apenas em valores de dados.

Um SIG permite ao usuário gerar saídas gráficas rapidamente, e resumir ou relacionar dados estatísticos num contexto geográfico. Essa técnica gráfica fornece um método efetivo de avaliação dos resultados da análise, particularmente com grandes conjuntos de dados (Hsiao e Sterling, 1992). Com essas capacidades de armazenamento de dados e representações espaciais o usuário analisa o problema com mais facilidade, pois sua visualização torna-se muito mais clara. 
As principais funções que um SIG completo deve ter são: captura dos dados (gráficos ou atributos na forma de importação de dados, digitalização, scanner, importação dos formatos CAD - Computer Aided Design, e levantamentos de campo, entre outros), gerência dos atributos (edição, gerência da base de dados), manipulação espacial (edição), análise dos dados (consultas condicionadas, sobreposições, modelagens) e saída dos dados (mapas, relatórios e imagens) (Viviani, 1998).

Outra potencialidade dos SIGs é a criação de mapas temáticos, unindo as informações da base de dados de atributos ao mapa. Desta forma, um SIG combina a habilidade gráfica de um sistema com a capacidade de armazenamento da informação de uma base de dados (Viviani, 1998). Um mapa temático apresenta uma visão geográfica compreensível que é mais facilmente interpretada que um relatório textual, especialmente para grandes volumes de dados com muitas comparações (Vonderohe et al., 1994).

Lewis (1990) afirma que um sistema CAD diferencia-se de um SIG no sentido de que tipicamente ele tem mais procedimentos desenvolvidos para criar e manipular objetos gráficos, mas não deduz e armazena informações sobre a relação entre os objetos. O CAD não cria, ou armazena, a topologia. Tanto os SIGs como os CADs trabalham com pontos, linhas e áreas, porém os SIGs armazenam também as inter-relações entre esses elementos.

Em um SIG, as representações geométricas podem ser do tipo Matricial (Raster) ou Vetorial. Os sistemas Matriciais são utilizados no processamento de imagens de satélite com múltiplas aplicações no campo florestal, marítimo, ambiental e militar, entre outros. Os sistemas Vetoriais são apropriados para o modelamento de sistemas, controle terrestre, análises de redes, etc. (Bravo e Cerdá, 1995). Antenucci et al. (1991) e Vonderohe et al. (1993) definem o que seria um sistema Matricial e um sistema Vetorial:

$>$ O sistema Matricial divide o espaço em elementos discretos. Consiste de uma matriz de células homogêneas (geralmente quadradas), obtida a partir de uma malha com linhas verticais e horizontais espaçadas regularmente. A área de cada célula define a resolução espacial, onde quanto maior o tamanho da célula, menor a precisão da informação, e quanto menor a célula, maior a base de dados resultante. Cada célula armazena um número associado para o tipo, valor ou índice do atributo que está sendo mapeado na área. Uma célula individual em uma imagem Matricial é denominada de "pixel - picture element", o qual pode ser definido como um elemento gráfico bidimensional que apresenta o menor elemento indivisível de uma imagem.

No sistema Vetorial a posição dos dados é representada por coordenadas horizontais (x e y), codificando a localização e extensão de feições espaciais, bem como as relações de incidência e conectividade ao longo das feições. Um modelo topológico de dados Vetoriais enquadra-se bem nas análises de conectividade e de adjacência espacial; estes dados Vetoriais definem polígonos, objetos e outras entidades complexas, que podem ser manipuladas ou mostradas graficamente com base em seus atributos. As redes de transporte geralmente são representadas por modelos vetoriais. 


\subsection{Aplicações e Vantagens do Uso dos SIGs}

O SIG é uma convergência de campos tecnológicos, dos quais provêm algumas técnicas e metodologias que implementam o sistema. Com base no aspecto de multidisciplinaridade do SIG pode-se observar sua aplicação em diversas áreas: planejamento urbano, geografia, agronomia, ambiental, florestal, engenharia, processamento de dados, pesquisas operacionais, arquitetura e urbanismo, gerenciamento de serviços, engenharia de transportes e outros.

O uso do SIG pode proporcionar grandes benefícios quando implantado numa organização. Ferrari (1997), classifica as atividades de uma organização em três níveis: operacional, gerencial e estratégico. O SIG pode ser usado nos três níveis, proporcionando benefícios distintos para cada um. No nível operacional, os benefícios são: ganho de produtividade, redução ou eliminação de custos ou riscos e qualidade na execução de tarefas. No nível gerencial, o benefício imediato é a eficácia administrativa: melhores informações, melhores decisões de caráter tático: planejamento, gerenciamento, alocação de recursos. Finalmente, no nível estratégico, o benefício é o avanço estratégico: melhor imagem junto aos clientes e parceiros, novas fontes de receita, aumento da receita.

Os SIGs também podem ser utilizados servindo diretamente à sociedade, proporcionando um avanço social e estratégico: melhores serviços ou serviços adicionais à população, melhor qualidade de vida, participação da sociedade nas decisões. Os benefícios à sociedade não são resultantes apenas do uso de SIGs, mas sim do projeto, no qual se inserem, como um todo. O SIG é uma ferramenta para viabilizar estes projetos (Ferrari, 1997).

Segundo Calijuri e Röhm (1993), o SIG pode ser utilizado numa série de análises: otimização do sistema de transporte coletivo, avaliação da tendência de crescimento dos bairros; definição da forma de como se deve proceder o avanço das redes de infra-estrutura urbana (água, esgoto, pavimentação, iluminação, telefonia); definição de locais estratégicos para a instalação de postos de saúde, hospitais, escolas, creches, áreas de lazer, áreas potenciais de ocupação residencial e industrial; avaliação da percentagem de cobertura natural e cultivada pelo homem, determinação da extensão de áreas industriais, residenciais, agrícolas e outras.

O SIG vem sendo largamente utilizado na Engenharia de Transportes, obtendo então a denominação de SIG-T. O campo de aplicação dos SIG-T é amplo, tanto na área de planejamento, como em operação de transportes. Dentre as diversas aplicações do SIG em transportes podem ser citadas: projeto geométrico de vias, monitoramento e controle de tráfego, oferta e demanda de transportes, prevenção de acidentes, otimização de rotas, monitoramento e controle de operações rodoviárias, dentre outras (Viviani et al., 1994, Silva, 1998a).

Fazendo-se uma abordagem do estado da arte dos trabalhos já realizados na área da Engenharia de Transportes podem ser observados vários campos de aplicação. Conforme o trabalho apresentado por Dantas et al. (1996), na área de operação de transportes já foram abordadas questões de Transporte de Carga, Transporte Rodoviário, Engenharia de Tráfego e Transporte Coletivo Urbano; em planejamento prevaleceram os temas relacionados a definição de Zonas de Análise de Tráfego, Transporte de Carga e Transporte Regional; e 
finalmente na área de gestão observou-se uma preocupação com a criação de bases de dados. Verificou-se, mais especificamente, em projetos e pesquisas já apresentadas, sua utilização como instrumento de gestão de transporte coletivo (Siqueira e Cassundé, 1994); para gerenciamento de vias não pavimentadas, especificamente estradas municipais (Viviani et al., 1994); roteirização de veículos (Rosseto e Cunha, 1994); planejamento de rotas de ônibus (Alencar e Aquino, 1994); simulação de estacionamentos (Waerden e Timmermans, 1994).

Silva (1998a), faz uma revisão dos principais trabalhos desenvolvidos sobre SIG-T

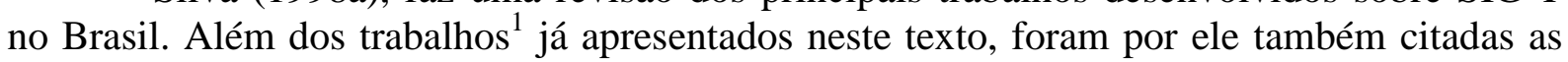
seguintes referências: associação de imagens de satélite a modelos matemáticos para o planejamento de transportes (Ferreira et el., 1994); geração de imagens para cadastro como auxílio ao planejamento do transporte público (Nassi et el., 1994); avaliação dos impactos do crescimento urbano sobre os transportes (Silva et al., 1995); reestruturação de um sistema de transporte público urbano (Silva e Kawamoto, 1995); roteirização para distribuição de jornais (Silva e Grubman, 1996 e Rocha, 1996); localização de pontos de parada com auxílio de um SIG (Tesima e Lapolli, 1996); análise do problema de roteirização de veículos para o processo de coleta e descarga de resíduos sólidos de serviços de saúde (Graciolli et al., 1997); definição de zonas de tráfego, a partir de setores censitários (Sanches, 1997); aplicações de SIG em coordenação semafórica (Oliveira e Ribeiro, 1997); modelos de geração de viagens (Taco et al., 1997); avaliação da acessibilidade aos transportes (Sales Filho, 1997; Raia Jr. et al., 1997; e o próprio Silva, 1998a); desenvolvimento de uma metodologia para otimização de frota e redução de custos operacionais para serviços de ônibus fretados para transporte de funcionários (Martins et al., 1997); entre outros.

As principais vantagens do uso dos SIGs em conjunto com modelos de transportes são: a integridade dos dados propiciada pelo SIG que, se também integrado aos modelos, permite a maior transparência de aspectos físicos dos dados para o usuário; operações préincorporadas aos SIGs eliminam ou simplificam tarefas realizadas normalmente por processos manuais ou em módulos computacionais isolados e não muito bem integrados; facilidade de edição e representação gráfica; tratamento topológico que facilita operações de edição da base geográfica; armazenamento e edição a um menor custo; realização de certos tipos de análises e representações antes praticamente inviáveis nos processos tradicionais, como, por exemplo, identificação de caminhos mínimos entre cada par de zonas origem/destino, entre outros (Kagan el al., 1992).

É importante entender que o SIG não é um "fim", e sim um "meio". É comum encontrar quem pense que o sistema soluciona tudo por si só, o que não é correto. O SIG é apenas uma ferramenta de análise e otimização de processos, portanto a potencialidade do sistema depende dos desenhos dos processos ou dos algoritmos que devem solucionar os problemas. É aí que se concentram os pontos fortes de um SIG: por um lado nas suas características e potencialidades, e por outro e principalmente, na capacidade dos operadores ou especialistas que o utilizam (Bravo e Cerdá, 1995). Deve haver uma organização de pessoas, instalações e equipamentos responsáveis pela implantação e manutenção de um SIG. Além disso, esta organização deve ter um objetivo e recursos para atingí-lo.

\footnotetext{
${ }^{1}$ Os trabalhos citados não constam nas referências bibliográficas deste documento, estando referenciados no trabalho de Silva (1998a).
} 
Vários autores já verificaram que, para que o SIG-T seja efetivamente implantado e corretamente utilizado, é necessária uma maior compreensão do que realmente seja um SIG e quais são suas potencialidades na resolução de problemas de transportes. Os SIG evoluíram no intuito de atingir as principais necessidades do mercado, portanto todos acabaram por ter funções semelhantes. Porém, mesmo assim eles apresentam diferenças na execução de cada função. Nenhum software é melhor que outros em todos os sentidos, cada um tem suas particularidades, portanto o conhecimento mais profundo do que o programa tem a oferecer é muito importante para uma escolha satisfatória. A escolha e implantação de um SIG requer um estudo prévio que determine o que se deseja obter, para poder determinar que sistema satisfará melhor suas necessidades.

Muitas vezes o custo inicial e de implantação do software desestimula sua utilização, mas é importante observar que várias aplicações do SIG geram um retorno financeiro; outras, apesar de não terem um retorno financeiro, melhoram a imagem da empresa, a qualidade de seus resultados e análises, viabilizam projetos; enfim, fatores que aumentam consideravelmente sua competitividade no mercado.

São relativamente poucos os trabalhos publicados tratando da comparação entre programas para Sistemas de Informação Geográfica, embora diversos autores reconheçam a importância de pesquisas nesta direção. Câmara (1994), por exemplo, sugere inclusive uma metodologia para comparações técnicas entre alguns software de geoprocessamento, onde são avaliadas as seguintes características: interfaces de sistemas, entrada de dados, funcionalidade de SIGs e sistema de armazenamento e recuperação. Ele afirma que o conjunto básico de funções de geoprocessamento consiste de: análise geográfica, processamento digital de imagens, modelagem de redes, produção cartográfica e modelagem numérica de terreno. Um dos poucos exemplos concretos de avaliação de software SIG, no entanto é aquele descrito por Jong e Ritsema van Eck (1991), que realizaram uma comparação, baseada nas diferentes análises de redes de transportes e funções analíticas relacionadas a distâncias entre diferentes localizações, de quatro produtos: ArcInfo, GenaMap, Span e TransCAD.

Assim, tendo como motivação o pequeno número de trabalhos avaliando software de SIG para aplicações em transportes, esta pesquisa irá se concentrar em três programas, cuja descrição geral será apresentada a seguir.

\subsection{Programas Estudados}

Neste item será apresentada uma abordagem geral dos software estudados, TransCAD, UfosNet e ArcView, conforme documentos de natureza predominantemente comercial para divulgação e apresentação dos mesmos, o que inclui material de informação constante na Internet, com o objetivo de identificar, de uma forma preliminar, as características e funcionalidades de cada software.

\subsubsection{Software TransCAD}

O TransCAD é um Sistema de Informação Geográfica projetado especificamente para o planejamento, gerenciamento, operação e análise das características dos sistemas de transportes (Caliper, 1996). Ele possui vários módulos para manipulação de dados com relação à entrada, armazenagem, análise e apresentação final. Suas aplicações podem ser em 
nível internacional, nacional, regional e local, podendo ser usado para qualquer modo de transportes, isoladamente ou combinado com outros modos.

O TransCAD realiza várias análises de transportes e possui um banco de dados projetado para capturar e analisar dados de transportes. Estes dados, por exemplo: de redes de transportes, fluxos de carga, rotas, programação, análise de transportes interzonais, demanda de passageiros, desempenho do sistema de transportes e outros, podem ser armazenados, vizualizados e analisados em qualquer escala espacial. Possui potencialidades para analisar vários tipos de redes: de transporte público, metrovias, ferrovias, rodovias, aerovias, submarinas ou multi-modais. Possui ferramentas para apresentação e visualização de dados de transporte e disponibiliza métodos e modelos para análises de transportes. No seu sistema, a localização geográfica de elementos de transporte, bem como as infra-estruturas relacionadas, podem ser combinadas com os dados que as descrevem. Os dados podem ser associados a pontos, linhas, áreas, redes ou rotas.

No TransCAD, o gerenciador de banco de dados espacial armazena os dados geográficos utilizando-se de uma estrutura de dados topológica, o que facilita a manipulação dos mesmos. Essa estrutura de dados define a localização e as relações espaciais entre pontos, linhas, áreas e outras entidades geográficas ou objetos. Ele suporta a definição de várias estruturas de dados de transporte como: redes, vias, nós, linhas e matrizes de fluxo. O TransCAD possui uma linguagem de consulta que inclui operadores SQL (Structured Query Language - Linguagem Estruturada de Consulta) e consultas geográficas. O usuário pode selecionar qualquer entidade geográfica para recuperar os dados tabulares relativos àquela entidade. Pode, também, utilizar consultas espaciais para localizar entidades dos mapas através de raios, polígonos ou contornos de buffer (áreas de abrangência) e overlay (sobreposição). Além dessas operações espaciais e ferramentas de geoprocessamento, o TransCAD realiza funções de agregação espacial e faz sobreposições entre dados vetoriais e dados matriciais, apresentando-os em conjunto.

A segmentação dinâmica facilita o gerenciamento eficiente dos atributos dos dados associados a rodovias, linhas férreas e outros campos lineares. É um método de divisão de linhas ou arcos em um banco de dados SIG para refletir seus atributos básicos, método utilizado pelo TransCAD para gerenciar dados de atributos gráficos lineares, particularmente quando os valores de diferentes atributos mudam em diferentes pontos ao longo do componente gráfico. Para minimizar erros de duplicação, os dados de atributos individuais são armazenados em tabelas de dados separadas. As rotinas de consulta fazem uma busca nas tabelas dos atributos relevantes para identificar e extrair os dados dos segmentos que coincidem com as condições da consulta. Os resultados dessas consultas podem ser armazenados como novos objetos e manipulados livremente, tornando possível realizar novas consultas ou produzir mapas e gráficos facilmente.

Com relação a apresentação de gráficos interativos dos dados, o TransCAD possui várias ferramentas para a definição de: símbolos, cores, espessuras de linhas, padrões, sombreamento, nomeação e outras. Os dados podem ser apresentados no mapa na forma de números ou textos, e o recorte automático de textos elimina apresentações desordenadamente preenchidas e realça a legibilidade. As telas podem ser apresentadas em qualquer escala com o auxílio dos comandos de zoom-in e zoom-out. É possível realizar a impressão de mapas e relatórios em praticamente todas as impressoras e plotters disponíveis no mercado (desde que 
compatíveis com o sistema operacional empregado); os mapas podem ser armazenados em formatos de arquivos gráficos comuns para uso como CAD ou outros.

O TransCAD possui um editor de dados com o propósito de facilitar a entrada, edição, recuperação e impressão dos dados. Os dados podem ser inseridos através do mouse ou mesa digitalizadora, ou importados de arquivos censitários, produzidos pela Agência Federal de Estatística Americana, e outros. Com relação à edição geográfica, o TransCAD possui um recurso interno, denominado Active Topology, que associado ao seu editor de elementos geográficos permite que as entidades possam ser adicionadas, excluídas, movidas, divididas, unidas, alteradas na sua forma e agregadas interativamente, garantindo sua integridade topológica e de atributos.

O TransCAD disponibiliza ferramentas para projetar e criar bancos de dados, preenchendo-os com os registros que os compõem e com os campos de atributos de dados necessários. É permitida a importação de vários arquivos de dados com conversão automática dos sistemas de coordenadas como, por exemplo, os formatos: TIGER, DLG, DXF, SPOT, LANDSAT, entre outros. Com a possibilidade de se converter arquivos de dados digitais para bancos de dados efetivamente acessíveis no SIG, pode-se importar e exportar dados de arquivos do tipo Lotus, dBASE e ASCII, tornando o processo de coleta de dados mais rápido, fácil e com menor custo.

O TransCAD fornece ferramentas para a execução dos comandos: address matching e geocode. $\mathrm{O}$ comando address matching realiza a procura e identificação gráfica de endereços. O comando geocode pode ser usado para identificar a que distância se está do início da rota (route-milepost), e para geocodificar dados internos de uma organização qualquer, originalmente apenas tabulares, para numa análise posterior integrá-los a dados externos, tabulares e geográficos, oriundos de diferentes fontes. Neste software pode-se combinar dados de um número grande de fontes numa só aplicação e vinculá-los para produzir novos elementos e resultados mais compreensíveis.

O TransCAD possui ferramentas e procedimentos para a análise e modelagem de sistemas de transportes, o que inclui: análise de redes, estatísticas, análise de mercado, alocação de tráfego, análise espacial, definição de rotas e programação, e planejamento. Podem ser estimados e aplicados modelos de previsão como regressão múltipla e modelos de escolha discreta. Segundo o fabricante, as redes do TransCAD podem conter milhares de linhas e zonas, limitadas apenas pela capacidade de memória do computador. Com relação ao planejamento de transportes, o TransCAD possui modelos clássicos para cálculos de demanda de viagens, estima e aplica modelos de geração de viagens em qualquer escala espacial, mesmo em níveis parciais, e posteriormente agrega aos níveis de zonas, constrói zonas de análise de tráfego, faz distribuição de viagens e análises de distribuições modais. Ele disponibiliza o comando UTP (Urban Transportation Planning - planejamento de transporte urbano) que facilita a construção e aplicação de modelos de transporte urbano; permite a ligação entre a engenharia de tráfego e modelos de interseções; integra a demanda por transporte com análises da qualidade do ar.

O TransCAD possui procedimentos e ferramentas para solucionar problemas de roteirização e programação, sendo eles: definição de rotas de entrega, zoneamento, redistritamento, locação de instalações, rotas de transporte público urbano, coleta de lixo, 
roteamento, transporte semipúblico e possibilidade de uso de diferentes unidades de medida, inclusive o sistema métrico. As rotinas de caminhos mínimos, fornecidas pelo software, permitem minimizar distâncias, tempo, custo, ou qualquer outra variável. A caixa de ferramentas padrão do TransCAD inclui, além das rotinas já mencionadas, rotinas que auxiliam a solução dos problemas de transportes mais importantes, permitindo a criação de tabelas de distância, modelagem dos fluxos de zona para zona, minimização dos custos de distribuição e espera em terminais, etc.

Em um prospecto ilustrativo do software, algumas das principais aplicações do TransCAD listadas pelo fabricante são:

\begin{tabular}{|c|c|c|c|c|}
\hline $\begin{array}{l}1 \\
= \\
\end{array}$ & $\begin{array}{l}\text { Inventário de } \\
\text { Facilidades }\end{array}$ & $\begin{array}{l}\text { Planejamento } \\
\text { Urbano }\end{array}$ & & $\begin{array}{l}\text { Roteirização e } \\
\text { Programação }\end{array}$ \\
\hline$\cdots$ & $\begin{array}{l}\text { Gerência de } \\
\text { Pavimentos }\end{array}$ & Obras Públicas & & $\begin{array}{l}\text { Planejamento } \\
\text { Rodoviário }\end{array}$ \\
\hline & Uso do Solo & $\begin{array}{l}\text { Análises } \\
\text { Demográficas }\end{array}$ & & $\begin{array}{l}\text { Pesquisa } \\
\text { Operacional }\end{array}$ \\
\hline & $\begin{array}{l}\text { Gerenciamento } \\
\text { de Registros }\end{array}$ & $\begin{array}{l}\text { Engenharia de } \\
\text { Tráfego }\end{array}$ & & $\begin{array}{l}\text { Planejamento } \\
\text { Comercial }\end{array}$ \\
\hline & $\begin{array}{l}\text { Análise de } \\
\text { Mercados }\end{array}$ & Seleção de Sítio & & Telecomunicações \\
\hline & $\begin{array}{l}\text { Avaliação } \\
\text { Ambiental }\end{array}$ & $\begin{array}{l}\text { Planejamento } \\
\text { Escolar }\end{array}$ & & $\begin{array}{l}\text { Segurança } \\
\text { Pública }\end{array}$ \\
\hline & $\begin{array}{l}\text { Planejamento de } \\
\text { Transporte Público }\end{array}$ & $\begin{array}{l}\text { Estatísticas } \\
\text { Espaciais }\end{array}$ & & $\begin{array}{l}\text { Gerência de } \\
\text { Infra-estrutura }\end{array}$ \\
\hline & $\begin{array}{l}\text { Estimação de } \\
\text { Demanda }\end{array}$ & $\begin{array}{l}\text { Mercado } \\
\text { Imobiliário }\end{array}$ & & $\begin{array}{l}\text { Sistema de } \\
\text { Informações } \\
\text { Executivas }\end{array}$ \\
\hline & $\begin{array}{l}\text { Mapeamento } \\
\text { Censitário }\end{array}$ & Previsões & & $\begin{array}{l}\text { Banco de Dados } \\
\text { para fins Editoriais }\end{array}$ \\
\hline & $\begin{array}{l}\text { Análise do } \\
\text { Levantamento } \\
\text { de Dados }\end{array}$ & $\begin{array}{l}\text { Análises da } \\
\text { Qualidade do Ar }\end{array}$ & 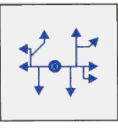 & $\begin{array}{l}\text { Distribuição Física } \\
\text { e Logística }\end{array}$ \\
\hline & $\begin{array}{l}\text { Recursos } \\
\text { Hídricos }\end{array}$ & $\begin{array}{l}\text { Monitoramento de } \\
\text { Veículos }\end{array}$ & & $\begin{array}{l}\text { Seleção de } \\
\text { Mercados }\end{array}$ \\
\hline
\end{tabular}




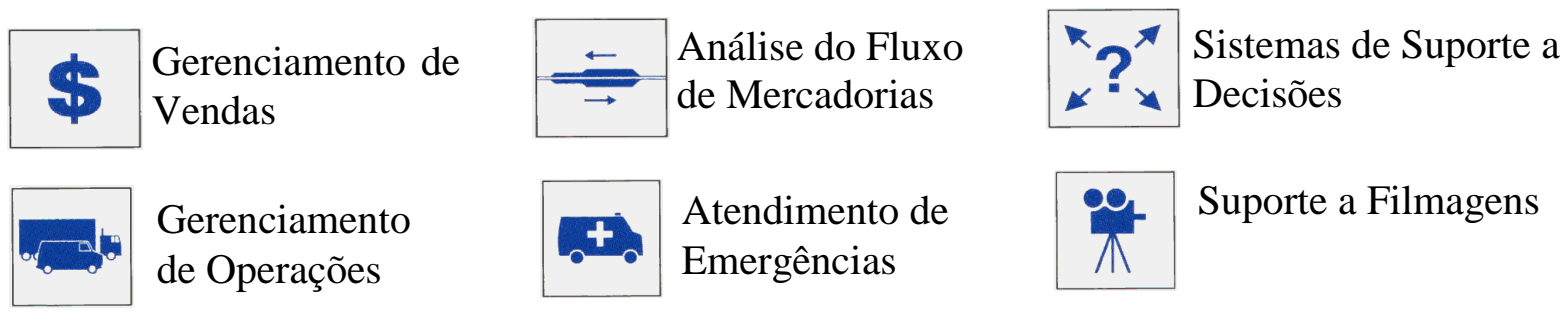

O TransCAD possui uma arquitetura modular, aberta, que pode ser customizada e ampliada com procedimentos escritos pelo usuário, em qualquer linguagem de programação, os quais podem realizar inúmeras funções específicas. O TransCAD possui sua própria linguagem de programação e disponibiliza dois manuais específicos a este respeito: o primeiro, denominado GISDK (Geographic Information System Development Kit), lista vários comandos. O segundo trata em detalhes de sua linguagem de programação, denominada Caliper Script. O software TransCAD versão 3.0 for Windows, produzido pela Caliper Corporation, pode ser utilizado nas plataformas do Windows 3.1, 95, 98 e NT. As configurações de hardware seguem as exigências feitas pelas plataformas Windows, apresentando apenas a necessidade de no mínimo $14 \mathrm{MB}$ de espaço disponível em disco rígido.

\subsubsection{Software UfosNet}

O UfosNet é um sistema de simulação e previsão de demanda de viagens baseado em SIG. A sigla "Ufos" significa "Urban Form Optimization System", isto é, Sistema de Otimização da Forma Urbana, logo o UfosNet tem a finalidade de desenvolver um sistema de simulação da integração do transporte com o uso do solo (RST, 1997). As principais características do UfosNet são: apresenta facilidade para mapeamentos e uso de SIG, permite realizar simulações de sistemas de transporte público urbano e redes multimodais, possui uma grande variedade de ferramentas de edição, realiza cálculos de bancos de dados e matrizes, importa e exporta vários tipos de arquivos e gera gráficos de apresentação dos dados.

Quanto à facilidade de mapeamento e uso de SIG, o UfosNet possui um extrator de arquivos TIGER/Line, que são dados geográficos produzidos e distribuídos pelo U.S. Census Bureau. Todas as linhas podem ser extraídas através de códigos de classificação censitária de atributos gráficos, e os pontos que os definem podem ser inseridos automaticamente. Linhas de rodovias podem ser transformadas em uma rede com nós e links, e utilizadas em modelagens de transportes. As linhas de definição do contorno de cidades e regiões censitárias podem ser transformadas em polígonos contendo todas as informações censitárias, as quais podem ser utilizadas na produção de mapas temáticos de representação. O programa importa vários tipos de arquivos usuais em SIGs, tais como: ArcInfo, MapInfo, Atlas GIS e AutoCAD.

Para a simulação de transporte público urbano e redes multi-modais o UfosNet disponibiliza vários métodos de alocação de tráfego, tais como: tudo-ou-nada, incremental, do equilíbrio. Faz cálculos dinâmicos de atrasos em interseções baseados em movimentos de retorno críticos, integra análises de planejamento LOS (level of service - nível de serviço) com a tela de trabalho para facilitar as análises de capacidade de interseções. Fornece os métodos de planejamento HCM 209 (Highway Capacity Manual's planning method, Chapter 
9, 1995) e TRC 212 (Transportation Research Circular 212's planning method). O processo de alocação de TPU (transporte público urbano) inclui as opções de se utilizar na análise, uma zona, linha ou segmento, uma matriz de custos de passagem e ainda restringir áreas de estacionamento.

Quanto às ferramentas de edição, o UfosNet possui várias caixas de ferramentas para edição de camadas de nós, links, linhas de transporte público e anotações. Toda edição é executada interativamente na tela. $\mathrm{O}$ editor de redes permite mover nós e unir ou separar links. Áreas e perímetros podem ser calculados com base em coordenadas de latitude e longitude. Matrizes, penalidades de retorno e funções de atraso também podem ser editadas na tela. Com relação a cálculos de bancos de dados e matrizes, o UfosNet automaticamente cria bancos de dados internos para zonas, nós, links e fatores-F (fatores de fricção), nos quais podem ser definidos mais de 65.000 campos de dados, do tipo numérico ou de caracteres. A estrutura do banco de dados pode facilmente ser modificada e definida. Todos os bancos de dados podem ser importados e exportados de/para arquivos dBase III facilitando a troca de dados com os principais aplicativos de planilhas e banco de dados. O UfosNet possui um editor que possibilita a definição de expressões com a utilização de várias funções. Realiza cálculos em uma matriz, que incluem distribuição de viagens para análises de impacto pontuais e cálculos entre matrizes, utilizados para o desenvolvimento de modelos de escolha modal. O UfosNet gera gráficos de apresentação dos dados, sendo que os dados podem ser visualizados utilizando-se bandas, círculos, gráficos de barras e do tipo "pizza", linhas de desejo, vistas 3D e mapas temáticos. Ele permite gerar, também, gráficos de representação de movimentos de retorno em interseções. Virtualmente, o programa não possui limites quanto ao tamanho da rede, sendo este limite determinado pela capacidade do hardware.

O UfosNet fornece os métodos de regressão usuais para estimar a geração de viagens, bem como o método de resposta rápida TRB 187 (TRB, 1978). Possui ferramentas para converter os dados de viagens do tipo PA (produção/atração) em OD (origem/destino) e balanceamento de OD. Na etapa de distribuição de viagens o programa fornece ferramentas para o cálculo dos tempos de viagem entre zonas baseado no vizinho mais próximo e nos métodos dos centróides ponderados. Disponibiliza os modelos gravitacional e Fratar para estimar a distribuição de viagens. Possui um modelo padrão de escolha modal multinomial e de determinação de áreas de estacionamento. Outros métodos de geração e distribuição de viagens e modelos de escolha modal podem ser incorporados ao programa através da utilização de macros escritas pelo usuário. O UfosNet possui os métodos do equilíbrio, incremental e AON (all or nothing - tudo ou nada) para alocação de tráfego, a qual pode ser feita apenas no modo selecionado. Permite o cálculo de caminhos mínimos e possui um editor de funções de congestionamento com formas BPR (função desenvolvida pelo U.S. Bureau of Public Roads), cônica e livre. É possível a realização de análises com mais de 100 zonas, análises de links com operadores e/ou controles de agrupamento, análises multiclasse com um VDF (volume delay function - função de atraso pelo volume) para cada classe e cálculos de atraso em nós baseado nos movimentos críticos. Permite a geração de matrizes com dados de penalidades ou taxas (toll matrix) e matrizes de subáreas OD baseadas em links definidos pelo usuário.

A definição de rotas para transporte público urbano pode ser feita com base em um ou mais elementos de uma camada de linhas, ou seja, por um conjunto de links aos quais podem ser associados pontos de parada. Podem ser definidos fatores de tempo de viagem para 
embarque/desembarque, espera inicial, embarque/desembarque em transferências, espera em transferências e espera dentro do veículo. A velocidade de embarque/desembarque pode ser definida para cada link. Os volumes nas linhas de TPU e nos links de embarque/desembarque podem ser salvos em campos de links separados e os volumes de embarque inicial, embarque em transferências, desembarque final, desembarque em transferências e através das paradas podem ser armazenados em campos de nós separados. Podem ser salvas matrizes de tempo para todos os componentes de tempo de viagem. Viagens podem ser armazenadas para um conjunto de zonas selecionadas, para uma linha de TPU, para uma seleção de segmentos do TPU e para um modo de TPU selecionado. As penalidades para transferências podem ser especificadas entre modos de TPU e as viagens com transferências podem ser salvas entre os modos de TPU. A matriz de custos totais de passagens (tarifas) pode ser calculada utilizandose as taxas de embarque e de transferências. O UfosNet permite realizar análises LOS de capacidade de interseções através dos métodos de planejamento HCM 209 (HCM, 1985) e TRC 212 (TRC 212). As definições de geometria das interseções são feitas em campos de nós e links e as suas orientações podem ser detectadas ou especificadas automaticamente. Podem ser obtidos relatórios das planilhas resultantes das análises LOS para todas as interseções.

Para a edição de redes o UfosNet disponibiliza as ferramentas de edição de nós: adicionar, mover, excluir, atributos, localizar, copiar/colar coordenadas X e Y e determinar penalidades de retorno; e edição de links: adicionar, excluir, dividir, unir, atributos e cálculo do comprimento de links na tela. Pode-se, também, encontrar o caminho mínimo entre dois nós, a árvore de menores caminhos a partir de qualquer nó e o menor caminho de TPU entre dois pontos de parada quaisquer, executar funções de roteirização utilizando-se do método TSP (Travel Salesman Problem - Problema do Caixeiro Viajante), fazer cálculos com base em expressões, construir linhas de TPU adicionando ou excluindo segmentos na tela, editar o itinerário de linhas de TPU pelo número do nó e encontrar linhas de TPU utilizando um ponto de parada ou um link. Com relação a matrizes, o UfosNet permite a definição de matrizes de qualquer dimensão e suporta até 255 matrizes em um arquivo de projeto. As matrizes são classificadas em 20 tipos, para facilitar o gerenciamento de arquivos, sendo eles: OD, PA, de procura (Lookup), penalidades de retornos, movimentos de retorno, fator $\mathrm{K}$, matriz de tempo, matriz de custos, etc. Matrizes podem ser facilmente adicionadas, excluídas e modificadas; pode-se executar cálculos em matrizes utilizando expressões algébricas, e as células de uma matriz podem se editadas como células de uma planilha eletrônica. O UfosNet apresenta, ainda, ferramentas para expandir, comprimir, transpor e aplicar modelos logit em matrizes.

As ferramentas de SIG fornecidas pelo UfosNet permitem a extração de arquivos TIGER/Line por campo (por exemplo, áreas, rodovias, ferrovias, etc.), criar redes e definir contornos de áreas a partir de linhas TIGER. O programa possui várias ferramentas para edição e manipulação de áreas, permite criar regiões de buffer com retângulos, círculos, polígonos e rotas. A criação de regiões de buffer em rotas pode ser feita utilizando-se caminhos, linhas de TPU ou caminhos de TPU. Pode-se efetuar o cálculo da parte das regiões de buffer que cruzam com áreas zonais e vice-versa.

O UfosNet é um software escrito com base na linguagem de programação $\mathrm{C} / \mathrm{C}^{++}$, que é de aprendizado rápido e fácil. Ele possui um editor executável de scripts (tex to que descreve os passos relativos a execução de um programa), através do qual o usuário pode adaptar o programa às suas necessidades. A linguagem de macros do UfosNet é denominada Uscript, cuja base é o mecanismo CodeScript $\mathrm{C} / \mathrm{C}^{++}$, que pode interpretar scripts escritos em $\mathrm{C} / \mathrm{C}^{++}$. 
No guia do usuário pode-se encontrar uma lista das funcionalidades das linguagens Uscript e CodeScript. O UfosNet pode ser utilizado nas plataformas do Windows 3.1, 95, 98 e NT e em qualquer computador com no mínimo $16 \mathrm{MB}$ de memória RAM e $20 \mathrm{MB}$ de espaço disponível em disco rígido. As tabelas de dados podem conter mais de 65.000 campos e um número grande de registros, os bancos de dados podem conter dados numéricos e textos, sendo que todos os dados numéricos são armazenados com precisão dupla.

\subsubsection{Software ArcView}

De acordo com a ESRI (1996), o ArcView GIS Versão 3.0a oferece uma solução para criar, visualizar, analisar e apresentar melhor e mais claramente a informação. A diferença entre este software e os demais estudados, TransCAD e UfosNet, é que para que ele possa executar operações específicas de transportes devem ser instalados módulos auxiliares. Os módulos a serem estudados são: ArcView Network Analyst, que torna possível solucionar vários problemas envolvendo redes geográficas (ruas, rodovias, rios, etc) e ArcView Spatial Analyst, que faz análises com dados do tipo raster e faz a integração dos dados matriciais com os dados raster.

O ArcView é um programa de geoprocessamento no qual pode-se criar mapas inteligentes e dinâmicos utilizando-se dados de quaisquer recursos virtuais e plataformas computacionais mais populares. Possui uma interface amigável que fornece ferramentas e dados para realizar análises e trabalhar com mapas, tabelas de bancos de dados e gráficos. Realiza atualização dinâmica de dados e operações de endereçamento e geocodificação. Possui inúmeros comandos e opções para a edição e visualização de mapas e dados, dentre eles: métodos de classificação de dados, apresentação e edição de legendas, mapas temáticos, adição de pontos, linhas ou polígonos a mapas existentes, apresentação e edição de rótulos a qualquer campo do mapa e fornece um número elevado de fontes e símbolos gráficos. $\mathrm{O}$ ArcView permite a edição dos campos geográficos e seus atributos e a entrada/edição desses através do mouse ou mesa digitalizadora. Realiza operações complexas de edição de vértices (adicionar, mover, apagar) e figuras (união, interseção, combinação e extração de parte de uma figura). Realiza, também, atualização automática dos atributos editados e calcula novos valores para bancos de dados a partir de outras informações.

Quanto à importação e acesso aos dados, o programa em questão lê dados de mapas nos seguintes formatos: Shapefiles (*.SHP, extensão do próprio ArcView), ArcInfo, PC ArcInfo, AutoCAD (*.DXF e *.DWG) e MicroStation (*.DGN), e importa dados do tipo MapInfo, Atlas GIS e ASCII. Permite o acesso à imagens com extensão: GIF, RLC, EPS, TIFF, BIL, PICT, Landsat, BIP, JPEG, BSQ, BMP, SPOT, WMF, SunRaster ou ERDAS IMAGINE. Utiliza bancos de dados, diretamente, nos formatos dBASE, INFO, Spatial Database Engine (SDE) e ASCII; e, através de operações ODBC, nos formatos ACCESS, Paradox, FoxPro, Oracle, SYBASE, INFORMIX, DB2 e INGRES. Quanto aos dados espaciais, são aceitos os formatos RDBMS.

O ArcView pode ser utilizado no âmbito governamental na gerência de zoneamentos, uso do solo, e outros serviços municipais. Outras aplicações estão na segurança pública, identificação de locais comerciais em desenvolvimento, planejamento de transportes, saúde pública, cadastramentos, serviços de emergência, análises criminais, logística, recursos naturais, educação, gerência de instalações, gerência do meio ambiente, turismo, entre outras. 
É uma ferramenta que auxilia na tomada de decisões, fornecendo um grande número de informações, o que pode resultar em melhores serviços, custos reduzidos e acesso a mais clientes.

O ArcView é um software modular, sendo que a sua configuração padrão não apresenta um grande número de ferramentas avançadas, tornando-o mais acessível a usuários com a necessidade de utilização de um programa SIG que apresente as ferramentas básicas de geoprocessamento e não seja tão específico quanto os demais. Devido a isso, para o presente estudo, comparação de SIG's aplicados aos transportes, fez-se necessária a aquisição dos módulos complementares já citados e brevemente descritos na seqüência deste texto.

O programa fornece módulos auxiliares que acompanham a sua versão padrão e podem ser ativados/desativados conforme a necessidade do usuário. São eles: Projection UtilityI, Report Writer, CAD Reader, Database Access, Dialog Designer, Digitizer, Geoprocessing, Graticules and Measured Grids, Image Readers, Legend Tool, Military Data Readers, VPF Viewer, DXF Export, SDTS Data Import, DIGEST (ASRP/USRP), MGRS Coordinate Display, S-57 Data Converter e RPF Indexer. Além destes, os seguintes módulos opcionais podem complementar o software ArcView:

- ArcView Spatial Analyst

- ArcView 3D Analyst

- ArcView Image Analysis

- ArcView Tracking Analyst

- ArcView Business Analyst

- ArcView Network Analyst

- ArcView StreetMap

- ArcView StreetMap 2000

- ArcPress for ArcView

Dado o interesse particular deste trabalho em dois destes módulos opcionais, as ferramentas disponíveis nos mesmos serão listadas a seguir. No módulo ArcView Network Analyst estas ferramentas são:

- Acessar dados de uma rede geográfica;

- Encontrar a melhor rota entre duas localizações ou o melhor caminho para cobrir vários pontos;

- Criar áreas de serviço com base no tempo de viagem ou distância;

- Encontrar a instalação mais próxima;

- Executar análises de tempo de viagem.

As ferramentas disponíveis no módulo ArcView Spatial Analyst são:

- Converter temas (pontos, linhas ou polígonos) em uma grade;

- Criar áreas de abrangência com base no parâmetro distância a partir de qualquer elemento ou conjunto de elementos vetoriais ou raster;

- Criar mapas de densidade a partir de uma camada de pontos;

- Criar superfícies contínuas a partir de uma camada de pontos;

- Realizar vários tipos de análises em mapas de superfícies;

- Criar mapas de relevo topológicos e hidrológicos;

- Realizar mapeamento de distâncias e densidade; 
- Realizar análises zonais;

- Realizar análises célula por célula em separado;

- Mostrar e reclassificar dados de uma grade;

- Importar dados no formato: TIFF, BIL, Sun Raster, USGS DEM e DTED;

- Apresentar os dados utilizando processos de renderização.

É através da linguagem de programação do ArcView, denominada Avenue, que o usuário pode criar suas próprias rotinas, aprimorando assim o software. Os módulos auxiliares também podem ser customizados. O ArcView pode ser utilizado nas plataformas: Microsoft Windows (3.x, 95, NT), Power Macintosh, Data General AviiON, Digital UNIX Alpha, HP 9000/700 and 8x7, IBM RS/6000, SiliconGraphics, Solaris 1 e 2.

\subsection{Considerações Finais}

Agora que já se tem uma visão geral dos três programas estudados pode-se dar início à avaliação propriamente dita dos mesmos, segundo os passos detalhados na metodologia que será exposta na seqüência. 


\section{Metodologia}

Em linhas gerais, procurou-se identificar neste capítulo os aspectos que se apresentam como relevantes para uma análise comparativa de Sistemas de Informação Geográfica aplicados aos transportes. O primeiro passo numa análise comparativa se dá a partir do conhecimento geral dos elementos a serem comparados, no caso em questão, dos programas TransCAD, ArcView e UfosNet. Este foi o propósito da abordagem geral das ferramentas e potencialidades de cada programa, mostrada no capítulo 2 deste texto. No entanto, aquela primeira listagem, realizada apenas com base em documentos de divulgação e apresentação dos programas (de cunho mais comercial do que técnico), não seria suficiente para uma avaliação mais profunda dos recursos por eles oferecidos, o que poderia comprometer a análise comparativa aqui almejada.

Para uma avaliação minuciosa de cada ferramenta/opção disponível nos software estudados seria necessário, antes de qualquer outro procedimento, listar todos os itens a serem analisados, de maneira clara e objetiva, de forma a facilitar o levantamento e análise dos recursos presentes em cada um dos software. Com este propósito, os itens e suas seqüências de comandos nas diversas telas de menus devem ser identificados e apresentados, inclusive sob a forma de figuras, procurando-se respeitar, tanto quanto possível, a ordem de apresentação dos mesmos nos programas. A ilustração dos itens comentados facilita a compreensão e futura identificação do software pelo leitor. Neste processo de inventário de recursos, todos os procedimentos, parâmetros e variáveis necessários à execução de cada item devem ser descritos passo a passo. Deve ser apresentado, também, ainda que de uma forma mais geral, a que comando corresponde cada ícone disponível nas telas dos programas.

Para organização e utilização das informações obtidas no procedimento descrito no parágrafo anterior com o intuito de se proceder a uma análise coerente e precisa dos software em questão é necessária, no entanto, uma definição prévia de parâmetros de comparação. Para tanto procurou-se identificar as principais ferramentas e aplicações de cada programa, levando-se em consideração, principalmente, as necessidades e dúvidas dos potenciais usuários. Para este fim, tomou-se como referência o trabalho de Kemp (1994), que afirma que, para se especificar um SIG, devem ser examinados quatro aspectos: as tarefas, as pessoas, as limitações e os dados. Isto é, definir exatamente qual será a utilidade do SIG; quem irá utilizá-lo; quais as limitações com relação a: tipo de representação geométrica de dados espaciais a ser usada (matricial ou vetorial), necessidade de treinamento dos usuários (simplicidade do sistema), hardware (processamentos e saída de dados), coleta e manutenção de dados (como será feita, verificação da qualidade, controle de manutenção dos dados), suporte do sistema (interno e do fornecedor), tempo (instalação, teste, desenvolvimento) e 
risco. E ainda com relação aos dados: determinação da sua necessidade, fonte, processamento (validade, precisão), volume e estrutura.

Com base nos itens listados por Kemp (1994) podem ser definidas quais informações relativas aos programas são necessárias em primeira instância, aqui apresentadas como parte das características básicas de SIG que constituem os primeiros Parâmetros de Comparação, como mostrado na seqüência deste texto. O tópico engloba, como subdivisões, os aspectos Características Funcionais Básicas de SIG e Características Operacionais Básicas de SIG. As funções que definem as etapas de análise de dados e apresentação de resultados são listadas em seguida, sob o título Rotinas Avançadas de SIG.

A análise das ferramentas utilizadas em aplicações de transportes, por ser o foco de interesse deste trabalho, exige um tratamento diferenciado, para o qual foram definidas duas diretrizes. A primeira consiste de um check list dos recursos apresentados como Rotinas Específicas de Transportes, reunidos como um último subitem dentro dos Parâmetros de Comparação. Na segunda estratégia adotada para comparar os software, apresentada como um novo item do capítulo, foi proposta a solução de um problema de transporte envolvendo redes e matrizes, conceitos largamente utilizados neste campo de aplicações.

\subsection{Parâmetros de Comparação}

Algumas características que podem ser consideradas básicas em Sistemas de Informações Geográficas são principalmente aquelas que se referem à criação e manutenção de bases de dados.

- Em primeiro lugar deve-se verificar qual é o equipamento necessário, isto é, quais são as configurações de hardware exigidas pelo programa com relação a CPU (Central Processing Unit, Unidade Central de processamento), memória RAM (Random Access Memory, Memória de Acesso Randômico), armazenagem em disco e outras.

- É importante observar os tipos de dados processados pelo programa (matricial ou vetorial). Em se tratando de problemas de transportes, a maioria das bases de dados é do tipo vetorial, mas deve-se considerar a necessidade de se trabalhar, também, com dados raster (matriciais).

- Deve-se observar se o software possui uma interface amigável, com operação através de menus e aprendizado rápido, dispondo de um suporte técnico constante, atualizações permanentes, treinamento básico, ampla literatura e manuais de fácil compreensão.

- Deve ser observada a possibilidade de customização do software, isto é, adequação do mesmo às necessidades do usuário através de macros ou linguagem de programação.

\subsubsection{Características Funcionais Básicas de SIG}

Normalmente, o SIG realiza as seguintes funções básicas (Paredes, 1994):

- aquisição de dados;

- gerenciamento de dados;

- análise, consulta e manipulação de dados;

- exibição de resultados. 
A função de aquisição está relacionada com a coleta de dados e a conversão dos mesmos para serem empregados num SIG. Estes dados podem ser apresentados na forma de tabelas de atributos, mapas, arquivos digitais de mapas e dados associados de atributos, levantamentos topográficos e aerofotogramétricos, imagens de satélite, dados de população, seja em arquivos pré-existentes ou inseridos através do teclado, scanner ou mesa digitalizadora.

A função de gerência consiste na inserção, remoção ou modificação dos dados e inclui as seguintes operações: armazenamento em banco de dados, manutenção e recuperação de dados, preservação da integridade dos dados, controle do processo e manipulação de arquivos (criar, inserir, modificar).

Segundo Barcelos (1995) apud Paredes (1994) as funções de análise, consulta e manipulação dos dados determinam quais informações podem ser geradas pelo SIG. Nesta etapa podem ser realizadas as seguintes funções: seleção e agregação de informações, controle da geometria e topologia, conjugação de informações temáticas e extração de informações estatísticas.

Com relação a exibição dos resultados, as funções de relatórios de saída de um SIG variam mais na qualidade, precisão e facilidade do que em recursos disponíveis. Relatórios podem ser apresentados como mapas, tabelas de valores ou textos impressos, ou arquivos digitais.

\subsubsection{Características Operacionais Básicas de SIG}

Em nível operacional, algumas das principais características do SIG a serem verificadas estão descritas abaixo (adaptadas de Rodrigues, 1987 apud Paredes, 1994).

a) Quanto a modelagem dos dados, se o sistema:

- aceita dados descritos em termos de feições com atributos, ou seja, a descrição lógica dos dados deve ser orientada para feições ou objetos;

- suporta complexas modelagens de feições, de maneira a suportar o agrupamento lógico de feições simples ou complexas;

- permite a adequada codificação de redes (geometria e topologia) com vistas a operações de roteirização, etc;

- suporta interface com sistemas gerenciadores de bancos de dados relacionais;

- permite a estruturação topológica de dados geométricos;

- distingue a representação gráfica dos dados de sua representação geométrica;

- suporta o armazenamento de séries temporais de dados;

- de consulta de dados apresenta acesso aos mesmos através de linguagem de alto nível, estrutura de menus e ícones ou linguagem padrão SQL (Structured Query Language).

b) Quanto a linguagem de consulta (query language), se o sistema:

- dispõe de interface amigável com o usuário;

- suporta uma interface que permita ao usuário gerar e manipular comandos SQL; 
- permite a integração de extensões de operadores SQL lógicos e aritméticos, de maneira a incluir operadores espaciais. Estes operadores permitirão, por exemplo, a busca de feições, num raio de 100 metros de um ponto, que apresentem atributo acima de um dado valor;

- permite o agrupamento lógico temporário de campos de mais de uma tabela;

- permite a gerência de conjuntos selecionados de dados e a sua utilização integrada por parte de funções de análise de dados;

- permite que registros extraídos de conjuntos selecionados de dados sejam ordenados segundo mais de uma chave de ordenação;

- suporta a apresentação de dados alfanuméricos.

c) Quanto a geração de relatórios, importação e exportação de arquivos, se o sistema:

- permite que o usuário defina o conteúdo e formato de seus relatórios;

- apresenta os relatórios em tela de forma WYSIWYG (what-you-see-is-what-youget), ou seja, que a apresentação em tela reflita perfeitamente o que será produzido em papel.

- facilita a importação e exportação de vários tipos de arquivos, sejam eles bancos de dados, arquivos de texto ou imagens.

d) Quanto a entrada de dados, se o sistema:

- permite ao usuário associar códigos de feição ou atributo a pontos, linhas e áreas;

- suporta o usuário em processos como atribuição de códigos a pontos, linhas e áreas, fechamento de polígonos, reconhecimento de proximidade entre nós e extremidades de linhas, etc;

- suporta plenamente o usuário na criação da topologia. Por exemplo, monta arquivos de arcos e nós, mesclando novos arcos quando necessário, monta polígonos a partir de arcos, gera centróides de áreas, etc;

- oferece recursos de ajuste de bordas entre folhas de mapa, quadras, arruamentos, etc;

- suporta a transferência de dados entre bases de dados.

e) Quanto a edição de dados, se o sistema:

- localiza ou identifica, com eficiência e rapidez, quaisquer feições, ou conjunto de feições, a partir de códigos, coordenadas ou coordenadas de cursor;

- permite a remoção de feições ou parte de feições, a criação de feições e a criação ou modificação de atributos de feições;

- permite a junção forçada de pontos (por exemplo, extremidades de linhas), o alinhamento forçado de pontos em uma linha, inserção de nódulos nas linhas, etc;

- realiza o posicionamento automático de textos e símbolos em mapas, realizando o reposicionamento automático destes quando da mudança de escala ou criação de janelas;

- permite que o usuário defina o posicionamento de símbolos e textos;

- permite ao usuário definir limites de tolerância para que dois pontos sejam considerados um único, em processos de codificação, edição e análise;

- permite a inserção automática de indicação de escala, bem como a sua configuração e edição; 
- permite e facilita a inserção de indicativos de norte fornecendo um banco de símbolos;

- permite a geração de mapas temáticos com diferentes padrões, cores e legendas.

\subsubsection{Rotinas Avançadas de SIG}

Como rotinas avançadas são identificadas algumas funções de análise de dados e apresentação de resultados, sendo necessário verificar se o sistema:

- permite a extração de dados por código ou classe de feição, por atributo ou classe de atributo, por localização ou por critérios combinados espaciais/não-espaciais;

- realiza operações geométricas básicas tais como cálculo de distâncias, perímetros, áreas, etc;

- dispõe de um banco de fórmulas que possam ser aplicadas na filtragem de dados, geração de novas colunas, etc;

- dispõe de recursos para geração de buffers (áreas de abrangência) em torno de pontos, linhas e áreas;

- dispõe de recursos para manipulação e criação de redes (rurais, multimodais, de transporte público);

- dispõe de recursos para a realização de agrupamentos, particionamentos e locação de instalações;

- dispõe de recursos para a obtenção de caminhos mínimos entre dois pontos quaisquer da rede e cálculo de custos de deslocamento;

- realiza sobreposição (overlay) entre polígonos ou famílias de polígonos, propiciando a geração de operações de união e de interseção. O resultado de tais operações deve ser um conjunto de polígonos identificáveis (novas feições);

- gera áreas de busca através da utilização de recursos de buffer e overlay utilizados em conjunto com critérios lógicos (verdadeiro ou falso) de busca;

- realiza operação de generalização e suavização de linhas e polígonos conforme adequado às mudanças de escala e aplicações antevistas;

- dispõe de recursos para a geração e utilização de modelo digital de terreno, para análises de visibilidade, cálculo de altitudes, etc;

- dispõe de recursos para a geração de curvas de nível a partir de modelos digitais de terreno;

- dispõe de recursos para a geração de desenhos de perspectiva de modelos digitais de terreno com superposição de feições ou temas;

- dispõe de recursos que facilitem a extração de informações estatísticas (somatório de todos os valores, maior valor (máximo), menor valor (mínimo), valor médio (média), desvio padrão, etc.), tabelamentos ou classificações, matrizes de correlação, modelos de estimação e avaliação (regressão linear múltipla, logit);

- dispõe de recursos para a geração de gráficos de representação dos dados;

- realiza a procura e identificação de endereços, localizando-os espacialmente. 


\subsubsection{Rotinas Específicas de Transportes}

As rotinas específicas de transportes abrangem uma gama de problemas usuais de transportes, dos quais os principais estão listados a seguir:

- desenvolvimento de matrizes: as quais podem conter inúmeros tipos de dados (origem/destino, de distâncias), extremamente úteis em análises de transportes;

- definições zonais: o processo de definição zonal consiste na determinação dos limites de áreas a serem utilizadas como zonas de tráfego;

- geração de viagens, processo que consiste de três etapas:

- Produção: para estimar o número total de viagens produzidas em cada zona;

- Atração: para prever o número de viagens atraídas para cada zona;

- Balanceamento: consiste na adequação dos totais estimados de viagens produzidas e atraídas, normalmente diferentes quando as etapas de produção e atração são calculadas por diferentes modelos;

- distribuição de viagens: consiste na utilização de modelos para estimar o padrão de viagens entre um conjunto de zonas de origem e destino num ano horizonte de projeto. Os modelos mais conhecidos são:

- Modelo de Fratar;

- Modelo gravitacional;

- Modelos entrópicos;

- Método do Fator de Crescimento Uniforme.

- divisão modal: os modelos de divisão modal foram desenvolvidos para se analisar a escolha do usuário frente a uma oferta de diferentes modos de transportes;

- alocação de tráfego: os métodos de alocação de tráfego são utilizados para estimar o fluxo de tráfego sobre uma rede a partir de uma matriz de fluxos. São eles:

- Método tudo-ou-nada;

- Método incremental;

- Método do equilíbrio;

- Método da restrição da capacidade.

- sistema de rotas: é definido por várias rotas, que constituem-se de uma série de linhas (trechos de vias) e pontos (pontos de parada);

- roteirização: o processo de roteirização consiste na solução do problema de transporte de mercadorias, através da determinação do número de veículos necessários para ligar um depósito a um conjunto de pontos (clientes), bem como do itinerário a ser seguido por cada um, de forma a reduzir os custos de deslocamento de todo o sistema.

\subsection{Uma Avaliação Específica de um Problema de Transportes}

Algumas ferramentas são consideradas básicas na solução da maioria dos problemas de transportes e necessariamente devem estar presentes em um SIG, de forma a permitir sua aplicação plena na área de transportes. Somente com estas ferramentas, dois conceitos de grande importância no planejamento de transportes, que são matrizes e redes, podem ser trabalhados em um SIG-T, de acordo com Silva e Waerden (1997). Ainda segundo os mesmos autores, uma matriz pode conter os valores de caminhos mínimos, calculados em função de rotas de menor custo entre dois pontos, que servirão de base para qualquer análise envolvendo 
redes de transportes. Redes são estruturas compostas de nós e arcos, que unem esses nós, aos quais podem ser alocados fluxos de pessoas, cargas, veículos, etc.

Com o objetivo de avaliar as ferramentas disponíveis para criar, editar e manipular redes e matrizes, propôe-se aqui o uso de uma das mais simples e diretas medidas de acessibilidade encontradas na literatura de planejamento de transportes, a que mede a separação média entre pontos de uma rede. De acordo com Allen et al. (1993), este indicador de acessibilidade é uma medida de esforço para superar a separação espacial entre dois pontos dentro de uma área e pode ser matematicamente representado por:

$$
A_{i}=\frac{1}{N-1} \sum_{j} C_{i j}
$$

Onde $\mathrm{A}_{\mathrm{i}}$ é a acessibilidade da zona $i ; \mathrm{N}$, o número de localidades (pontos) usadas no cálculo; e $\mathrm{C}_{\mathrm{ij}}$ é o "custo" de viagem entre as zonas $i$ e $j$.

A solução deste problema envolve a criação de uma rede de transportes, de uma matriz de caminhos mínimos com todos os nós da rede, cálculos envolvendo colunas de uma matriz, aplicação de fórmulas e apresentação dos resultados em mapas temáticos. Para fins da comparação aqui visada, todos os passos necessários à solução do problema devem ser realizados nos três software e apresentados detalhadamente, com a seguinte seqüência:

- Descrição e objetivo do comando;

- Caminho do comando (como ele é encontrado no programa);

- As opções a serem preenchidas;

- Os resultados obtidos;

- O tempo gasto, quando este for relevante para a análise.

\subsection{Atividades Desenvolvidas}

Em vista do que foi até aqui exposto, a realização deste trabalho exigiu o planejamento de uma seqüência de atividades com a finalidade de direcionar o estudo para alcançar o objetivo do trabalho. Estas atividades, descritas a seguir de forma resumida, são apresentadas em detalhes nos dois próximos capítulos.

1. Análise, apresentação e descrição de todas as ferramentas presentes da diferentes telas de menus dos programas estudados (Capítulo 4);

2. Levantamento de alguns aspectos descritivos dos programas, os quais se enquadram como características básicas de SIG;

3. Levantamento das características básicas operacionais, subdivididas em:

- modelagem dos dados;

- linguagem de consulta;

- geração de relatórios, importação e exportação de arquivos;

- entrada de dados;

- edição de dados;

4. Apresentação das informações obtidas no item 2 sob a forma de check list, organizadas em tabelas;

5. Descrição e indicação do caminho para localização dos comandos utilizados na execução dos itens relacionados à manipulação dos dados; 
6. Check list dos comandos necessários à realização das rotinas específicas de transportes;

7. Apresentação das considerações gerais feitas com relação à solução do problema específico de transportes proposto;

8. Cálculo da medida de acessibilidade no software TransCAD;

9. Cálculo da medida de acessibilidade no software UfosNet;

10. Cálculo da medida de acessibilidade no software ArcView;

11. Apresentação e avaliação dos resultados e conclusões da análise comparativa, com caráter predominantemente quantitativo em alguns aspectos (itens de 2 a 6) e mais qualitativo em outros (itens de 7 a 10). 


\section{Inventário de Ferramentas dos Programas}

Verificou-se a necessidade de uma avaliação detalhada de cada software para que fossem identificados todos os comandos disponíveis, bem como as suas particularidades. Para isso serão mostradas todas as telas de menus dos programas, uma a uma. Estas telas serão mantidas na sua forma original, em língua inglesa, pois têm a finalidade de auxiliar o leitor na avaliação preliminar do software e facilitar a utilização do programa, no caso de uma aquisição posterior. Vale também frisar que o objetivo deste capítulo não é o de fornecer um tutorial ao leitor e sim uma listagem das ferramentas existentes em cada programa analisado.

Os próximos itens estão subdivididos por software analisado, e estes, nos sub-itens Comandos Básicos e Rotinas Avançadas de SIG e Rotinas Específicas de Transportes. No primeiro sub-item citado serão mostradas todas as telas de menu principal, acompanhadas de uma descrição detalhada de cada comando e opções disponíveis. O item Rotinas Específicas de Transportes tem por objetivo apenas relacionar as rotinas específicas de transporte oferecidas pelos programas em questão e ilustrar a sua disposição na barra de menu.

\subsection{Software TransCAD (Versão 3.2)}

\subsubsection{Comandos Básicos e Rotinas Avançadas de SIG}

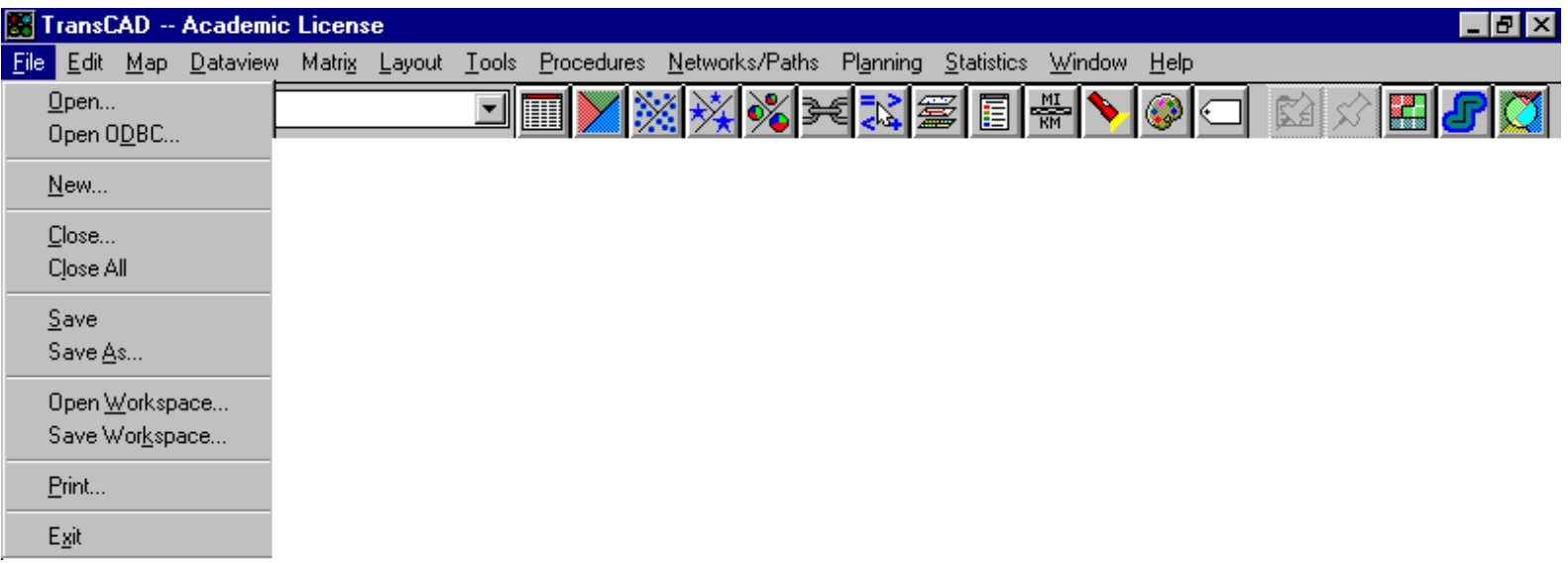

Figura 4.1 - Opção File do menu principal do TransCAD 
Na figura 4.1, no menu referente ao item File, a opção OPEN permite a abertura dos seguintes tipos de arquivos:

- Map (*.map); Dataview (*.dvw); Layout (*.lay), que são os arquivos de mapas, bancos de dados e leiautes, respectivamente, criados no TransCAD;

- Geographic File (*.dbd; *.cdf), arquivo geográfico que armazena a localização e a forma dos atributos gráficos numa camada do mapa;

- dBASE file (*.dbf); Comma-delimited Text (*.txt; .csv); Fixed-format Text (*.asc); Fixed-format Binary (*.bin), arquivos de texto;

- Workspace (*.wrk);

- Matrix (*.mtx); Network (*.net); Matrix View (*.mvw); Route System (*.rts); que são os arquivos de matrizes, redes e rotas com definições específicas requeridas pelo usuário;

- Tiff Image (*.tif); Spot Image (*.bil); Digital Ortophoto (*.doq); Caliper V2.1 Image (*.hdr); que são arquivos com dados gráficos armazenados com representação geométrica em formato matricial;

- Chart (*.cht); Slide Show (*.sli); arquivos de gráficos e apresentação de slides que podem ser criados no TransCAD;

- TIGER/Line (*.f41; *.f51; *.f61; *.zip); Etak Streets (*.mbs); Text Geography (*.geo); Atlas BNA (*.bna); Autocad DXF (*.dxf); BTS Nat. Trans. Atlas (*.Ink; *.nod; *.pnt; *.are); ESRI Export (*.e00); ESRI Ungenerate (*.lin; *.pts); Arc View Shape (*.shp); Interim Terrain Data (*.slf); MapInfo Interchange (*.mif); Ordnance Survey (*.ntf); Vector Product Format (*.dht); Version 2.1 Table (*.tab); que são na sua maioria arquivos originários de outros SIG.

A opção OpEn ODBC (Open DataBase Connectivity) permite diretamente, sem o programa original, a abertura de arquivos de outros bancos de dados. A opção NEW ativa uma caixa de diálogos destinada a criação de novos arquivos, que podem ser do tipo: Table File (arquivo de tabela); Point Geographic File (arquivo geográfico de pontos); Line Geographic File (arquivo geográfico de linhas); Area Geographic File (arquivo geográfico de áreas); Matrix File (arquivo de matriz) e Route Systems (sistemas de rotas). Em todas as opções citadas pode-se clicar na opção Fields (campos) para adicionar colunas ao banco de dados, quantas o usuário desejar, entrando com as seguintes informações: nome; tipo, que pode ser Integer (inteiro), Real Number (número real) ou Character (caracter); tamanho ou largura e número de casas decimais.

Quando da escolha da opção CLOSE aparecerá uma caixa de diálogos permitindo o salvamento das mudanças do mapa, o que pode ser feito nas extensões: Map File (*.map) ou Windows Bitmap (*.bmp), que são as mesmas extensões oferecidas nas opções SAVE e SAVE As. As opções OPEN WORKSPACE e SAVE WORKSPACE permitem abrir e salvar arquivos com extensão *.wrk que armazenam a configuração e posicionamento de telas definidos pelo usuário naquele momento específico. A opção ClOSE All fecha todos os arquivos ativos. Na opção PRINT pode-se efetuar a escolha da impressora (que são as mesmas disponíveis no Windows), o número de cópias, o tamanho do papel, orientação, alimentação do papel e resolução. Também são permitidas as seguintes opções para impressão: $\checkmark$ utilizar o tamanho atual dos pontos ou $\checkmark$ imprimir numa escala fixa. A opção ExIT finaliza a sessão e fecha o programa. 


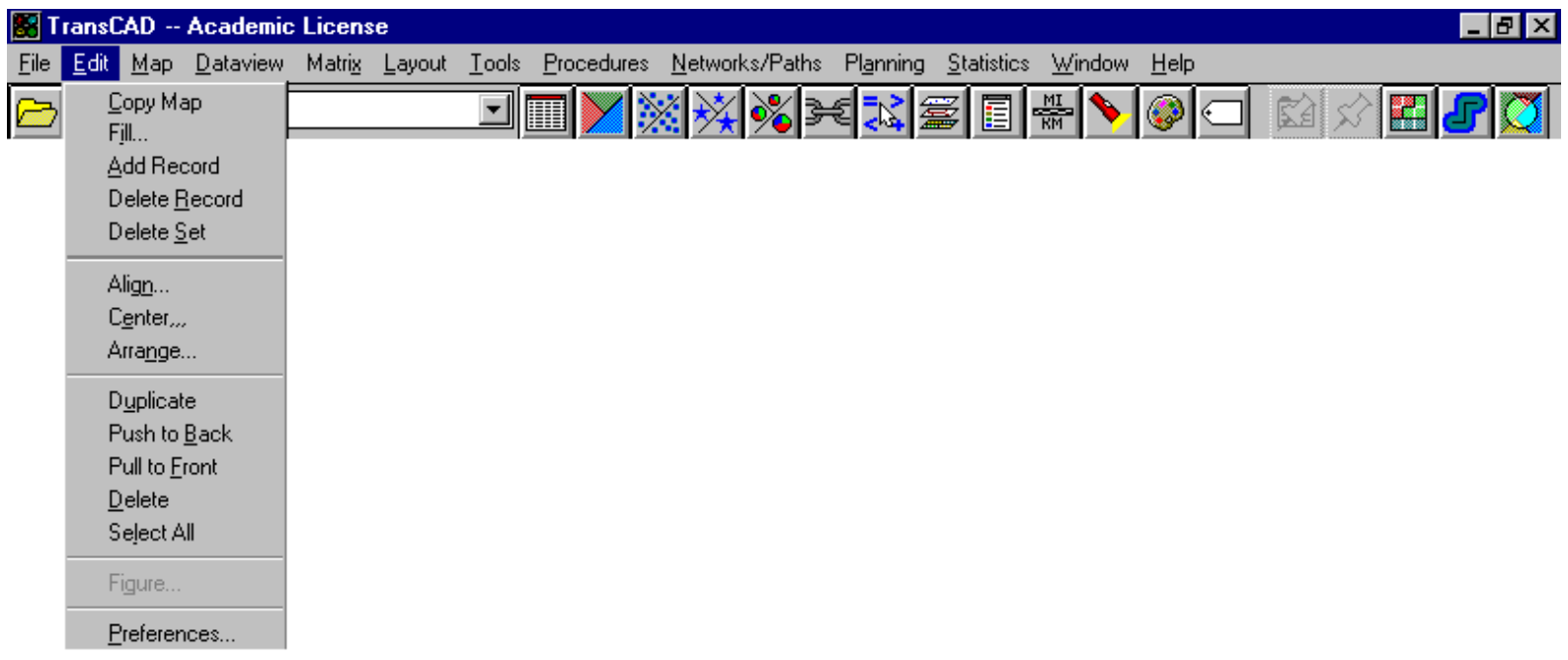

Figura 4.2 - Opção Edit do menu principal do TransCAD

A opção COPY MAP do menu principal Edit mostrado na figura 4.2, é utilizada para copiar o mapa ativo para utilizá-lo em outros aplicativos Windows. As opções FILL, ADD ReCord, Delete ReCord e Delete Set são utilizadas na edição do banco de dados e realizam as seguintes operações:

- FILL: utilizado para preencher uma coluna ou um conjunto de registros. Disponibiliza as seguintes opções para preenchimento: Single Value (um único valor), Sequence (pode ser definida uma seqüência numérica), Formula (esta opção abrirá uma nova caixa de diálogos que permite a criação e edição de fórmulas fornecendo a lista de campos existentes, uma lista de operadores e uma lista de funções disponíveis), Tag (permite o preenchimento dos registros utilizando-se de informações de um determinado campo de outra camada do mapa), Aggregate Data (permite agregar dados de outra camada, que podem ser calculados com base no total dos valores, na média, maior valor ou menor valor), Clear All Values in the range (exclui todos os valores de um conjunto de registros);

- ADD RECORD: comando utilizado para adicionar registros ao banco de dados, um a um, o que só pode ser feito em arquivos geográficos de pontos. A adição de registros nos arquivos de linhas e áreas só pode ser feita diretamente no mapa através das ferramentas de edição próprias para isto;

- DELETE RECORD: exclui um registro;

- DELETE SET: exclui todos os registros selecionados no mapa.

As opções Align, Center, Arrange, Duplicate, Push to Back, Pull to Front, DELETE e SELECT All são utilizadas para editar os desenhos inseridos "à mão livre" pelo usuário (Freehand Items). A inserção desses objetos pode ser feita através de uma caixa de ferramentas ativada pela opção Tools $\Rightarrow$ Toolbox, que será detalhada em momento oportuno. Ressalta-se que as opções CENTER e ARRANGE só estão ativas quando se está trabalhando com leiautes. A opção FIGURE não encontrou-se ativa em nenhuma das janelas de trabalho.

A opção PREFERENCES permite a definição de configurações dos itens: System, Map, Themes, Dataview e Freehand/Layout. Deixando-se ativa a opção System pode-se definir: a 
unidade do mapa (milhas, quilômetros, metros, jardas, pés, milhas náuticas, furlongs = 201,17m, ou varas), a unidade da página (polegadas, centímetros, pontos de impressão, etc.), as margens do papel, o fator de zoom, segmentos/bandas e identificação do caminho para localização do arquivo. Na opção Map pode-se definir os estilos de pontos, linhas e áreas, no início do programa. Podem ser definidos os seguintes parâmetros: cores, opções de seleção de atributos gráficos, para que estejam total ou parcialmente contidos em outro objeto; posicionamento de legendas, no mapa ou em uma janela separada; e opções para definição das fontes (tipo, tamanho, etc.) dos rótulos e legendas. Na opção Themes permite-se a definição do número de classes, cores e estilos de cada mapa temático. Na opção Dataview são definidas as configurações de fontes dos bancos de dados, podendo-se optar pela seleção ou não dos itens: grade, permissão apenas para leitura, mostrar os itens selecionados e definir o método para ordenar campos numéricos (do maior para o menor ou do menor para o maior). $\mathrm{Na}$ opção Freehand/Layout é possível determinar as características do desenho (estilo, espessura e cor da borda, estilo e cor do preenchimento) e definir o tipo, cor e espaçamento da fonte.

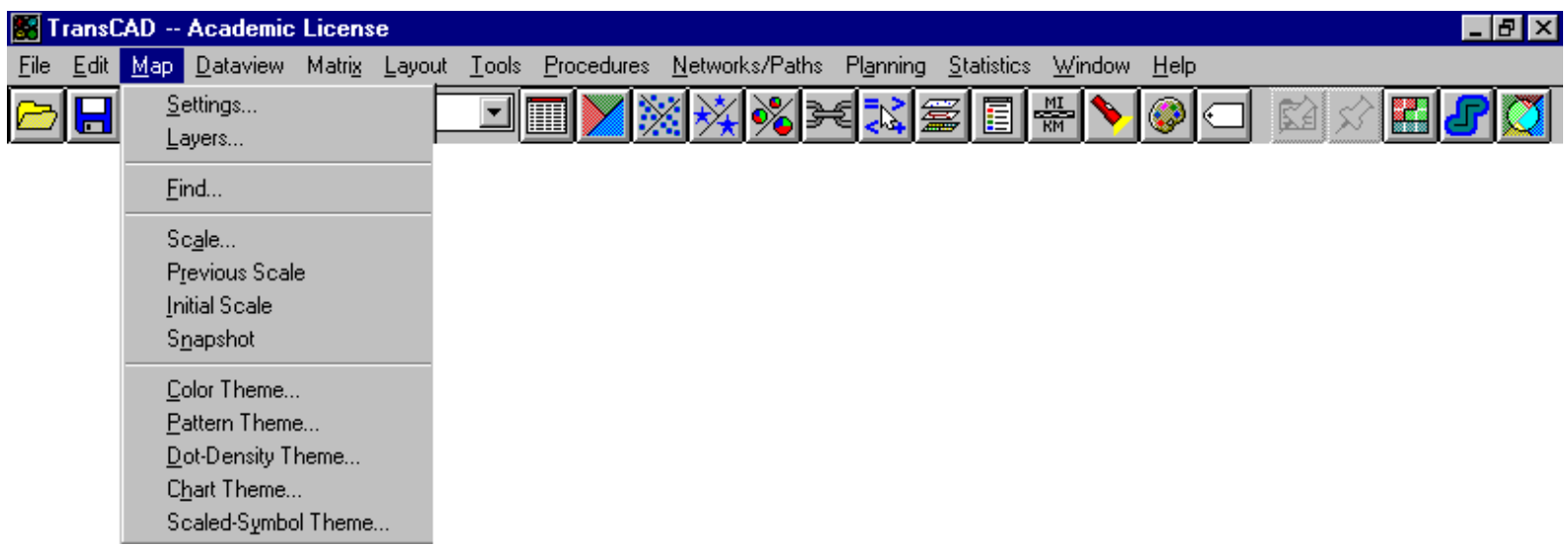

Figura 4.3 - Opção Map do menu principal do TransCAD

No menu Map da figura 4.3, a opção SETTINGS possui informações relativas ao mapa, tais como: nome do arquivo e localização, nome do mapa, estilo e cor do fundo, projeções (podendo ser configuradas a partir de uma lista de classes com suas respectivas projeções disponíveis ou ainda, podendo ser escolhido um sistema de coordenadas baseado em latitude e longitude ou nos eixos X e Y), e a opção de mostrar ou não a legenda. No caso desta última, é possível configurá-la clicando na caixa Legend Settings e definindo as opções: localização (em uma janela separada ou anexada ao mapa), título, nota de rodapé, conteúdo da legenda (níveis, registros selecionados e mapas temáticos), escala, subtítulos e configurações das fontes.

Na opção LAYERS é possível visualizar todos as camadas existentes no mapa e a sua posição no momento de redesenho do mapa (sobre ou sob as demais), o que pode ser alterado modificando-se a seqüência de apresentação. Podem ser incluídas novas camadas ou excluídas camadas existentes, sendo que todas as existentes podem ser configuradas quanto ao seu estilo, rótulos e escala, renomeadas e definidas como aparentes ou não no mapa. A opção FIND possibilita a procura por um endereço, escrevendo o mesmo e indicando a cidade, o estado e o código postal, por uma cidade, estado, país, lugar conhecido e um código postal. Qualquer atributo gráfico do mapa pode ser encontrado fornecendo-se as informações de 
camada, campo da camada e o valor relativo ao atributo constante naquele campo, e podem ser identificados pontos através de suas coordenadas, entrando com os valores de latitude e longitude.

A opção SCALE disponibiliza as seguintes alternativas para se definir a escala a ser utilizada: razão (variando de 1:1 até 1:5000000), milhas por polegadas (definindo-se um valor), largura e altura do mapa, e mostrar inteiramente uma camada (pode-se identificar a camada desejada, sendo possível enquadrar todos os registros ou apenas uma seleção preestabelecida e ajustar a forma da janela). A opção PREVIOUS SCALE restaura o mapa à última escala utilizada e o centraliza, INITIAL SCALE restaura o mapa à sua escala original e o centraliza, SNAPSHOT restaura o desenho do mapa ao modo como ele se parecia quando foi aberto ou criado.

As opções Color Theme, Pattern Theme, Dot-Density Theme, Chart Theme e SCALED-SYMBOL THEME são destinadas a criação de mapas temáticos, o que também pode ser feito diretamente, com a utilização dos ícones disponíveis na tela de menu (o que será abordado posteriormente), ou a partir de uma seleção no banco de dados. As duas primeiras opções, COLOR THEME e PATTERN THEME são semelhantes, elas agrupam os atributos gráficos em classes baseadas nos valores contidos nos campos de dados. É permitida a definição dos seguintes parâmetros: Field (pode-se escolher a classe, constante no banco de dados, a ser utilizada), Method (igual número de campos, igual tamanho de intervalos, igual área dos campos, igual comprimento dos campos, lista de valores, desvio padrão, médias aninhadas), \# Classes (número de classes), Options (ignorar valores acima ou abaixo de determinado valor, desvio padrão por classe, forçar a separação entre as classes em determinado valor, tratar zeros como valores ausentes, completar os maiores e menores valores em cada classe para facilitar a leitura da legenda) e Clear (limpar o mapa temático). Opções disponíveis com a abertura de novas caixas de diálogo: definir estilos de cores e padrões (Style), definir o método de agrupamento manualmente (Manual) e confirmar a criação de determinado número de grupos (Sets).

A opção de mapa temático Dot-DENSITY THEME, disponível apenas para camadas de áreas, utiliza pontos ou outros símbolos no mapa para demonstrar os valores de um ou mais campos de dados, sendo que cada ponto representa uma quantidade de dados. As opções disponíveis neste comando são: definição de um ou mais campos a serem utilizados, utilizar a opção MapWizard ou definir o valor do ponto manualmente, limpar o mapa temático (Clear) e definir estilos (Style). Os valores dos dados podem ser ilustrados utilizando-se temas gráficos, disponíveis na opção PIE AND BAR CHART THEME, a qual permite a utilização de gráficos do tipo "pizza" ou barras (opção em 3D), que podem ser verticais ou horizontais e empilhadas (quando se está trabalhando com mais de um campo de dados). As opções disponíveis nesta janela são: definição dos valores, o que pode ser feito automaticamente (utilização de MapWizard) ou manualmente (definindo-se os menores e maiores valores, bem como o tamanho do gráfico, para os gráficos com barras pode-se alterar também a largura das barras), Clear e Style. Finalmente, a opção ScAled-Symbol THEME utiliza símbolos de diferentes tamanhos ou linhas de diferentes espessuras para representar os valores dos dados, e as opções disponíveis para configuração são semelhantes às oferecidas pela opção PIE AND CHART THEME: definição de valores automática ou manual, Clear e Style. 


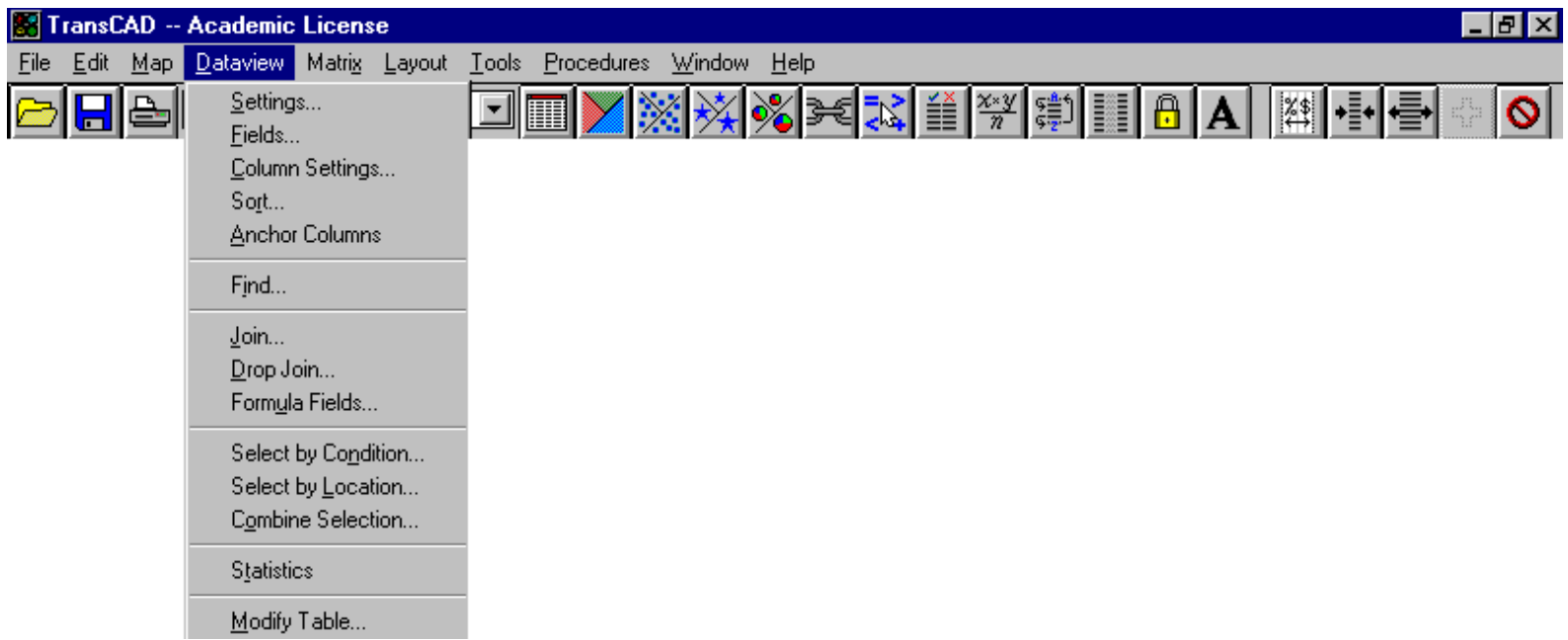

Figura 4.4 - Opção Dataview do menu principal do TransCAD

A opção SETTINGS do menu principal Dataview, figura 4.4, permite a definição e visualização de parâmetros relativos ao banco de dados, tais como o nome do arquivo, nome do banco de dados, fontes e opções de: ausência ou não de grade, arquivo só para leitura e realce para conjuntos de registros selecionados. Na opção FIELDS pode-se adicionar ou excluir campos do banco de dados (vale observar que os campos excluídos neste caso não são apagados, apenas não serão visualizados no banco de dados). Na opção ColuMN SETTINGS é definido, para cada coluna, o formato numérico e pode ser ativada ou não a opção apenas leitura. A opção SORT permite a classificação ascendente ou descendente dos valores segundo determinada(s) coluna(s) e a opção ANCHOR COLUMNS é utilizada para fixar e liberar colunas. Através da opção FIND pode-se encontrar determinado valor em determinado campo ou coluna.

As opções JoIn, DROP JOIN e FORMUla FIELDS são utilizadas para executar operações com bancos de dados. A opção JoIN permite unir tabelas com dados a uma camada do mapa, sendo necessário definir a camada do mapa que se deseja unir, o banco de dados (que deverá ser um arquivo extensão *.dbf, *.txt, *.csv, *.asc ou *.bin) e o campo comum ao banco de dados referente à camada do mapa e ao outro banco de dados, através do qual o TransCAD poderá associar uma tabela à outra. As demais opções disponíveis nesta janela são: mostrar ou não a janela contendo a união e permitir ou não todos os tipos de uniões. A opção DROP JOIN apresenta a tabela unida ativa e o ícone drop, que, quando acionada, exclui a tabela selecionada. A opção FORMULA FIELDS apresenta uma caixa de diálogos idêntica à mostrada na opção Edit $\Rightarrow$ Fill $\Rightarrow$ Formula e é utilizada para adicionar e preencher novas colunas a partir de uma fórmula. As opções SELECT by CONDition e SElECt by LocATiOn executam operações para a seleção de dados. A primeira, SElECT By CONDITION, abrirá uma caixa de diálogos que permite a definição de uma condição de seleção, disponibilizando listas de campos existentes, operadores, funções e valores presentes no campo selecionado. Permite a alteração ou definição do nome destinado à seleção, o método de seleção (criar uma seleção, adicionar a uma já existente, remover de uma seleção ou fazer uma sub-seleção) ou utilizar uma condição prévia, além de oferecer as opções: Clear (para limpar a seleção ativa na caixa de diálogos), Save (pode-se salvar a seleção como um arquivo *.txt) e Load (para abrir uma seleção salva em arquivo *.txt). Na caixa de diálogos ativada pela opção SELECT BY LOCATION são definidos os seguintes parâmetros: camada e conjunto de seleções, se já 
existente, na qual se baseará a seleção; condições especiais usadas para a seleção (dentro ou não, dentro de, não dentro de ou perto e dentro de " $x$ " milhas); determinação de um nome para o conjunto de seleções que está sendo criado; e determinação do método de seleção (criar uma nova seleção, adicionar a uma já existente, remover de uma seleção ou fazer uma subseleção). Na opção COMBINE SELECTION pode-se combinar seleções através dos seguintes métodos: oposto de uma seleção, quaisquer das seleções, ambas as seleções e uma seleção ou outra; está disponível, também, a opção para nomear a nova seleção.

A opção Statistics faz os cálculos estatísticos para todas as colunas numéricas do banco de dados ativo e salva esta nova planilha como um arquivo do tipo *.dbf. As operações estatísticas realizadas são: contagem de valores, somatório, maior e menor valores, média e desvio padrão. A opção MODIFY TABLE ativa uma caixa de diálogos que contém dados relativos a cada campo da tabela visível na tela naquele momento: nome, tipo, largura, número de casas decimais e índice, os quais podem ser alterados pelo usuário. Pode-se também inserir ou excluir campos e alterar a sua posição (seqüência de visualização). A opção Automatically Generate Records abre a janela Settings, na qual pode-se optar por três diferentes métodos para gerar registros: adicionar um número fixo de registros; adicionar registros provenientes de um banco de dados existente, especificando a seleção e o campo do qual serão copiados os dados; adicionar registros para cada valor único de determinado campo de um banco de dados.

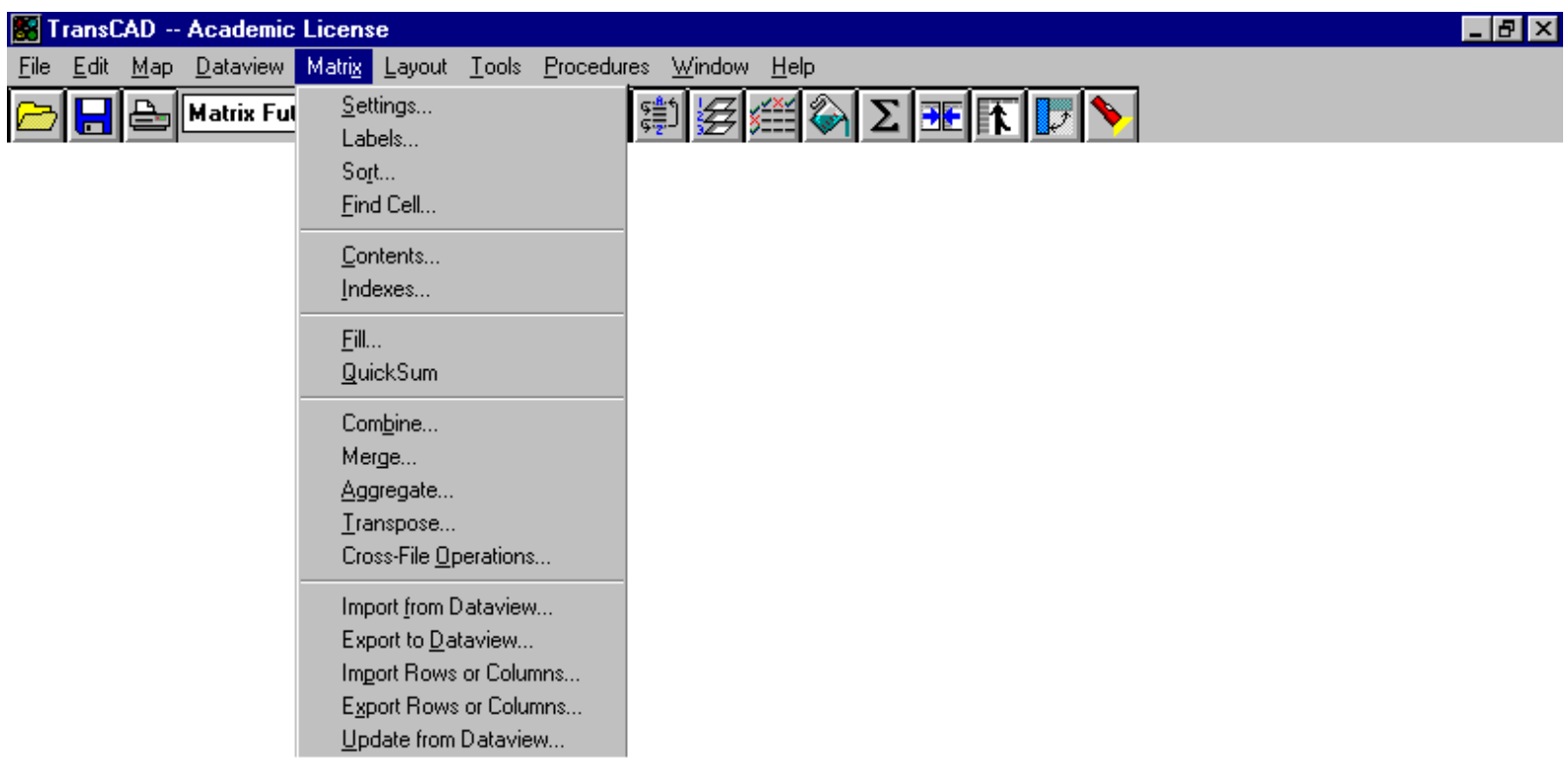

Figura 4.5 - Opção Matrix do menu principal do TransCAD

As opções disponíveis no menu Matrix, figura 4.5, são utilizadas na manipulação de matrizes. Nota-se que primeiramente deve-se criar uma matriz através da seqüência de comandos File $\Rightarrow$ New $\Rightarrow$ Matrix File. A opção SETTINGS permite a definição e visualização dos seguintes parâmetros da matriz: nome, definições de fontes e as opções de: grade visível ou não, arquivo somente para leitura, marginais (normalmente o somatório de linhas e colunas, o que neste caso pode ser também a média, valor mínimo, valor máximo ou uma contagem do número de valores) e número de casas decimais. A opção LABELS ativa a caixa de diálogos Matrix Labels destinada a rotular linhas e colunas de uma matriz, determinando- 
se o banco de dados do qual serão retirados os nomes, o campo contendo o número de identificação (ID) e o campo contendo os rótulos (nomes) desejados; a opção Clear é utilizada para excluir a definição de rótulos e voltar à condição de identificação original de linhas e colunas. A opção SORT permite a classificação dos dados através dos métodos: rótulos, marginais ou campo do banco de dados, nesta última opção é necessária a definição do banco de dados a ser utilizado, o campo contendo os IDs de linhas ou colunas e o campo no qual a classificação irá se basear. Através da opção FIND CELL pode-se identificar um registro informando-se os rótulos da linha e coluna.

No comando CONTENTS pode-se visualizar o conteúdo de um arquivo de matrizes, bem como adicionar, remover ou renomear as matrizes constituintes nesse arquivo. O ícone File Info acessa uma caixa de diálogos contendo as seguintes informações relativas ao arquivo de matrizes: o caminho para localização do arquivo no computador (path), o tamanho em bytes, descrição, dimensões ( $\mathrm{n}^{\circ}$ de matrizes, $\mathrm{n}^{\circ}$ de linhas e colunas e $\mathrm{o} \mathrm{n}^{\circ}$ total de células), dados (tipo, formato, modo e ordem), índices ( $n^{\circ}$ de índices, nome, tipo e tamanho). A opção INDEXES permite adicionar, remover ou renomear índices e mostra uma listagem de todos os índices de linhas e colunas disponíveis. Índices de matrizes são utilizados para se visualizar parte de uma matriz, e nada mais são que uma lista de IDs de linhas e colunas. Na adição de um novo índice (Add Index) será ativada uma caixa de diálogos onde o usuário deverá definir: o banco de dados a partir do qual a matriz originou-se, o campo que contém os IDs das linhas ou colunas da matriz, um nome para o novo índice, a utilização de linhas, colunas ou ambas, o campo contendo os IDs para o novo índice e a seleção a ser utilizada, se houver alguma.

A opção FILL permite o preenchimento das células de uma matriz através dos seguintes métodos: preencher com determinado valor, multiplicar ou dividir por determinado valor, adicionar ou subtrair algum valor de cada célula, adicionar os valores de uma matriz ou somatório dos valores de várias matrizes à matriz que está sendo preenchida, preencher com o resultado da divisão ou multiplicação de duas matrizes, utilizar uma fórmula (aparecerá uma caixa de diálogos para a construção da fórmula com base nas listas de matrizes existentes, operadores e funções) ou limpar todas as células. O preenchimento pode ser feito em todas as células, na diagonal principal ou em uma seleção; apenas na matriz ativa, em todas as matrizes ou em uma seleção de matrizes. A opção QUICK SUM realiza um somatório de todas as matrizes do arquivo e mostra o resultado em uma nova matriz.

As opções Combine, Merge, Aggregate, Transpose e Cross-File Operations são comandos utilizados para executar operações comuns em matrizes. A opção COMBINE combina um número qualquer de arquivos de matrizes unindo-os em um arquivo de matrizes que contém todos os dados das matrizes originais. Para realizar esta operação estão disponíveis dois métodos: manter todas as linhas e colunas ou manter apenas linhas e colunas que aparecem em todas as matrizes. A opção MERGE é utilizada para acrescentar os valores de uma matriz em outra. Na caixa de diálogos ativada por esta opção deve-se definir: a matriz na qual serão incluídos os valores (matriz ativa), o arquivo de matrizes, e a matriz a partir da qual serão retirados os valores a serem incluídos. As demais opções disponíveis nesta janela são: os valores ausentes devem ser ignorados ou devem substituir os valores existentes, e podem ser atualizados todos os dados da matriz ou uma seleção de dados. O comando AGGREGATE agrega linhas e/ou colunas de uma matriz e produz um novo arquivo de matriz contendo os valores agregados. Nesta opção é necessário definir: o banco de dados que contém a informação requerida, os campos da matriz que contêm os IDs de linhas e colunas e os 
campos que contêm os IDs da nova matriz. A opção TRANSPOSE transforma cada linha da matriz em uma coluna e vice-versa, criando um novo arquivo de matriz, salvo com extensão *.mtx. Nesta opção pode-se acessar uma janela, através do ícone Options disponível na caixa de diálogos Save As de matrizes ativada pela ferramenta em questão, que fornece uma descrição da matriz que está sendo gerada, opções para armazenamento (automático, short integer, long integer, números com pontos flutuantes, números com precisão dupla), para armazenamento em arquivo (automático, memória, arquivo), modo de armazenamento (automático, denso, escasso) e ordem de armazenamento (automático, maior linha, maior coluna). A opção CROSS-FILE OpERATIONS permite realizar operações em arquivos de matrizes. Na caixa de diálogos ativada estão disponíveis as seguintes operações: multiplicação, divisão, adição ou subtração de cada célula de uma matriz pela célula correspondente de outra matriz e multiplicação de duas matrizes. Em quaisquer das opções devem ser definidos: os arquivos de matrizes e as matrizes a serem utilizadas na operação, um fator de escala, além de especificar se os valores ausentes serão tratados como zeros ou não.

Um banco de dados pode ser convertido em uma matriz utilizando-se da opção IMPORT FROM DATAVIEW, onde são definidos os IDs de linhas e colunas da nova matriz, optando-se pela utilização de uma seleção ou todos os valores e especificando-se os campos do banco de dados a serem utilizados, o que pode ser apenas uma seleção ou todos os valores. O caminho inverso, transformar uma matriz em um banco de dados, também pode ser feito utilizando-se do comando EXPORT TO DATAVIEW, o qual criará um nova tabela contendo uma coluna com os identificadores de linha, uma coluna com o identificadores de coluna e uma coluna de dados para cada matriz dentro do arquivo de matrizes. Pode-se importar linhas ou colunas de uma matriz para uma tabela e vice-versa, e exportar linhas ou colunas de uma matriz para uma tabela, utilizando-se dos comandos IMPORT ROWS OR COLUMNS e EXPORT ROWS OR COLUMNS. Na opção IMPORT ROWS OR COLUMNS deve-se definir, primeiramente, as linhas ou colunas para as quais deseja-se importar os dados (podendo-se neste caso utilizar uma seleção ou todas as linhas ou colunas da matriz ou banco de dados), o banco de dados/matriz de onde serão extraídos os dados, o campo do banco de dados/matriz que contém os IDs da linha ou coluna e os campos do banco de dados/matriz que contêm os dados a serem importados para cada linha ou coluna selecionada. Na opção EXPORT ROWS OR CoLUMN podem ser exportados os dados de uma seleção de colunas ou linhas e/ou os valores marginais de uma matriz para uma nova tabela, que será armazenada num arquivo extensão *.dbf, ou para uma tabela existente. Nesta última opção deve ser definido o banco de dados para o qual deverão ser exportados os dados, o campo do banco de dados que contém o ID da linha ou coluna da matriz e os campos onde serão inseridos os dados. A atualização de uma matriz com base em um banco de dados pode ser feita com a utilização do comando UPDATE FROM DATAVIEW. Nesta opção são especificados o banco de dados do qual serão retirados os dados, os IDs da linha e coluna, o campo dos dados, a seleção e o método a ser utilizado: substituir os valores em um matriz ou adicionar os valores à matriz, tratando os valores ausentes como zeros ou não. 


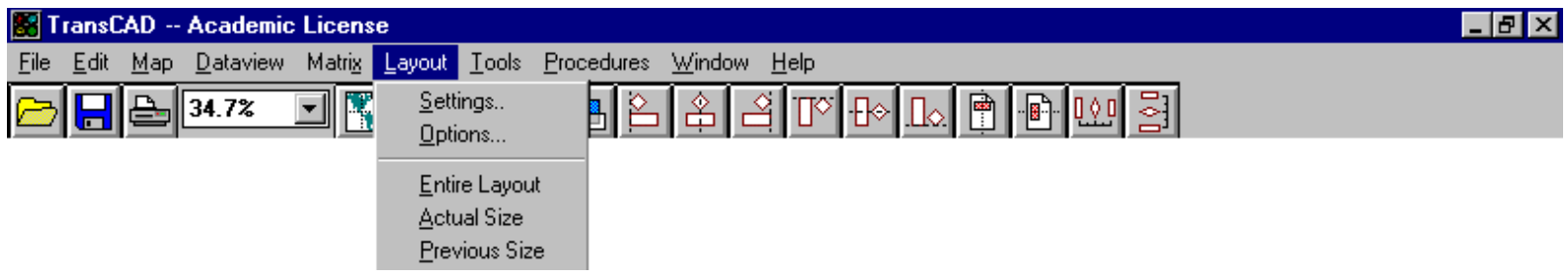

Figura 4.6 - Opção Layout do menu principal do TransCAD

O menu Layout, figura 4.6, só está ativo quando se está trabalhando com leiautes, ele apresenta as opções: SETTINGS e OptiOns para definir-se configurações e opções de visualização, respectivamente. Na opção SETTINGS é indicado o nome do arquivo e são definidos: o nome do leiaute, a impressora a ser utilizada (todas as disponíveis no Windows), o tamanho do papel, a orientação (Portrait ou Landscape) e a altura e largura (em $\mathrm{n}^{\mathrm{o}}$ de páginas). O comando OPTIONS apresenta as seguintes opções: $\checkmark$ mostrar réguas, $\checkmark$ mostrar linhas de corte do papel, $\checkmark$ mostrar a grade de amarração, $\checkmark$ amarrar os itens à grade, definir as unidades da régua e grade (polegadas, centímetros, pontos de impressão e picas), mostrar marcas a cada uma polegada, uma polegada e 1/2, uma polegada e $1 / 4$, etc e as opções de visualização como leiaute inteiro, tamanho atual ou tamanho anterior.

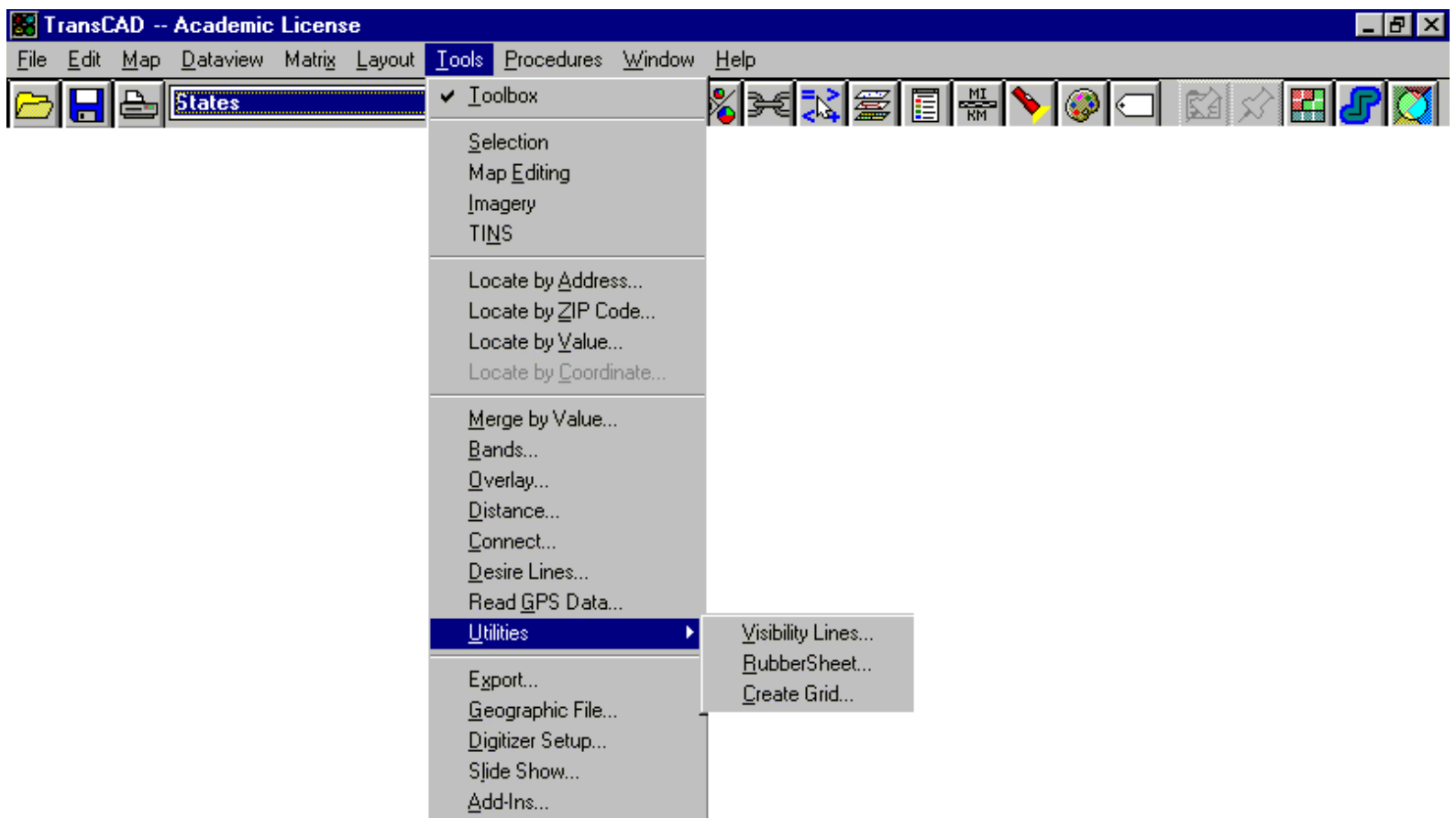

Figura 4.7 - Opção Tools do menu principal do TransCAD

A primeira opção do menu Tools, figura 4.7, ativa a caixa de ferramentas ToOLBOX mostrada na figura 4.8 . 


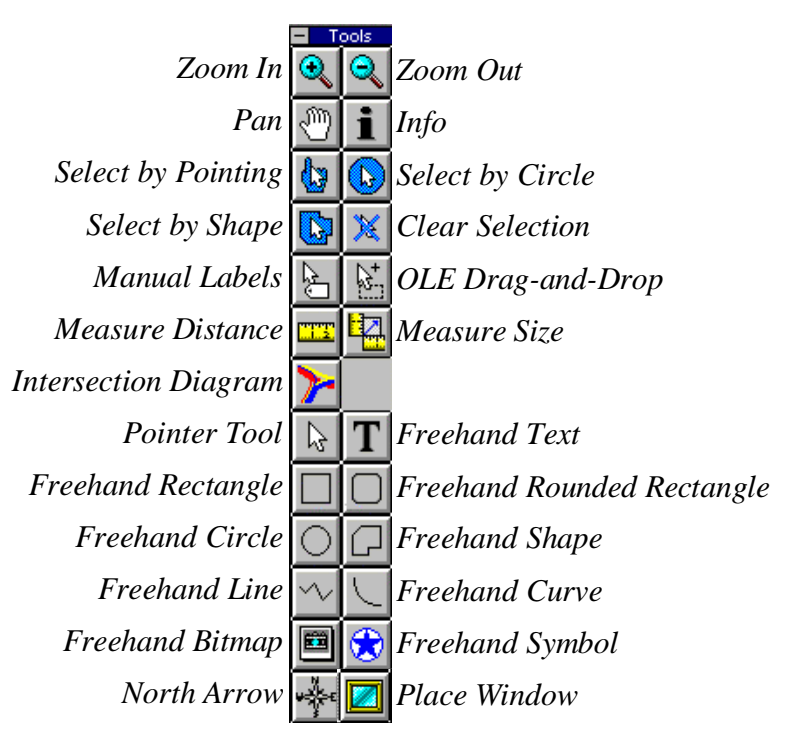

Figura 4.8 - Caixa de ferramentas do TransCAD

Na caixa de ferramentas da figura 4.8, as opções Zoom In, Zoom Out e Pan são utilizadas para alterar a visualização da tela, a opção Info permite a obtenção de informações alfanuméricas relativas aos atributos gráficos do mapa. As opções de seleção (by Pointing, by Circle e by Shape) são utilizadas para selecionar os atributos gráficos do mapa; esta seleção pode ser removida utilizando-se o ícone Clear Selection. As opções utilizadas para se obter medidas no mapa são: Measure Distance (distâncias) e Measure Size (áreas e perímetros). A opção Intersection Diagram é utilizada na criação de diagramas de interseção, os quais ilustram o fluxo presente em interseções de três ou mais vias de transporte. Esta opção ativa uma caixa de diálogos na qual definem-se os campos que contêm os fluxos em ambos os sentidos e as configurações a serem apresentadas na tela de visualização do diagrama, tais como: título, nota de rodapé, campo contendo os nomes das vias, para que o TransCAD possa rotulá-las e mostrar ou não os rótulos dos valores dos fluxos atuais. O TransCAD estima os movimentos na interseção e apresenta o diagrama da interseção. Os ícones intitulados Freehand... são utilizados na criação de desenhos "à mão livre"; sendo que as opções Freehand Bitmap e Freehand Symbol permitem a inserção de um arquivo de bitmap (*.bmp) e de símbolos, presentes nas bibliotecas do Windows e do TransCAD, respectivamente. Na opção North Arrow pode-se inserir uma indicação de norte, O TransCAD possui, também, uma biblioteca com este tipo de símbolo. E, por fim, a opção Place Window, ativa somente para leiautes, facilita a inserção de telas (janelas) em um leiaute.

A opção SELECTION, mostrada na figura 4.7, ativa uma caixa de diálogos, figura 4.9, que é utilizada para editar seleções existentes e seus respectivos nomes. As seleções são definidas no banco de dados e podem ser visualizadas tanto no banco de dados como no mapa. Pode-se identificar inclusive o número de registros da seleção ativa. 


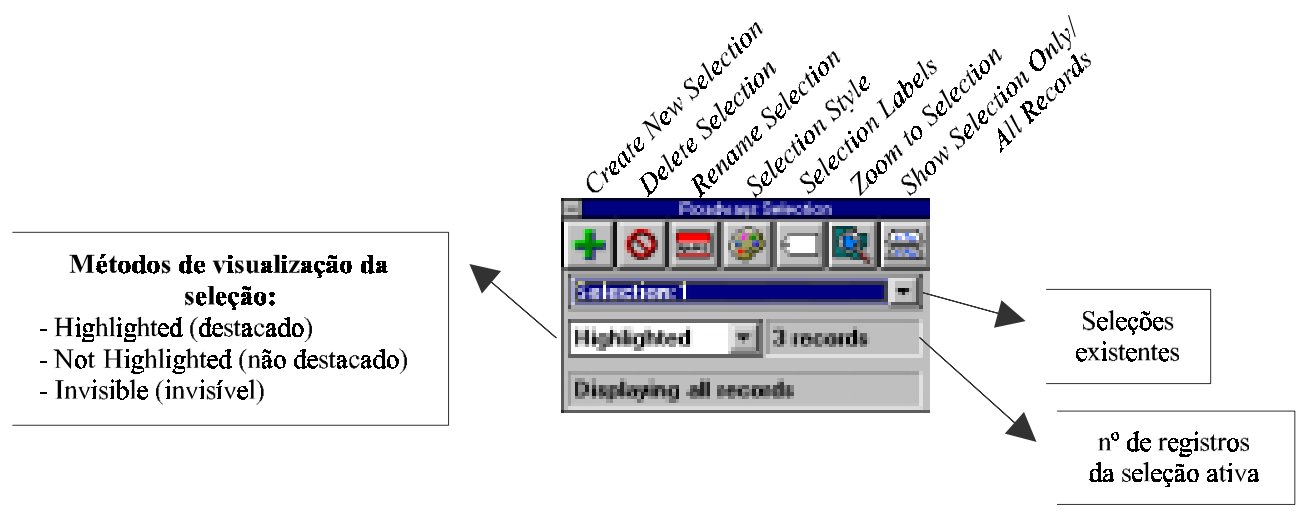

Figura 4.9 - Caixa de diálogos ativada pela opção SELECTION

A opção MAP EDITING, figura 4.7, ativa uma caixa de diálogos utilizada na edição, inserção e remoção de elementos do mapa. A sua configuração varia de acordo com a camada do mapa ativa: pontos, áreas ou linhas, como é mostrado nas figuras 4.10, 4.11 e 4.12, respectivamente.

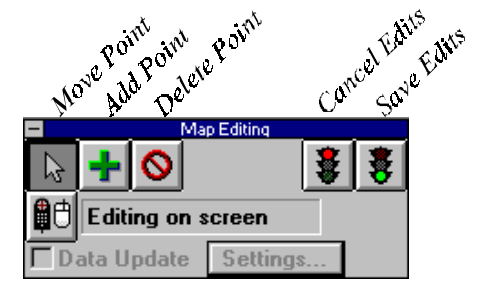

Figura 4.10 Edição de pontos do mapa

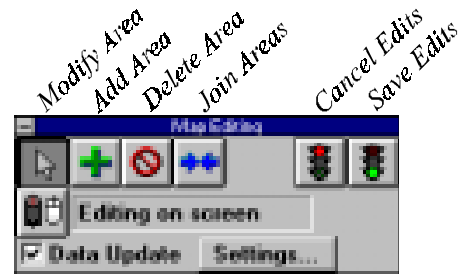

Figura 4.11 Edição de áreas do mapa

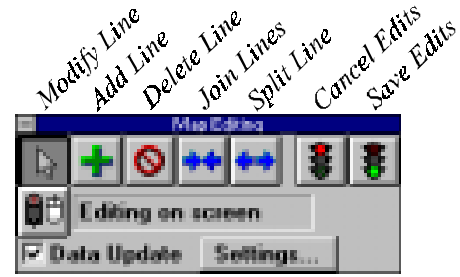

Figura 4.12 Edição de linhas do mapa

O ícone 哩, presente nas figuras 4.10, 4.11 e 4.12, é usado para alterar o modo de edição do mapa: na tela ou utilizando uma mesa digitalizadora, que possibilita a edição com base em mapas ou desenhos em papel. A opção Data Update, disponível apenas nas figuras 4.11 e 4.12, atualiza os dados estimando os valores corretos dos dados constantes nas tabelas quando são agrupados atributos gráficos ou divididos os já existentes. Na opção Settings é ativada uma caixa de diálogos, onde pode ser visualizado e alterado o modo de atualização dos dados quando da união ou separação de atributos gráficos. As opções disponíveis quando se está unindo elementos são: deixar o novo campo em branco, copiar o primeiro dos valores do campo original para o novo campo (utilizado para campos de textos), adicionar os novos valores aos valores originais (utilizado para campos numéricos), copiar o maior ou o menor valor dos campos originais para o novo campo ou utilizar a média entre dois valores (o primeiro do campo ativo e o outro de um campo a escolher dentre os demais disponíveis). $\mathrm{Na}$ separação de elementos pode-se utilizar os seguintes métodos de atualização: deixar o novo campo em branco, copiar os valores do campo original para o novo campo (normalmente utilizado para campos de textos), dividir o valor original entre os novos campos, baseado na área ou comprimento relativo (utilizado para campos numéricos).

A opção IMAGERY da figura 4.7, disponível apenas quando se está trabalhando com imagens, ativa a caixa de diálogos ilustrada na figura 4.13, a qual possibilita a inserção de pontos na imagem, cuja localização é identificada por valores de latitude e longitude, bem 
como a utilização de diferentes projeções de mapas para minimizar distorções causadas pela curvatura da terra. O TransCAD armazena todas as informações de localização em arquivos geográficos utilizando valores de longitude e latitude em milionésimos de graus, o que significa que as localizações podem ter uma boa precisão. Quando novos arquivos geográficos são criados e adicionados campos a eles, o TransCAD converte as localizações definidas pelo usuário em graus de longitude e latitude e armazena estes valores no arquivo geográfico. As informações importadas de outro programa para o TransCAD são automaticamente convertidas em graus (e respectivas frações) de longitude e latitude.

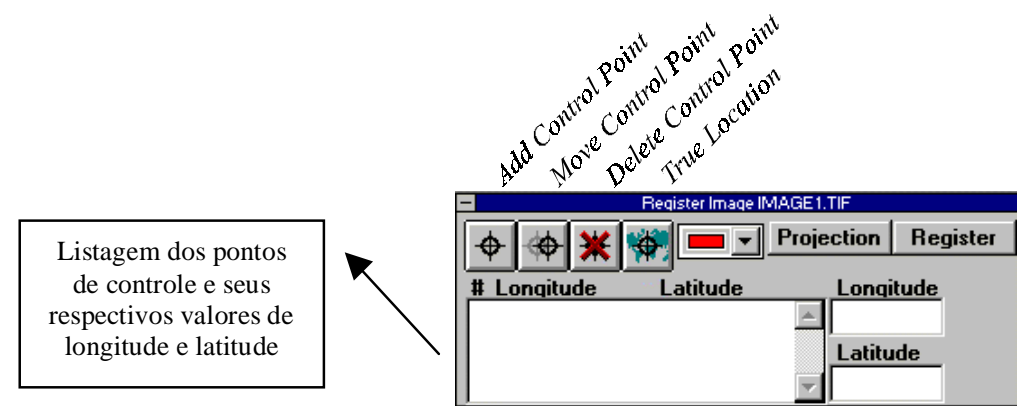

Figura 4.13 - Caixa de diálogos ativada pela opção IMAGERY

Na figura 4.13, a opção Projection permite alterar a projeção da imagem ou desenho acessando uma caixa de diálogos com as opções: Projection e Coordinate System. As classes de projeções disponíveis são: The U.S. and Canada, The World, The Equatorial Regions, The Polar Regions e The Middle Latitudes. As classes de sistemas de coordenadas disponíveis são: U.S. State Plane (NAD 27), U.S. State Plane (NAD 83), Universal Transverse Mercator (UTM) e World Coordinate Systems. Utilizando-se de um sistema de coordenadas pode-se optar pelas opções: $\checkmark$ Longitude and Latitude ou $\checkmark X$ and $Y$ (feet). A opção Register registra os pontos de controle definidos pelo usuário.

Um Modelo Digital do Terreno (MDT) ou Digital Elevation Model (DEM) é um banco de dados específico que representa o relevo de uma superfície entre pontos de elevação conhecida. O MDT é referenciado a um sistema de coordenadas conhecido, sendo que os valores das coordenadas são armazenados como graus de longitude e latitude. Para que o TransCAD utilize funções tridimensionais deve-se, primeiramente, criar um TIN (triangulated irregular network), que é uma estrutura de dados transitória criada, a partir de um processo de interpolação dos pontos de elevação, para suportar as funções de elevação da superfície. A opção TINS, figura 5.7, ativa uma caixa de diálogos onde são definidos os seguintes parâmetros para a criação de um TIN: o campo do banco de dados que contém os valores da dimensão "z" a ser utilizado, o nível de interpolação $(0,1,2$ ou 3$)$ e e a opção de desenhar ou não um contorno no TIN gerado. Através desta caixa de diálogos pode-se, também, abrir um TIN existente. Após a criação ou abertura de um TIN a caixa de ferramentas TINs Toolbox, ilustrada na figura 4.14, estará disponível. 


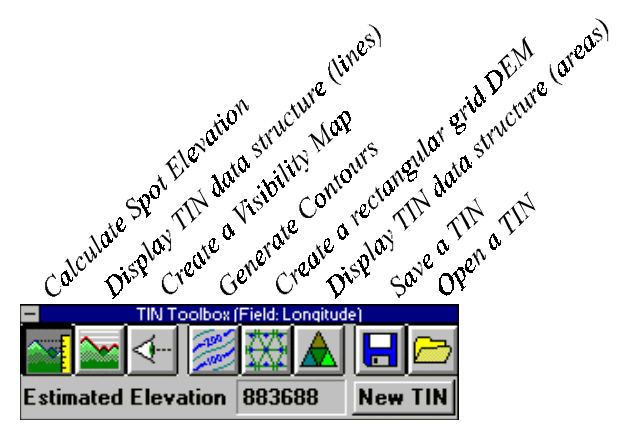

Figura 4.14 - Caixa de ferramentas TINs Toolbox

O ícone 国, denominado ferramenta de elevação, é utilizado para determinar o valor

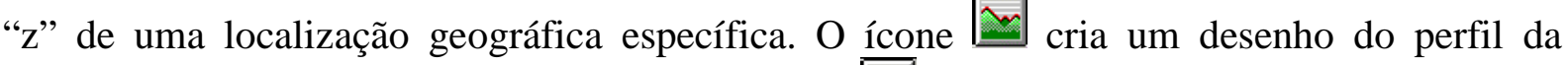
superfície entre dois pontos quaisquer. $\mathrm{O}$ ícone $\$$ permite a realização de análises de visibilidade, calculando as áreas que podem ser vistas de uma localização e elevação específicas e armazenando o resultado em um arquivo geográfico que contém dois campos de áreas: as que podem ser vistas e as que estão obscuras. O ícone permite a geração de curvas de nível como campos de áreas ou campos de linhas, armazenando o resultado em bancos de dados de áreas ou linhas, e disponibiliza as opções manual ou automático para definição dos intervalos entre curvas. O ícone ativa a caixa de diálogos destinada a gerar uma grade retangular (Rectangular Grid), que é outra estrutura de dados de MDT comumente utilizada. Para a realização deste comando é necessário definir o número de pontos a serem posicionados nos eixos x e y. É possível mostrar um TIN e salvá-lo como um arquivo

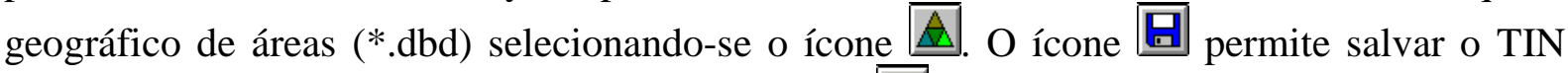
ativo como um arquivo do tipo TIN (*.tin) e o ícone $\boxminus$ permite abrir um TIN existente.

Uma maneira de associar dados de um banco de dados a um mapa é criar um novo arquivo geográfico que contenha um único ponto no mapa para cada registro do banco de dados. Este processo é chamado pin mapping, pois é semelhante a fixar um mapa na parede e marcar os locais com alfinetes. O TransCAD possui quatro comandos para localização de

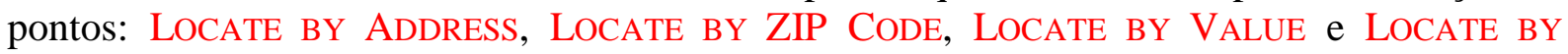
COORDINATE, figura 4.7, sendo que cada um deles utiliza um método diferente para identificar onde os pontos devem ser posicionados no mapa. O comando LOCATE BY ADDRESS localiza os dados baseado nos endereços de ruas, que é uma combinação do número, nome e tipo da rua, e nos códigos postais. O TransCAD localiza registros por endereço utilizando o arquivo TransCAD Streets, que é um arquivo geográfico contendo todas as ruas dos Estados Unidos. Este arquivo contém um atributo gráfico (linha) para cada bloco de cada rua, com informações sobre o nome da rua e o intervalo de endereços que estão em cada bloco. $\mathrm{Na}$ caixa de diálogo ativada por esta opção devem ser identificados: os registros a serem localizados, as colunas que possuem as informações do endereço a ser localizado (ID, número e rua, código postal) e o modo de procura, que pode ser automático ou perguntar ao usuário o que escolher em caso de incerteza na localização. O ícone Options ativa uma caixa de diálogos com as seguintes opções: salvar padronização, tentar apenas códigos postais próximos, método de combinação muito exato, normal ou não exato, definir a distância a partir das ruas: fixa em um determinado valor ou ler a partir de determinada coluna do banco 
de dados que está sendo utilizado. A opção LOCATE BY ZIP CODE localiza registros com base no código postal utilizando o arquivo TransCAD 5-digit ZIP Code, que contém uma área para todos os códigos postais dos EUA, e o arquivo TransCAD ZIP Code Centroid, que contém um ponto para cada código postal dos EUA. Nesta opção são definidos os seguintes parâmetros: registros a serem localizados, a coluna com a informação do código postal e o campo de ID. As opções de como localizar cada ponto são: no centro da área, espalhar dentro da área ou espalhar próximo ao centro. A opção LOCATE BY VALUE permite combinar os registros de um banco de dados com qualquer arquivo geográfico, baseado em valores de um ou mais campos escolhidos. Para cada registro do banco de dados o TransCAD tenta encontrar um atributo gráfico que coincida com os valores. Nesta opção devem ser definidos: os registros a serem localizados, a camada onde se encontram estes registros, os campos dos dois bancos de dados que devem conter os mesmos valores, ou pelos menos próximos, e o campo de ID. Os valores podem ser comparados através de dois métodos: coincidência exata ou aproximada. As opções para localização de cada registros são: no centro de, espalhados dentro ou espalhados próximo ao centro (para áreas), no centro ou espalhados (para linhas) e no ponto ou espalhados (para pontos). E, por fim, a opção LOCATE BY COORDINATE cria um arquivo geográfico novo baseado nas informações de coordenadas armazenadas num arquivo de dados. Devem ser definidos apenas: os registros a serem localizados, o campo de ID, os campos que contêm as informações das coordenadas e um nome para a camada do mapa. Nesta opção, ainda, pode ser definido e utilizado um outro sistema de coordenadas.

O TransCAD possui uma variedade de comandos para criar, unir e medir atributos gráficos em um mapa. Estes comandos serão discriminados a seguir. O comando MERGE BY VALUE cria uma nova camada de áreas, onde cada campo é gerado pelo agrupamento de um ou mais campos de uma camada de áreas diferente e menor, por exemplo: agrupar os dados de áreas e população de várias cidades em registros referentes ao estado. Este comando automaticamente calcula os atributos das novas áreas com base nos dados da camada existente. É necessário se especificar os registros a serem analisados, o campo que servirá de base para o agrupamento e um nome para a nova camada de áreas. Os critérios para agrupar estes dados podem ser: copiar o valor, adicionar, usar a média de valores e copiar ou adicionar o maior ou menor valor. Na opção BANDS pode-se determinar uma área, com largura específica, ao redor de atributos gráficos. Esta área é denominada banda ou buffer. Na caixa de diálogos ativada por este comando devem ser definidos: os atributos gráficos ao redor dos quais será criada a banda, um nome para a nova camada, o tamanho da banda (tamanho fixo, igualmente espaçada ou tamanho variável segundo determinado campo da tabela), a unidade de medida a ser utilizada e optar por gerar bandas unidas ou separadas. O comando OVERLAY combina os dados de duas camadas de áreas, com o objetivo de definir, por exemplo, a população de uma área de 2 quilômetros ao redor de uma rodovia. Para que este comando possa ser utilizado o mapa deve conter, obrigatoriamente, duas camadas de áreas. Satisfeita esta condição resta definir os seguintes parâmetros: os atributos gráficos dos quais deseja-se determinar algumas características, a camada a ser tomada como referência e a seleção de atributos a ser utilizada. Os critérios para extrair estes dados podem ser: copiar o valor, adicionar, usar a média de valores e copiar ou adicionar o maior ou menor valor. $\mathrm{O}$ comando DisTANCE cria uma matriz que contém a distância entre atributos gráficos de uma camada, bastando para isto escolher uma camada do mapa e determinar a seleção de atributos a serem avaliados. O comando CONNECT possibilita a conexão entre uma camada de linhas e atributos gráficos externos, e é utilizado na análise de redes. Devem ser definidos: a camada do mapa cujos atributos serão conectados, a seleção de atributos, a camada de linhas a ser utilizada, os 
nós (todos ou uma seleção) ou ativar a opção conectar à linha mais próxima, neste caso as opções de atualização dos campos dos novos links gerados, quando da divisão de linhas, são: deixar vazio, copiar ou dividir. As opções de conexão disponíveis na caixa de diálogos deste comando são: ignorar os atributos que estão afastados a uma distância maior que " $x$ " (a determinar), preencher todos os campos novos com um valor constante ou com os IDs da camada cujos atributos estão sendo conectados e definir ou não os campos dos nós e linhas. $\mathrm{O}$ comando DESIRE LINES é utilizado para mostrar os valores de uma matriz em um mapa com o objetivo de ilustrar o fluxo de pessoas ou mercadorias de um ponto para outro. Os parâmetros a serem definidos nesta opção são: um nome para a nova camada, a matriz a ser utilizada, a camada do mapa e o campo de ID. A opção READ GPS DATA realiza a leitura de dados GPS diretamente do aparelho, sendo definidas as opções de leitura por: serial port, baud rate, stop bits, parity e data fields, ou de um arquivo do tipo *.gps, o arquivo que contém os dados e a velocidade de importação. As opções para obtenção do relatório desses dados são: $\checkmark$ definir a posição no mapa, $\checkmark$ definir a posição utilizando a caixa de ferramentas, $\checkmark$ criar um arquivo de armazenamento dos dados, $\checkmark$ registro contínuo com uma camada, $\checkmark$ registrar com uma camada mediante chamada, definir a camada do mapa ou uma nova camada (para as duas últimas opções) e definir o intervalo em segundos de importação dos dados. O comando UTILITIES $\Rightarrow$ VISIBILITY LINES cria uma rede com linhas de visibilidade, que identificam os pontos do terreno visíveis a partir de uma origem. Neste comando devem ser definidos: a camada do mapa e a seleção de pontos a serem servidos, a camada que contém as áreas dos obstáculos, o tamanho máximo de links, selecionar ou não a opção de simplificar a rede e optar pelas opções de relação entre pontos e obstáculos: os pontos estão fora das áreas de obstáculos ou dentro. O comando UtILITIES $\Rightarrow$ RUBBER SHEET .... Através do comando UTILITIES $\Rightarrow$ CREATE GRID pode-se criar uma grade no mapa como uma nova camada. Devem ser definidos os seguintes parâmetros: nome da camada, tipo (áreas, linhas ou pontos), número de pontos da grade, o sistema de coordenadas (utilizar as coordenadas baseadas nos valores de longitude e latitude ou definir um novo sistema de coordenadas ou projeção) e o método para criação da grade (entrando com a origem, o espaçamento e o número de células; cobrir a janela do mapa com uma grade com espaçamento fixo ou com um número fixo de células).

A opção EXPORT ativa uma caixa de diálogos utilizada para exportar todos ou uma seleção de registros de uma camada do mapa para um arquivo que pode ser do tipo: Standart Geographic File, Compact Geographic File, Text/Geography, AutoCAD DXF, MapInfo Interchange, Atlas BNA, ESRI Ungenerate ou ArcView Shape. Conforme o formato de arquivo escolhido e o tipo de dados a ser exportado é necessário definir: o campo de ID ou de dados, o campo de nós dos dados (quando de linhas), optar por incluir ou não os dados préexistentes e exportar ou não áreas como centróides, o sistema de coordenadas e o método de transformação de coordenadas. Utilizando-se do comando GEOGRAPHIC FILE é possível visualizar, para determinada camada, a localização do arquivo, os nomes dos arquivos que armazenam os dados referentes a esta camada e o tamanho total dos arquivos. Podem, também, ser realizadas as seguintes funções: copiar os dados da camada do mapa para um novo arquivo geográfico, renomear todos os arquivos referentes a esta camada, apagar todos os arquivos que fazem parte de um arquivo geográfico, armazenar o arquivo geográfico num formato *.ZIP, restaurar um arquivo armazenado em formato *.ZIP, otimizar os arquivos e reduzir o tamanho de um arquivo. A opção Digitizer SETUP ativa a caixa de diálogos Map Projection, que é a mesma apresentada na utilização dos comandos Tools $\Rightarrow$ Imagery $\Rightarrow$ Projection, figuras 4.7 e 4.13, explicada anteriormente. Após a alteração da projeção estará disponível a caixa de diálogos Register Image, ilustrada na figura 4.13. Os comando 
disponíveis nesta caixa também já foram detalhados. A opção SLIDE SHOWs permite a criação de apresentações contendo mapas, bancos de dados e leiautes, os quais devem, previamente, ter sido salvos como arquivos de bitmap (*.bmp). Na caixa de diálogos desta opção pode ser configurada uma apresentação, através da inserção de arquivos e definição da ordem de apresentação dos slides, tempo de apresentação e título de cada slide. As apresentações são armazenadas em arquivos do tipo *.sli. A opção ADD-INs é utilizada para inserir rotinas externas programadas pelo usuário.

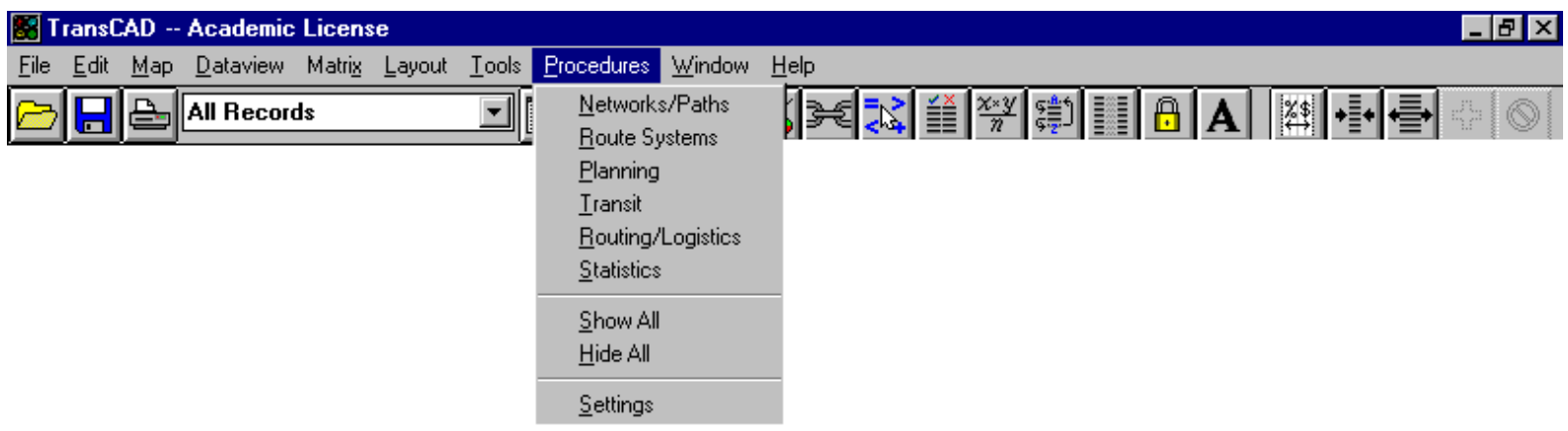

Figura 4.15 - Opção Procedures do menu principal do TransCAD

A opção Procedures do menu do TransCAD, figura 4.15, apresenta um listagem de comandos que, quando selecionados, são incluídos no menu principal e possuem sua própria listagem de comandos específicos. A opção SHOW All mostra todos os comandos, incluindoos no menu principal, ea opção HIDE ALL esconde todos comandos. Nesta etapa do trabalho serão abordados apenas os itens NETWORKS/PATHS e STATISTICS pois são considerados como rotinas avançadas de SIG. As demais opções da figura 4.15 se enquadram como rotinas específicas de transportes e constam de outro tópico deste capítulo.

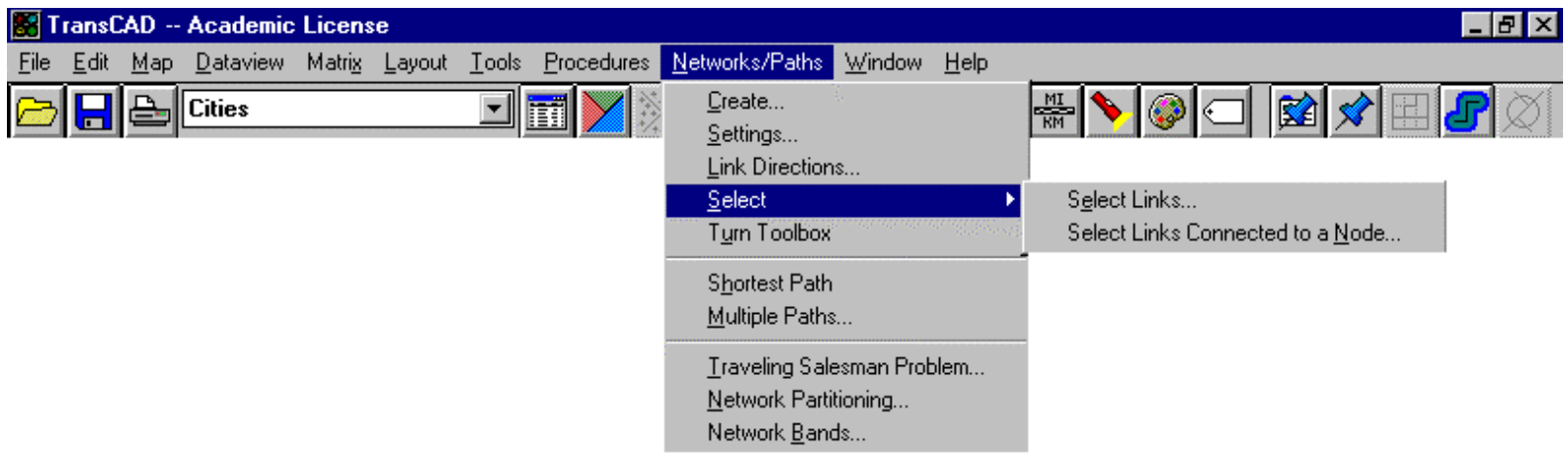

Figura 4.16 - Opção Networks/Paths do menu principal do TransCAD

Uma rede (network) é uma estrutura de dados especial do TransCAD que armazena importantes características dos sistemas de transportes e facilidades. As redes são utilizadas para analisar o modo como pessoas ou mercadorias se movimentam de uma localização para outra. Uma rede é definida por um conjunto de nós (localizações) e links (condutores). Para criar uma rede deve-se escolher a opção CREATE, figura 4.16, e definir os links que constarão da rede, o campo do banco de dados que contém as informações de comprimentos de linhas, uma descrição da rede, selecionar ou não a opção para incluir informações de retornos, escolher campos adicionais que contém informações sobre os atributos de links e nós e 
selecionar ou não as opções: excluir links duplicados e ignorar as direções dos links. $\mathrm{Na}$ opção SETTINGS pode-se visualizar o nome do arquivo de rede ativo e a sua localização, e optar pelos itens: tipos de links, penalidades para transferências e penalidades para retornos. $\mathrm{O}$ item tipos de links permite classificar os links por tipo ou identificar conectores de centróides, sendo necessário definir o campo do banco de dados que possui estas informações e o código de conectores utilizado. O TransCAD permite criar tabelas de procura que possuam valores padrão de velocidades, capacidade ou outro atributo de rede para cada tipo de link. Estas tabelas podem ser utilizadas quando da definição de tipos de links selecionando-se o ícone lookup e identificando-se o arquivo de tabela a ser utilizado. O item Transfer Penalties permite a definição de custos adicionais quando é feita uma transição entre links similares ou diferentes tipos de links. Neste item é necessário identificar os campos que contêm as informações relativas aos números das linhas e seus valores de penalidades. A terceira opção, Turn Penalties, permite aplicar restrições, penalidades ou atrasos quando são feitos retornos entre links de uma rede ou quando são feitas transições entre diferentes tipos de links. Podem ser definidas penalidades ou proibições para quatro tipos de ações: virar à esquerda, virar à direita, passar por uma interseção e fazer um retorno do tipo U. As informações com relação a penalidades para cada tipo de link ou para transições entre links podem ser definidas criandose uma tabela e ativando-a através dos ícones Default (para penalidades por tipo de link) e Specific (para penalidades na passagem de um link para outro). Nesta caixa de diálogos (Network Settings), ativada pela opção SETTINGS, pode-se, ainda, alterar o arquivo de rede ativo (item Network). Ativando ou desativando todos ou uma seleção de links pode-se atualizar a rede (item Update), atualizando os custos em todos os links com base em um campo do banco de dados da rede. Pode-se ainda obter informações relativas à rede (ícone Info), tais como: descrição, campos do banco de dados, número de nós, links e links desativados e se a rede contém informações de retornos. A opção LinK DiRECTIONS permite definir os sentidos dos links de acordo com as opções: sentido duplo ou sentido único para o norte, sul, leste ou oeste. A opção SELECT $\Rightarrow$ SELECT LINKS permite realizar a seleção de todos os links da rede ou apenas os ativos ou desativados, definir um nome para a seleção criando uma nova seleção, adicionando ou removendo de uma já existente ou criando uma subseleção. A opção SELECT $\Rightarrow$ Select Links ConneCted TO A NODE realiza a seleção de links conectados a um nó. Para ativar a caixa de ferramentas para definição de penalidades de retornos no mapa deve-se escolher a opção TURN TOOLBOX e selecionar uma das seguintes opções: nova tabela, abrir uma tabela existente ou abrir um banco de dados existente. Ao optar-se por uma dessas alternativas será ativada a caixa de ferramentas mostrada na figura 5.17 , a qual permite adicionar ou excluir penalidades, mostrar ou não todas as penalidades no mapa e configurar sua aparência no mesmo.

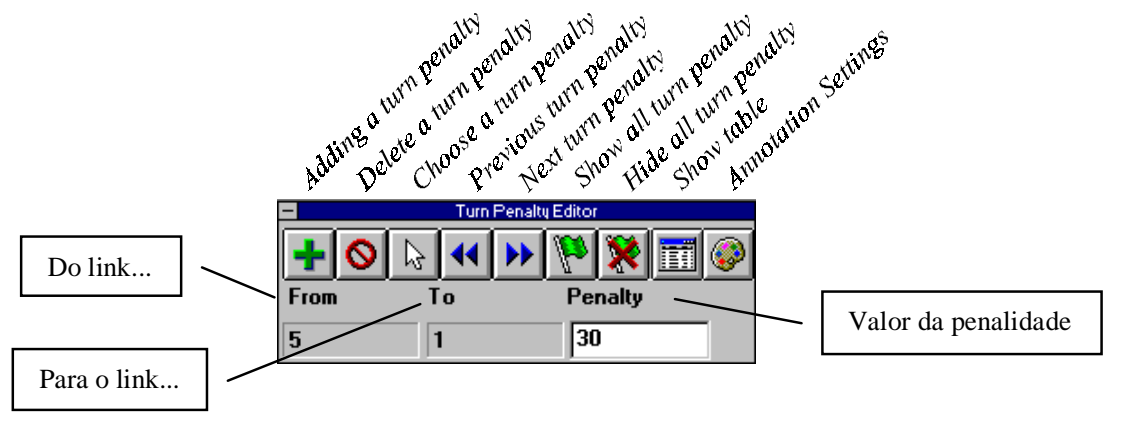

Figura 4.17 - Caixa de ferramentas Turn Penalty Editor 
Caminhos mínimos (shortest paths) são rotas sobre uma rede de transportes que possuem o menor custo generalizado, este custo pode ser uma combinação de fatores tais como: distância, tempo ou custo da viagem. A opção SHORTEST PATH, figura 4.16, permite encontrar o caminho mínimo entre dois pontos da rede. Este comando ativa a caixa de ferramentas Shortest Path Toolbox mostrada na figura 4.18.

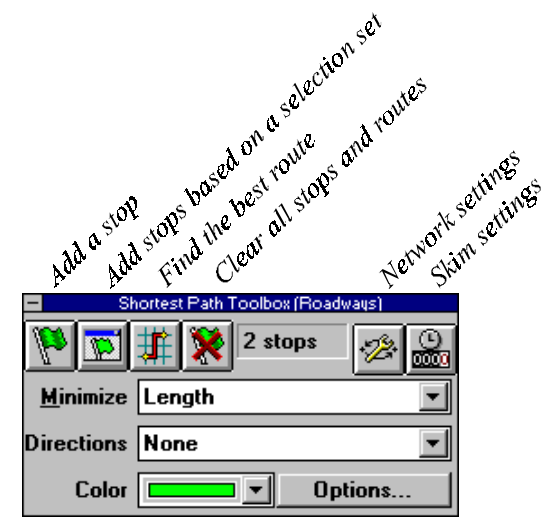

Figura 4.18 - Caixa de ferramentas Shortest Path Toolbox

Na figura 4.18, o ícone abre a mesma caixa de diálogos ativada pela opção Networks/Paths $\Rightarrow$ Settings, utilizada para visualizar e definir as características da rede. O ícone ativa a caixa de diálogos Network Skim Settings. Na opção Settings pode ser identificada a camada de linhas do mapa que está sendo utilizada e a localização e o arquivo de rede ativo, podem ser definidas as opções de saída dos dados como uma seleção ou não, $\checkmark$ mostrar o caminho na tela, $\checkmark$ gerar relatório de custos e $\checkmark$ gerar relatório de skims (resumo). A opção MUlTiPle PATHS, figura 4.16, permite encontrar vários caminhos mínimos através de um único comando. É útil quando se deseja criar vários caminhos partindo de várias origens para vários destinos, ou para calcular a distância ou tempo de viagem entre muitas origens e destinos. Na caixa de diálogos ativada por esta opção devem ser definidos: o campo que contém os dados a serem minimizados (distância, tempo, etc.), as seleções de pontos de origem, destino e pontos intermediários que devem ser interligados e como serão armazenados os dados, em um sistema de rotas ou em um arquivo de matriz.

O comando Traveling SAlesman Problem (problema do caixeiro viajante) permite encontrar o melhor caminho (ou com menor custo) para se proceder uma série de entregas ou paradas, sendo que a ordem de entregas/paradas não foi previamente definida. Para a execução deste comando devem ser especificados os pontos de parada, o campo que contém os dados a serem minimizados e as opções de saída dos resultados: $\checkmark$ mostrar o caminho na tela, $\checkmark$ gerar relatório de custo, $\checkmark$ gerar relatório de skims e mostrar direções (este item gera um arquivo do programa Notepad do Windows). A opção NETWORK PARTITIONING divide uma camada de linhas em zonas ou distritos, cada qual centralizada em torno de um ponto de localização. Nesta opção devem ser definidos os pontos que representam a localização dos serviços, o campo do banco de dados em que se baseará a rotina (distância, tempo, etc.), o valor máximo do serviço e definir a opção de saída dos resultados: tabela de links (divide apenas os links), tabela de nós (divide apenas os nós) ou ambas (divide ambos os links e nós). A opção NETWORK BANDS gera bandas/áreas de impedância com base em uma variável (p.ex. distância). 


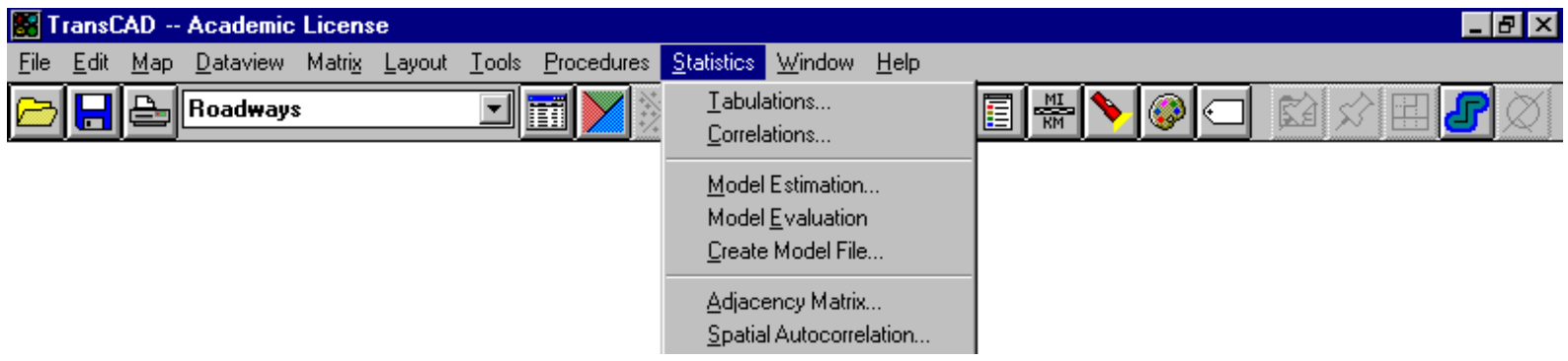

Figura 4.19 - Opção Statistics do menu principal do TransCAD

O menu Statistics, figura 4.19, fornece comandos para a realização de operações e análises estatísticas dos dados. O comando TABULATIONS conta o número de registros com determinados valores em um ou mais campos do banco de dados. Podem ser criadas tabulações a partir de um ou dois campos de dados diferentes. Na caixa de diálogos ativada por esta opção devem ser definidos um título para a nova tabela, os registros a serem tabulados, no caso de tabulações em apenas um sentido (one-way, isto é analisa os dados tomando como referência linhas ou colunas): o campo do banco de dados a ser utilizado como referência, o método (igual número de campos, igual tamanho de intervalos, lista de valores, desvio padrão ou médias), as opções de ignorar valores acima ou abaixo de um valor especificado, utilizar o desvio padrão calculado por determinada classe, interromper em um determinado valor, tratar zeros como valores ausentes e completar os valores em cada classe. No caso de tabulações em dois sentidos (two-way, analisa os dados tomando como referência linhas e colunas) deve ser definido, também, o segundo campo a ser utilizado, o qual possui as mesmas opções de configuração listadas no primeiro (one-way). A opção CORRELATIONS identifica o grau de correlação entre os valores de dois campos de uma camada do mapa ou de um banco de dados. O TransCAD calcula as correlações entre qualquer número de campos e armazena os valores de correlação em uma matriz, que contém uma linha e uma coluna para cada campo. Para executar este comando devem ser identificados a seleção de registros e os campos a serem utilizados.

O TransCAD possibilita ao usuário estimar e aplicar dois tipos de modelos matemáticos: regressão linear múltipla e modelo logit, os quais são utilizados para obter relações estatísticas entre dados de campos de uma tabela. Primeiramente deve-se estimar/calcular o modelo através da opção ModEL Estimation, definindo-se a variável dependente, as variáveis independentes, os registros a serem utilizados e o tipo do modelo (regressão ou logit). O cálculo de estimativa do modelo produz um arquivo de texto denominado arquivo do modelo (model file), com as informações que podem ser usadas para avaliar o modelo em um conjunto de dados que possuem campos similares. Para aplicar um modelo deve-se utilizar a opção ModEl EvaluATION e identificar um arquivo que contenha o modelo a ser utilizado. Na caixa de diálogos, denominada Forecast, mostrada após a execução destes comandos deve-se definir: o banco de dados que irá armazenar os resultados, o campo a ser utilizado para armazená-los, a seleção de registros na qual será aplicado o modelo, escolher os campos que possuem os valores das variáveis independentes, o novo coeficiente a ser utilizado para ajustar os parâmetros do modelo e o tipo do modelo. Um arquivo de modelo pode ser criado manualmente através do comando CREATE MODEL FILE, definindo-se os campos de variáveis a serem incluídos na análise e, na caixa de diálogos que 
aparece em seguida, são definidos os coeficientes para todas as variáveis da equação do modelo.

Vários modelos estatísticos supõem que as observações do exemplo usado para estimar o modelo são independentes. Em muitos casos essa suposição é justificada, mas em análises geográficas e de transportes isso é uma exceção. Quando as observações de um exemplo são áreas que formam uma região, há um tendência de áreas adjacentes possuírem valores correlacionados. Este fator é chamado de correlação espacial (spacial autocorrelation). O primeiro passo para calcular a correlação espacial é produzir uma matriz de adjacências (adjacency matrix) que identifica as áreas que possuem limites comuns, o que pode ser feito através do comando ADJACENCY MATRIX identificando-se os registros a serem utilizados e definido-se um nome para o arquivo de saída da matriz. A matriz de adjacências pode ser utilizada para calcular a correlação espacial de qualquer campo de dados em uma camada do mapa. A opção SPACIAL AUTOCORRELATION calcula a correlação espacial, sendo necessário definir o campo de interesse, o arquivo da matriz de adjacências, a matriz (de adjacências, nível de adjacência ou comprimento do contorno comum) e um nome para identificação do relatório.

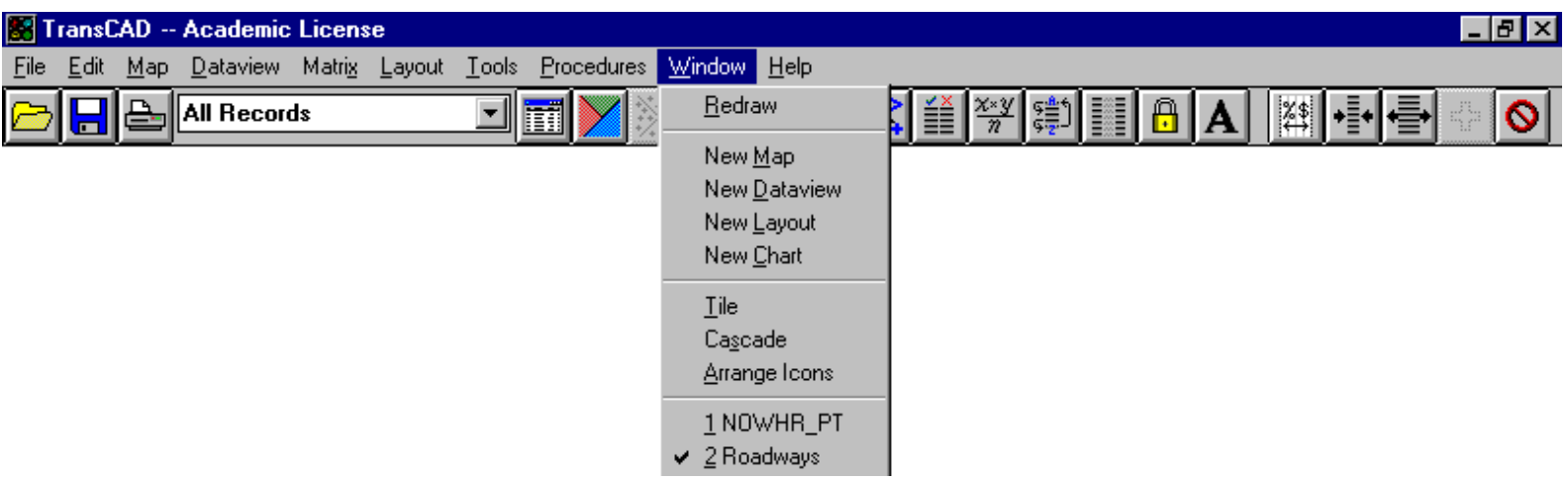

Figura 4.20 - Opção Window do menu principal do TransCAD

No menu do item Window, figura 4.20, a opção REDRAW redesenha a tela ativa. A opção NEW MAP cria um novo mapa, sendo necessário definir um nome para o mapa e as camadas que nele deverão estar contidas. A opção NEW DATAVIEW permite criar um novo banco de dados a partir de uma camada do mapa ou de uma tabela. A opção NEW LAYOUT permite criar e definir as características de um novo leiaute e apresenta uma caixa de diálogo igual à ativada pela opção Layout $\Rightarrow$ Settings. A opção NEW CHART permite criar um gráfico a partir de uma seleção de colunas numéricas de um banco de dados ou tabela. Na primeira caixa de diálogos apresentada por este comando deve-se definir o campo do qual será feita a leitura dos rótulos do gráfico ou proceder a esta leitura a partir do número da linha. $\mathrm{Na}$ próxima caixa de diálogos apresentada devem ser definidos: o tipo do gráfico (barras, barras agrupadas, áreas, linhas, "pizza" ou dispersão), as opções (horizontal e apresentar rótulos para gráficos de barras e 3D para gráficos de barras, áreas ou pizza), ordenação (nenhuma, crescente ou decrescente, em ordem alfabética ou reversa) e os textos do gráfico (título, nota de rodapé e rótulos dos eixos X e Y). Selecionando-se o ícone Style pode-se definir o estilo do gráfico (padrões de cores e preenchimentos), o estilo do ícone, copiar o estilo e a cor para todos os itens, optar por fazer um gráfico multicolorido, definir os rótulos dos dados, valores máximos e mínimos para o eixo $\mathrm{Y}$, o formato numérico dos dados e o intervalo utilizado entre 
tics. As opções TILE e CASCADE arrumam as posições das janelas ativas na tela do computador, tornando-as todas visíveis ao mesmo tempo ou organizadas em forma seqüencial (como uma cascata), respectivamente. A opção ARRANGE ICONS reposiciona todos os ícones ativos na tela. Na última subdivisão da listagem de comandos da figura 4.20 estarão listadas todas as janelas ativas.

Muitos dos comandos descritos acima podem ser ativados através de ícones, disponíveis no menu do TransCAD. Os ícones disponíveis variam de acordo com o tipo de tela em que se está trabalhando, por exemplo: mapa, banco de dados, leiaute, etc. Estes ícones serão ilustrados a seguir, acompanhados da indicação da função a que são destinados. Os três primeiros ícones da esquerda para a direita não serão apontados em nenhuma das figuras a seguir, pois são comuns ao sistema operacional e sempre se destinam às mesmas operações: abrir, salvar e imprimir arquivo.

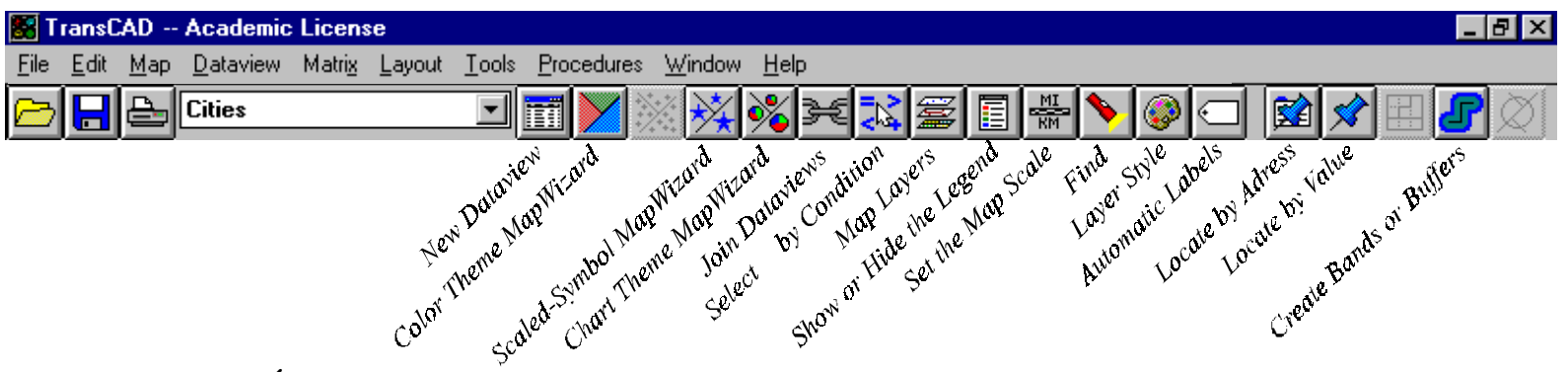

Figura 4.21 - Ícones disponíveis na barra de menu do TransCAD quando a janela de mapa está ativa e uma camada de pontos selecionada

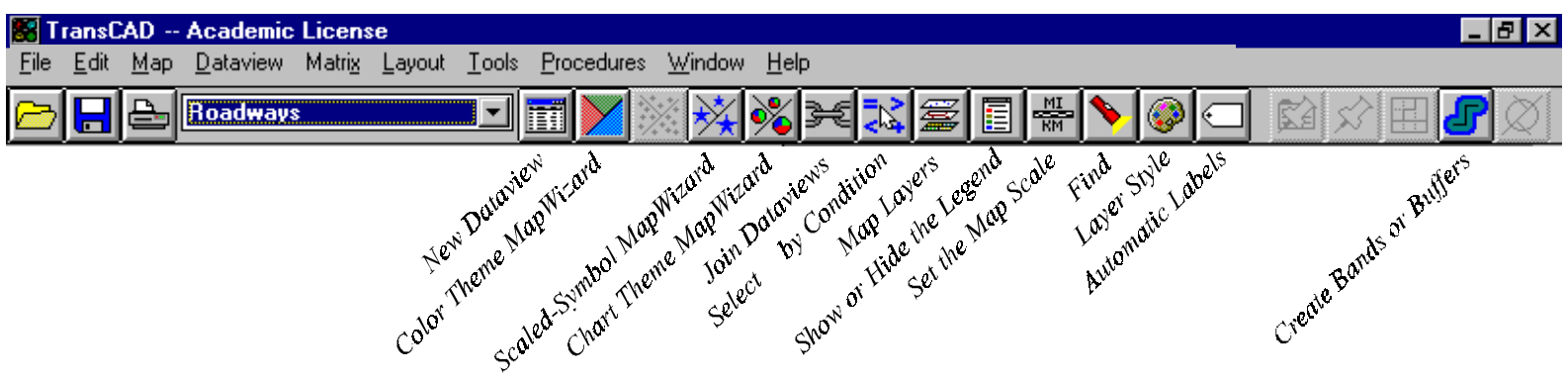

Figura 4.22 - Ícones disponíveis na barra de menu do TransCAD quando a janela de mapa está ativa e uma camada de linhas selecionada

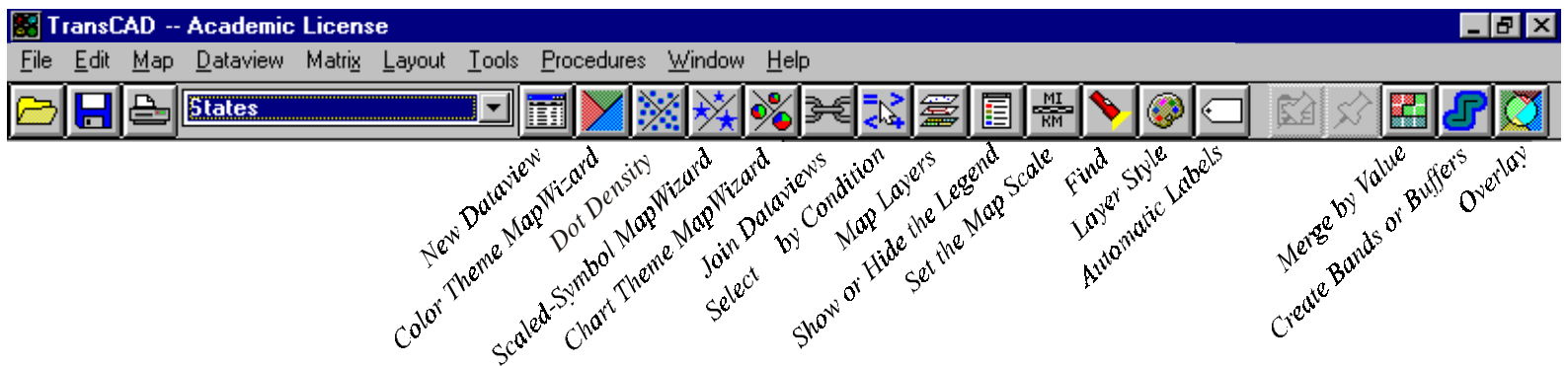

Figura 4.23 - Ícones disponíveis na barra de menu do TransCAD quando a janela de mapa está ativa e uma camada de áreas selecionada 


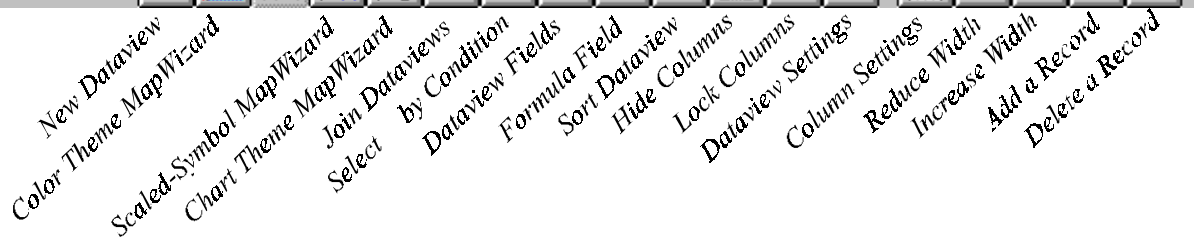

Figura 4.24 - Ícones disponíveis na barra de menu do TransCAD quando a janela de banco de dados de uma camada de pontos está ativa

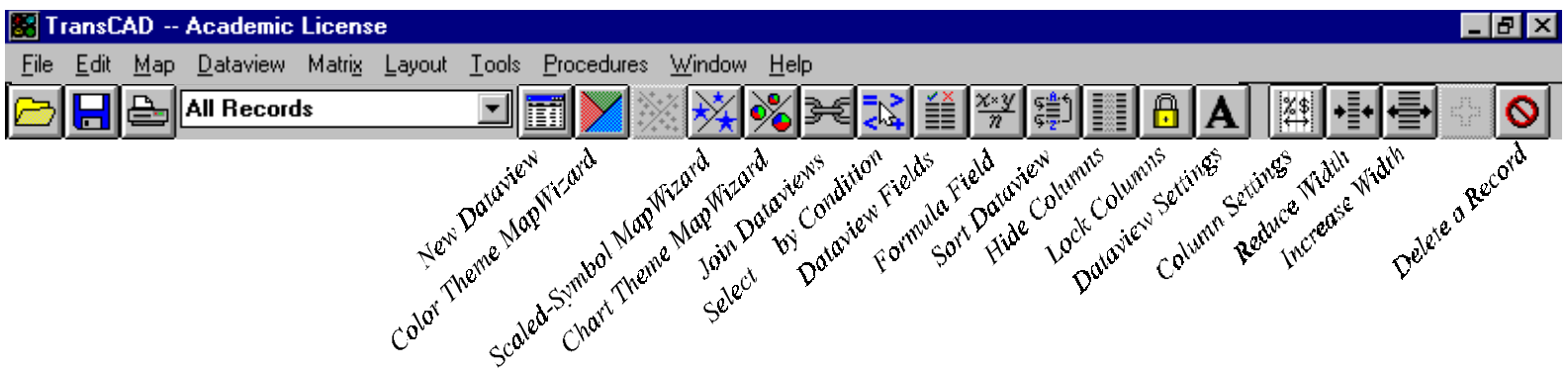

Figura 4.25 - Ícones disponíveis na barra de menu do TransCAD quando a janela de banco de dados de uma camada de linhas está ativa

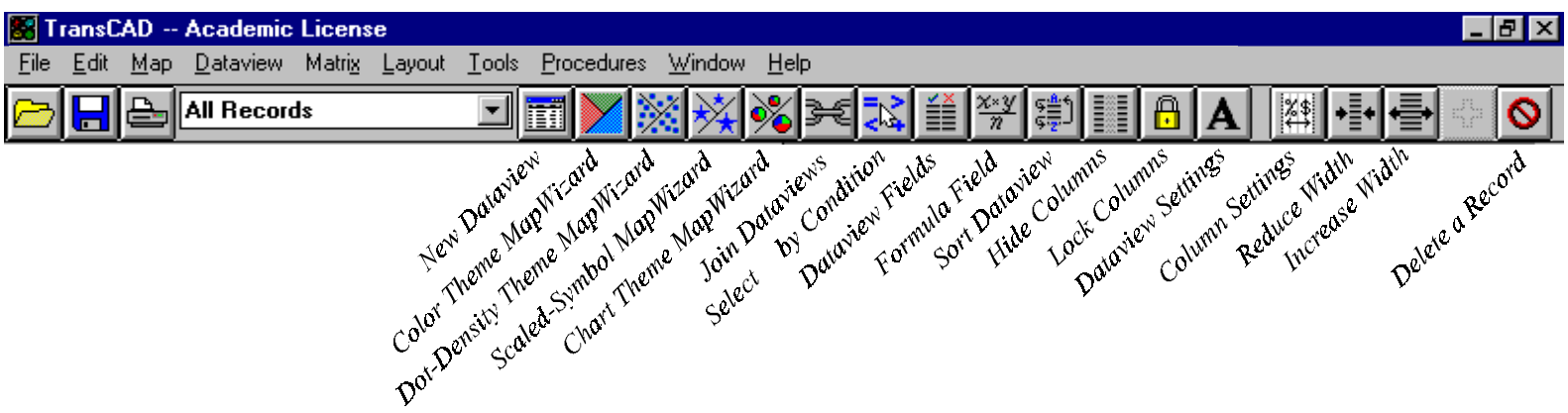

Figura 4.26 - Ícones disponíveis na barra de menu do TransCAD quando a janela de banco de dados de uma camada de áreas está ativa

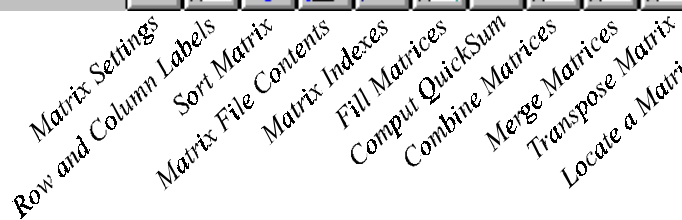

Figura 4.27 - Ícones disponíveis na barra de menu do TransCAD quando a janela de uma matriz está ativa 
TransCAD -- Academic License

File Édit Map Dataview Matrix Layout Iools Procedures Window
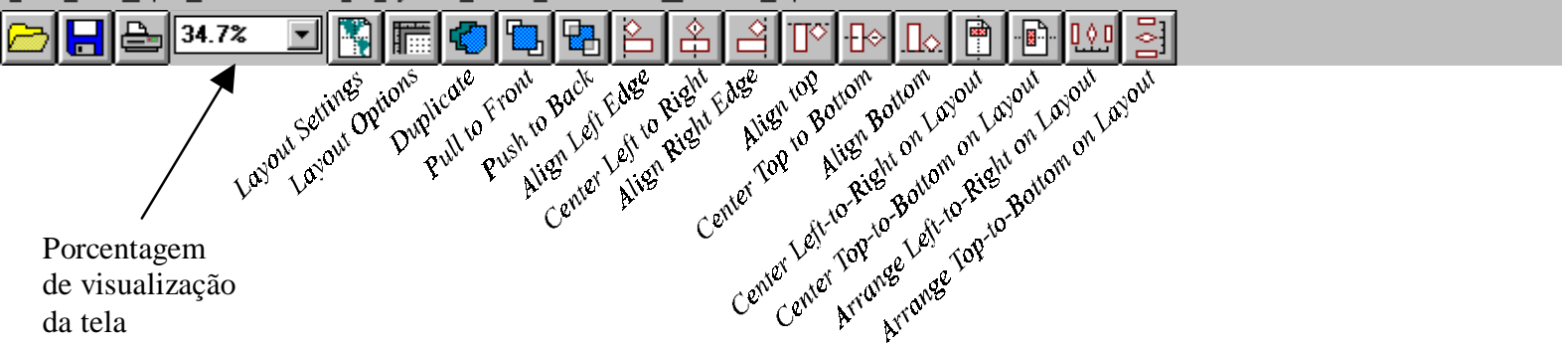

Figura 4.28 - Ícones disponíveis na barra de menu do TransCAD quando a janela de um leiaute está ativa

\subsubsection{Rotinas Específicas de Transportes}

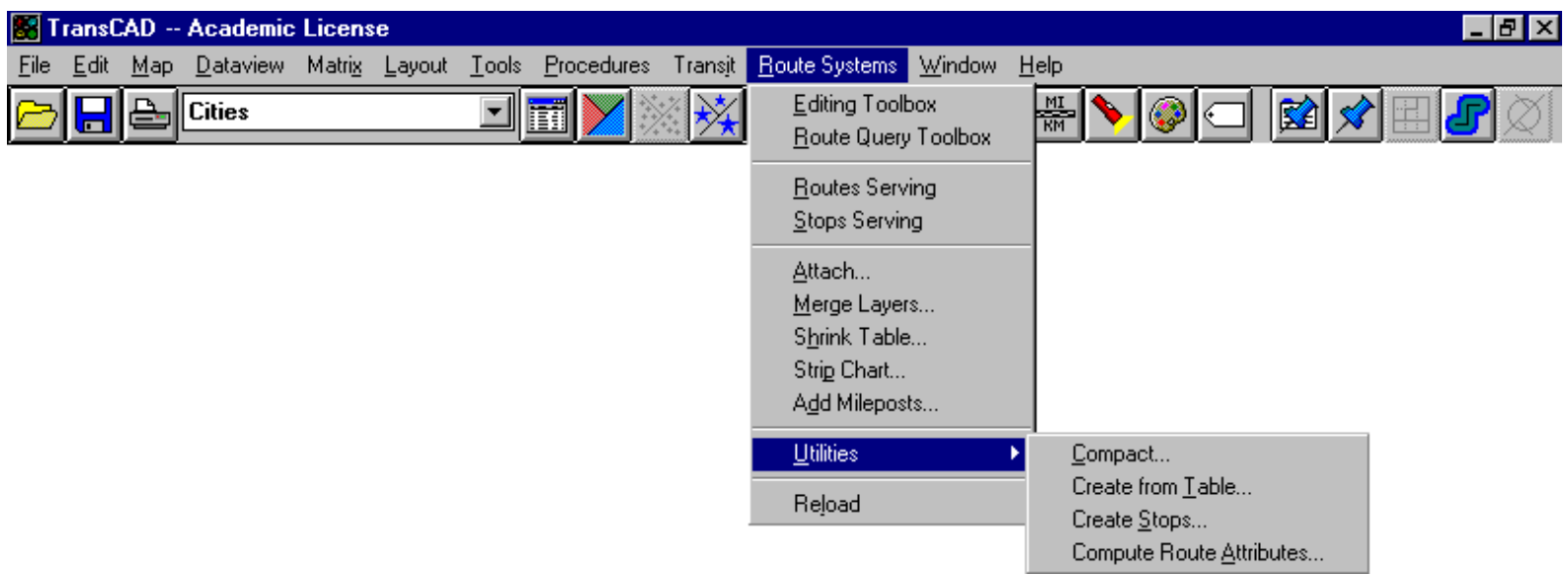

Figura 4.29 - Opção Route Systems do menu principal do TransCAD

Um sistema de rotas é definido por várias rotas, que por sua vez constituem-se de uma série de linhas (ruas) e pontos (pontos de parada). Os comandos disponíveis na opção Route Systems, figura 4.29, do menu principal do TransCAD são utilizados para trabalhar com um sistema de rotas. A opção EdiTing Toolbox ativa uma caixa de diálogos, figura 4.30, que apresenta as ferramentas necessárias à edição e criação de rotas. 


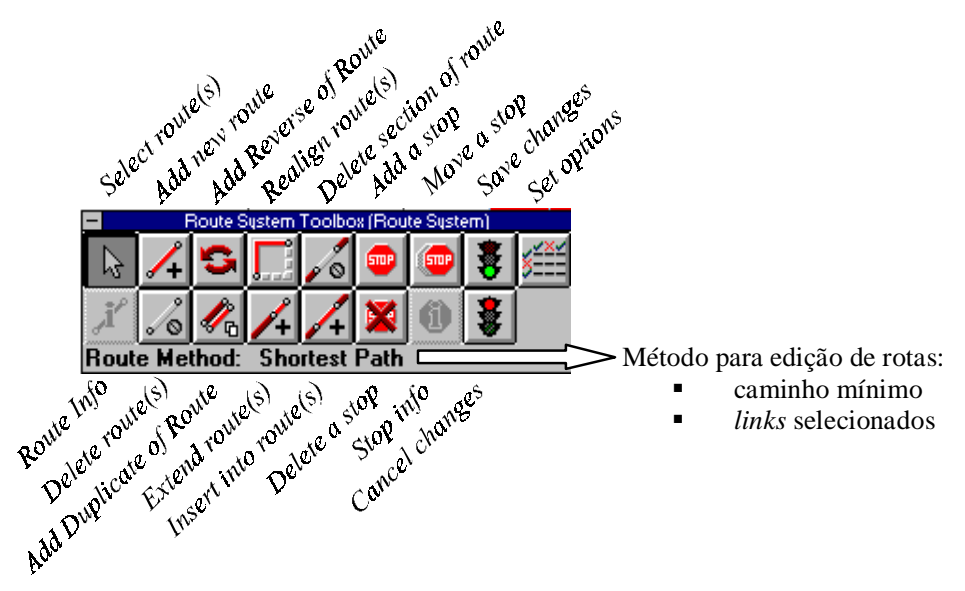

Figura 4.30 - Opção EDITING ToOLBOX do menu Route Systems do menu principal do TransCAD

A opção RouTE QUERY TOOLBOX abre a caixa de diálogos mostrada na figura 4.31, através da qual pode-se obter informações relativas ao sentido das rotas e a distância entre o ponto de início da rota e um ponto qualquer selecionado pelo usuário e alterar o valor de referência do ponto de início.

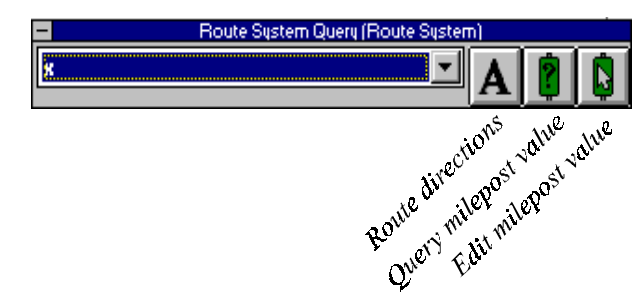

Figura 4.31 - Opção Route QueRY TOOLBOX

As opções Routes SERVING e STOPS SERVING são utilizadas para identificar as rotas que fazem a ligação entre dois pontos quaisquer do mapa e entre dois pontos de parada de rotas, respectivamente. As opções ATTACH, MERge LAYERS e SHRINK TABLE são utilizadas para realizar as seguintes funções: anexar uma tabela de marcos (indicadores de distância) à camada de sistema de rotas; unir duas camadas de marcos; diminuir a tabela de marcos extraindo um ou mais campos. A opção STRIP CHART permite a realização de um gráfico com as variáveis rota, os campos de dados da rota escolhida e um intervalo de marcos. Através da opção ADD MILEPOSTS pode-se adicionar marcos a uma determinada camada de rotas.

A opção UTILITIES $\Rightarrow$ COMPACT é utilizada para compactar (reduzir de tamanho) um arquivo de rotas. As opções UtILITIES $\Rightarrow$ CREATE FROM TABLE, UTILITIES $\Rightarrow$ CrEATE STOPS e UTILITIES $\Rightarrow$ COMPUTE ROUTE ATTRIBUTES permitem a criação de um sistema de rotas a partir de uma tabela, a criação de pontos de parada para um sistema de rotas a intervalos constantes ou no final das rotas e adicionar a uma rota a partir de uma camada de linhas ou de pontos de parada. A opção RELOAD recarrega todas as rotas de um sistema de rotas. 


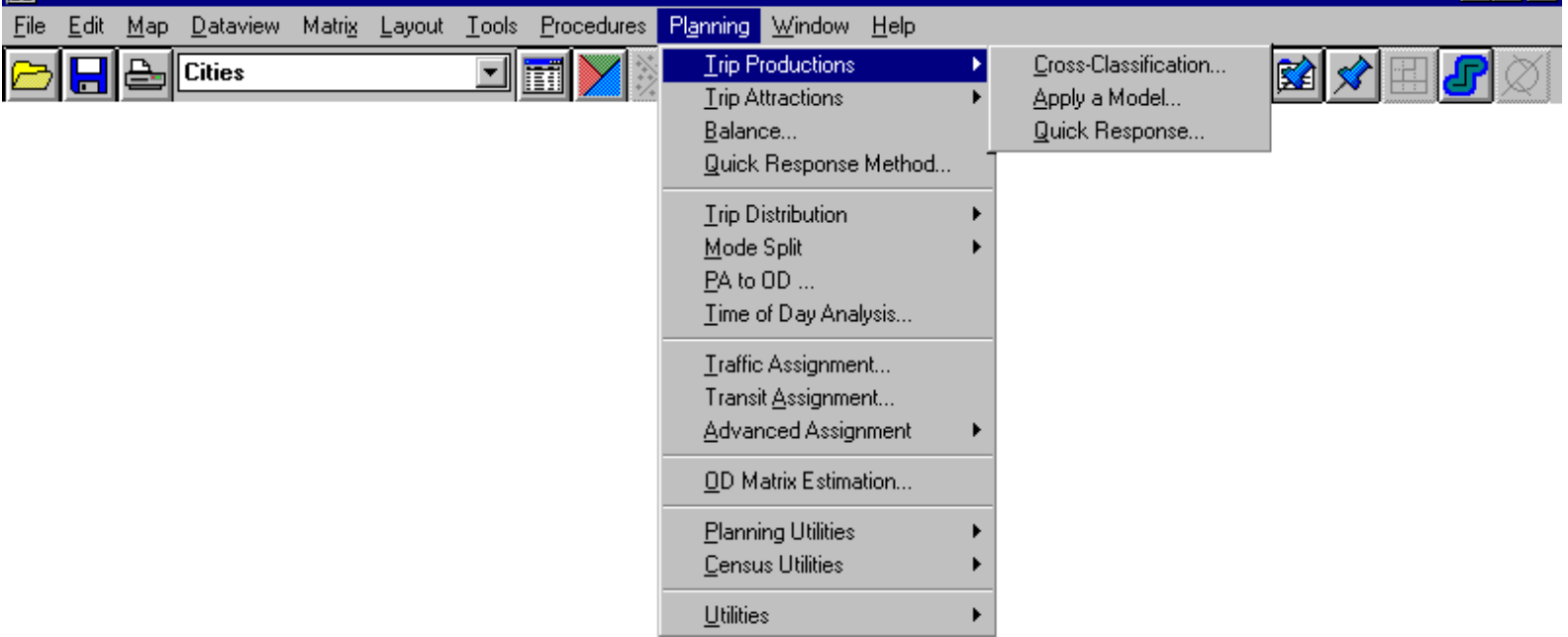

Figura 4.32 - Opção TRIP PRODUCTIONS do menu Planning menu principal do TransCAD

Os comandos disponíveis na opção Planning do menu principal do TransCAD, figura 4.32, são utilizados na execução das etapas necessárias à aplicação dos modelos seqüienciais de um planejamento de transportes. A primeira opção TRIP PRODUCTIONS permite o cálculo para estimativa do número de viagens produzidas em determinada zona através dos modelos de classificação cruzada, utilizando-se arquivos de modelos contendo os parâmetros estimados a partir de um modelo de regressão ou Modelo Logit e do método de resposta rápida (ver Sosslau, 1978).

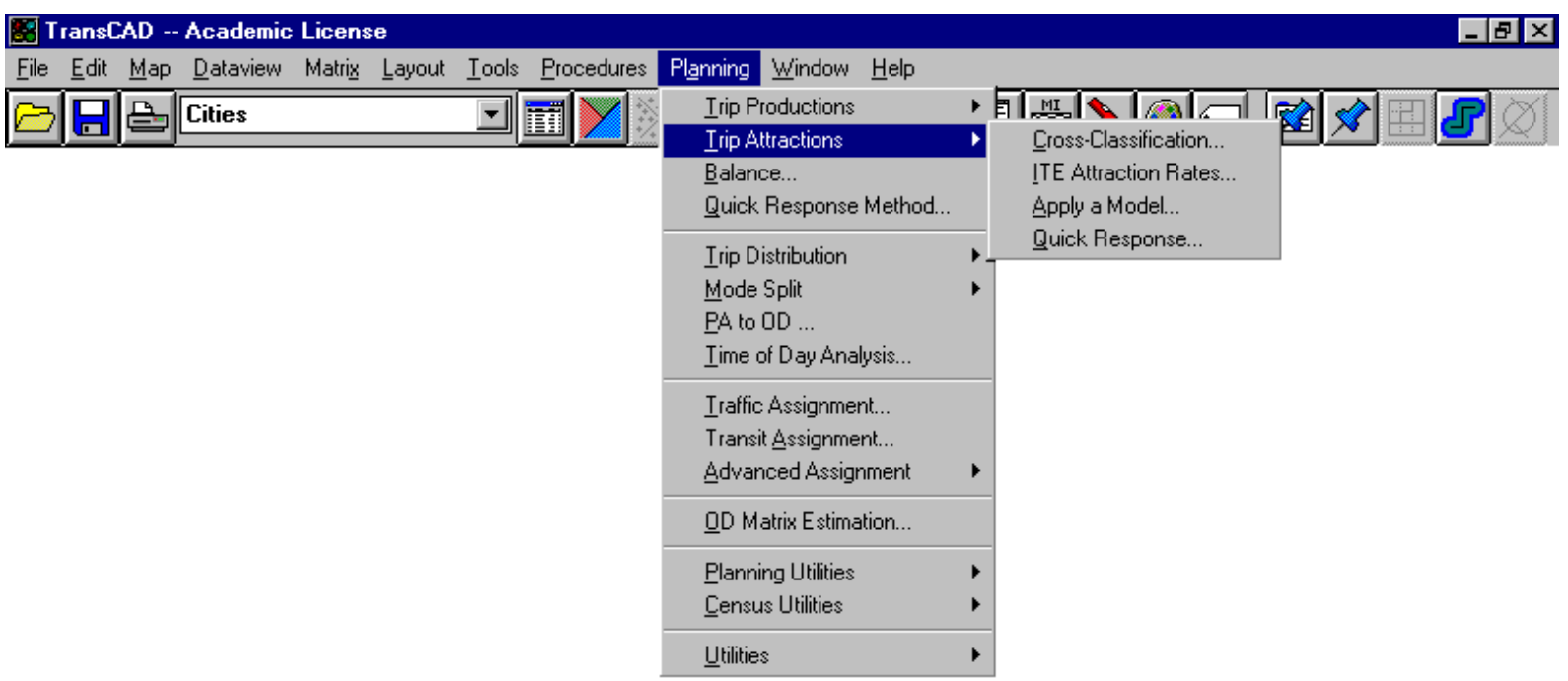

Figura 4.33 - Opções Trip AtTRactions, BALANCE e Quick Response Method do menu Planning do menu principal do TransCAD

A opção TRIP ATTRACTIONS, figura 4.33, permite o cálculo do número de viagens atraídas por determinada zona através do modelo de classificação cruzada, de taxas de atração utilizando dados coletados nos Estados Unidos pelo ITE (Institute of Transportation Engineers), de arquivos de modelos contendo os parâmetros estimados a partir de um modelo de regressão ou Modelo Logit e do método da resposta rápida. A opção BALANCE permite o 
balanceamento das viagens produzidas e atraídas tornando um ou outro valor como constante ou, ainda, ajustando ambos. Para o balanceamento de viagens pode-se, também, utilizar a opção QUiCK RESPONSE METHOD, método de resposta rápida.

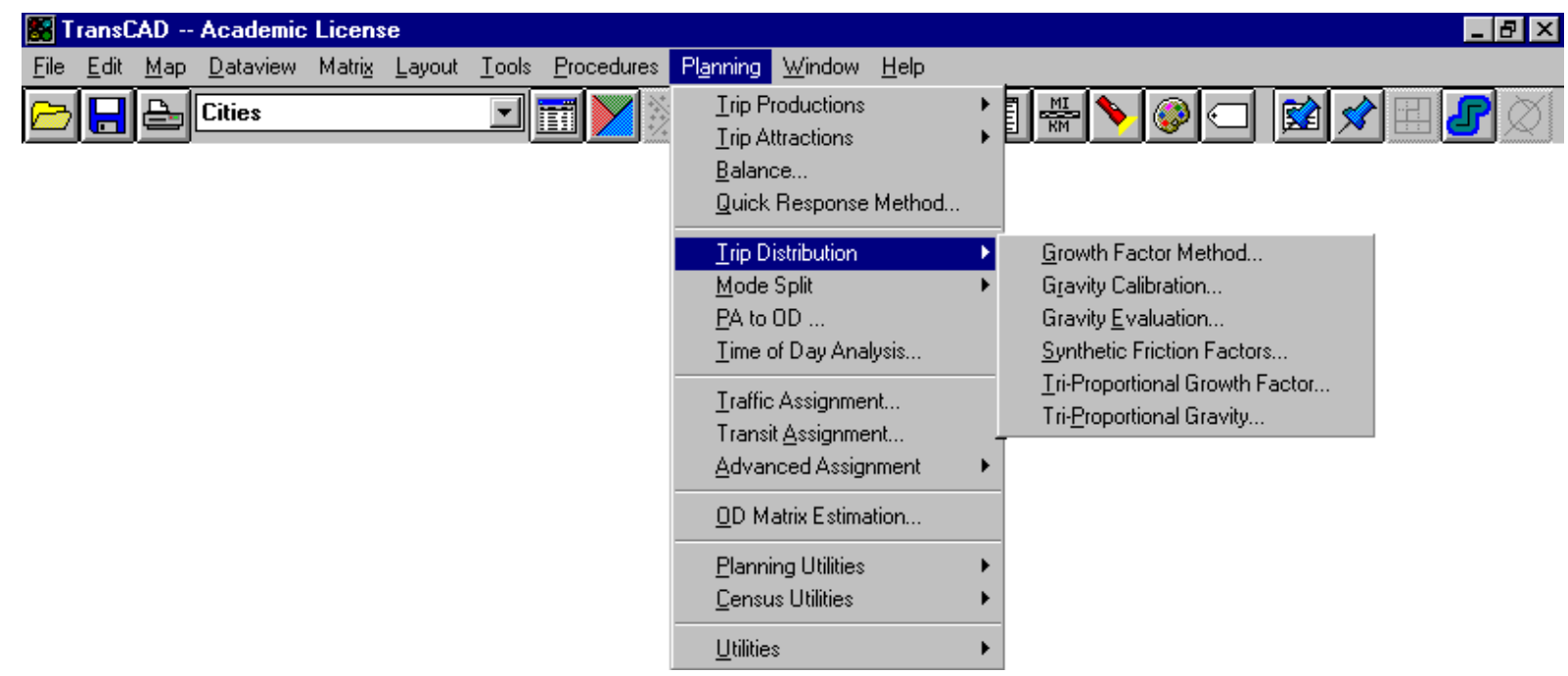

Figura 4.34 - Opção TRIP DiSTRIBUTION do menu Planning do menu principal do TransCAD

Para o processo de distribuição de viagens, no qual estima-se o padrão de viagens entre cada par origem-destino, o TransCAD fornece as seguintes ferramentas na opção TRIP DisTRIBUTION, figura 4.34:

- Growth Factor Method: esta opção possibilita a utilização dos métodos do fator de crescimento uniforme, restringido simples ou duplamente restringido (Modelo de Fratar);

- Gravity Calibration: opção utilizada na calibração do modelo gravitacional;

- Gravity Evaluation: opção utilizada na estimativa do número de viagens entre origens e destinos através do modelo gravitacional;

- Synthetic Friction Factors: opção para criar uma matriz de fatores de fricção utilizando-se uma matriz e uma função de impedância (caminhos mínimos). Os fatores de fricção representam o desestímulo para a realização da viagem à medida que a distância de percurso (ou ao tempo, ou o custo generalizado) aumenta;

- Tri-Proportional Growth Factor e Tri-Proportional Gravity: essas duas opções permitem basicamente a realização dos mesmos procedimentos padrões descritos acima para estimar a distribuição de viagens. Seu diferencial está na utilização de uma terceira dimensão ou variável, para tanto devem ser definidas as células que correspondem a esta terceira dimensão, e o valor a ser acrescido a estas células. 


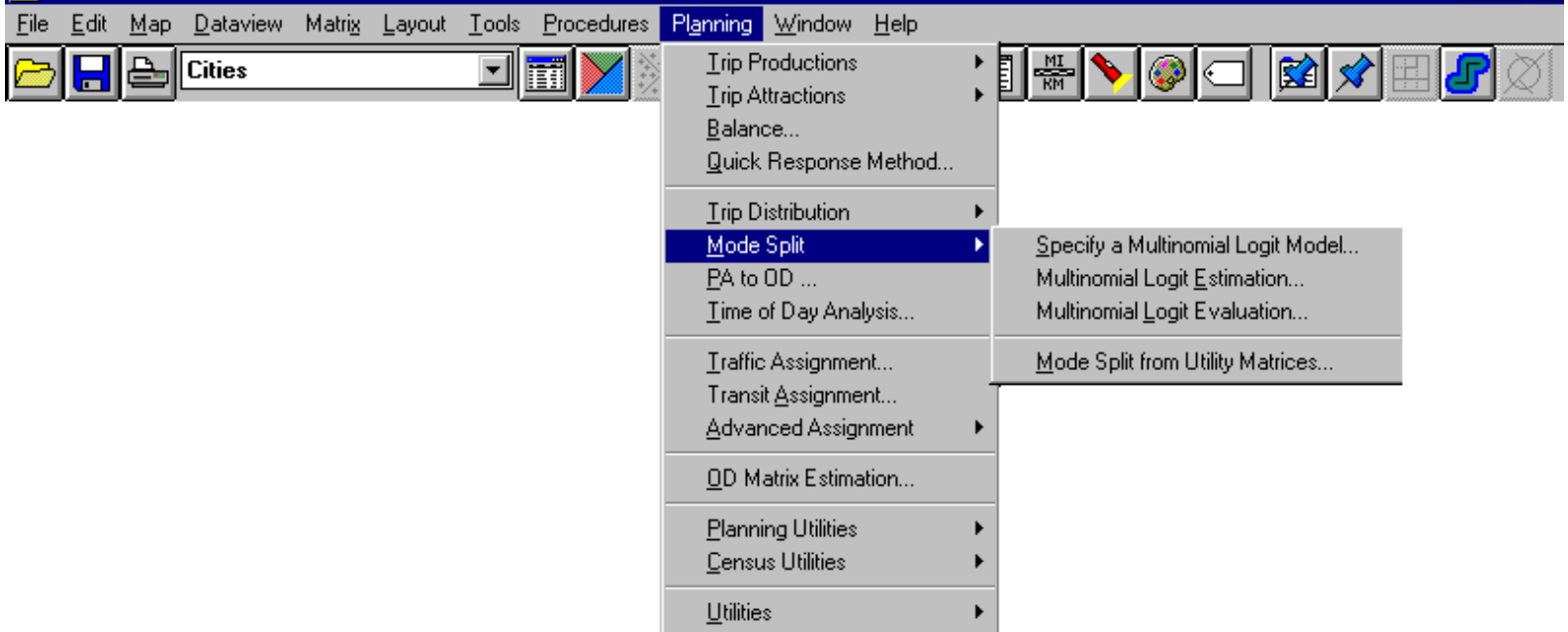

Figura 4.35 - Opção Mode SPliT do menu Planning do menu principal do TransCAD

Os modelos de escolha modal são utilizados para analisar e estimar as escolhas que os indivíduos fazem ao definirem o modo de transporte a ser utilizado para determinados tipos de viagens. O objetivo é prever o número de viagens realizadas em cada modo. Para tanto, o TransCAD fornece as seguintes ferramentas, disponíveis na opção MoDE SPLIT da figura 4.35:

- Specify a Multinomial Logit Model: esta opção possibilita a criação e edição da tabela utilizada na avaliação de modelos do tipo Multinomial Logit;

- Multinomial Logit Estimation: nesta opção, a palavra estimar significa determinar os melhores ou os mais adequados valores para os parâmetros do modelo Multinomial Logit.

- Multinomial Logit Evaluation: a avaliação de modelos Logit é feita com o objetivo de estimar o padrão de viagens realizadas, a partir de parâmetros conhecidos. Nesta opção pode-se realizar uma avaliação baseada em dados desagregados e dados agregados com ou sem uma pesquisa origem-destino;

- Mode Split from Utility Matrices: utilizando-se esta opção pode-se estimar dados agregados com uma pesquisa origem-destino baseada na escolha modal utilizando equações do tipo Logit. Este método só pode ser utilizado se o usuário já tiver as matrizes contendo as vantagens para cada alternativa.

As opções PA TO OD e TIME OF DAY ANALYSIS, figura 4.35, permitem, respectivamente, converter os dados de produção/atração de viagens em uma matriz origem/destino e decompor os dados de fluxo em 24 horas de uma matriz O-D (origemdestino) em matrizes individuais com os dados de fluxo por hora. Através da opção TRAFFIC ASSIGNMENT, pode-se estimar o fluxo de tráfego sobre uma rede utilizando-se dos seguintes métodos: tudo-ou-nada, incremental, equilíbrio, restrição da capacidade, equilíbrio estocástico, STOCH Assignment e System Optimum Assignment, estes dois últimos descritos a seguir. O método STOCH Assignment distribui as viagens entre cada par origem-destino através de múltiplos caminhos alternativos, tendo maior probabilidade de escolha o caminho que apresentar menor tempo de viagem. O método System Optimum Assignment minimiza o tempo total de viagens em uma rede. Os modelos para alocação do tráfego de passageiros de transporte público urbano (TPU), disponíveis na opção TRANSIT ASSIGNMENT, são utilizados 
para estimar o número de passageiros que utilizam linhas de uma rede de TPU como uma função do nível de serviço do TPU.

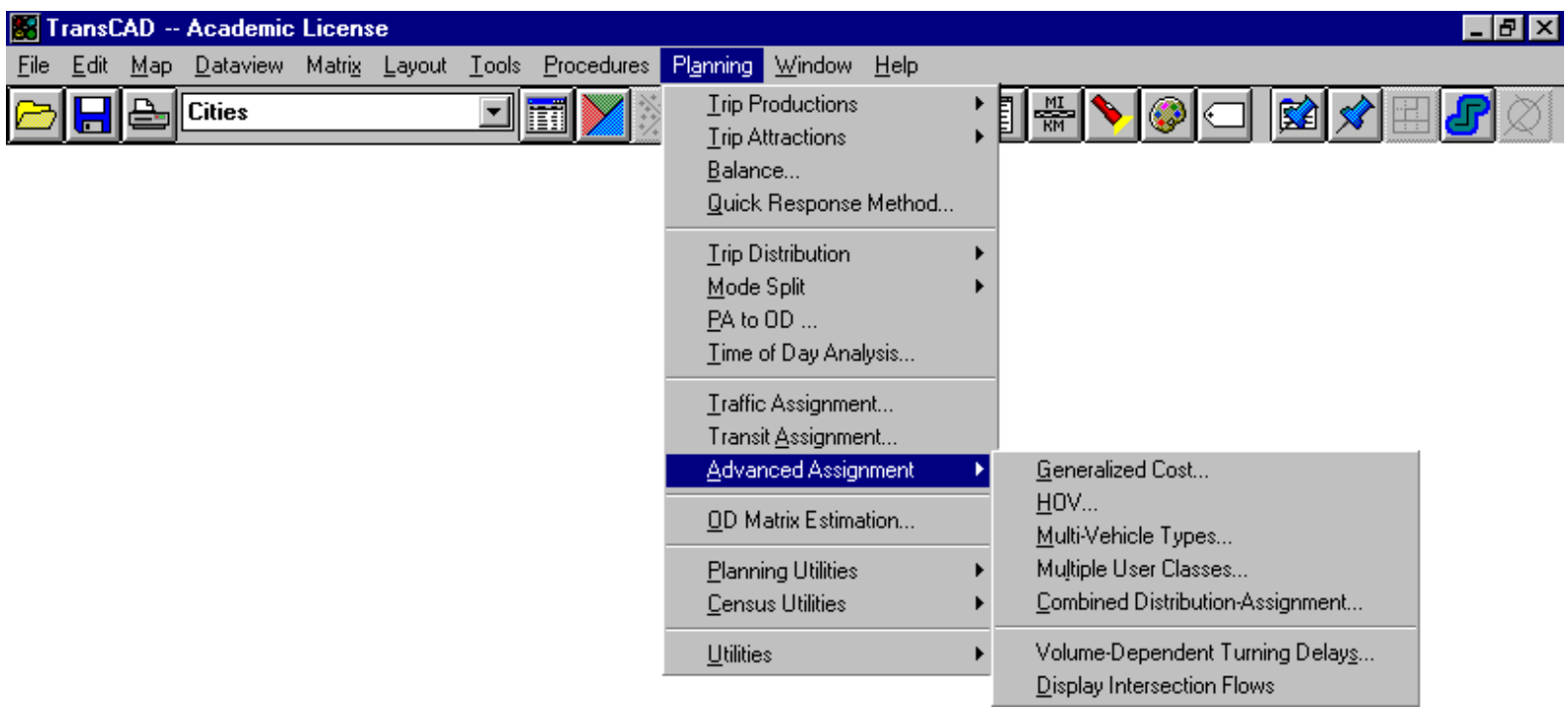

Figura 4.36 - Opção AdVANCED AssignMENT do menu Planning do menu principal do TransCAD

O TransCAD fornece ainda algumas ferramentas mais avançadas, como a opção ADVANCED ASSIGNMENT da figura 4.36, para a realização da etapa de alocação de tráfego, brevemente descrita a seguir:

- Generalized Cost: esta opção fornece maior flexibilidade na aplicação e calibração do modelo, possibilitando a utilização de mais variáveis, tais como taxas de pedágio e fatores de segurança;

- HOV: permite a utilização de faixas de tráfego exclusivas para veículos com alta ocupação (HOV - High Occupancy Vehicle);

- Multi-Vehicle Types: permite realizar a distribuição de viagens na rede classificando-as por tipo de veículo;

- Multiple User Classes: modelo desenvolvido para definir e encontrar o equilíbrio entre diferentes classes de usuários;

- Combined Distribution-Assignment: esta opção possibilita a combinação entre os modelos de distribuição de viagens e de alocação de tráfego com o objetivo de solucionar problemas em ambos os processos. Esta união permite ao mesmo tempo prever o padrão espacial de viagens entre cada par origem-destino e estimar o fluxo de tráfego nas linhas de uma rede;

- Volume-Dependent Turning Delays: este procedimento integra os procedimentos de alocação de tráfego com modelos detalhados de interseções, otimizando os tempos de semáforo e assumindo que as interseções operam isoladamente;

- Display Intersection Flows: mostra graficamente os dados de fluxos em interseções;

A opção OD MAtrix Estimation do menu Planning, figura 4.36, permite estimar e/ou atualizar uma matriz origem-destino, com base em um exemplo de contagem de tráfego e uma tabela de viagens. 
File Edit Map Dataview Matrix Layout Iools Procedures Planning Window Help

F

Trip Attractions

Balance..

Quick Response Method..

Irip Distribution

Mode Split

PA to OD.

Iime of Day Analysis.

Iraffic Assignment.

Transit Assignment.

Advanced Assignment

QD Matrix Estimation..

Planning Utilities

Census Utilities

Import Planning Networks...

Import TranPlan Tables..

Untilities

Build Cross Class Table.

Irip Length Distribution...

Intrazonal Travel Times..

Screenline Analysis

Subarea Analysis.

Centroid Connectors.

Figura 4.37 - Opção Planning UtiLITIES do menu Planning do menu principal do TransCAD

As ferramentas disponíveis na opção PlanNing UtilitiEs, figura 4.37, realizam as seguintes funções:

- Import Planning Networks: importar um arquivo de redes;

- Import TranPlan Tables: importar uma tabela no formato TranPlan;

- Build Cross Class Table: criar uma tabela de classificação cruzada;

- Trip Length Distribution: gerar uma distribuição em classes de tempos ou distâncias de viagem a partir de uma matriz de fluxos e de uma matriz de impedância (p.ex. tempo de viagem ou distância de viagem);

- Intrazonal Travel Times: calcular os valores dos tempos de viagens intrazonais;

- Screenline Analysis: analisar uma Screenline (linha imaginária definida em um mapa, que cruza uma ou mais linhas de uma rede);

- Subarea Analysis: analisar o padrão do tráfego em uma subárea (p.ex. centro da cidade);

- Centroid Connectors: conectar centróides de áreas aos nós de uma camada de linhas. 
File Édit Map Dataview Matrix Layout Iools Procedures Planning Window Help F 3 (1)

Trip Attractions

Balance..

Quick Response Method..

Irip Distribution

Mode Split

PA to OD.

Iime of Day Analysis.

Iraffic Assignment.

Transit Bssignment..

Advanced Assignment

QD Matrix Estimation.

Planning Utilities

Census Utilities

Qpen CTPP Data Table

Untilities

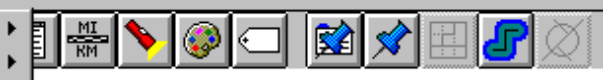

Create a CTPP Journey to Work

Open PUMS Data Table

Figura 4.38 - Opção CEnsus UtiLiTiEs do menu Planning do menu principal do TransCAD

A opção Census Utilities, figura 4.38, fornece três ferramentas para importar e manipular dados censitários:

- Open CTPP Data Table: abrir uma tabela de dados censitários CTPP (Census Transportation Planning Package), encontrados nos CD-ROMs publicados pelo Bureau of Transportation Statistics e Bureau of the Census;

- Create a CTPP Journey to Work: transformar arquivos censitários CTPP em matrizes origem-destino;

- Open PUMS Data Table: abrir uma tabela de dados PUMS (Public Use Microdata Samples) a qual contém os registros dos chefes de família a partir do censo de $1 \%$ a 5\% da população dos Estados Unidos. 
Através da opção Check Nodes, disponível na figura 4.39, menu UTILITIES, pode-se checar erros topológicos dos nós em uma camada de linhas. As demais opções apresentadas estão disponíveis apenas na versão completa do TransCAD, não utilizada nesta pesquisa.

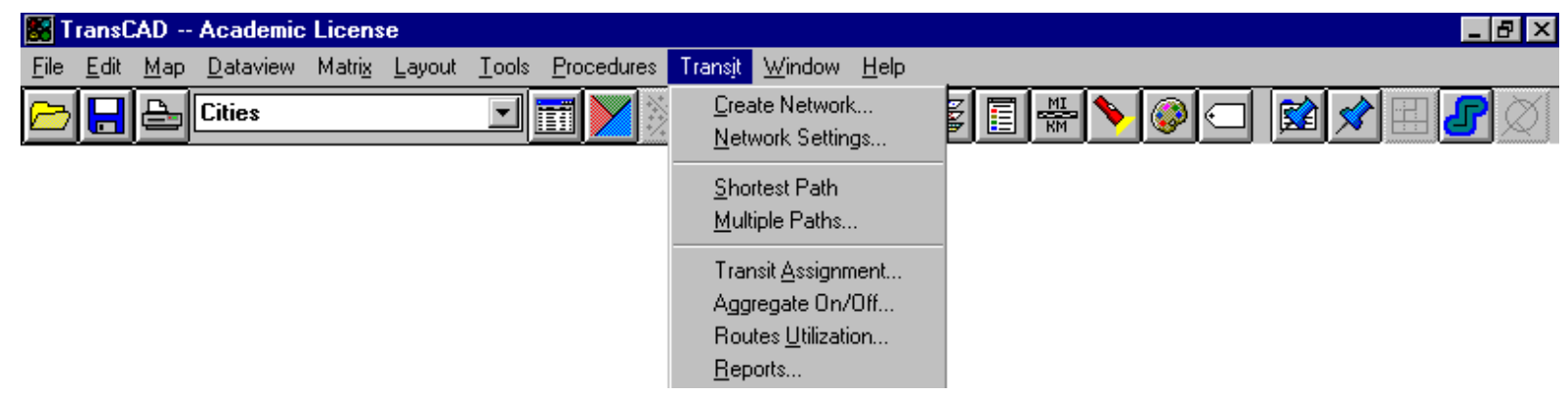

Figura 4.40 - Menu Transit do menu principal do TransCAD

O menu Transit, figura 4.40, fornece ferramentas para criar e trabalhar com redes de transporte público urbano (TPU). As opções CREATE NETWORK e NETWORK SETTings realizam as seguintes funções, respectivamente: criar uma rede de TPU a partir de um sistema de rotas e pontos de parada; definir/configurar os parâmetros que atuam sobre esta rede. As opções ShORTEST PATH e Multiple PATHS são utilizadas na definição do caminho mínimo entre duas zonas ou dois pontos de parada e entre um conjunto de origens e destinos de uma rede de TPU, respectivamente.

Através da opção TRANSIT ASSIGNMENT pode-se definir ou alterar os parâmetros globais de uma rede de TPU, tais como: taxas de transferência, tempos de espera dentro do veículo, em terminais, de caminhada, etc. A opção AGGREGATE ON/OFF permite agregar definições de embarque e desembarque para cada ponto de parada e a opção RoUTES UTILIZATION permite agregar o número de passageiros em cada embarque e desembarque. $\mathrm{Na}$ opção REPORTS pode-se obter relatórios relativos aos resultados de análises efetuadas em uma rede de TPU.

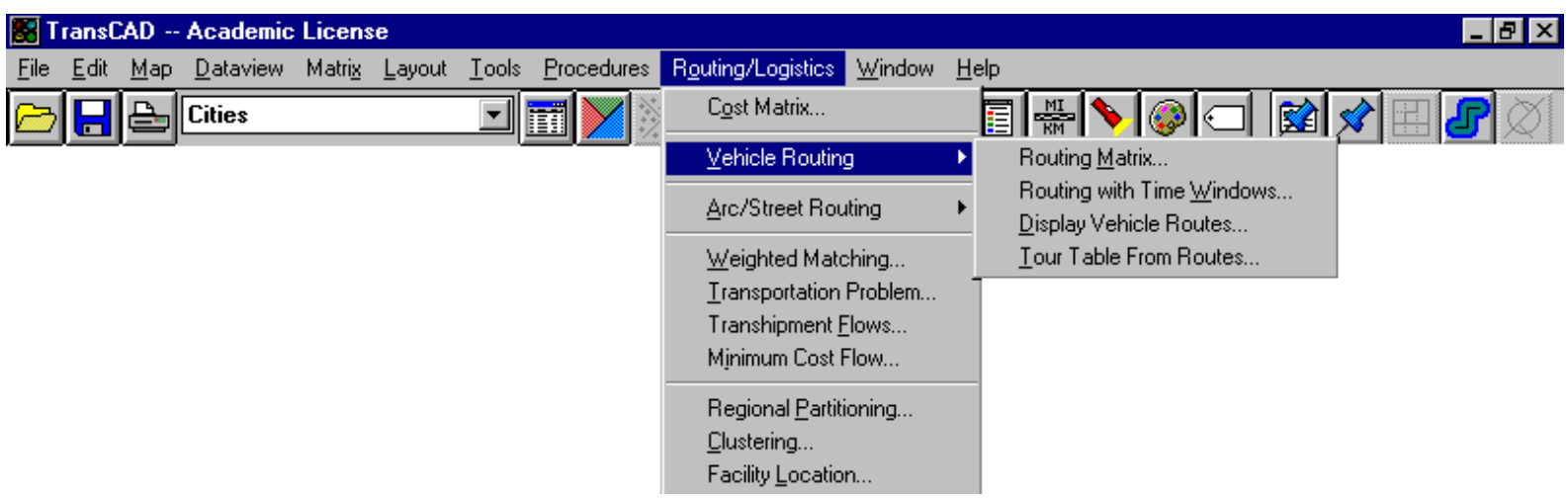

Figura 4.41 - Opções Cost MATRIX e Vehicle Routing do menu Routing/Logistics do menu principal do TransCAD

Otimização de rotas é uma solução eficiente para problemas de entrega de mercadorias. Tem por definição percorrer uma seleção de links de uma rede de transporte fornecendo um conjunto de uma ou mais rotas que cobrem todos os links, considerando que 
todas as rotas começam e terminam em um depósito. Solucionar um problema de roteirização envolve determinar o número de veículos necessários à operação e o tempo gasto por cada um. As opções disponíveis no menu Routing/Logistics, figura 4.41, fornecem as ferramentas necessárias para a solução desses problemas.

Através da opção COST MATRIX pode-se obter uma matriz de custos de transporte baseada em uma rede minimizando qualquer variável (p.ex. distância). As opções disponíveis no sub-menu VEHICLE RouTinG realizam as seguintes funções:

- Routing Matrix: criar uma matriz de distâncias mínimas e tempo de viagem entre o depósito e cada ponto de entrega e entre cada par de pontos de entrega;

- Routing with Time Windows: solucionar o problema de roteirização de veículos podendo-se levar em consideração restrições de tempo, p. ex. tempo de funcionamento do depósito;

- Display Vehicle Routes: mostrar em tela a solução de rotas fornecida pelo programa;

- Tour Table From Routes: criar uma tabela contendo uma lista dos pontos de parada utilizados em cada rota e variáveis como distância total, distância entre cada parada, entre outras.

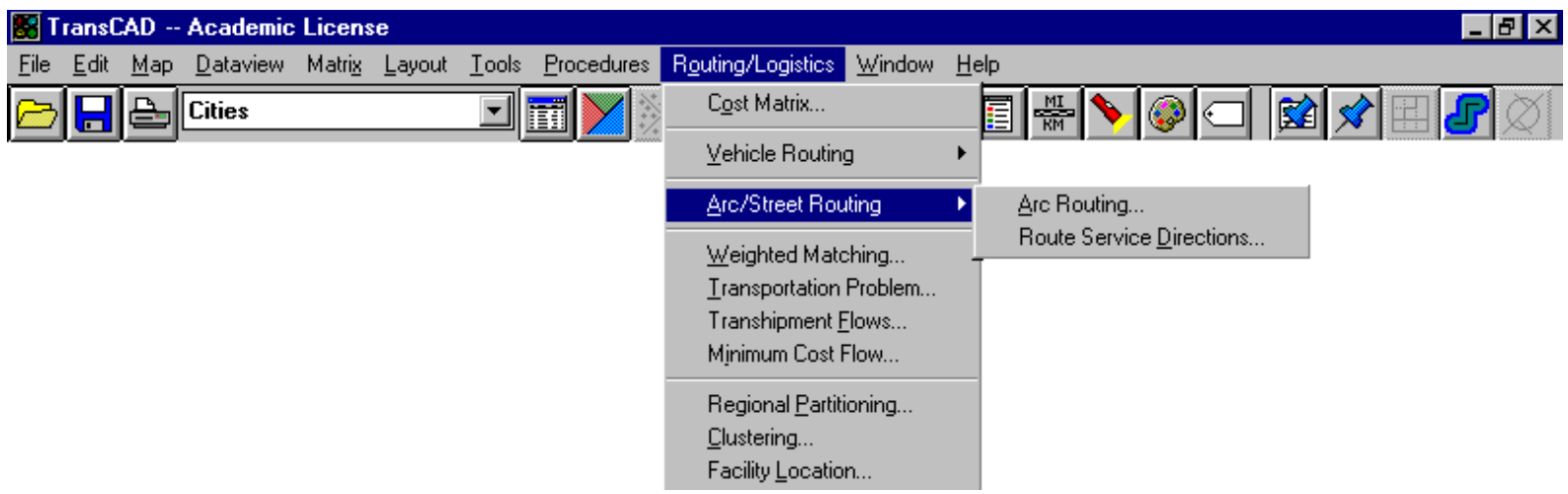

Figura 4.42 - Opção ARC/STREET RoUTING do menu Routing/Logistics do menu principal do TransCAD

Os comandos apresentados na opção ARC/STREET RouTing, figura 4.42, são:

- Arc Routing: a roteirização em arco é utilizada na solução de problemas do tipo: entrega de cartas, coleta de lixo ou outras operações realizadas de porta em porta;

- Route Service Directions: opção utilizada para definir dados de uma rota a partir de um banco de dados.

Através da opção TRANSPORTATION PROBLEM pode-se solucionar problemas de entrega de mercadorias envolvendo vários postos de entrega e vários postos de distribuição. As opções Transhipment Flows e Minimum Cost Flow permitem criar uma tabela contendo o volume de mercadorias que fluem em cada linha da rede e solucionar problemas de distribuição considerando as limitações da rede viária, respectivamente. As opções Regional PARTitioning e Clustering permitem a criação de grupos de áreas em uma camada com base no parâmetro proximidade ou em medidas de similaridade. Finalmente, a opção FACILITY LOCATION é utilizada na identificação da melhor localização para hospitais, lojas de aluguel de veículos, supermercados e outros tipos de instalações pontuais. 


\subsection{Software UfosNet (Versão 3.5.1)}

\subsubsection{Comandos Básicos e Rotinas Avançadas de SIG}

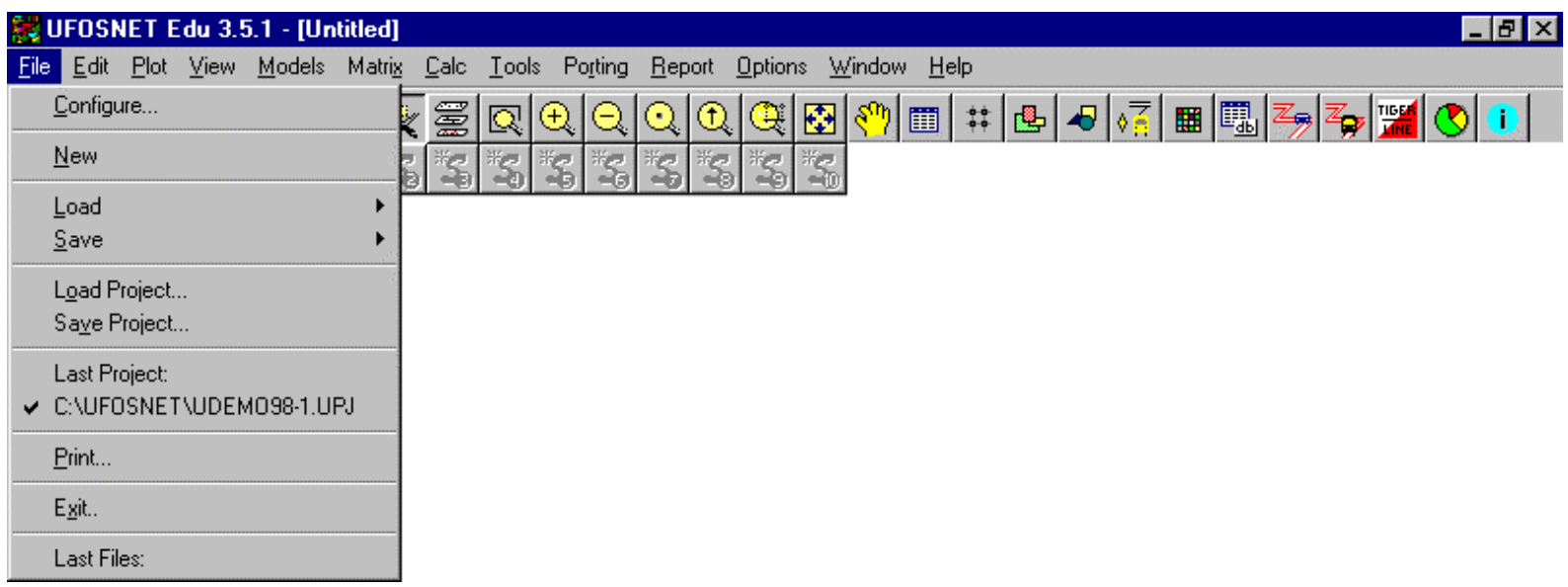

Figura 4.43 - Opção File do menu principal do UfosNet

No menu File, figura 4.43, a opção CONFIGURE permite a definição do número máximo de zonas, nós, links e pontos, campos de zonas, nós, links, pontos, fatores de fricção, o maior valor do fator de fricção ou de impedância em minutos, o maior número de pontos em uma linha de contorno para definição de limites de áreas, o maior número de segmentos de TPU e o maior número de matrizes. Nesta caixa de diálogos pode ser definido, também, o sistema de coordenadas: TIGER, longitude/latitude, ou uma grade, onde define-se o número de unidades equivalentes a 1 milha/km; a unidade de distância (milhas ou quilômetros), e as configurações de fonte (tipo, estilo, tamanho). Na opção NEW cria-se uma nova tela de trabalho e a anterior é apagada. A opção LOAD permite carregar arquivos existentes um a um, sendo que o tipo de arquivo a ser carregado pode ser escolhido com base no menu apresentado por esta opção.

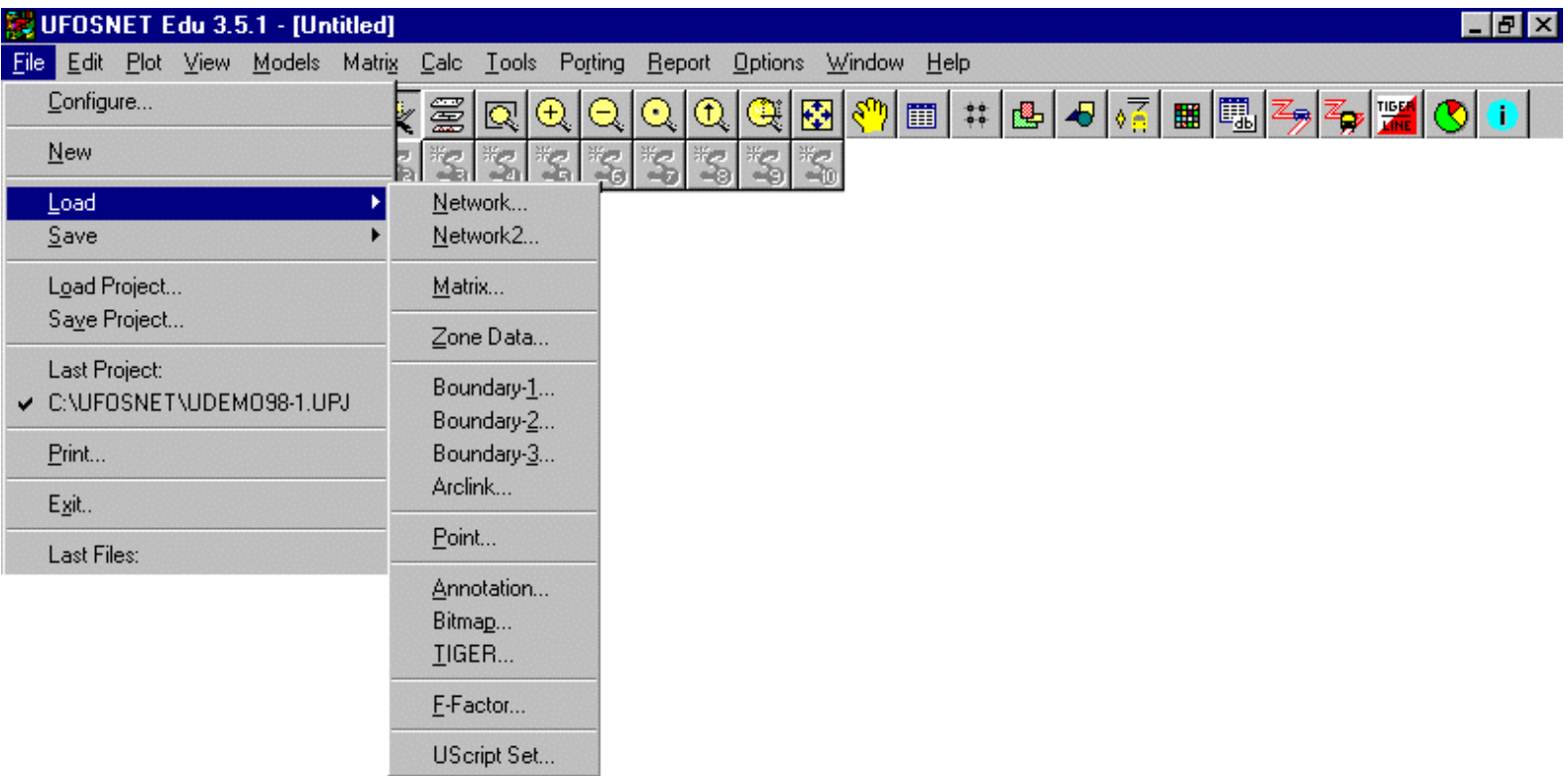

Figura 4.44 - Opção LOAD do menu File do menu principal do UfosNet 
Seguindo a ordem de disposição do menu da figura 4.44, os tipos de arquivos que podem ser carregados no UfosNet são:

- Network e Network2 (*.net); Matrix (*.tmx); Zone Data (*.zon), que são arquivos de redes, matrizes e dados zonais, respectivamente, criados no UfosNet;

- Boundary-1, Boundary-2 e Boundary-3, que são arquivos de linhas de limites (áreas) e possuem extensão (*.zby). O UfosNet carrega cada arquivo de limites em uma camada de limites 1, 2 ou 3 do mapa, conforme a opção selecionada Boundary 1, 2 ou 3, sendo que a primeira camada (1) pode ser editada e vinculada a uma tabela de zonas, as demais não. A opção ArcLink carrega um arquivo de limites (*.zby) para uma camada de arclinks. Arclinks são arquivos especiais de áreas, que são utilizados para armazenar pontos de links de rodovias;

- Point Data (*.upt) e Annotation (*.ann) são arquivos de pontos e anotações, criados pelo UfosNet;

- Bitmap (*.bmp, pcx, tga, tif, jpg), que são arquivos com dados em formato matricial;

- Tiger (*.tgr), arquivos do tipo Tiger/Line;

- F-Factor (*fac), arquivos de fatores de fricção;

- Uscrip Set (*.uss), arquivos com macros escritas pelo usuário.

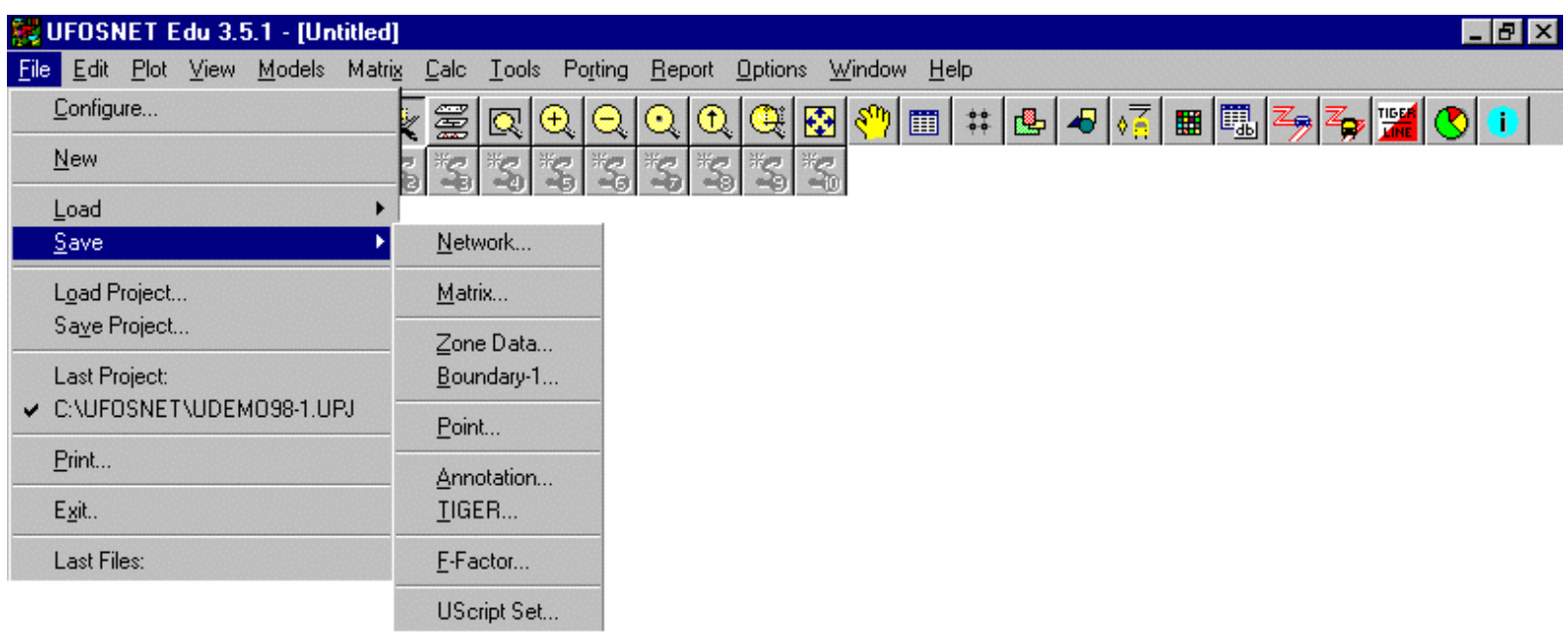

Figura 4.45 - Opção SAVE do menu File do menu principal do UfosNet

O menu ativado pela opção SAVE permite o salvamento dos arquivos listados na figura 4.45, cujas extensões já foram indicadas anteriormente. As opções LOAD PROJECT e SAVE PROJECT, figura 4.43, permitem, respectivamente, carregar um projeto e salvar o projeto ativo. Um projeto pode conter um conjunto de arquivos com suas respectivas camadas, sendo que todas as camadas ativas do mapa no momento do salvamento do projeto constarãodo mesmo. Cada projeto pode possuir uma senha de acesso, a qual permite que o arquivo seja usado somente para leitura. Desta forma, as alterações futuras só poderão ser salvas mediante a apresentação da senha. Abaixo da opção LAST PROJECT pode ser identificado o último projeto carregado pelo software.

A opção PRINT permite imprimir a janela ativa do mapa e todos os objetos visíveis. $\mathrm{Na}$ caixa de diálogos ativada por esta opção pode-se determinar a impressora a ser utilizada 
(todas as disponíveis no Windows) e suas configurações, especificar três linhas de texto que aparecerão como notas de rodapé e as suas configurações de fontes, e optar pelos itens: $\checkmark$ escala de cinza, $\checkmark$ moldura, $\checkmark$ moldura retangular com bordas arredondadas, $\checkmark$ escala fixa e $\checkmark$ definir margens. A opção ExiT finaliza e sai do programa, fornecendo uma tela final indicando o tempo da sessão de utilização do software. Abaixo da opção LAST FILES pode-se visualizar os últimos arquivos trabalhados.

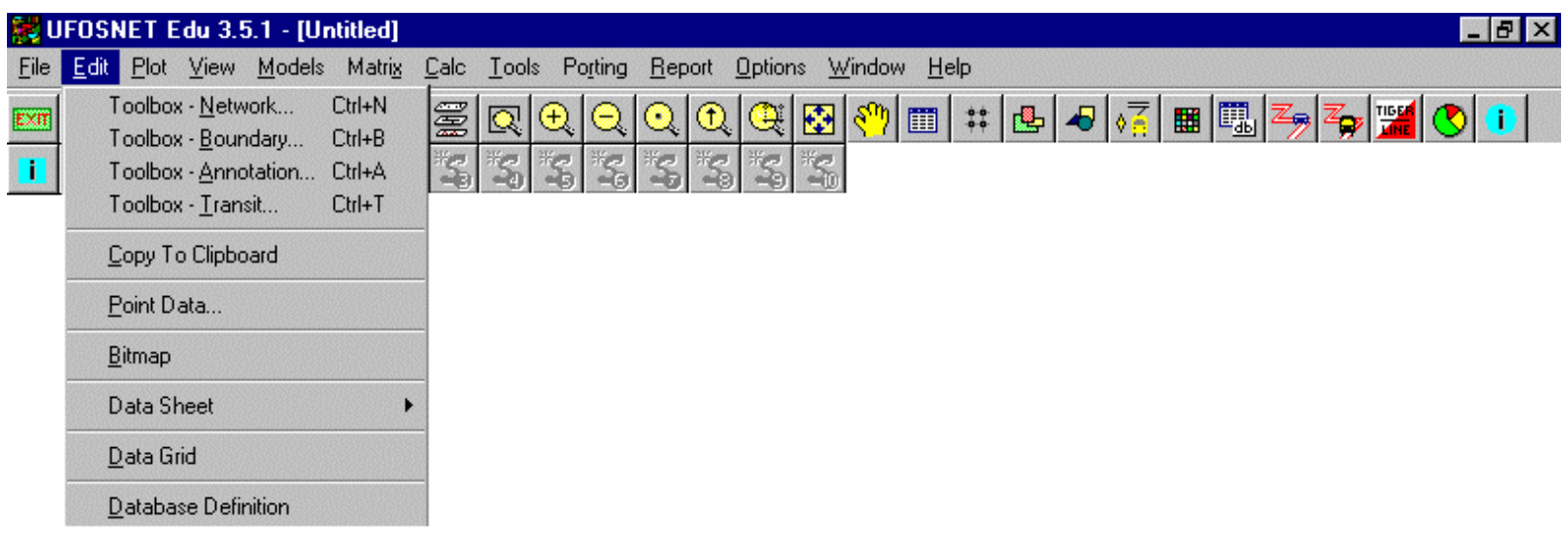

Figura 4.46 - Opção Edit do menu principal do UfosNet

No menu Edit da figura 4.46, a opção TOOLBOX - NETWORK ativa uma caixa de ferramentas, figura 4.47, utilizada para edição de nós e links de redes.

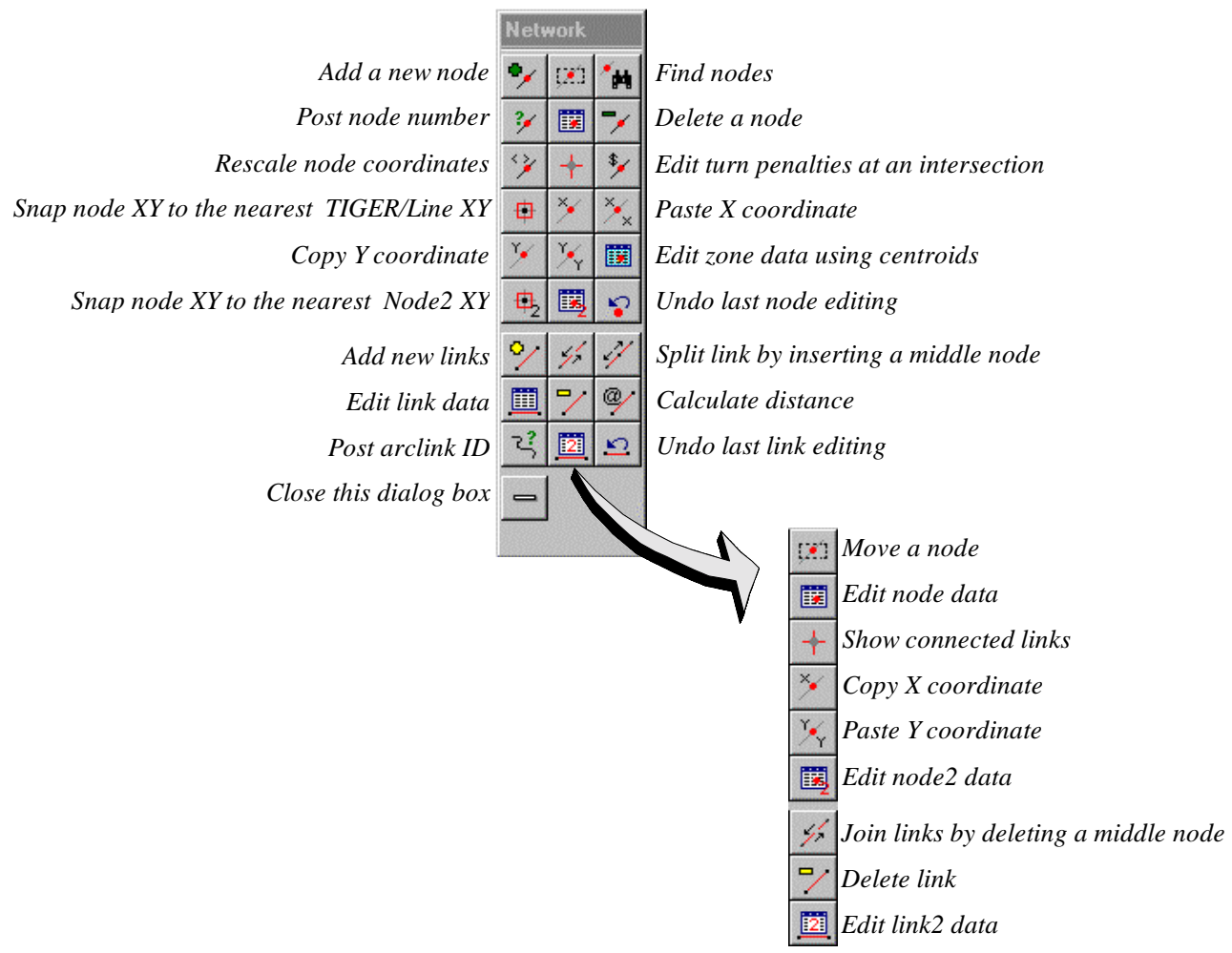

Figura 4.47 - Caixa de ferramentas Network 
Na figura 4.47, as opções Add a new node, Move a node e Delete a node permitem adicionar um novo nó, mover um nó existente e excluir um nó, respectivamente. Através da opção Find nodes pode-se localizar um nó ou um intervalo de nós informando-se o primeiro e o último nó a ser encontrado. A opção Post node number é utilizada para visualizar o número de identificação (ID) dos nós. Esta operação pode ser permanente ou temporária, isto é, quando a tela for redesenhada, o ID irá desaparecer. A opção Edit node data ativa uma caixa de diálogos que apresenta uma listagem dos valores dos atributos de cada campo do banco de dados do nó selecionado e permite realizar as seguintes funções: Store, armazena os valores dos dados do nó selecionado em um arquivo temporário para ser usado posteriormente, Retrieve, substitui os campos de dados correntes pelos valores de dados armazenados anteriormente, Lock, fixa a posição do cursor em determinado campo de dados, Unlock, volta a posição do cursor para a célula inicial, Modify, salva os valores dos dados dos campos selecionados que aparecem nesta caixa de diálogos na tabela de nós, Check, seleciona todos os campos de dados ou desfaz a seleção de todos os campos de dados tornando sua edição proibida, Paste, copia todos os registros de dados existentes na área de transferência para o nó selecionado, Auto Modify, copia os valores dos campos de dados selecionados diretamente para uma seleção de nós e Clear, apaga todos os valores dos dados.

A opção Rescale node coordinates permite alterar a escala das coordenadas XY dos nós utilizando-se de uma regressão linear simples e sendo definidos os pontos base a serem utilizados (3 pontos) e as variáveis das equações. A opção Show connected links permite visualizar e destacar todos os links conectados a um nó selecionado. A opção Edit turn penalties... é utilizada para penalizar ou restringir certos movimentos de retorno. Na caixa de diálogos ativada por esta opção, indicando-se o nó a ser analisado, automaticamente aparecerão todos os nós conectados a este por meio de um link e suas respectivas penalidades (se houver). Nesta mesma caixa podem ser determinadas novas penalidades ou proibições. Vale ressaltar que no UfosNet as penalidades de retorno são medidas em segundos. A opção Snap node $X Y$ to the nearest TIGER/Line $X Y$ permite posicionar um nó sobre um ponto da camada TIGER e as coordenadas deste ponto serão copiadas para o nó. A opção Snap node XY to the nearest Node $2 X Y$ é semelhante à descrita anteriormente, sendo que as coordenadas a serem utilizadas como referência são as de um segundo nó selecionado e a opção Edit node2 data ativa a caixa de diálogos para edição e visualização dos atributos dos campos de dados do nó 2. As opções Copy e Paste X/Y coordinates são utilizadas para copiar o valor de uma coordenada $\mathrm{X} / \mathrm{Y}$ e atribuir este valor a um nó selecionado. A opção Edit zone data... permite editar os dados de uma zona selecionando-se o nó correspondente ao centróide da área. A opção Undo last node editing permite desfazer o último comando de edição de nós.

As opções disponíveis na caixa de ferramentas da figura 4.47 descritas a seguir são destinadas a edição de links. A opção Add new links permite adicionar um ou dois links (duplo sentido) entre dois nós. As opções Join links... e Split link... permitem unir dois links excluindo o nó da interseção e dividir um link em dois adicionando um nó neste, respectivamente. A opção Edit link data ativa uma caixa de diálogos igual a apresentada na opção Edit node data, com a diferença de esta referir-se a links e habilitar a opção Reverse link, utilizada para visualizar os dados do link no sentido oposto (caso de vias de mão dupla). A opção Delete link é utilizada para excluir um link, definindo-se os nós que são unidos por ele. A opção Calculate distance permite calcular a distância entre dois pontos quaisquer da tela. A opção Post Arclink ID é utilizada para visualizar o número de ID de um arclink. E, finalmente, a opção Undo, é utilizada para desfazer o último comando de edição de links. 
A opção TOOLBOX - BoundARY, figura 4.46, ativa uma caixa de ferramentas, ilustrada na figura 4.48, destinadas a edição de áreas.

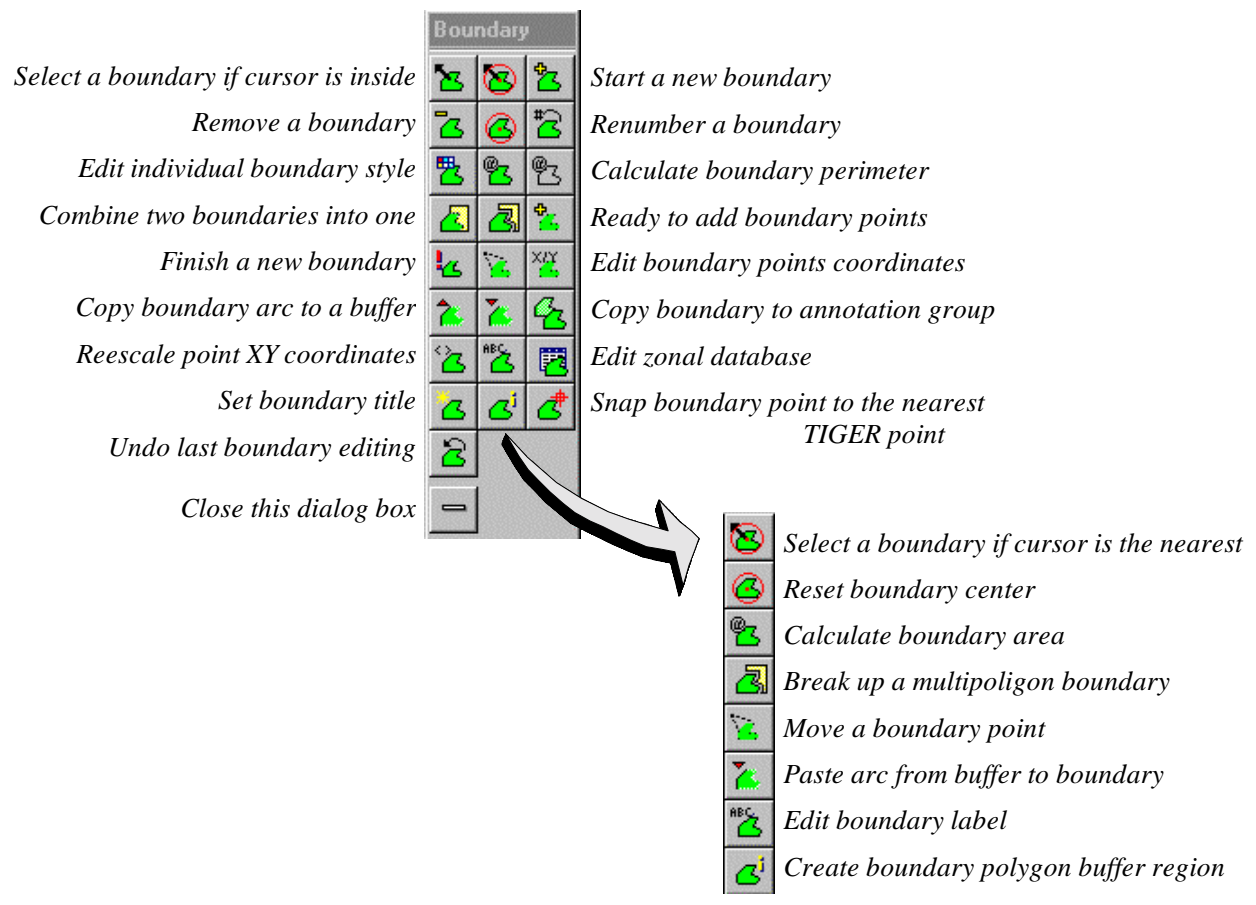

Figura 4.48 - Caixa de ferramentas Boundary

Na figura 4.48, as opções de seleção de áreas são: Select a boundary if cursor is inside, se o cursor está posicionado dentro da área e Select a boundary if cursor is the nearest, se o cursor está próximo ao centróide da área, utilizado quando há áreas sobrepondo-se. A opção Start a new boundary permite criar uma nova área formada por um polígono ou um conjunto de polígonos, informando-se o ID e o rótulo para identificação e indicando-se os pontos que delimitarão as novas áreas. Esses pontos são inseridos através da opção Ready to add boundary points. Para se indicar o término da operação de criação de uma área e confirmá-la deve-se selecionar a opção Finish a new boundary. A opção Remove a boundary é utilizada para se excluir uma área; Reset boundary center, para alterar a posição do ponto central da área; Renumber a boundary, para renumerar uma área existente; Calculate boundary area, para calcular a área e Calculate boundary perimeter, para calcular o perímetro de determinada área.

A opção Edit individual boundary style ativa uma caixa de diálogos que permite definir os seguintes parâmetros: visualizar o número ou o rótulo da área (definindo o tamanho e o tipo de fonte a ser utilizada), definir a espessura e cor da borda, optar pelo preenchimento da área com determinada cor, padrão ou utilização de um mapa temático, para o qual deve ser definido o campo do banco de dados de áreas a ser utilizado, as cores e os intervalos dos valores. A opção Combine two boundaries into one permite combinar dois polígonos em um só, recebendo a numeração do primeiro polígono selecionado. Break up a multipoligon boundary é utilizada no caso de uma área conter vários polígonos, transformando cada polígono em uma área individual. Move a boundary point utilizada para alterar a posição de um ponto da área e Edit boundary points coordinates permite alterar as coordenadas de 
determinado ponto da área. As opções Copy boundary arc... e Paste arc from... permitem copiar um arco (seção do polígono da área selecionada) de uma área e colá-lo em outra área. A opção Copy boundary to annotation... permite copiar a área selecionada para o grupo de anotações correntes (camada ativa); Reescale point XY coordinates permite alterar as coordenadas de todos os pontos da área multiplicando-as por determinado valor; e Edit boundary label permite alterar o rótulo da área selecionada.

A opção Edit zonal database ativa uma caixa de diálogos, semelhante à ativada pela opção Edit $\Rightarrow$ TOOLBOX-NETWORK $\Rightarrow$ EDIT NODE, destinada à edição e visualização dos atributos de cada área selecionada do mapa. A opção Set boundary title é utilizada para adicionar ou modificar o título da camada de áreas; na opção Create boundary poligon buffer region pode-se definir uma região de buffer e todos os cálculos e consultas feitas após este comando se referirão somente aos objetos dentro desta área; a opção Snap boundary point to... permite posicionar um ponto da área sobre um ponto próximo a este contido na camada TIGER e, por fim, a opção Undo last... permite anular a última edição feita na camada de áreas ativa.

A opção TOOLBOX - AnNOTATiOn, figura 4.46, ativa a caixa de ferramentas ilustrada na figura 4.49. Estas ferramentas são utilizadas para melhorar a área de impressão adicionando-se objetos de anotação que podem ser símbolos, linhas, textos e metafiles.

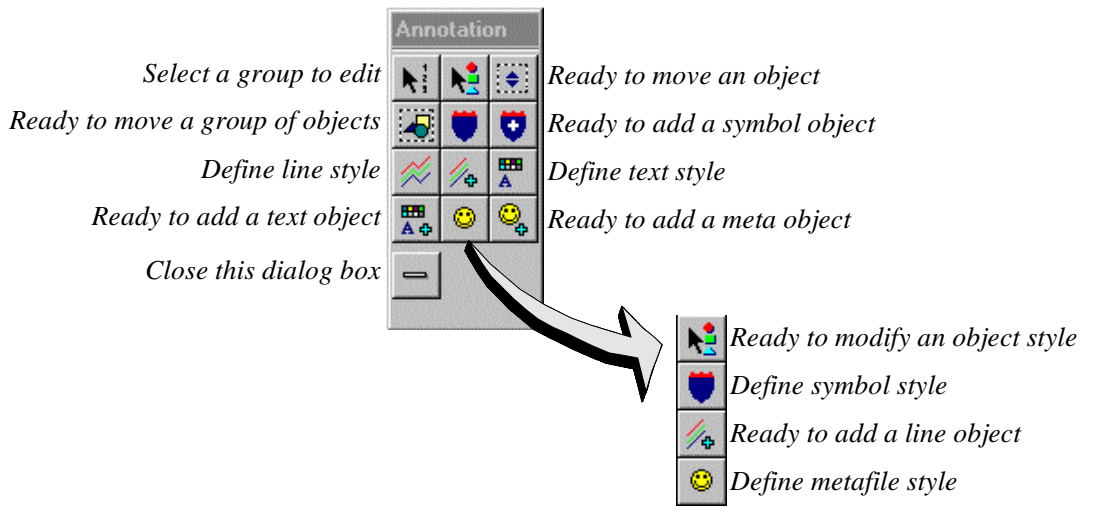

Figura 4.49 - Caixa de ferramentas Annotation

Na figura 4.49, a opção Select a group to edit possibilita, através de uma caixa de diálogos, que contém uma listagem dos grupos existentes indicando o grupo que está ativo, que pode ser visualizado na tela e o número de objetos que possui, e permite a seleção de determinado grupo para que este possa ser editado. A edição dos objetos de um grupo pode ser feita através dos comandos Ready to modify an object style, para alterar estilos de linhas, cores, tamanho, Ready to move an object, para mover um objeto e Ready to move a group..., para mover um grupo de objetos. As opções Define symbol style, line style, text style e metafile style ativam caixas de diálogos utilizadas para definir as configurações do objeto (símbolo, linha, texto ou metafile) a ser inserido na tela. Após a definição do objeto a ser inserido deve-se selecionar as opções Ready to add a... (conforme o objeto) e indicar uma posição na tela.

A opção ToOlBOX - TRAnsit, figura 4.46, ativa uma caixa de diálogos destinada a edição de linhas de transporte público urbano. Como este tópico se enquadra como rotina 
específica de transportes, esta opção será descrita posteriormente. A opção COPY TO CLIPBOARD copia a janela do mapa, permitindo que ela seja utilizada por outros aplicativos Windows. A opção POINT DATA ativa uma caixa de diálogos semelhante à fornecida pelas opções Edit $\Rightarrow$ TOOLBOX-NETWORK $\Rightarrow$ EDIT NODE, utilizada para visualizar e editar os atributos de pontos do mapa. A opção BITMAP permite a edição de um bitmap presente no mapa. Conforme a figura 4.50, a seguir, as opções DATA SHEET $\Rightarrow$ ZONE, NODE, LinK, POINT ou F-FACTOR abrem os bancos de dados relativos a zonas, nós, links, pontos e fatores de fricção respectivamente, possibilitando, também, a edição dos dados constantes nos mesmos.

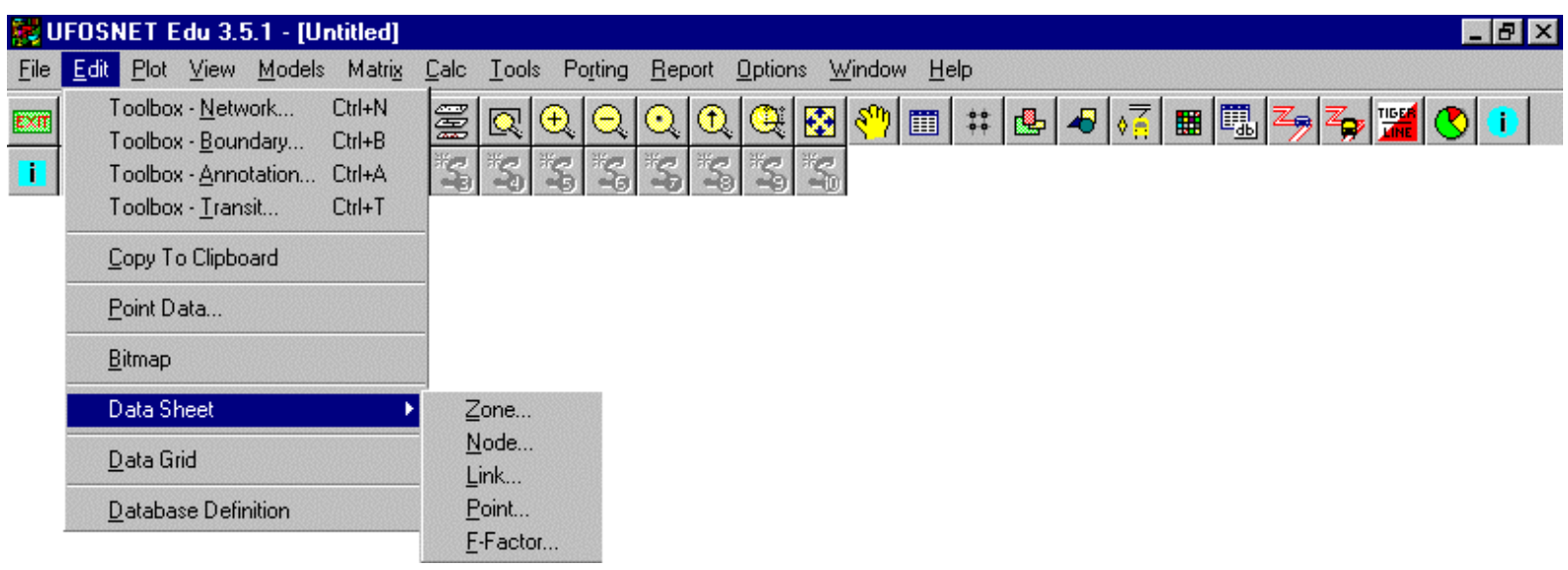

Figura 4.50 - Opção DATA SHEET do menu Edit do menu principal do UfosNet

A opção DATA GRID, figura 4.46, fornece um método mais direto para edição de banco de dados do que o fornecido pelas opções DATA SHEET..., pois permite a edição automática dos dados (pode-se utilizar caixa de diálogos com o formato usado no Windows) sem a necessidade de confirmação das alterações através da tecla Modify presente na outra opção. A última opção presente na figura 4.46, DATABASE DEFINITION, ativa uma caixa de diálogos destinada a criação, visualização e edição dos campos dos bancos de dados, onde podem ser definidos os seguintes itens: nome, tipo (caracter ou numérico), comprimento, número de casas decimais, considerar como dados de distância (indicando que este campo se refere a dados de distância linear) e gerar relatório (gera um relatório dos dados, armazenando-o em um arquivo formato *.txt). 


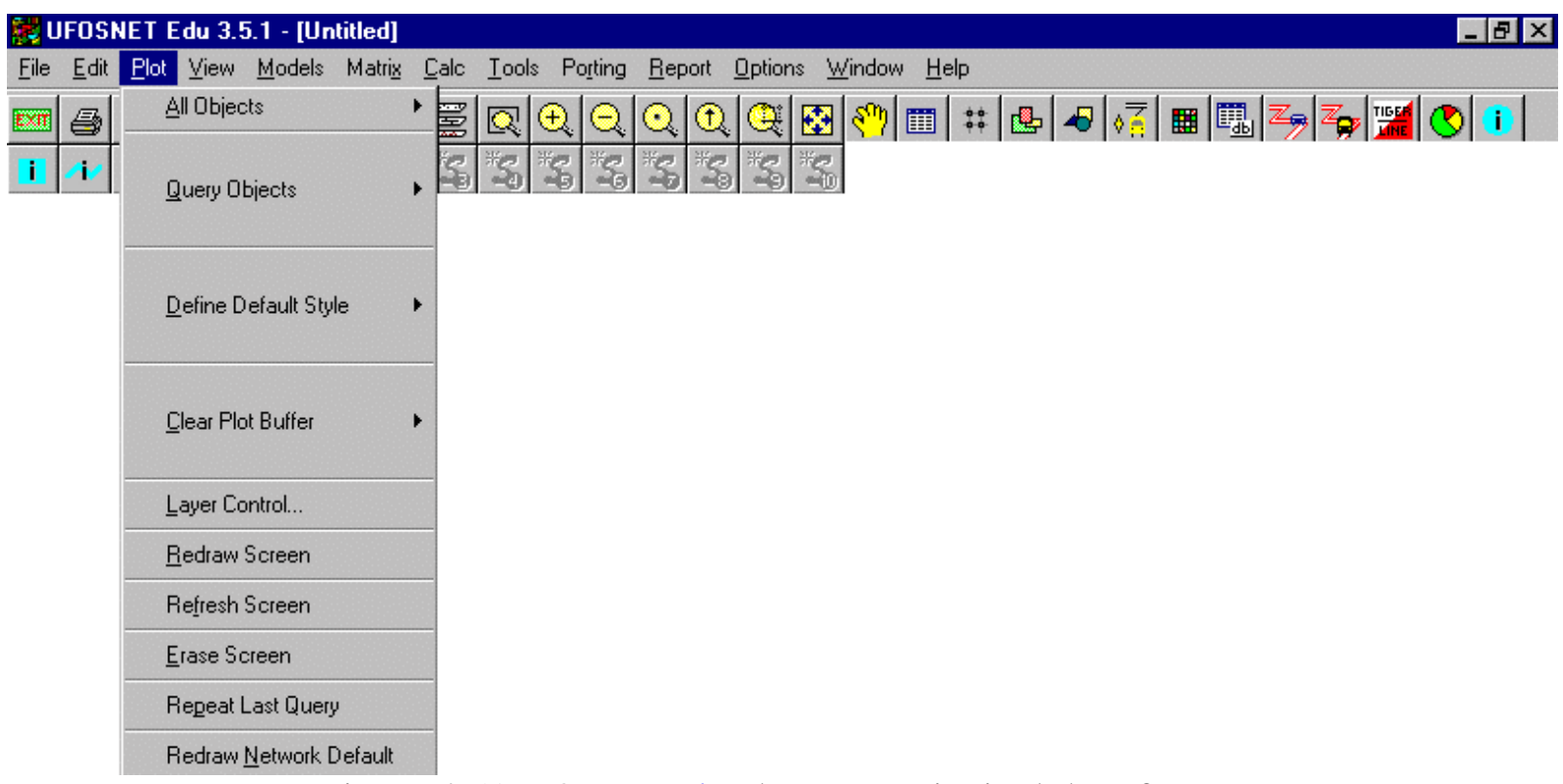

Figura 4.51 - Opção Plot do menu principal do UfosNet

Na figura 4.51 pode-se identificar os comandos disponíveis na opção Plot do menu principal do UfosNet, utilizados para visualizar os objetos contidos em determinada camada do mapa ou que se enquadram em consultas ou intervalos de valores definidos pelo usuário. As opções ALL OBJECTS $\Rightarrow$..., mostradas na figura 4.52, são utilizadas para mostrar (tornar visível) na tela, com as respectivas definições de padrão de estilo e camada de impressão ativa, todos os nós e links de uma rede, pontos, áreas e pontos de áreas (quantas camadas de área existirem - 1, 2...), anotações, objetos do tipo TIGER/Line e Bitmaps inseridos no mapa.

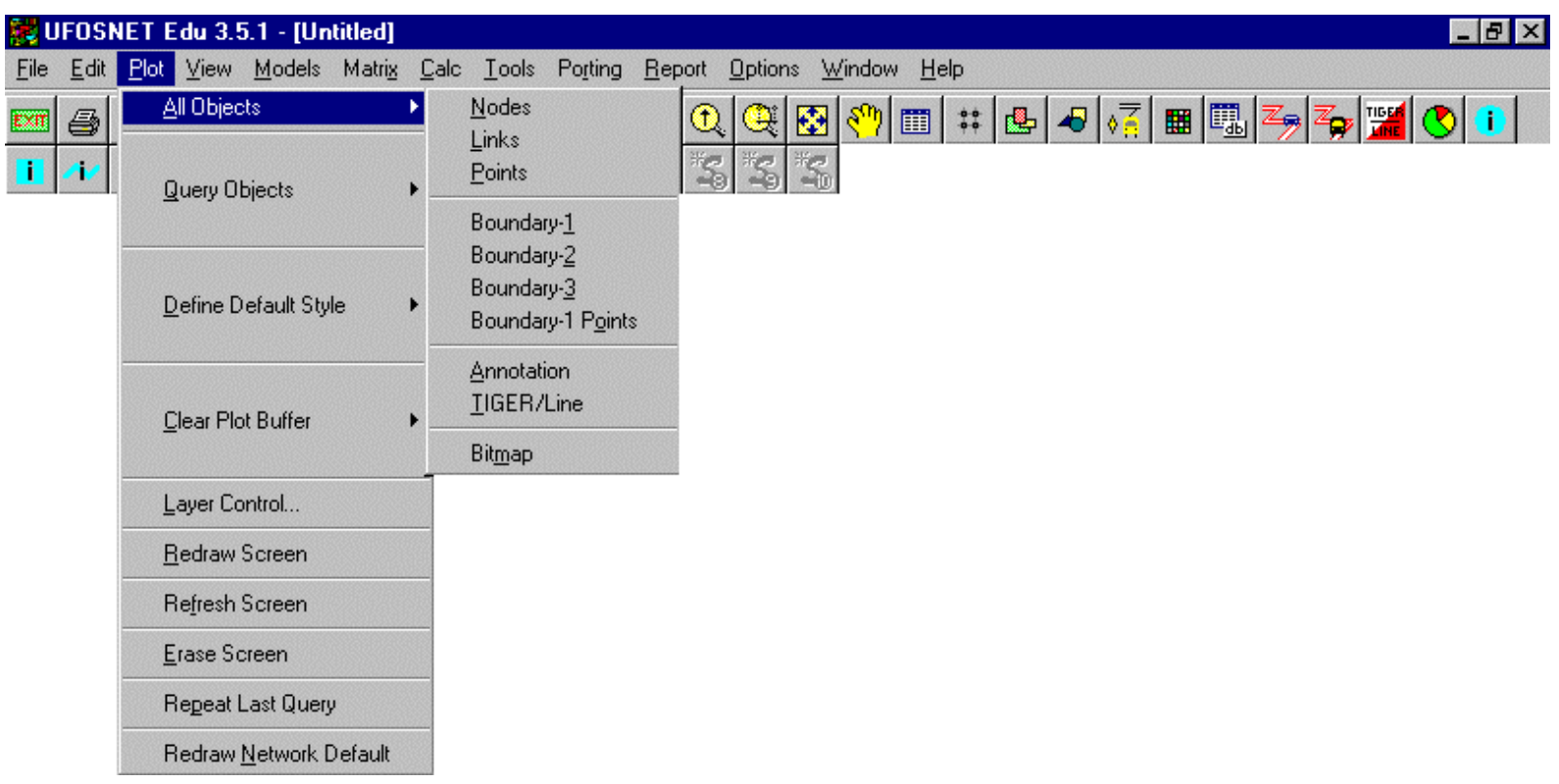

Figura 4.52 - Opção All OBJECTS do menu Plot do menu principal do UfosNet

As opções QUERY OBJECTS $\Rightarrow$... (figura 4.53) permitem a visualização de objetos utilizando critérios de consulta baseados nos valores dos dados. Quando estão ativas regiões de buffer, somente os objetos presentes dentro destas regiões serão considerados. O comando 
QUERY OBJECTS $\Rightarrow$ ZONES ativa uma caixa de diálogos onde podem ser especificados os seguintes parâmetros: mostrar a área (quando esta opção está selecionada a área é preenchida com a cor escolhida, caso contrário serão mostrados apenas os nós dos centróides das áreas com seu estilo padrão previamente definido); definir um critério para a zona, onde é especificado um intervalo de valores (definindo-se o valor máximo e o mínimo) a ser utilizado como filtro e o campo do banco de dados a ser utilizado; definir uma sequiência de critérios (no máximo três) especificando seus valores máximos e mínimos, cujo intervalo pode ser excluído ou inserido na seleção optando-se pela opção de exclusão; definir a forma de visualização do primeiro critério apenas, podendo-se utilizar círculos ou barras (cujo tamanho será proporcional ao valor de cada área) e mostrar o valor dos dados, definindo-se o tamanho do caracter (que pode ser variável de acordo com o valor), e se ele aparecerá em negrito.

O comando QueRY OBJECTS $\Rightarrow$ NODES ativa uma caixa de diálogos com a opção de se definir um critério de valores máximos e mínimos referentes ao número do nó e o campo do banco de dados que contém estas informações e os valores máximos e mínimos das coordenadas X e Y; pode-se, como no comando descrito anteriormente, definir uma sequiência de critérios e a forma de visualização do primeiro critério; utilizar os movimentos de retorno em interseções, indicando-se a matriz válida a ser utilizada, a forma de visualização, que pode ser em valores e/ou barras com variação de tamanho proporcional ao valor do fluxo, o valor máximo e a espessura máxima das barras a ser considerada. O comando QUERY OBJECTS $\Rightarrow$ LiNKS ativa uma caixa de diálogos onde são definidas: as restrições quanto aos valores máximos e mínimos dos links, nós A e B para a realização da filtragem e o campo do banco de dados que contém os valores referentes ao número de links; uma seqüência de critérios e a forma de visualização do primeiro critério; o estilo da linha; e as opções $\checkmark$ apenas para a janela corrente, $\checkmark$ pular os centróides dos links e $\checkmark$ gerar relatório.

Na caixa de diálogos ativada pelo comando QUERY OBJECTS $\Rightarrow$ NODES são definidos: a cor para visualização dos pontos selecionados e o campo do banco de dados contendo os valores relativos a esses pontos; uma seqüência de critérios; a forma de visualização do primeiro critério, podendo-se definir o tamanho do ponto com um valor fixo e as configurações de caracter, quando mostrado o valor do ponto. Em todos os comandos para consulta de objetos descritos acima estão disponíveis as opções: New Query, para iniciar um nova operação de consulta onde todos os registros constantes na camada ativa serão analisados, e Sub Query, para iniciar uma consulta apenas nos registros selecionados previamente. 


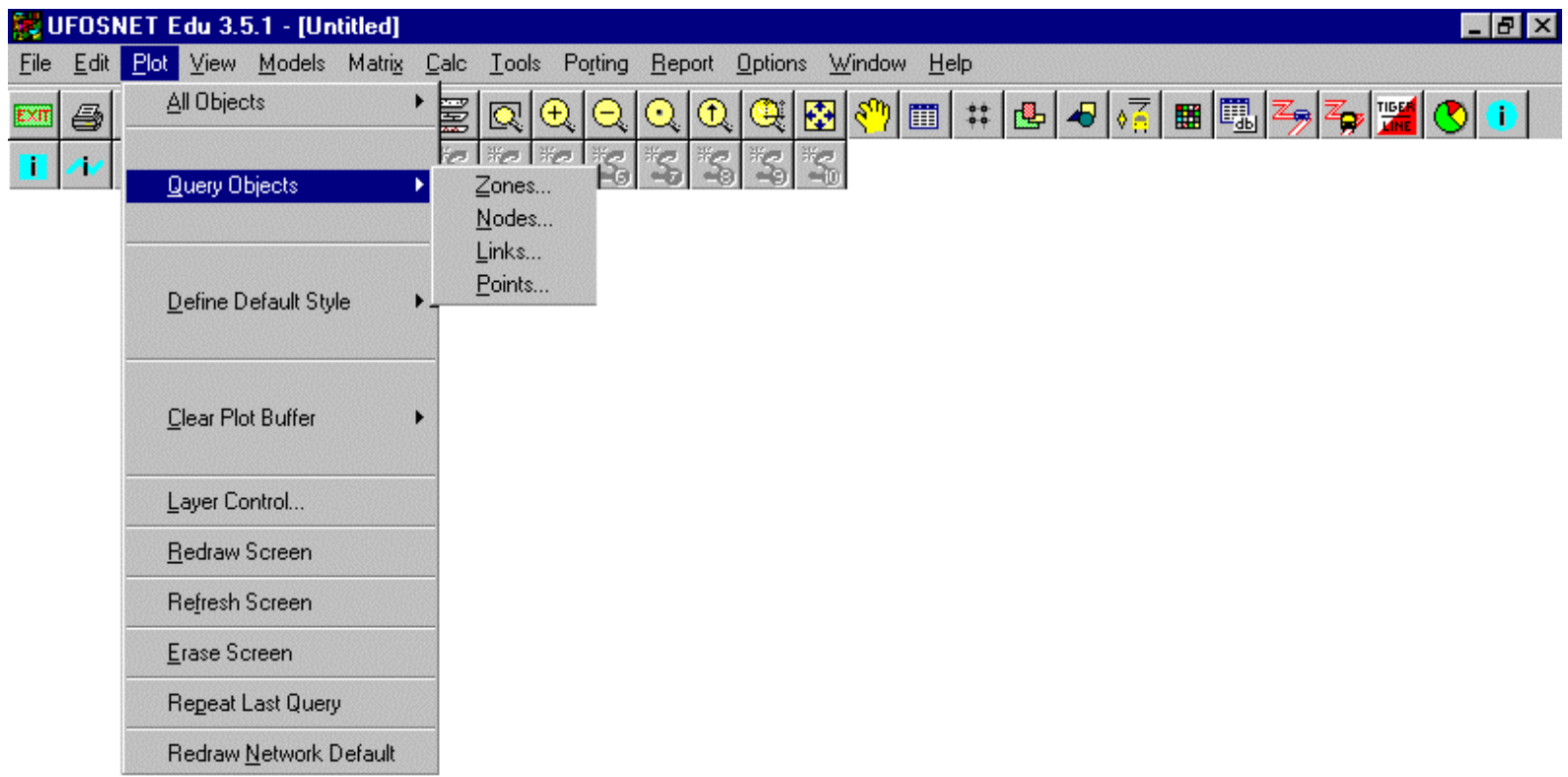

Figura 4.53 - Opção QUERY OBJeCts do menu Plot do menu principal do UfosNet

As opções Define Default STYLE $\Rightarrow$..., ilustradas na figura 4.54, ativam caixas de diálogos usadas para se especificar o estilo de visualização de nós, links, pontos, centróides, áreas $(1,2,3 \ldots)$, TIGER/Line, arclink, nós2 e links2. Na opção NoDE podem ser definidos os seguintes itens: uma escala para representação do nó como uma caixa retangular com largura e altura variáveis, um padrão de preenchimento, mostrar o número do nó, fazer um mapa temático, representação dos nós em 3D (quando da utilização do modo de visualização em três dimensões as coordenadas do eixo $\mathrm{Z}$ podem ser representadas como elevações). Na opção LINK pode-se definir os itens: estilo, com a opção de inserção de flechas nas extremidades, offset entre linhas, espessura e cor da linha, um campo no banco de dados de links contendo os códigos dos modos para redes multimodais e os símbolos dos diversos modos incluídos, construir um mapa temático, utilizar um campo de links selecionado como arclinks (sendo que os links serão mostrados utilizando-se os arcos correspondentes armazenados na camada de arclinks), definir uma ordem de aparecimento dos links e utilizar sinais e valores para a representação de cada link.

Na opção PoINT podem ser definidos: estilo, cor e tamanho da fonte, os campos a serem utilizados como coordenadas X e Y, um segundo par de coordenadas XY para ligar origens e destinos com o objetivo de mostrar as viagens em um levantamento de O/D, um mapa temático e um campo contendo valores de coordenadas $\mathrm{Z}$ para representações em 3D. Nas opções Centroid e NODE2 são definidos, como na opção NODE, o estilo do nó: representado como uma caixa retangular com largura e altura variáveis, padrão de preenchimento e a opcão de mostrar o número de ID. Nas opções BoundARY1, 2 E 3 pode-se determinar: o tamanho e tipo da fonte utilizada para mostrar o número de ID da área, com a opção de apresentar ou não rótulos utilizados como uma segunda identificação da área, as configurações da linha de contorno da área, a cor do preenchimento ou a utilização de um mapa temático.

A opção TIGER/LINE permite configurar os estilos (cor e espessura) das camadas extraídas de um arquivo TIGER. Estas camadas podem representar: rodovias interestaduais, 
estaduais ou outras, ferrovias, oleodutos/gaseodutos, lugares conhecidos e outros, cidade/lugar, regiões censitárias, grupos em blocos, hidrografia e não visíveis. As opções para redesenho dos atributos destas camadas são: Redraw with Extracted Style, com a qual serão conservados os estilos do arquivo original e Redraw with Default Style, com a qual serão utilizados os estilos definidos na caixa de diálogos ativada pela opção TIGER/LINE em questão. Na opção ARCLINK podem ser definidos: o tipo e tamanho da fonte que indica o número do arclink, a cor e espessura do arclink e as opções de representá-lo como uma policurva e mostrar o ponto de início. E, na opção LINK2, podem se definidos apenas o estilo da linha (espessura, offset e setas) e o campo de identificação dos modos.

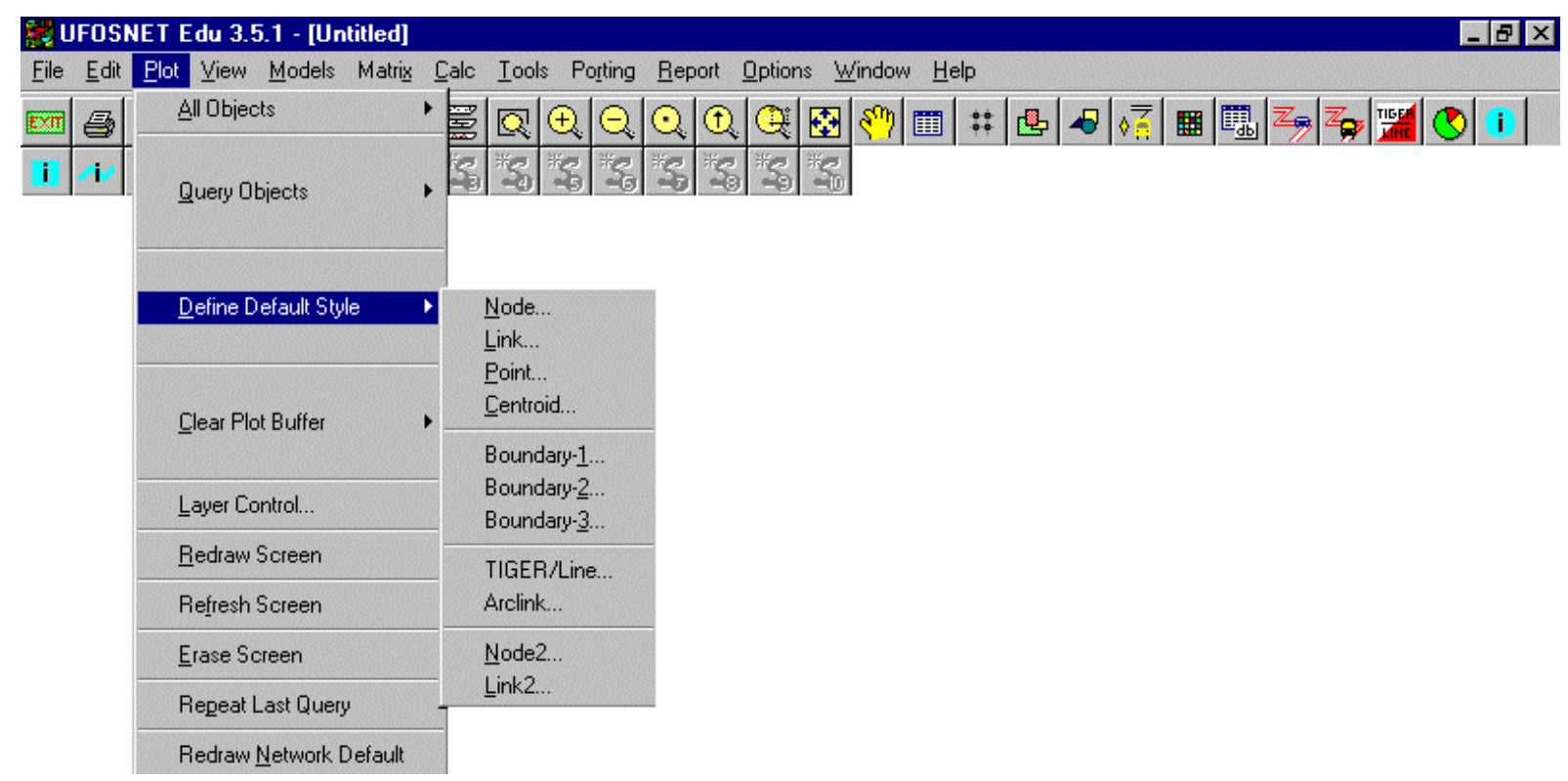

Figura 4.54 - Opção Define Default Style do menu Plot do menu principal do UfosNet

As opções CleAR Plot BufFer $\Rightarrow$..., mostradas na figura 4.55, tornam não visíveis na tela os seguintes objetos especificados: nós, links, nós/links ou pontos e desativa a sua camada de impressão (plot layer). Após a execução de algum destes comandos a tela será redesenhada. 


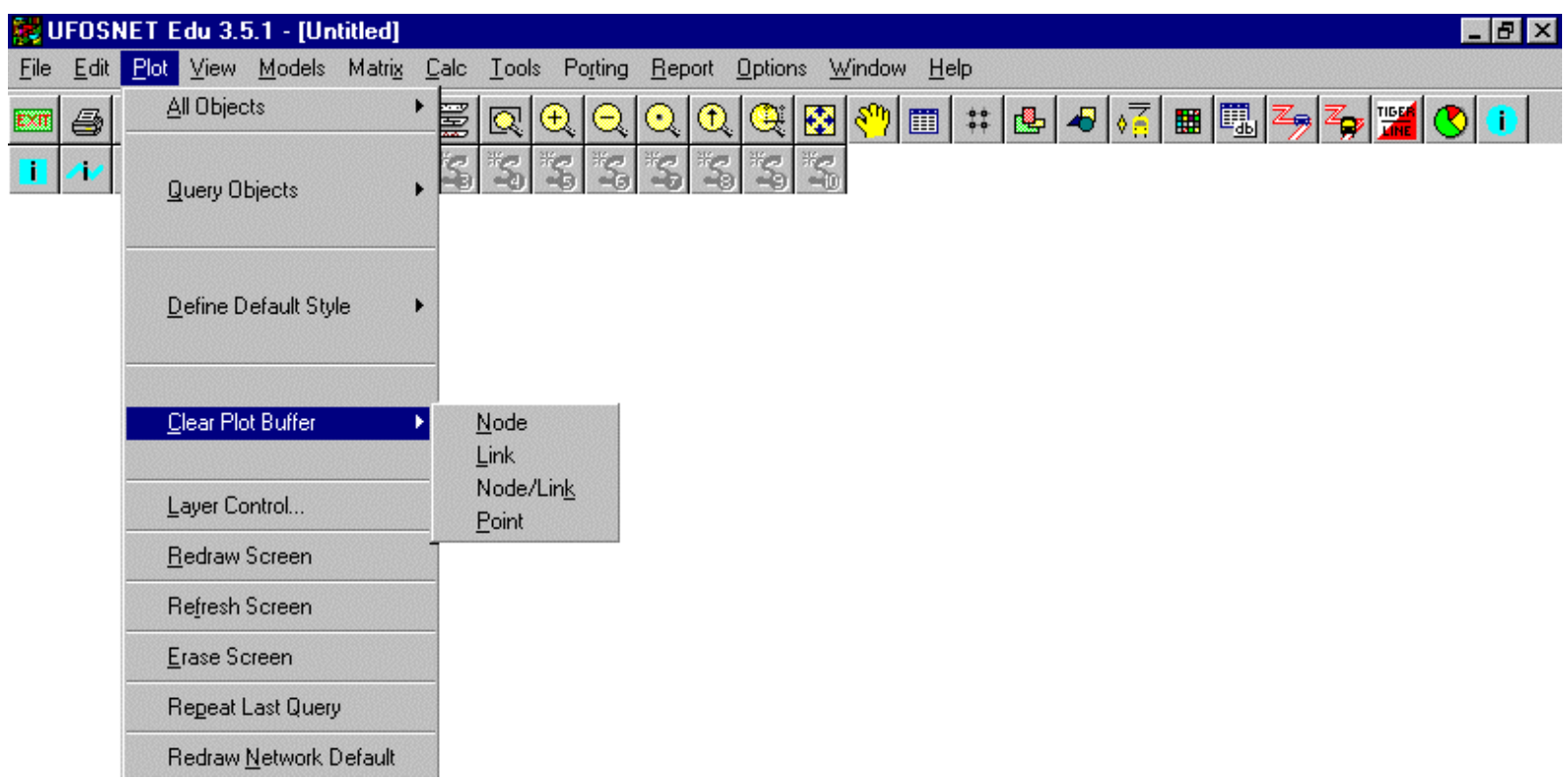

Figura 4.55 - Opção Clear Plot BufFer do menu Plot do menu principal do UfosNet

A opção LAYER CONTROL, figura 4.51, acessa uma caixa de diálogos onde podem ser definidas quais camadas do mapa estarão visíveis e a ordem de aparecimento das mesmas na tela (pode ser utilizado um valor entre 1 e 255 , sendo que as camadas com números menores serão desenhadas primeiro). Só serão editáveis as camadas existentes no mapa. As demais opções têm as seguintes funções: REDRAW SCREEN, redesenha a tela com as configurações e estilos de todos os objetos das camadas correntes; REFRESH SCREEN, utilizada para remover objetos com visualização temporária ou restabelecer a tela anterior; ERASE SCREEN, apaga todos os objetos visíveis na tela; REPEAT LAST QUERY, repete a última consulta de objetos tais como, zonas, nós, links, pontos ou anotações, sem ativar a respectiva caixa de diálogos utilizada para executar esta operação; REDRAW NETWORK DEFAULT, redesenha os nós e links da rede ativa após a execução de alguma edição.

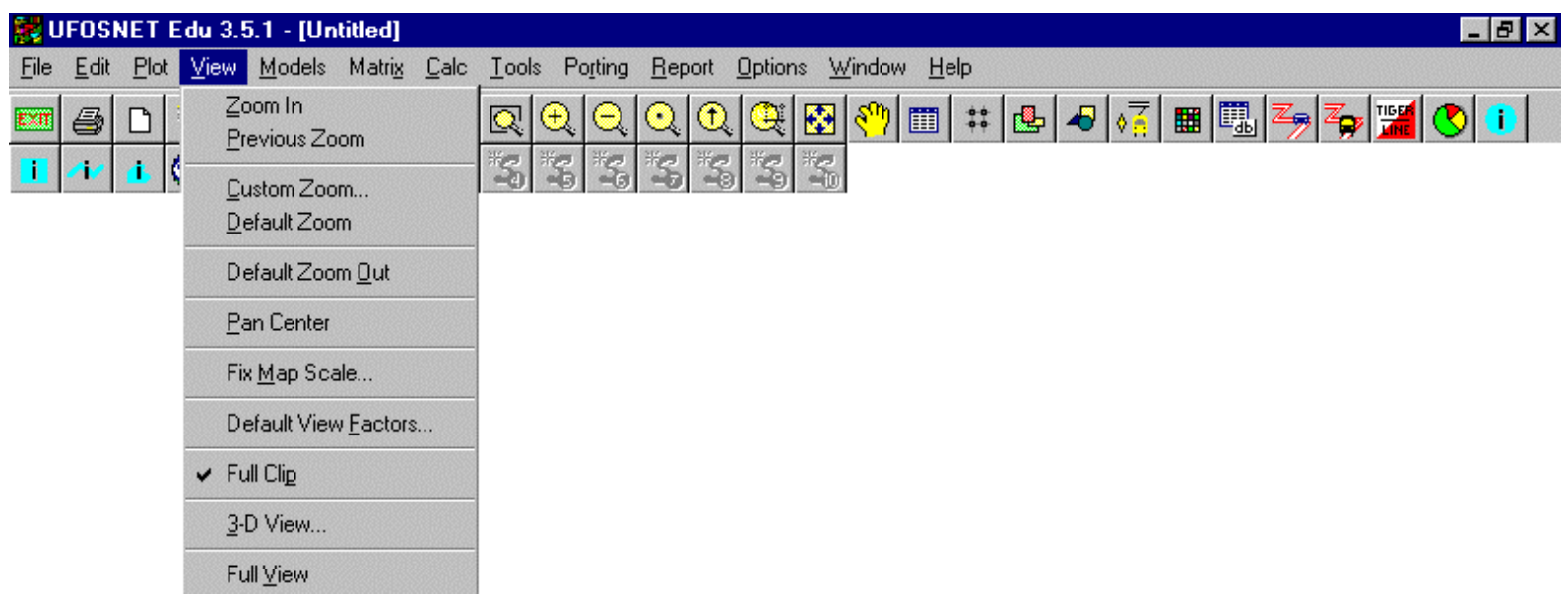

Figura 4.56 - Opção View do menu principal do UfosNet 
As opções constantes no menu View, figura 4.56, são utilizadas para definir o modo de visualização da tela. As opções Zoom In, Previous Zoom, Default Zoom e Default ZOOM OUT realizam as seguintes operações, respectivamente: permite a definição de uma janela para execução de um zoom dentro da janela ativa, redesenha o mapa com o zoom anterior, reduz a abrangência do zoom-in da janela baseado em um fator padrão definido em $\%$ na opção DEFAUlT VIEW FACTORS, aumenta o zoom-out da tela também baseado em um fator padrão predefinido em \%. A opção Custom ZoOM ativa uma caixa de diálogos destinada à definição de janelas com configurações de zooms comumente requeridas pelo usuário, através de coordenadas $\mathrm{X}$ e $\mathrm{Y}$ determinando o novo posicionamento dos pontos superior à esquerda e inferior à direita da nova janela. Cada janela pode possuir uma descrição e uma tecla de atalho, com o objetivo de facilitar ao usuário ativar tais janelas de zoom. A opção PAN CENTER centraliza a janela do mapa em um ponto definido pelo usuário.

Na opção FIX MAP SCALE pode-se definir uma escala para o mapa através da especificação de um fator de equivalência que relaciona milhas/quilômetros a uma polegada. Na opção DeFAUlT VIEW FACTORS pode-se determinar os fatores (em \%) de panning, zoomin e zoom-out a serem utilizados nos comandos Default ZoOM e DEFAUlT Zoom OUT. Quando a opção FULL CLIP está acionada todos os objetos serão processados e desenhados em um espaço virtual, sendo que apenas a porção que se encontra dentro da janela ativa é visível. No caso desta opção não estar ativa, apenas os objetos que possuem seu ponto central dentro da janela de zoom serão desenhados. A opção 3-D VIEW permite a visualização dos objetos em perspectiva. Para a realização deste comando devem ser definidos: o tamanho (quanto maior o valor, menor o desenho), a rotação, a elevação (move o ponto de visão para cima ou para baixo), a distância (entre o ponto de visão e os demais objetos) e a altura máxima para Z. O ícone $3 D$ Off redesenha a tela sem qualquer configuração de três dimensões (3D) e o ícone $3 D$ View redesenha a tela utilizando as configurações 3D definidas. A opção Full VIEW redesenha todas as camadas em uma janela inteira, desfazendo todas os comando de zoom-in executados.

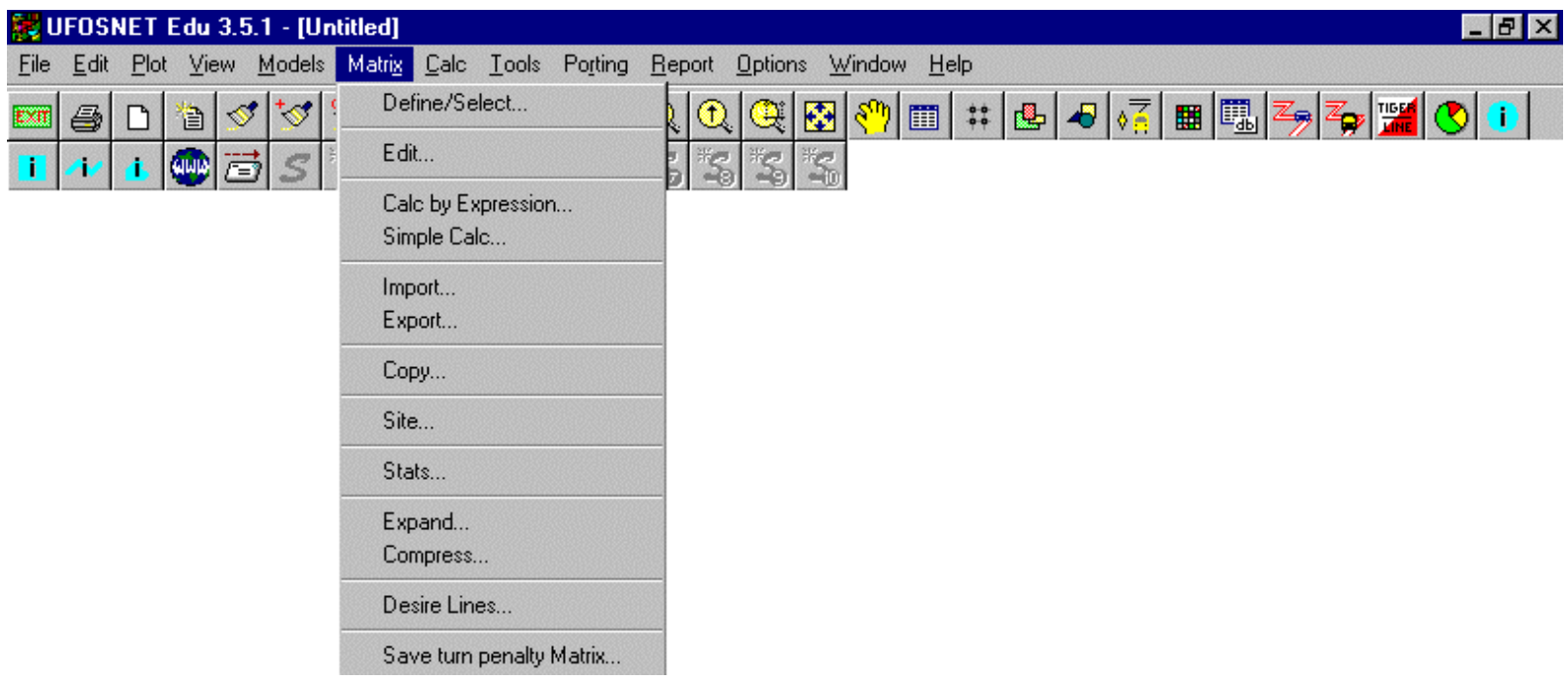

Figura 4.57 - Opção Matrix do menu principal do UfosNet 
O UfosNet fornece 20 tipos de matrizes que podem ser definidas e editadas. São elas:

- MOTHR (outro tipo): este tipo de matriz pode ter qualquer combinação de linhas e colunas;

- MPATT (tabela de produção/atração de viagens): utilizada para armazenar tabelas de produção e atração de viagens interzonais com fins aos processos de distribuição de viagens e escolha modal;

- MODTT (tabela de origens e destinos de viagens): utilizada para armazenar tabelas de origens e destinos, será utilizada nos processos de alocação de tráfego;

- MTIME (tabela de tempos de viagens): armazena as tabelas de tempos de viagens interzonais utilizada nos processos de distribuição de viagens e alocação de tráfego;

- MPROD (lista de produção): utilizada para armazenar o total de viagens produzidas em cada zona. É uma matriz que possui formato n x 1 ( $\mathrm{n}$ linhas por 1 coluna);

- MATTR (lista de atração): utilizada para armazenar o total de viagens atraídas por cada zona. É uma matriz do tipo $1 \mathrm{x} \mathrm{n}$;

- MORIG (lista de origens): utilizada para armazenar o total de zonas de origem, que são os valores armazenados nas linhas da matriz MODTT;

- MDEST (lista de destinos): utilizada para armazenar o total de zonas de destino, que são os valores armazenados nas colunas da matriz MATTR;

- MSPAS (sparse matrix): armazena o número de viagens interzonais para cada par origem-destino. É uma matriz do tipo $\mathrm{n} \times 3$;

- $M L O O K$ (tabela de procura): utilizada para armazenar valores procurados em uma série de intervalos. É uma matriz do tipo n x 3;

- MKFAC (tabela de fatores $\mathrm{K}$ ): armazena os valores dos fatores $\mathrm{K}$ para cada zona, será utilizada nos processos de distribuição de viagens;

- MROWS (lista do somatório de linhas): utilizada para armazenar o total das linhas de quaisquer matrizes. É uma matriz do tipo n x 1 e será utilizada no processo de cálculo de matrizes utilizando a função ROWSUM;

- MCOLS (lista do somatório de colunas): utilizada para armazenar o total das colunas de quaisquer matrizes. É uma matriz do tipo $1 \mathrm{x} \mathrm{n}$ e será utilizada no processo de cálculo de matrizes utilizando a função COLSUM;

- MEQEX (fatores de equivalência de expansão): utilizada para armazenar fatores a serem utilizados para expandir uma matriz pequena para uma dimensão maior. É uma matriz do tipo n x 3 e será utilizada no módulo de expansão de matrizes;

- MEQSQ (fatores de equivalência de compressão): armazena a equivalência zonal para comprimir uma matriz maior para uma dimensão menor. É uma matriz do tipo n x 1 e será utilizada no módulo de compressão de matrizes;

- $M M O D E$ (tabela do modo de transporte público): matriz utilizada para armazenar as penalidades para o transporte público intermodal ou dados de transferência de transporte público intermodal. É uma matriz do tipo 10 × 10;

- MTURN (tabela de movimentos de retorno): matriz utilizada para armazenar movimentos de retorno em interseções. É uma matriz do tipo n x 5 e será utilizada nos processos de alocação de tráfego e análises de capacidade de interseções;

- MTPEN (tabela de penalidades de retorno): utilizada para armazenar penalidades de retorno entre nós. É uma matriz n x 4 e será utilizada no processo de alocação de tráfego;

- MCOST (tabela de custos de viagens interzonais): utilizada para armazenar os dados de custo de viagens interzonais e custo de transporte público urbano. É uma matriz n x n e será utilizada no módulo de escolha modal; 
- MSHAR (tabela de divisão modal interzonal): matriz utilizada para armazenar divisões modais interzonais de um modelo de escolha modal. É uma matriz do tipo $\mathrm{n}$ x $\mathrm{n}$ e será utilizada no módulo de escolha modal;

- MPARK (tabela de escolha de park/ride lot interzonal): matriz utilizada para armazenar os números de praças de estacionamento associadas a um sistema de transporte público em um modelo de escolha das praças a serem escolhidas pelos usuários. É uma matriz do tipo $\mathrm{n} \times \mathrm{n}$ e será utilizada no módulo de escolha park/ride.

No menu Matrix, figura 4.57, a opção DeFINE/SELECT ativa uma caixa de diálogos utilizada para definir os seguintes itens relativos a uma matriz: nome, tipo (dentre os fornecidos pelo UfosNet, utilizando-se das siglas descritas anteriormente), um valor padrão para inicializar a matriz e uma descrição da matriz. Essas definições poderão ser visualizadas numa listagem, apresentada na mesma caixa de diálogos, de todas as matrizes definidas para este projeto. Além da definições já mencionadas, pode-se especificar a dimensão da matriz (número de linhas e colunas), os valores mínimo e máximo e o somatório dos valores. Os ícones presentes nesta caixa são: Select, para copiar os valores da matriz selecionada para uma área de memória temporária para usos posteriores (tais como: edição de matriz, importação/exportação de matriz, tabela de inicialização de movimentos de retorno, tabela de inicialização de penalidades de retorno, etc); New, para criar uma nova matriz; Update, para modificar informações alteradas de determinada matriz; Redim, para alterar a escala de dimensão da matriz; Delete, para apagar e remover uma matriz; Initialize, para inicializar uma matriz com um valor padrão e Close, para fechar esta caixa de diálogos.

Através da opção EDIT pode-se abrir e editar a matriz selecionada na opção DEFINE/SELECT. As opções disponíveis na janela de uma matriz são: $O K$, para fechar a janela; Select, para abrir a caixa de diálogos ativada pela opção Matrix $\Rightarrow$ DEFINE/SELECT; Save, para salvar as alterações e configurações feitas na matriz corrente dentro do banco de dados; Options, fornece as opções de posicionar o cursor na primeira ou última célula da coluna, ativar ou desativar as linhas de grade, colorir (destacar) as células em toda quinta linha, selecionar todas as células de uma linha, determinar a largura das colunas, determinar o número de casa decimais a ser utilizado e colorir (destacar) a diagonal principal; Copy, copia os valores da matriz corrente para serem utilizados em outras aplicações Windows; Sort, ordena os valores da matriz segundo determinada coluna.

A opção CALC BY EXPRESSION permite executar cálculos em uma matriz através da utilização de expressões algébricas, compostas por operadores matemáticos e funções predefinidas. A caixa de diálogos ativada por esta opção apresenta uma lista das matrizes existentes e fornece uma lista de funções matemáticas, lógicas e especiais. Para se definir uma expressão pode ser especificado o intervalo de células a serem calculadas, uma sub-expressão, que é uma condição de filtragem dos valores de uma matriz para a operação seguinte, e a expressão principal a ser utilizada no cálculo dos novos valores dos dados. Pode-se ainda selecionar uma matriz na qual serão salvos os resultados dos cálculos e selecionar uma matriz a ser utilizada como uma tabela de procura quando da utilização da função de procura. $\mathrm{O}$ ícone Clean, apaga a expressão definida; Back apaga a última especificação adicionada na expressão e Calculate, procede ao cálculo. A opção SIMPLE CALC realiza operações simples de cálculo envolvendo matrizes. Na caixa de diálogos ativada por esta opção devem ser definidos: a matriz de entrada, o operador a ser utilizado $\left(+,-,{ }^{*}, /, \wedge\right)$, um valor constante para 
o cálculo e a matriz onde serão armazenados os resultados do cálculo. Os ícones Calculate e Close são utilizados para proceder ao cálculo especificado e fechar a caixa de diálogos, respectivamente.

As opções IMPORT e EXPORT são utilizadas para importar e exportar matrizes. Para importar uma matriz devem ser seguidos os seguintes passos: definir uma matriz para conter a matriz importada, cujas dimensões devem ser iguais às da matriz a ser importada, selecionar um arquivo de matriz (*.csv) a ser importado, atualizar o nome da matriz e o comentário. Para exportar uma matriz basta selecioná-la e definir um nome para o arquivo (*.csv) que irá conter a matriz exportada. A opção COPY é utilizada para copiar ou manipular um bloco de células de uma matriz para dentro da mesma matriz ou entre duas matrizes. Devem ser definidos os seguintes itens: selecionar uma matriz e especificar um intervalo de células a serem utilizadas como fonte, selecionar uma matriz e um intervalo de células a serem utilizadas como destino dos resultados e o método de operação dos valores na matriz resultante. Este último pode ser: substituir os valores da matriz resultado pelos valores da matriz fonte, adicionar aos, subtrair dos, multiplicar por ou dividir os valores da matriz fonte pelos valores da matriz resultado e mover os valores da matriz fonte substituindo os valores da matriz resultado e tornando os valores da matriz origem iguais a zero. Nesta opção, optando-se pelo ícone Select para selecionar a matriz fonte ou a matriz resultado será visualizada através da mesma caixa de diálogos ativada pela opção Matrix $\Rightarrow$ DEFINE/SELECT.

A opção SITE fornece os valores totais de uma linha e uma coluna de matrizes do tipo MPATT ou MODTT. Esta ferramenta pode ser utilizada para calcular os fluxos entre cada par de zonas baseados nas proporções em relação às zonas originais (parent zones). Para este comando primeiramente deve ser selecionada a matriz a ser utilizada na operação e posteriormente definir: o número de ID da parent zone, o número de ID da zona site (usualmente uma nova zona), o total da coluna como viagens que entram (inbound trips) e o total da linha como viagens que saem (outbound trips).

Através da opção STATS pode-se obter as seguintes informações estatísticas da matriz selecionada: somatório das células, menor e maior valores, média e desvio padrão de todos os valores. Pode-se, também, fazer um histograma (gráfico de barras) definindo-se o intervalo de valores e os menores e maiores valores a serem utilizados para criar o histograma. A opção EXPAND é utilizada para expandir uma matriz, devendo ser definidos: a matriz que contém os fatores de expansão (matriz do tipo $M E Q E X$ ), a matriz fonte e a matriz resultado (ambas matrizes do tipo MODTT ou MPATT). A opção COMPRESS realiza a compressão de uma matriz, devendo ser definidos: a matriz que contém a equivalência zonal (matriz do tipo $M E Q S Q$ ), a matriz fonte e a matriz resultado (ambas matrizes do tipo MODTT ou MPATT).

A opção DESIRE LINES é utilizada para mostrar graficamente os dados contidos em uma matriz. Para realizar este comando são necessárias: uma matriz, uma rede e uma camada de áreas. Este comando ativa uma caixa de diálogos onde devem ser especificados: o intervalo dos números de zonas a serem utilizadas como zonas de origem; o intervalo dos números de zonas a serem utilizados como zonas de destino; um intervalo de valores de fluxo (sendo que apenas os valores dentro deste intervalo serão processados e o maior valor especificado será usado como denominador para determinar as espessuras dos fluxos utilizadas na visualização); a cor a ser utilizada na visualização dos fluxos; a espessura para o fluxo máximo e o raio para determinar um círculo em torno dos pontos de destino e outro em torno 
dos pontos de origem, definindo uma área que não deve ser ultrapassada pelas linhas de fluxo para que as mesmas não se sobreponham. Podem ser também definidas as opções de estilo das linhas: $\checkmark$ espessura de linhas, $\checkmark$ mostrar o valor, $\checkmark$ preencher e especificar o tamanho da fonte. Estão disponíveis as demais opções: $\checkmark$ utilizar o centro da área, $\checkmark$ cortar na área de origem e $\checkmark$ cortar na área de destino. Nestas duas últimas opções a área é utilizada como uma linha de isolamento. Ainda na opção Matrix da figura 4.57, durante o processo de edição das penalidades de retorno, todas as mudanças são armazenadas em uma área temporária e para que essas mudanças sejam definitivamente salvas em uma matriz (tipo MTPEN) deve ser utilizada a opção SAVE TURN PENALTY MATRIX.

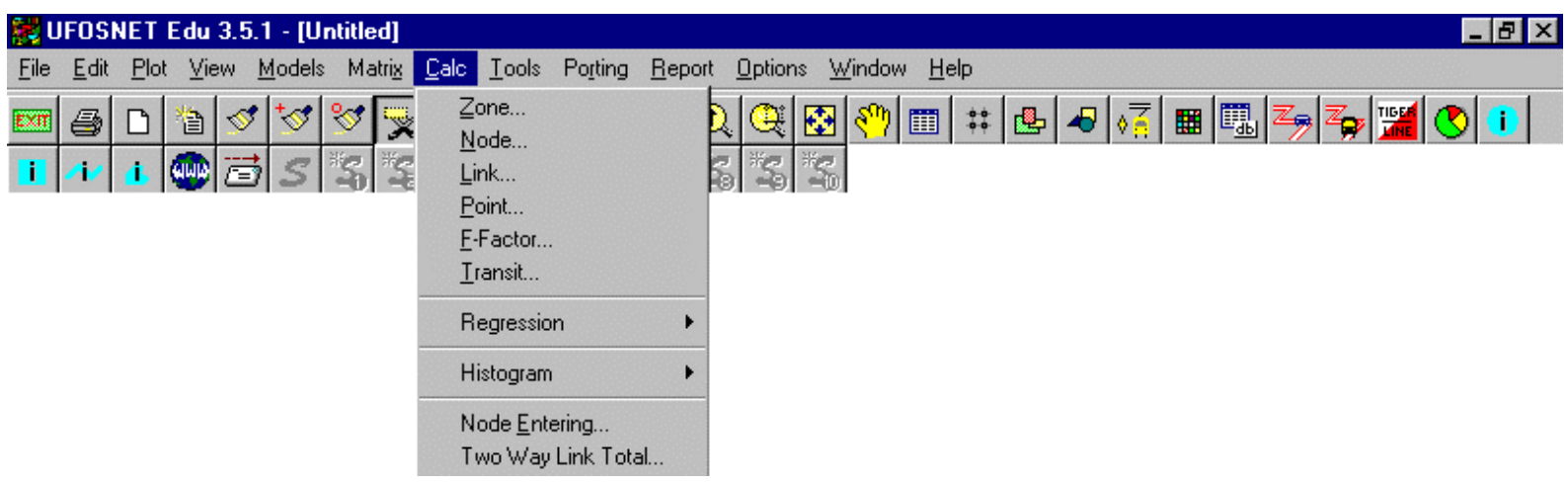

Figura 4.58 - Opção Calc do menu principal do UfosNet

As opções Zone, Node, Link, Point, F-FActor e Transit do menu Calc, figura 4.58, ativam uma caixa de diálogos utilizada para a realização de cálculos, através de expressões, nas tabelas de zonas, nós, links, pontos, fatores de fricção e linhas de transporte público, conforme a opção selecionada. Esta caixa de diálogos facilita o cálculo, fornecendo uma lista dos campos existentes em cada tabela, uma lista de funções e um resumo estatístico dos resultados calculados. Também permite a definição de uma sub-expressão, a ser utilizada para filtrar valores para operações posteriores, e uma expressão principal, que retornará o valor a ser salvo no campo de saída. Deve-se selecionar um campo para armazenar os resultados do cálculo e optar por selecionar uma matriz de procura no caso de utilizar a função de procura.

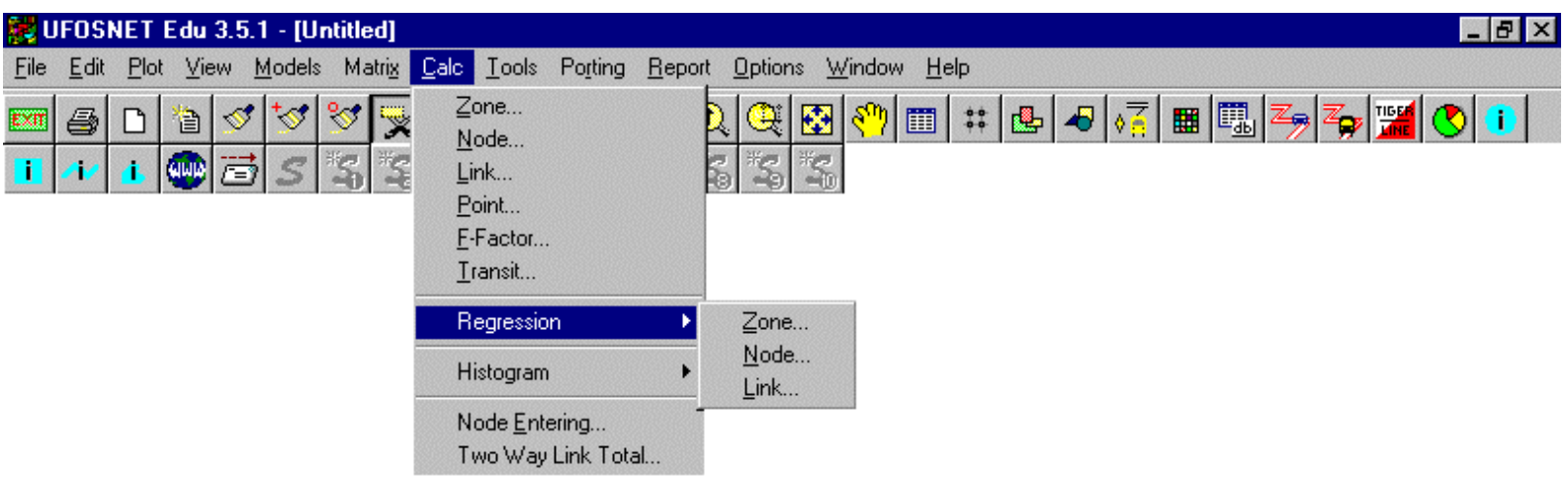

Figura 4.59 - Opção REGRESSION do menu Calc do menu principal do UfosNet

As opções REGRESSION $\Rightarrow$..., figura 4.59, realizam análises de regressão linear simples entre dois campos de dados numéricos de um banco de dados de zonas, nós ou links. 
Na caixa de diálogos ativada por esta opção devem ser definidos os campos de dados, de uma listagem de todos os campos existentes fornecida, que representarão as variáveis dependentes e as variáveis independentes. Selecionando-se o ícone Regression disponível o programa realiza os cálculos, apresentando os seguintes resultados (na mesma caixa de diálogos): $\mathrm{R}$ quadrado, constante, coeficiente t de student e o erro padrão. A opção Scattergram fornece um gráfico mostrando as relações relativas entre as variáveis dependentes e independentes.

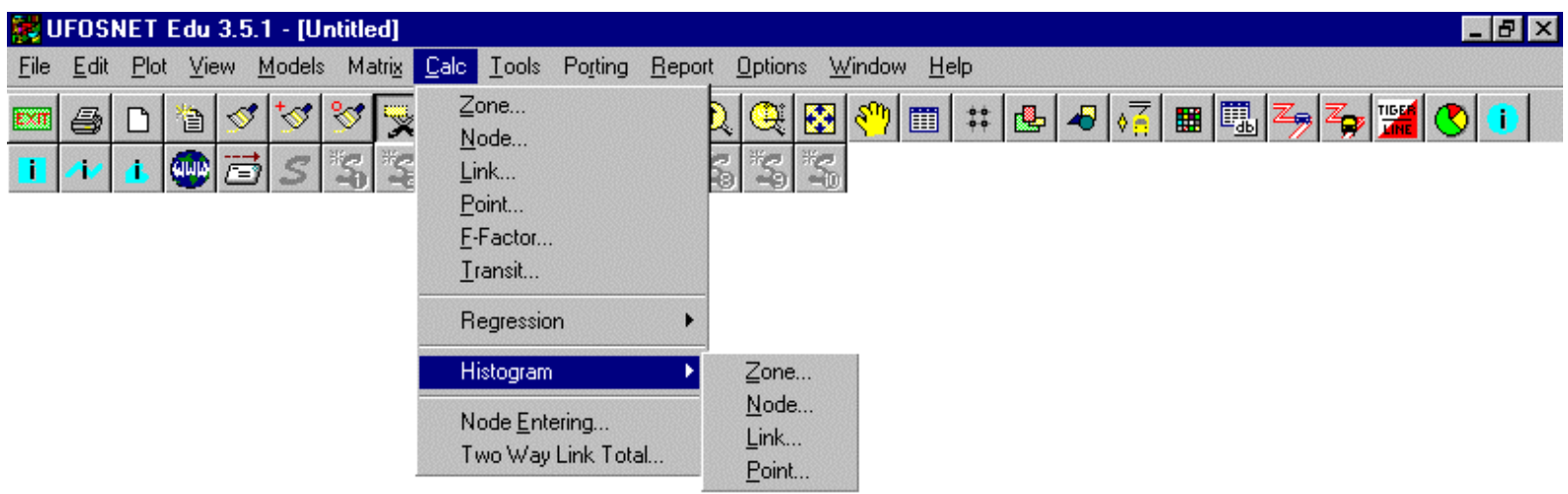

Figura 4.60 - Opção HistogRAM do menu Calc do menu principal do UfosNet

As opções HistogRAm $\Rightarrow$..., ilustradas na figura 4.60, fornecem ferramentas estatísticas para calcular a classificação ou distribuição de frequiência para um campo de dados numéricos de um banco de dados de zonas, nós, links e pontos, por um valor de intervalo fornecido. O número total de intervalos é calculado dividindo-se a diferença entre os valores máximos e mínimos pelo valor do intervalo. Nestes comandos devem ser especificados o campo de dados do banco de dados a ser utilizado na análise de histograma e, se for o caso, o valor a ser omitido para a análise. Selecionando-se o ícone Calculate, o software procederá ao cálculo apresentando os resultados na caixa de diálogos utilizada também para a entrada dos dados; estes resultados incluem: o número total de pontos, o somatório, os valores máximo e mínimo, a média, o desvio padrão e o intervalo utilizado. Através do ícone Histogram pode-se visualizar um gráfico de barras que mostra o valor de freqüência para cada intervalo.

A opção Node EnTERING, figura 4.58, calcula os totais de entrada em um nó, baseado num campo de dados de links. Pode ser utilizada para calcular a capacidade do nó ou os volumes baseados em todos os links que se aproximam deste nó. Para a execução deste comando basta definir um campo do banco de dados de links para ser usado como fonte de dados de entrada e um campo do banco de dados de nós a ser utilizado para salvar a saída de dados. O ícone Calculate realiza a operação de cálculo dos totais de entrada para todos os nós. A opção TwO WAY LINK TOTAL calcula os totais combinados de um campo de links para links com duplo sentido, e salva os totais para um sentido especificado. Para este comando são definidos o campo cujos valores serão agregados, o campo que contém os valores utilizados para decidir qual sentido irá conter o total agregado e o campo de dados que irá conter os totais agregados.

A opção Highway PATH do menu Tools, figura 4.61, permite realizar operações de caminho mínimo de várias formas: um para um, um para vários, vários para um, vários para vários, buffer trees e batch runs. O UfosNet realiza esta operação através da utilização dos 
algoritmos "tree builder" ou "vine builder", este último só será utilizado quando houver restrições de retorno. A opção em questão ativa uma caixa de diálogos onde pode-se definir os seguintes parâmetros: um intervalo de número de nós a serem incluídos no caminho mínimo como nós de origem; um intervalo de números de nós a serem incluídos como nós de destino; selecionar a camada do banco de dados que define o modo de transporte utilizado e inserir o seu código (esta opção permite que o usuário restrinja o caminho mínimo a apenas algumas infra-estruturas); escolher uma cor e uma espessura de linhas para visualizar os caminhos. Caso o usuário deseje visualizar os caminhos em vários intervalos, de acordo com os custos acumulados a partir do nó de origem, deve-se selecionar a opção Isochron, que irá mostrar cada intervalo com uma cor diferente, e especificar um intervalo (maior do que zero), o qual assumirá a mesma unidade dos dados de custo do link. Pode-se restringir um caminho a dois conectores de centróides adjacentes especificando-se o maior número da zona, neste caso o link que tiver o número do nó-final menor que ou igual ao maior número da zona é qualificado como um conector de centróide; deve-se indicar o valor do custo máximo e optar pelas alternativas: de (muitos para um) ou para (um para muitos). Estas opções devem ser definidas no caso de se utilizar o algoritmo buffer tree para encontrar o caminho mínimo; e pode-se optar por: $\checkmark$ utilizar penalidades de retorno, $\checkmark$ mostrar o custo do caminho, $\checkmark$ utilizar o algoritmo vine builder e $\checkmark$ criar uma região de buffer em torno da rota. Os ícones disponíveis para a execução deste comando são: One-to-One Query, utilizado para encontrar o caminho mínimo entre dois nós; Buffer Tree Query, utilizado para encontrar os caminhos de um nó para todos ou vice-versa, selecionando-se um nó na tela; Point Batch Run, utilizado para preparar a rede para o cálculo de caminhos mínimos com o mínimo custo através da função de cálculo de pontos chamada Path(), e Build Tree Forest, que é utilizada para encontrar caminhos mínimos entre os intervalos de pontos especificados nesta caixa de diálogos. A opção TRANSIT PATH da figura 4.61 será abordada posteriormente, pois refere-se a sistema de rotas de transporte público urbano, tópico que, para efeito deste trabalho, se enquadra no item de rotinas específicas de transportes.

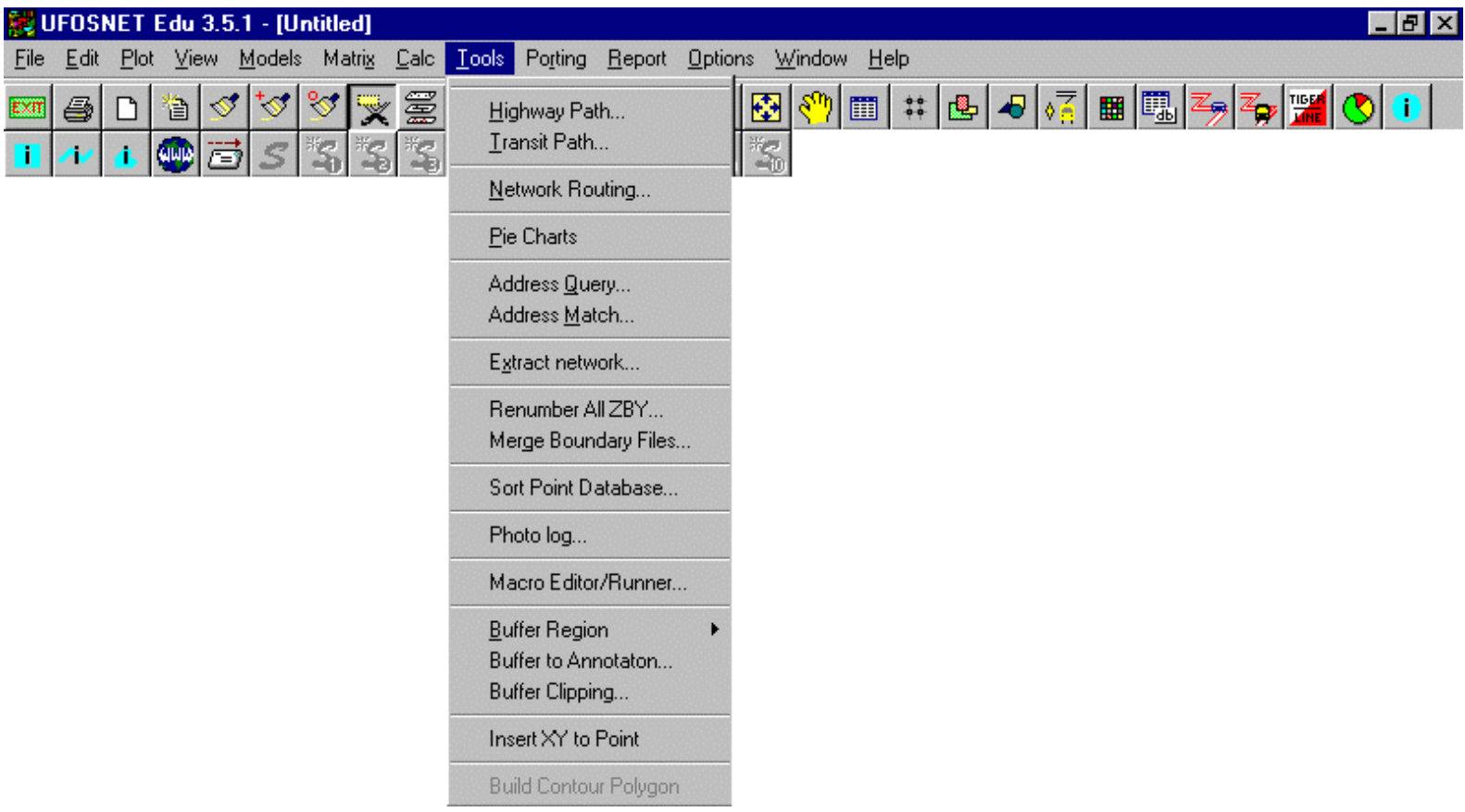

Figura 4.61 - Opção Tools do menu principal do UfosNet 
A opção NETWORK ROUTING soluciona o problema do caixeiro viajante (Travel Salesman Problem). Neste comando são considerados como parâmetros de entrada: uma rede com o custo de viagem em cada link, uma série de nós (paradas) a serem visitados, considerando que cada nó só pode ser visitado uma vez e a viagem deve terminar no nó de início (depósito); o objetivo do comando é encontrar uma rota, servindo todos os pontos, com o menor custo. Na caixa de diálogos aberta por esta opção é necessária a definição dos campos de dados que contêm as informações relativas ao custo do link, os nós a serem considerados como pontos de parada (todos os que possuírem valor diferente de zero serão considerados) e o campo que irá armazenar os resultados indicando a ordem em que os nós serão visitados; também são definidas as cores para representação da rota e dos nós e a espessura da linha da rota.

A opção PIE CHARTs pode ser usada para representar os atributos dos dados dos bancos de dados de zonas, nós e pontos, na forma de gráficos do tipo "pizza". Nesta opção são definidos: o banco de dados a ser utilizado (zonas, nós ou pontos), os campos que contêm os dados a serem considerados (no máximo 5) e a cor a ser utilizada para representar cada campo, o raio máximo do círculo correspondente ao valor base, o tamanho da fonte, a opção de $\checkmark$ mostrar os totais no gráfico e $\checkmark$ mostrar a legenda. Neste caso, pode-se definir um título para a legenda. $\mathrm{O}$ valor base mencionado é um fator de escala calculado pelo software com base no somatório dos valores dos campos selecionados. Os valores mínimos e máximos são, também, automaticamente identificados pelo programa.

O comando ADDRESS QUERY permite que o usuário localize um endereço válido a partir de um arquivo do tipo TIGER/Line ou compatível. Caso o endereço seja localizado, o programa retornará um par de coordenada X-Y. Para a execução deste comando deve-se informar o número do endereço, um prefixo, o nome da rua, o tipo da rua (por ex. avenida), um sufixo ou o código postal, sendo que pelo menos três informações devem ser fornecidas. Selecionando-se o ícone Find o software localizará o endereço e fornecerá as coordenadas X e Y de localização do endereço, informação que será mostrada na mesma caixa de diálogos utilizada para informar as particularidades do endereço. O comando ADDRESS MATCH realiza a procura e retorna a localização de vários endereços em uma rede. Os endereços a serem localizados são definidos em um banco de dados de pontos. Este comando ativa uma caixa de diálogos onde devem ser definidos os campos do banco de dados que contêm os números dos endereços, os prefixos, os nomes das ruas, o tipo das ruas, os sufixos e os códigos postais; devem, também, ser apontados os campos que armazenarão as coordenadas $\mathrm{X}$ e $\mathrm{Y}$ identificadas e pode-se optar por utilizar uma seleção de dados.

A opção EXTRACT NETWORK permite extrair parte de uma rede para um novo arquivo, sendo que apenas os links que se encontram dentro de uma área de buffer serão extraídos. Para esta opção deve ser definido o campo do banco de dados de links que identifica a seleção de links a serem considerados e especificado o arquivo de saída dos dados. A opção RENUMBER ALL ZBY permite renumerar cada área dentro da camada de áreas-1. As áreas renomeadas serão armazenadas em um novo arquivo. Nesta opção deve-se definir o campo de um banco de dados de zonas que contém os novos números de ID das áreas e especificar o nome do arquivo em que serão salvas as áreas renomeadas. O comando MERGE BOUNDARY FILES permite unir dois arquivos de áreas, sendo necessário definir ambos os arquivos de áreas a serem utilizados e o arquivo que irá armazenar o resultado da união. Neste 
comando estão disponíveis as opções: $\checkmark$ fixar e renomear todas as áreas ou, quando o ID de uma área no segundo arquivo já existir no primeiro: $\checkmark$ substituir (anular) ou $\checkmark$ pular.

A opção Sort Point DAtabase permite ordenar os valores do banco de dados de pontos utilizando um campo de dados numérico em ordem ascendente ou descendente. Para a realização deste comando basta definir o campo de dados a ser utilizado como referência e a ordem ascendente ou descendente. $\mathrm{O}$ comando PHOTO LOG permite que o usuário recupere e visualize na tela, de forma interativa, fotos armazenadas (imagens matriciais) . Esta opção ativa uma caixa de diálogos com as seguintes opções: Setup, que ativa outra caixa de diálogo, onde é definido o diretório em que se encontra o arquivo, o campo de fotos do arquivo e a opção de vincular a foto a uma tabela de nós ou pontos; e Cancel, para terminar o comando. A opção MACRO EDITOR/RUNNER ativa uma caixa de diálogos cujo menu fornece ferramentas para que o usuário manipule e crie rotinas (macros) personalizadas.

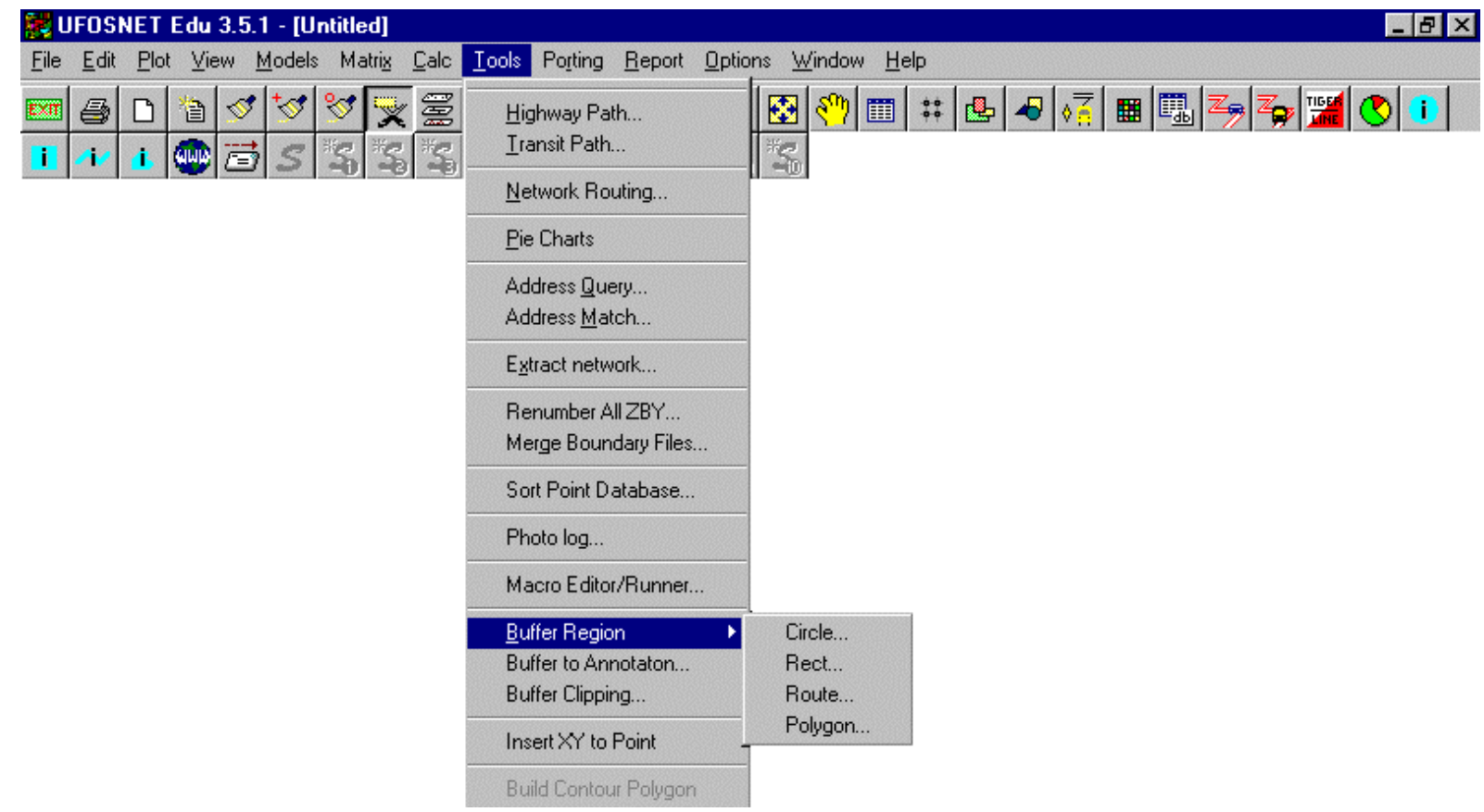

Figura 4.62 - Opção BUFFER REGION do menu Tools do menu principal do UfosNet

As opções BUFFER REGION $\Rightarrow$..., figura 4.62, são destinadas a geração dos seguintes tipos de regiões de buffer: círculo, retângulo, rota e polígono. As localizações e dimensões destas áreas são definidas pelo usuário com a utilização do mouse. A opção BUFFER TO ANNOTATION, figura 4.61, salva a região de buffer definida dentro de um grupo de anotações para que esta possa ser visualizada posteriormente, pois quando a tela é redesenhada, as regiões não salvas são apagadas. $O$ caminho inverso, transformar uma anotação em uma região de buffer, também pode ser feito. A opção BUFFER CliPPING permite calcular a interseção entre dois polígonos, sendo que um deles é uma região de buffer e o outro as áreas presentes na camada de áreas-1. Na caixa de diálogos aberta por esta opção pode-se definir as opções de cálculo da parte da área dentro de uma região de buffer ou parte da região de buffer dentro de uma área. Os resultados serão armazenados dentro de campos de zonas específicos. A opção INSERT XY TO POINT permite atribuir os valores das coordenada X-Y de uma posição do cursor a um par de campos de pontos. 


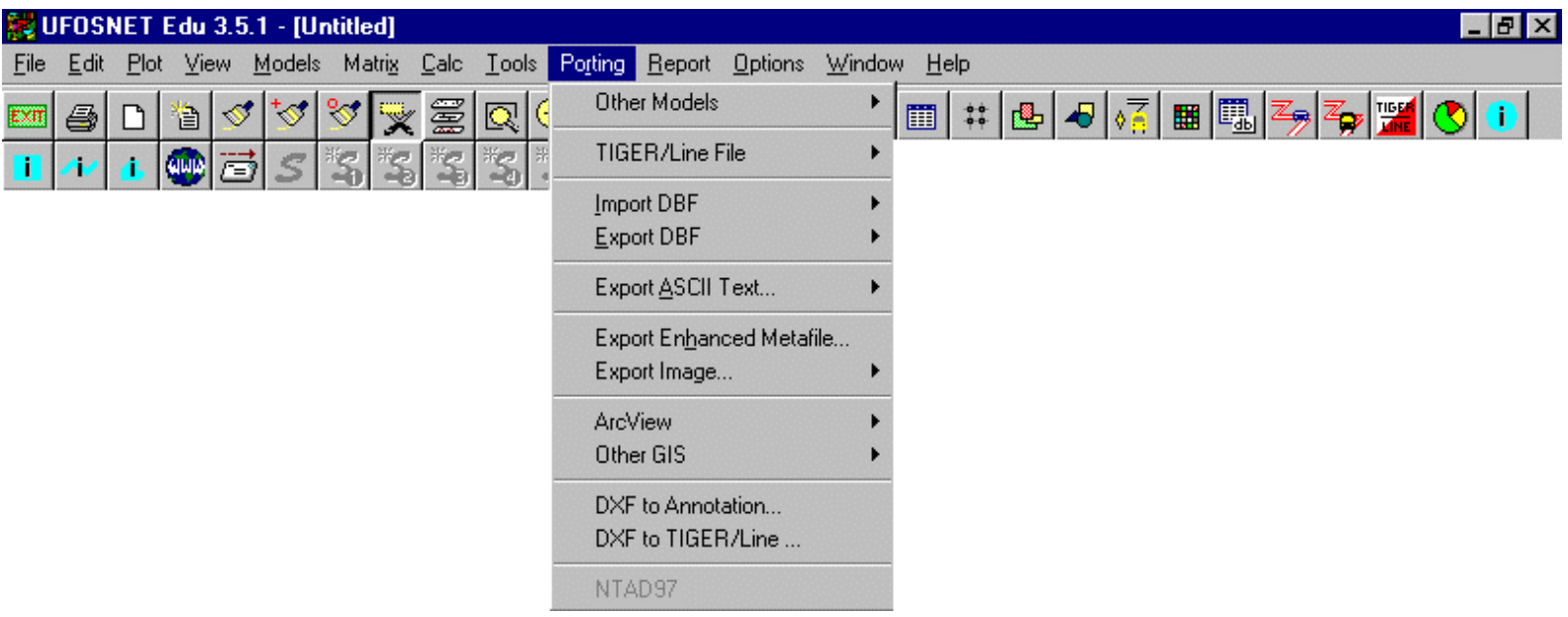

Figura 4.63 - Opção Porting do menu principal do UfosNet

As opções encontradas no menu Porting, figura 4.63, são destinadas a importação e exportação de arquivos e dados.

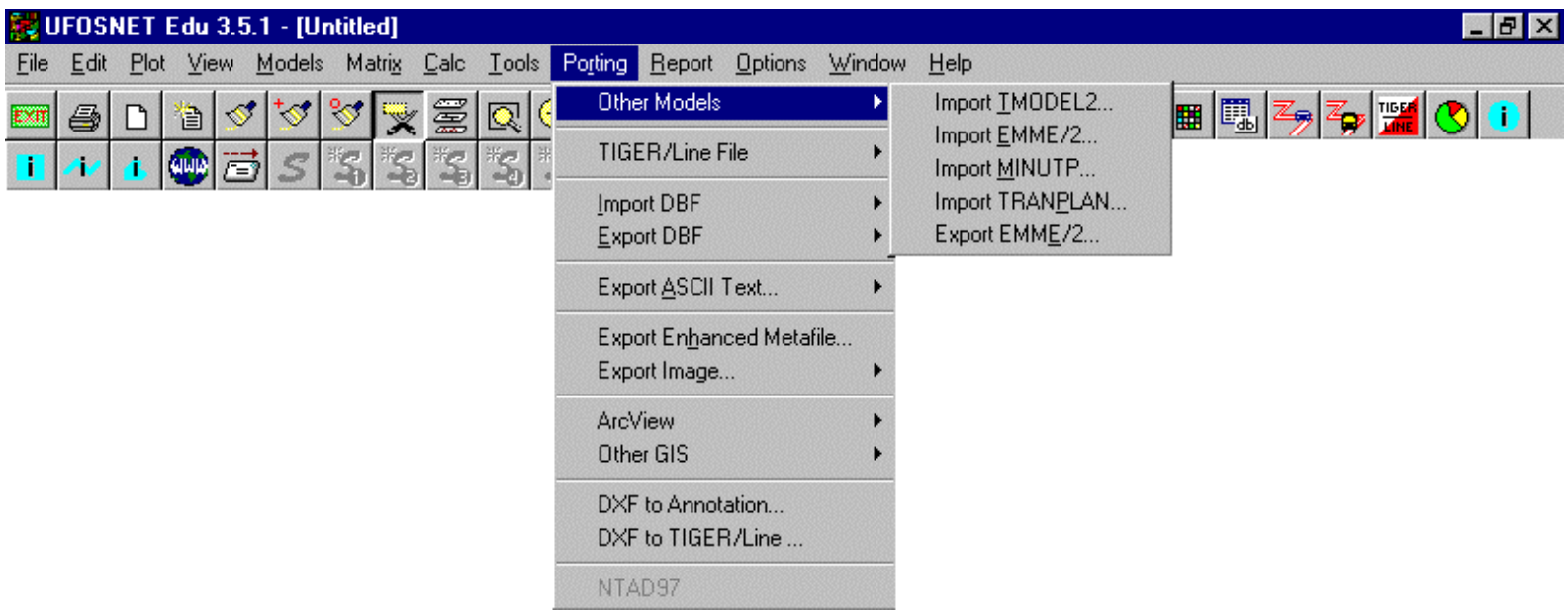

Figura 4.64 - Opção OTHER Models do menu Porting do menu principal do UfosNet

As opções OTHER Models $\Rightarrow$..., figura 4.64, realizam a importação de arquivos gerados em software de planejamento de transportes e serão descritas a seguir. O UfosNet realiza a importação de arquivos do tipo Tmodel/2 através da opção ... $\Rightarrow$ IMPORT TMODEL2. Estes arquivos podem ser de nós, links, penalidades de retorno e de tabelas de viagens. $\mathrm{Na}$ caixa de diálogos ativada por esta opção deve-se definir quais tipos de arquivos e o arquivo, propriamente dito, que se deseja importar. Através da opção ... $\Rightarrow$ IMPORT EMME/2 pode-se importar os seguintes tipos de arquivos produzidos pelo programa EMME/2 Punchout: arquivos de redes, de redes de transporte público urbano, de penalidades de retorno e de matrizes. A opção ... $\Rightarrow$ IMPORT MINUTP realiza a importação dos arquivos de nós e links de uma rede gerada pelo software MINUTP. É possível a importação de arquivos de redes e redes de transporte público processadas pelo programa TRANPLAN através da opção ... $\Rightarrow$ IMPORT TRANPLAN. A opção ... $\Rightarrow$ EXPORT EMME/2 permite exportar redes e matrizes do UfosNet para dentro de arquivos EMME/2 Punchout. 


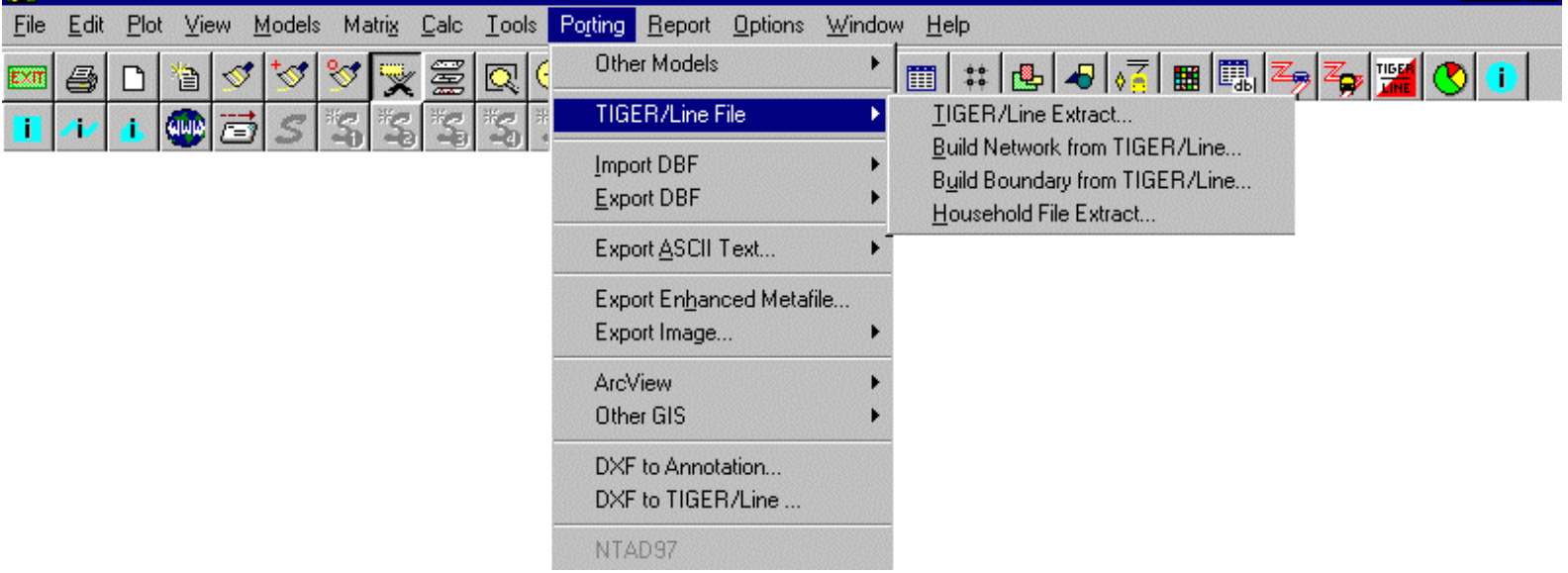

Figura 4.65 - Opção TIGER/LINE FILE do menu Porting do menu principal do UfosNet

As opções da figura 4.65, TIGER/LINE FILE $\Rightarrow$..., permitem a manipulação de arquivos TIGER/Line. Através da opção ... $\Rightarrow$ TIGER/LINE EXTRACT pode-se extrair arquivos TIGER/Line do banco de dados censitários de 1990 dos EUA (US 1990 Census database) armazenado em CDROM. O conjunto de linhas resultantes de uma extração TIGER/Line não possui topologia de nós e links e pode ser usado apenas para visualização. Para que estas linhas sejam interpretadas pelo UfosNet como uma rede é necessária a conversão dos dados, o que pode ser realizado através da opção ... $\Rightarrow$ BUILD NETWORK FROM TIGER/LINE. A conversão das linhas de contorno extraídas do arquivo TIGER/Line pode ser utilizada na construção de polígonos, através do comando ... $\Rightarrow$ BUILD BOUNDARY FROM TIGER/LINE. A opção ... $\Rightarrow$ HoUSEHOLD FILE EXTRACT permite a extração de informações censitárias de 1990, disponíveis na versão de 1992 do CD US Census TIGER/Line, e a construção de um banco de dados de zonas a partir destes dados.

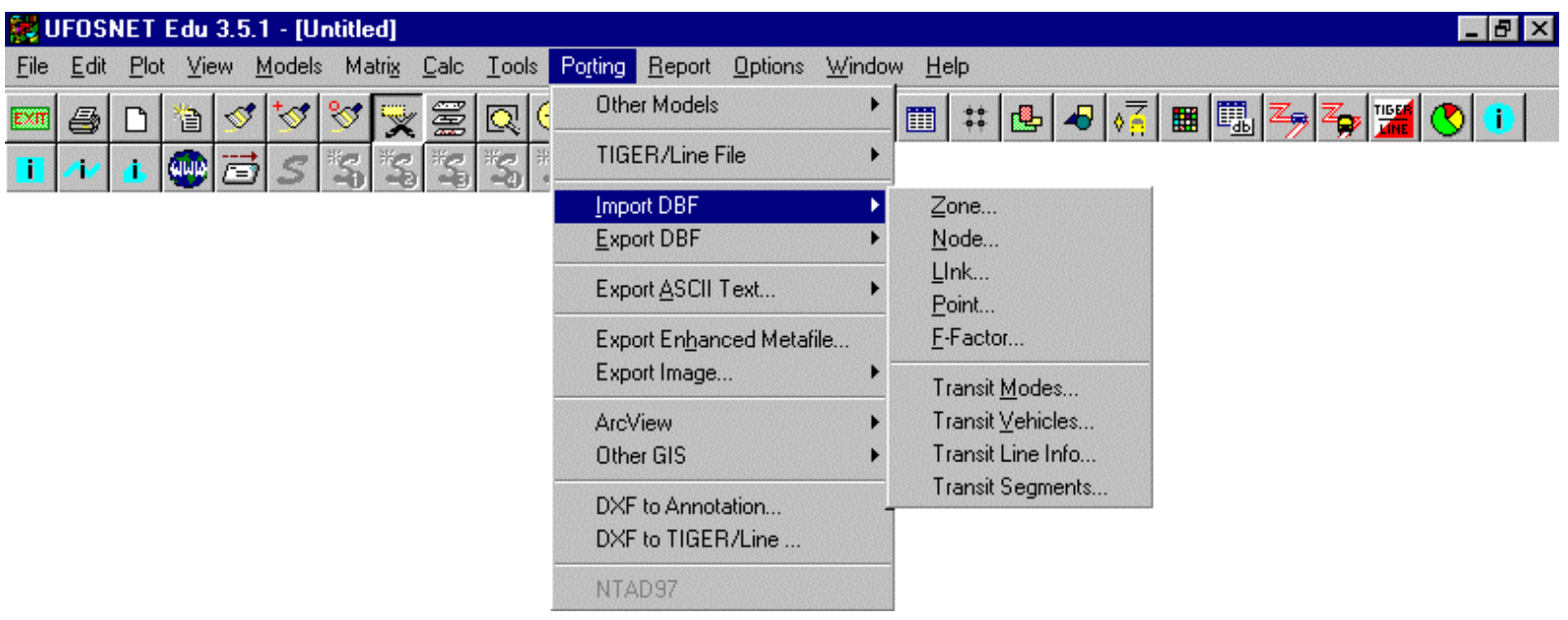

Figura 4.66 - Opção IMPORT DBF do menu Porting do menu principal do UfosNet

As opções IMPORT DBF $\Rightarrow$..., mostradas na figura 4.66, permitem a importação de dados armazenados em arquivos no formato dBase-III para a geração de tabelas de zonas, nós, 
links, pontos, fatores de fricção, modos de TPU, veículos de TPU, informações de linhas de TPU, segmentos de TPU. Os arquivos devem seguir as formatações exigidas e especificadas pelo UfosNet.

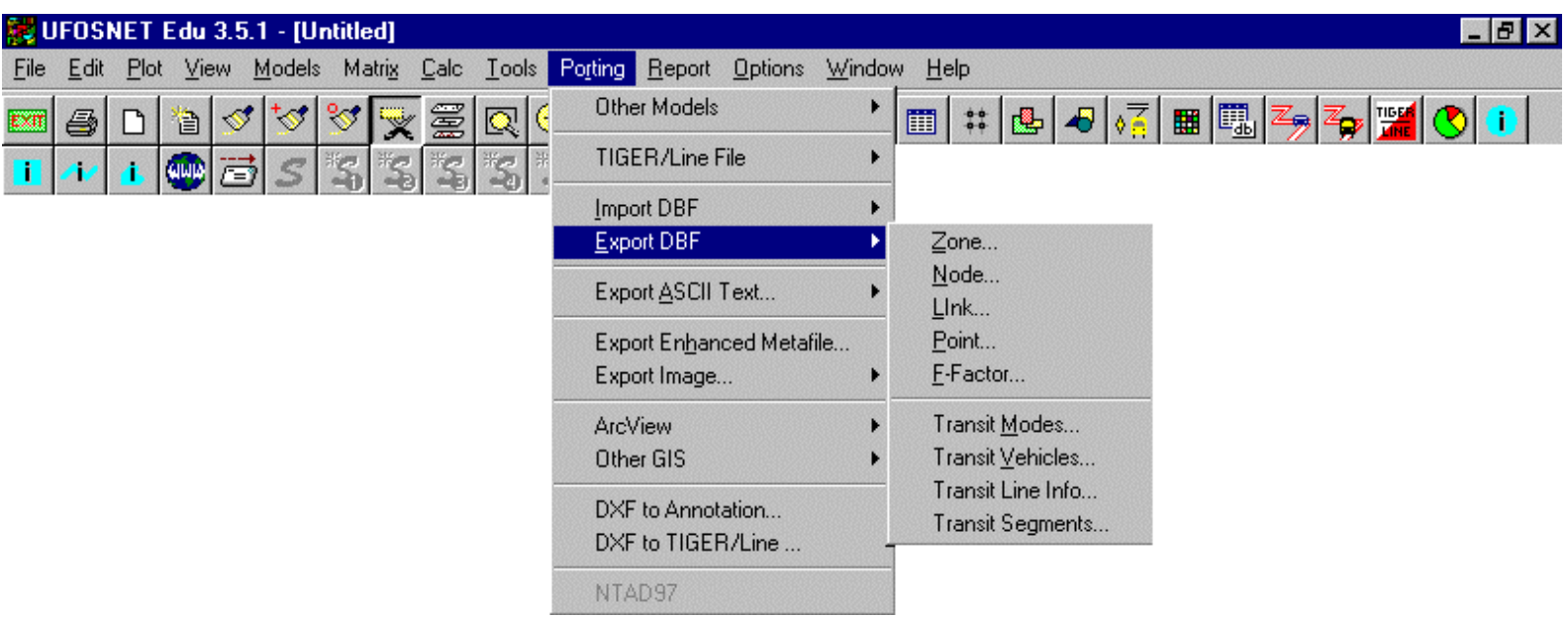

Figura 4.67 - Opção Export DBF do menu Porting do menu principal do UfosNet

As opções EXPORT DBF $\Rightarrow$..., figura 4.67, realizam a exportação de dados de bancos de dados de zonas, nós, links, pontos, fatores de fricção, modos de TPU, veículos de TPU, informações de linhas de TPU e segmentos de TPU do UfosNet para arquivos dBase-III.

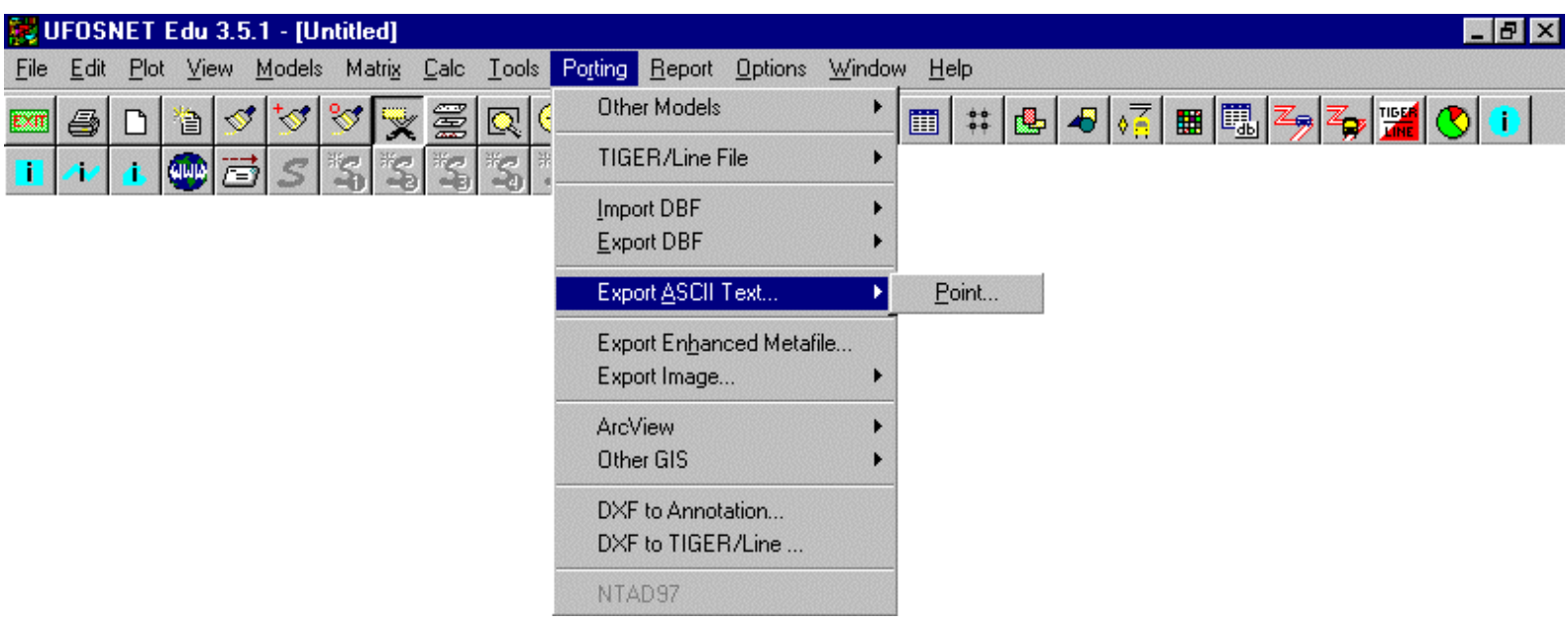

Figura 4.68 - Opção EXPORT ASCII TEXT do menu Porting do menu principal do UfosNet

A opção EXPORT ASCII TEXT $\Rightarrow$ POINT, figura 4.68, permite a exportação de um banco de dados do UfosNet para um arquivo do tipo texto formatado (*.txt).

A opção EXPORT ENHANCED METAFILE, figura 4.63, permite exportar as camadas gráficas do mapa visíveis na tela para um "Windows enhanced metafile" o qual possui a extensão *.emf. Esta opção pode ser utilizada para criar símbolos metafile para serem utilizados posteriormente como anotações. 
File Edit Plot View Models Matrix Cálc Iools Pogting Report Qptions Window Help

医泪

\begin{tabular}{l} 
TIGER/Line File \\
Import DBF \\
Export DBF \\
\hline Export ASCII Text... \\
\hline Export Enhanced Metafile... \\
\hline Export Image... \\
\hline ArcView \\
Other GIS \\
$\begin{array}{l}\text { DXF to Annotation... } \\
\text { DXF to TIGER/Line ... }\end{array}$ \\
\hline NTADS7
\end{tabular}

Figura 4.69 - Opção Export Image do menu Porting do menu principal do UfosNet

As opções ilustradas na figura 4.69, EXPORT IMAGE $\Rightarrow$..., são utilizadas para exportar a tela ativa para os seguintes arquivos de imagens: bmp, jpg, pcx, tif e tga.

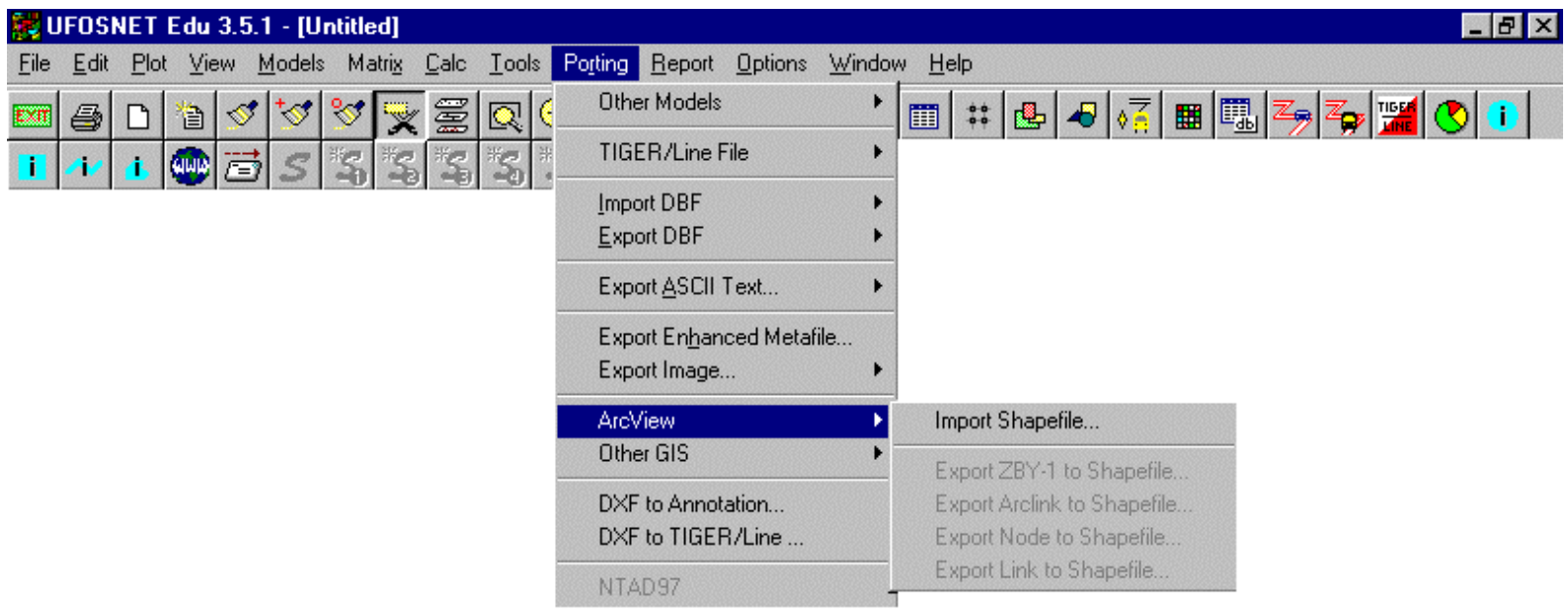

Figura 4.70 - Opção ARCVIEW do menu Porting do menu principal do UfosNet

A opção ARCVIEW $\Rightarrow$ IMPORT SHAPEFILE, figura 4.70, realiza a importação de shapefiles para objetos como: arcos e polígonos. Posteriormente os arcos poderão ser convertidos em camadas de arclinks ou de redes e os polígonos em camadas de limites de áreas. As opções ARCVIEW $\Rightarrow$ EXPORT realizam a exportação das camadas de áreas-1, arclinks, nós e links para shapefiles. 


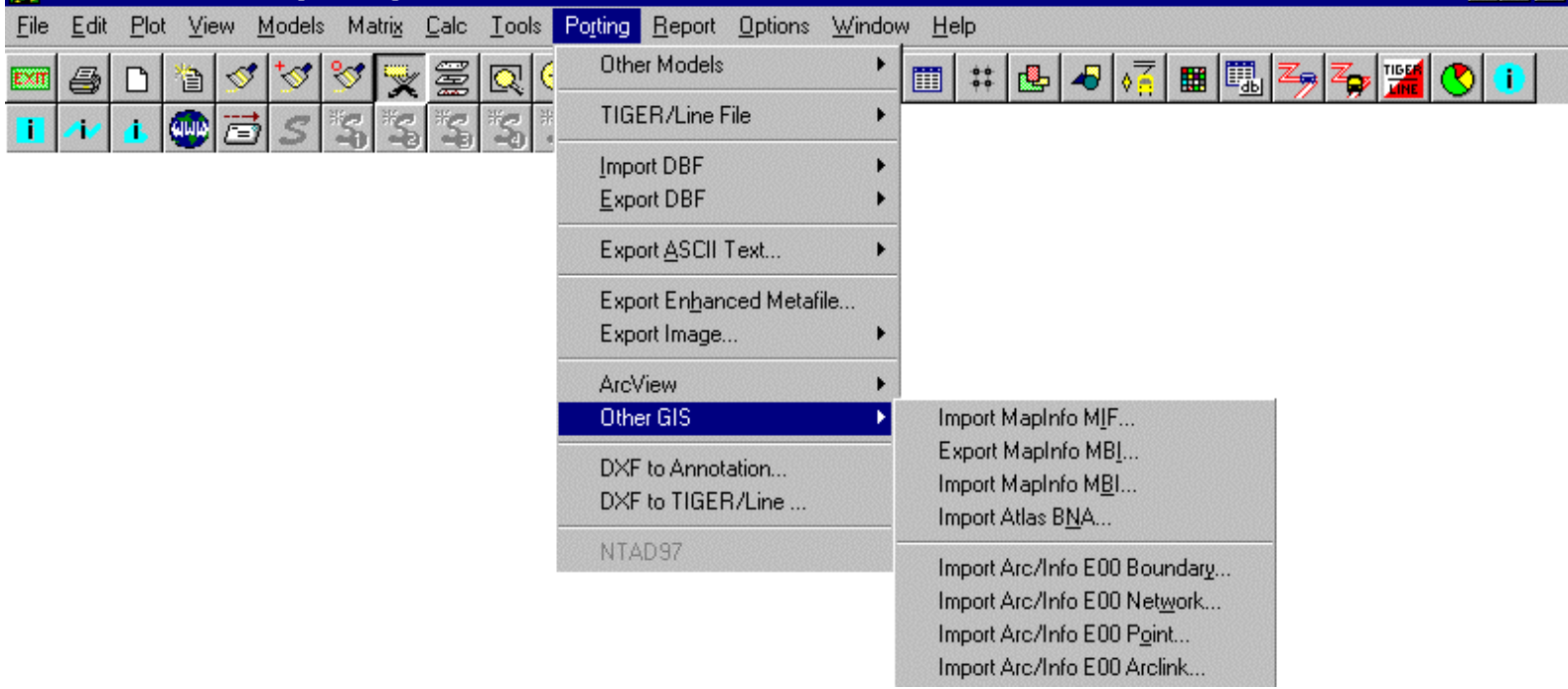

Figura 4.71 - Opção OTHER GIS do menu Porting do menu principal do UfosNet

As opções OTHER GIS $\Rightarrow$..., figura 4.71, realizam a importação de arquivos gerados por outros software SIG, tais como MapInfo, Atlas e ArcInfo, e a exportação das áreas contidas na camada de áreas-1 para um arquivo do tipo *.mbi (MapInfo Boundary Interchange).

A opção DXF to ANNOTATION, figura 4.63, realiza a conversão de um arquivo *.dxf do AutoCAD para um arquivo de anotações do UfosNet. A conversão de arquivos do AutoCAD para arquivos TIGER/Line pode ser feita através da opção DXF TO TIGER/LINE. E, por fim, a opção NTAD97 é utilizada para importar arquivos do CD-ROM "National Transportation Atlas Databases 1997", publicado pelo órgão americano "The Bureau of Transportation Statistics (BTS) of USDOT (United States Department of Transportation)". NTAD97 é um conjunto de bancos de dados geográficos nacionais referentes a transporte. Esses bancos de dados incluem informações espaciais de redes de transporte e terminais intermodais, além de informações dos atributos relacionados.

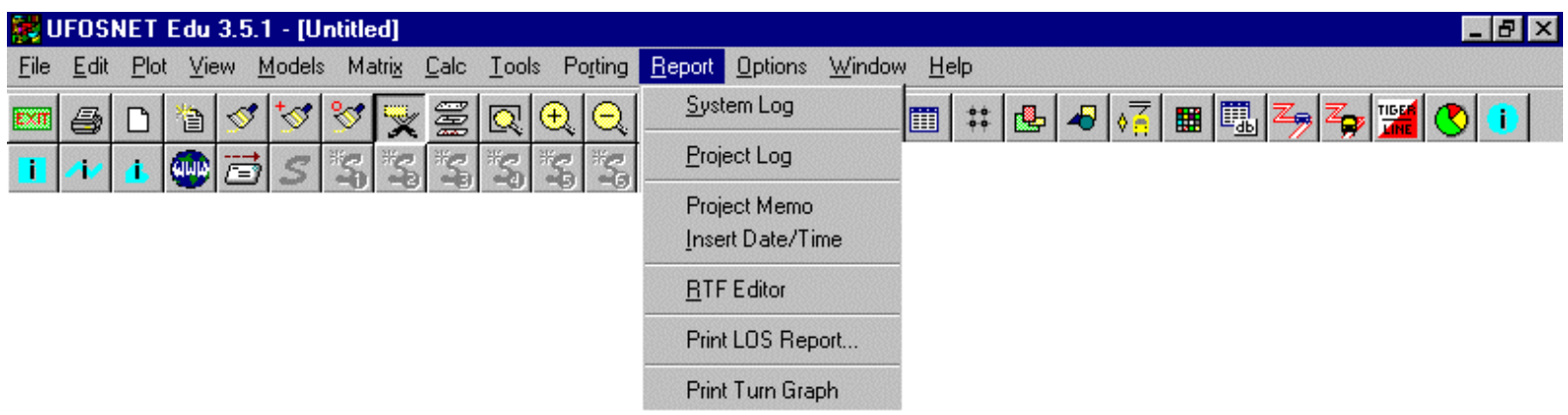

Figura 4.72 - Opção Report do menu principal do UfosNet

O UfosNet possui um editor de texto integrado, o qual suporta todas as suas funções de relatórios, tais como, System Log, Project Log e Project Memo, localizadas no menu Report, figura 4.72. A opção SYSTEM LOG é utilizada para visualizar e editar o arquivo de registros do sistema (syslog.txt), o qual é mantido no diretório padrão do UfosNet. Este 
arquivo armazena todas as atividades do UfosNet, tais como, o nome do usuário, nome utilizado para fazer o login no sistema, o nome do computador, tempo de início e término da sessão, arquivo carregado, arquivo salvo, etc. A opção PROJECT LOG é utilizada para visualizar e editar o arquivo de registros do projeto, o qual armazena todos os relatórios de consultas feitas pelo usuário, resultados de cálculos e mensagens de modelagens. Este arquivo é salvo e carregado juntamente com o arquivo do projeto. Através da opção PROJECT MEMO pode-se visualizar o arquivo Project Memo, que funciona como um bloco de notas (notepad) para armazenar qualquer informação essencial relativa ao projeto. Este arquivo também é salvo em conjunto com o arquivo do projeto. A opção InSERT DATE/TIME permite a inserção da data/hora (local) dentro do arquivo Project Memo. A opção RTF EDITOR abre um editor de texto acoplado ao UfosNet para a edição de qualquer texto. As opções PRINT LOS REPORT e PRINT TURN GRAPH são utilizadas para imprimir, respectivamente, os resultados de análises LOS (Level of Service) de interseções sinalizadas e os valores de movimentos de retorno e espessuras e geometria da pista na forma gráfica.

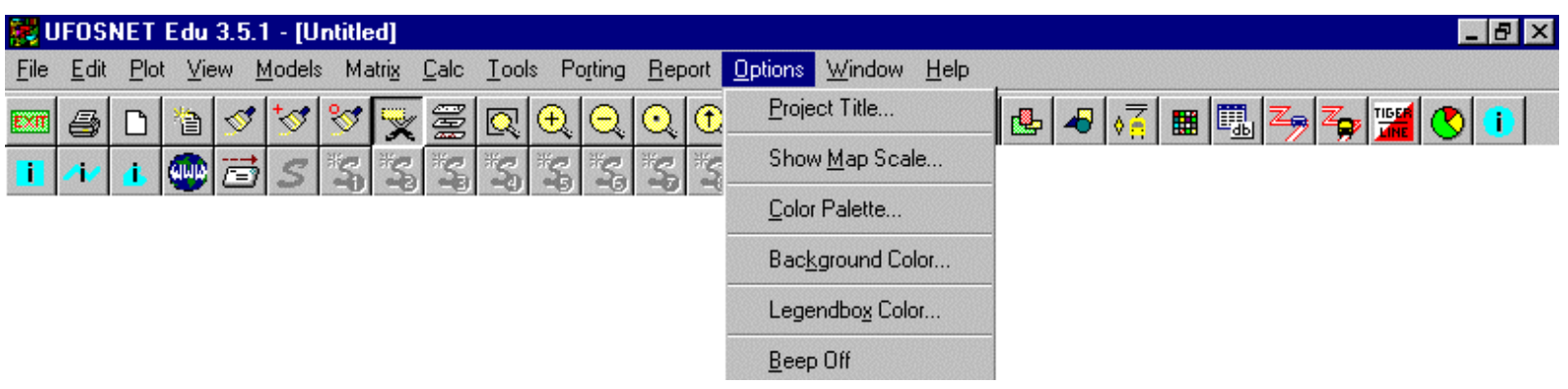

Figura 4.73 - Opção Options do menu principal do UfosNet

A opção Project Title do menu Options, figura 4.73, possibilita a definição de um nome para o projeto, com até 40 caracteres, o qual será salvo com o arquivo do projeto. A opção SHOW MAP SCALE mostra uma escala gráfica do mapa na tela. A opção CoLOR PALETTE ativa uma janela contendo a paleta de cores utilizada pelo projeto ativo. Paletas podem ser definidas, carregadas e salvas (extensão *.pal) pelo usuário. Através da opção BACKGROUND COLOR pode-se alterar e personalizar a cor da tela de fundo do mapa. A opção LEGENDBOX COLOR permite alterar a aparência da caixa da legenda ativa na tela. As opções disponíveis neste comando são: alterar as cores de fundo e definir uma sombra. Selecionandose a opção BEEP OFF pode-se ativar ou desativar o comando do som que é emitido pelo UfosNet quando aparecem mensagens de erro ou alerta.

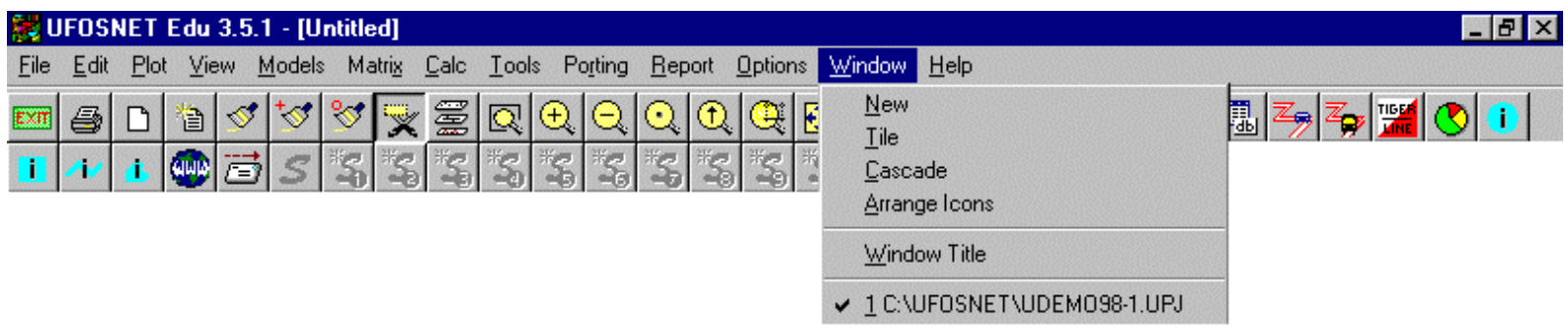

Figura 4.74 - Opção Window do menu principal do UfosNet

As opções disponíveis no menu Window, figura 4.74, são semelhantes às ofertadas pelo mesmo item do menu do TransCAD, e portanto já foram descritas. 
Muitos dos comandos descritos acima podem ser ativados através de ícones, disponíveis no menu do UfosNet, os quais serão mostrados a seguir, figura 4.75, e a indicação de suas respectivas funções, figuras 4.76 e 4.77 .

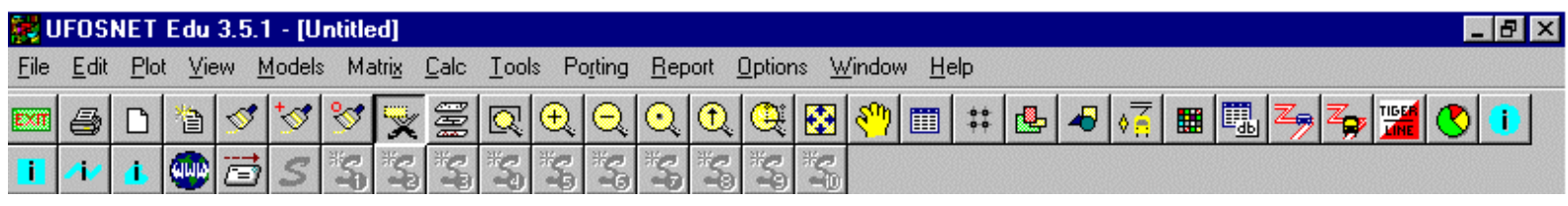

Figura 4.75 - Ícones disponíveis na barra de menu do UfosNet

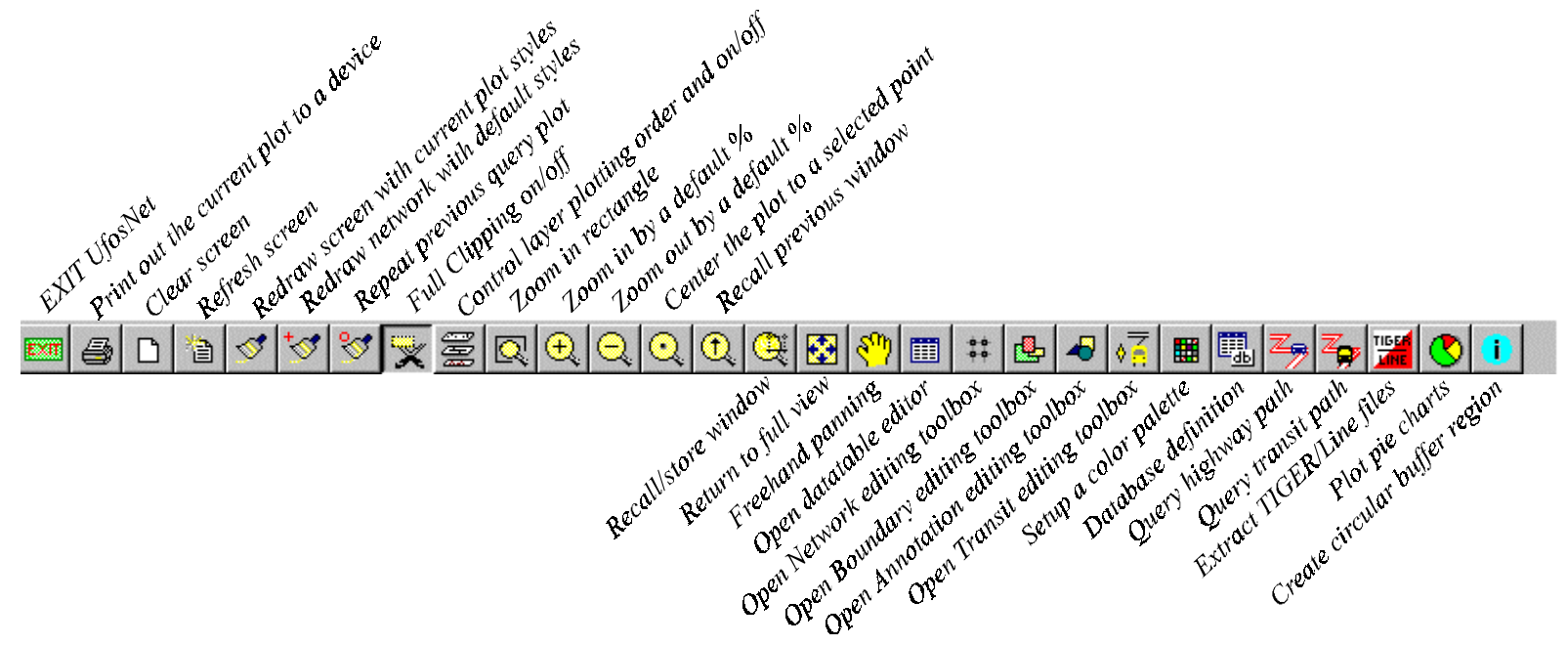

Figura 4.76 - Primeira linha de ícones disponíveis na barra de menu do UfosNet

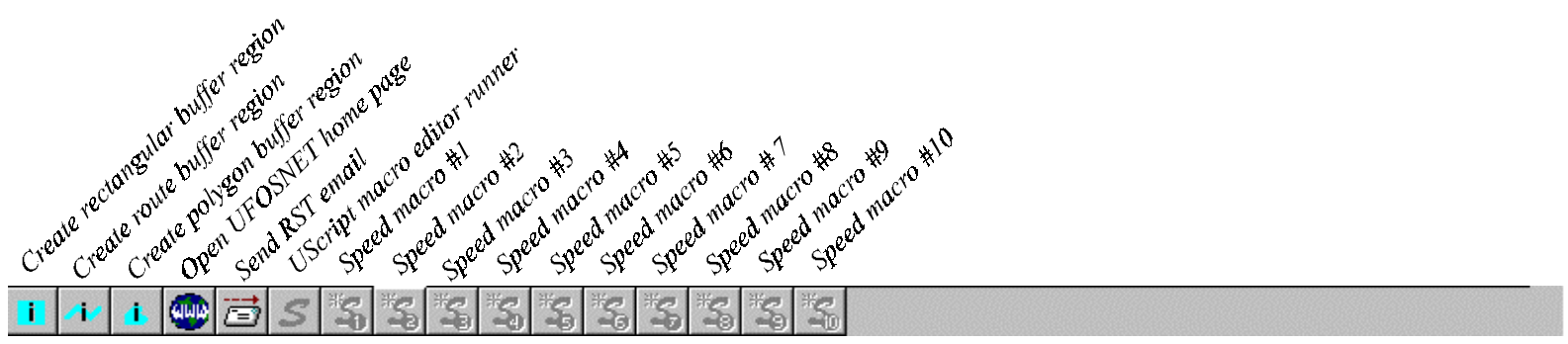

Figura 4.77 - Segunda linha de ícones disponíveis na barra de menu do UfosNet 


\subsubsection{Rotinas Específicas de Transportes}

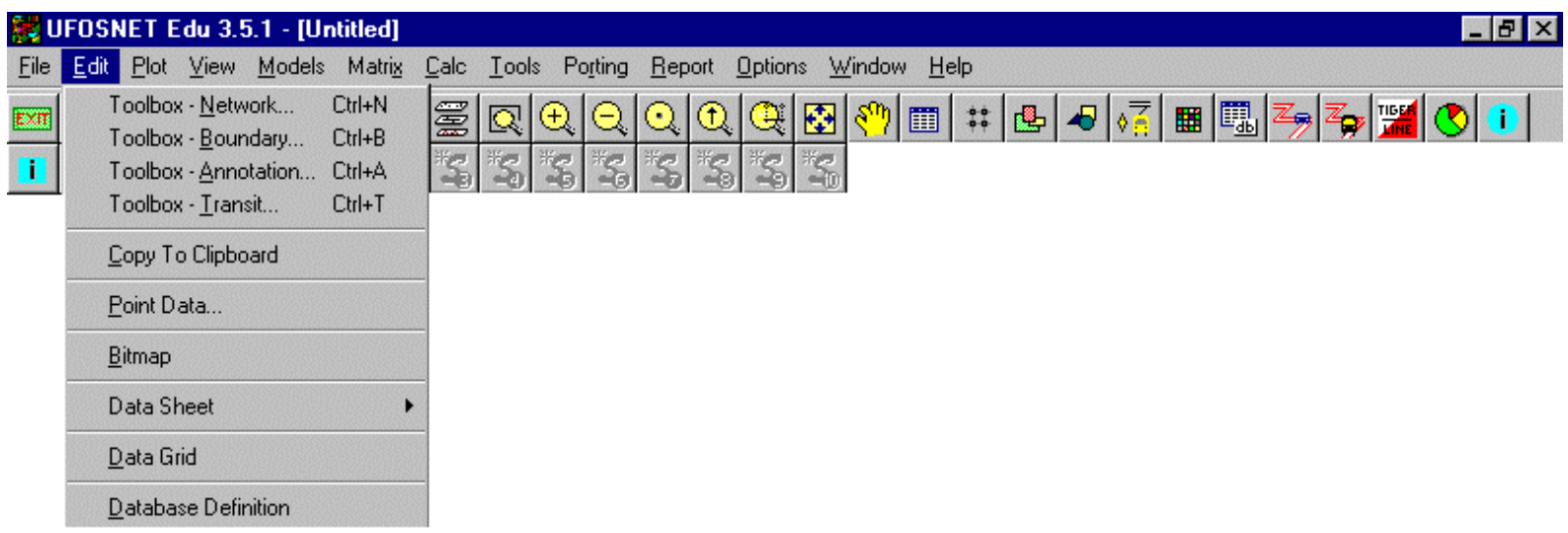

Figura 4.78 - Opção TOOLBOX - TRANSIT do menu Edit do menu principal do UfosNet

A opção TOOLBOX - TRAnsit, figura 4.78, abre a caixa de ícones, ilustrada na figura 4.79, destinados à edição e definição de linhas de transporte público urbano.

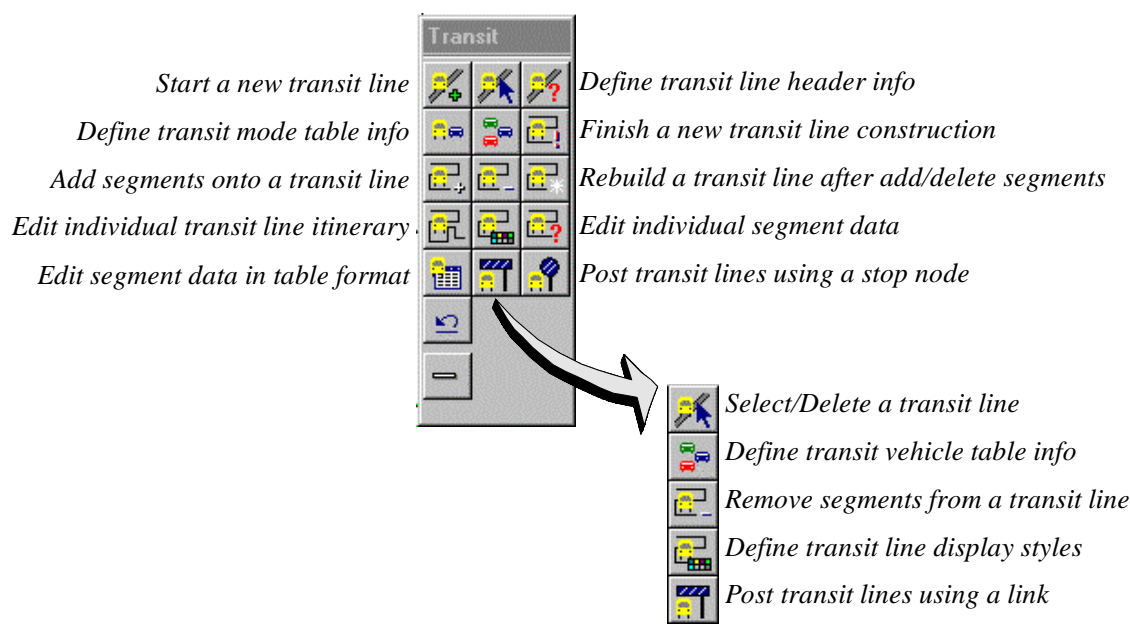

Figura 4.79 - Opção ToOlBoX - TRAnsit do menu Edit do menu principal do UfosNet

As funções dos ícones mostrados na figura 4.79 são, resumidamente:

$\Rightarrow$ inicia uma nova linha de TPU, através da definição dos seguintes parâmetros: o número, o rótulo e o modo da linha, o tipo do veículo, o headway padrão em minutos, a velocidade média de operação, o tempo de espera/parada do veículo, a função de tempo de trânsito a ser utilizada e uma descrição da linha;

$\Rightarrow$ ícone utilizado para selecionar ou apagar uma linha de TPU;

$\therefore ?$ ? $\Rightarrow$ ferramenta utilizada para visualizar e modificar os dados dos atributos de uma linha de TPU;

$\therefore=$ mais de dez modos podem ser definidos para uma rede de TPU, tais como: ônibus, metrô, balsa, etc. Cada modo pode ser representado com uma cor diferente e pode estar visível ou não. Um modo é identificado através de um código e de uma descrição; 
$\Rightarrow$ comando utilizado na definição dos atributos operacionais de cada tipo de veículo, os quais são utilizados nos cálculos de índices de performance. Tais atributos incluem: o número do tipo do veículo, o nome do tipo do veículo, um modo, o tamanho da frota, capacidade total ( $\mathrm{n}^{\mathrm{o}}$ de passageiros total e sentados), velocidade média, custo de operação (milhas $/ \mathrm{km}$ ), custo operacional por hora, consumo de energia por milhas/km e por hora;

|⿴囗玉: $\Rightarrow$ finaliza a construção de uma nova linha de TPU;

As ferramentas a seguir são utilizadas para modificar o itinerário de uma linha de TPU existente: $\Rightarrow$ inserindo-se novos segmentos; $\overrightarrow{\text { Pi: }} \Rightarrow$ - $\Rightarrow$ removendo-se segmentos existentes e

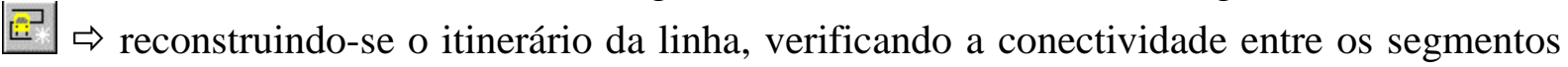
velhos e novos;

菑 $\Rightarrow$ ferramenta utilizada para editar um itinerário individual de uma linha de TPU;

i $\Rightarrow$ através deste ícone pode-se definir os estilos de visualização das linhas de TPU, tais como: offsets, espessuras de linhas e fontes;

蕅? $\Rightarrow$ ícone utilizado para editar os valores dos atributos de um segmento, um a um;

$\Rightarrow$ ferramenta utilizada para visualizar e editar os valores dos atributos dos segmentos na forma de uma planilha (tabela);

罚 $\Rightarrow$ ícone utilizado para mostrar todas as linhas de TPU que têm um segmento utilizando o mesmo link da via;

9 . $\Rightarrow$ ícone utilizado para mostrar todas as linhas de TPU que têm um ponto de parada em um certo nó.

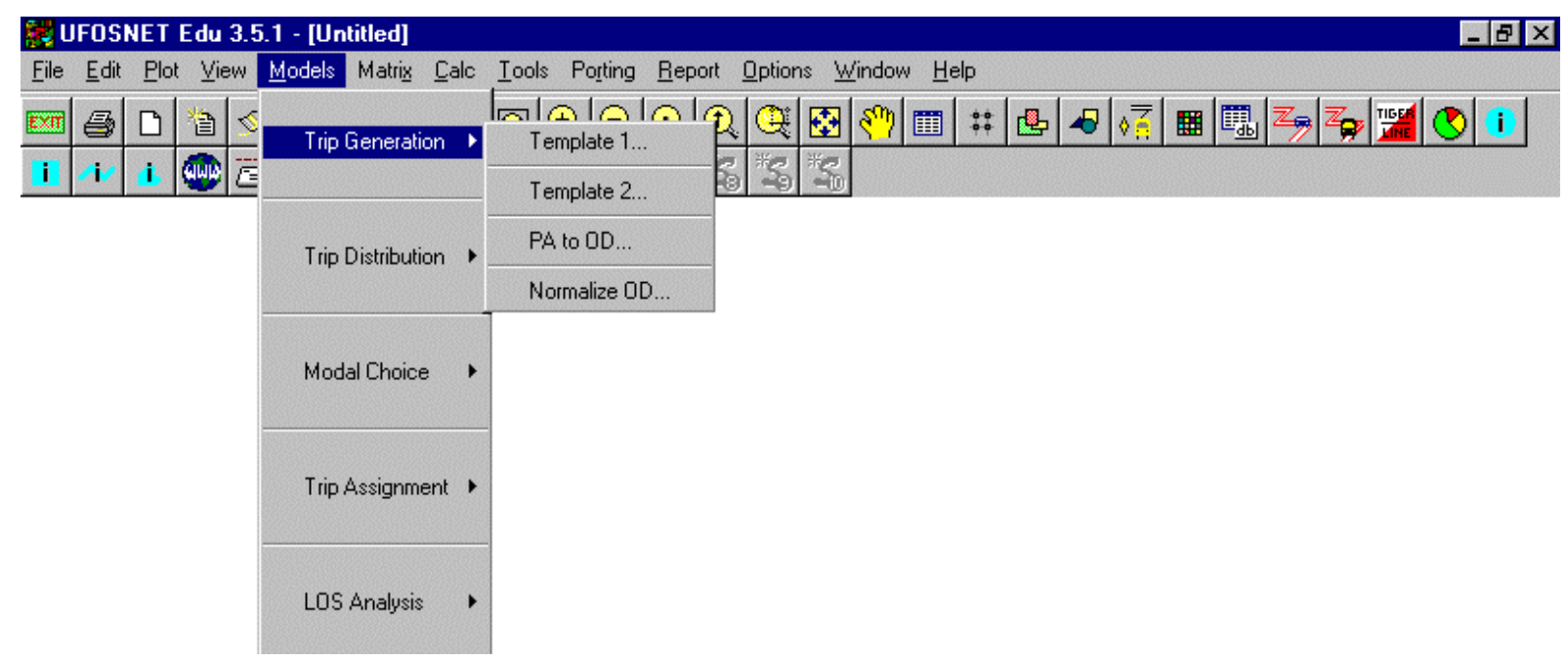

Figura 4.80 - Opção TRIP GENERATION do menu Models do menu principal do UfosNet

O processo de Geração de Viagens (Trip Generation) é utilizado para estimar o número total de viagens produzidas e atraídas por determinada zona. Basicamente, as viagens são calculadas com base nos dados de uso do solo e a razão média de viagens. O UfosNet fornece, na opção TRIP GENERATION, figura 4.80, dois padrões (Template 1 e Template 2) baseados no modelo de regressão para análises de resposta rápida; a ferramenta $P A$ to $O D$ para converter os dados de produção/atração de viagens para uma matriz origem/destino e a 
opção Normalize $O D$ para fazer o balanceamento de viagens antes da realização do processo de distribuição de viagens.

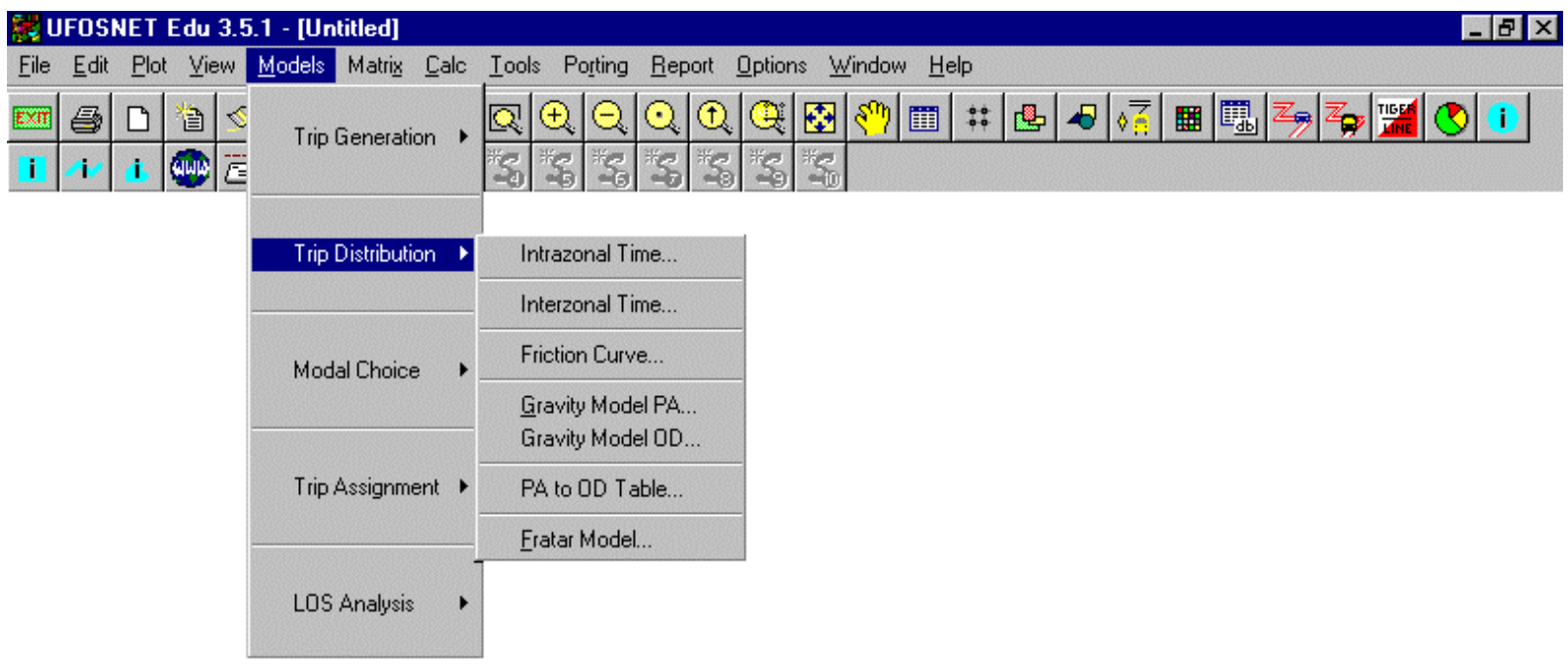

Figura 4.81 - Opção TRIP DistRIBUTION do menu Models do menu principal do UfosNet

O processo de distribuição de viagens é utilizado para a estimativa do padrão de viagens entre um conjunto de zonas de origem e destino. Na opção TRIP DISTRIBUTION, figura 5.81, são encontradas as seguintes opções para a realização do processo de distribuição de viagens:

- Intrazonal Time (tempo intra-zonal): representa o tempo médio necessário para fazer viagens dentro de uma mesma zona;

- Interzonal Time (tempo inter-zonal): representa o tempo de viagem entre cada par de zonas, não considerando o tempo intra-zonal e o tempo gasto em terminais.

- Friction Curve (Curva de fricção): através desta opção pode-se examinar a distribuição dos fatores de fricção em formato gráfico.

- Gravity Model PA: Modelo gravitacional utilizando as variáveis produção e atração de viagens. Nesta opção são consideradas as viagens ao longo do dia;

- Gravity Model OD: Modelo gravitacional com as variáveis origem e destino de viagens. Nesta opção são consideradas apenas as viagens na hora de pico;

- PA to OD Table: permite converter uma tabela de viagens PA em uma tabela OD;

- Fratar Model: Modelo de Fratar. 


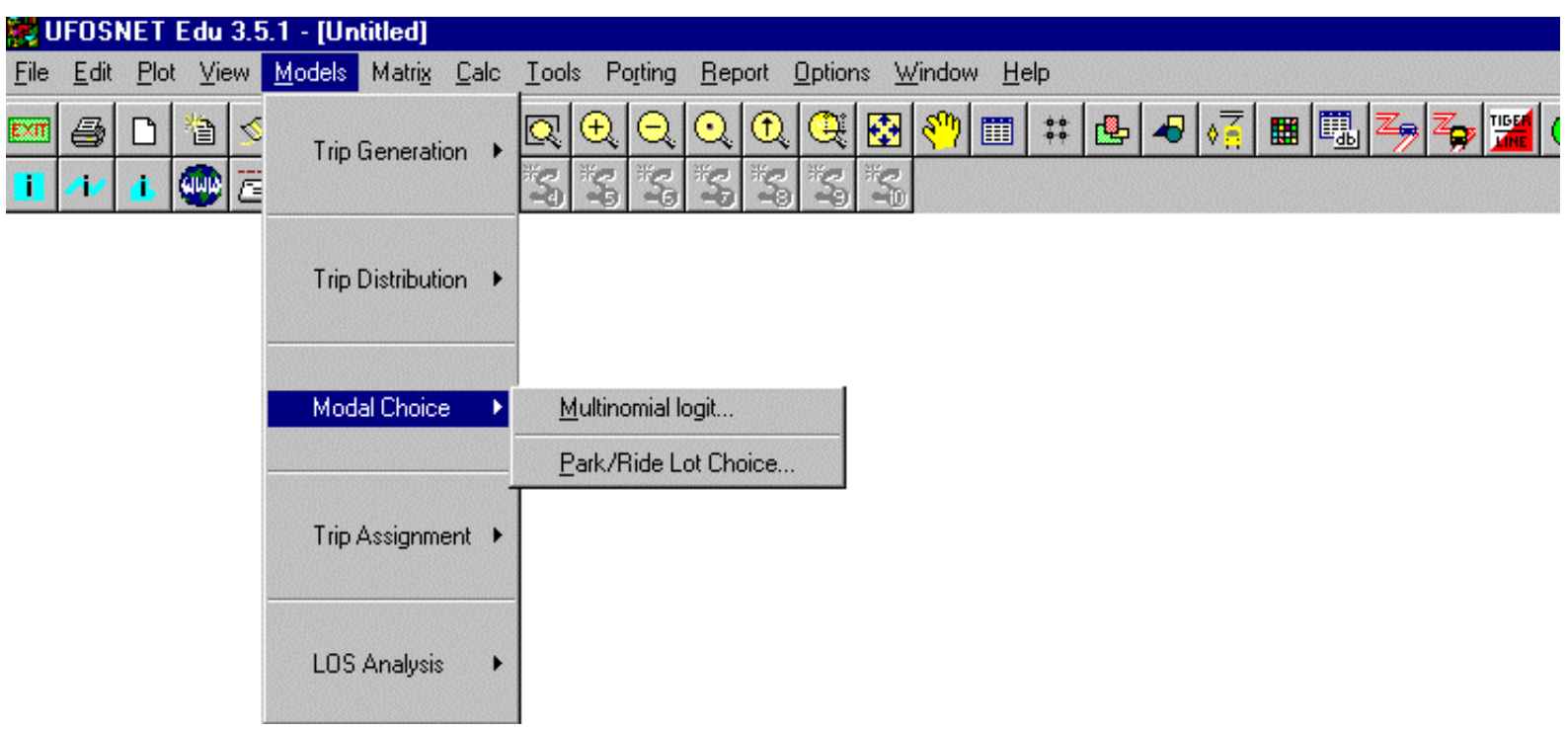

Figura 4.82 - Opção ModAl CHOICE do menu Models do menu principal do UfosNet

Escolha modal é o processo através do qual é determinado como as viagens são distribuídas entre os diferentes modos de viagens. Para isto, o UfosNet fornece, na opção mostrada na figura 4.82, as seguintes ferramentas estatísticas:

- Multinomial Logit: Modelo Logit Multinomial;

- Park/Ride Lot Choice: Modelo para escolha de praça deestacionamento associada a TPU.

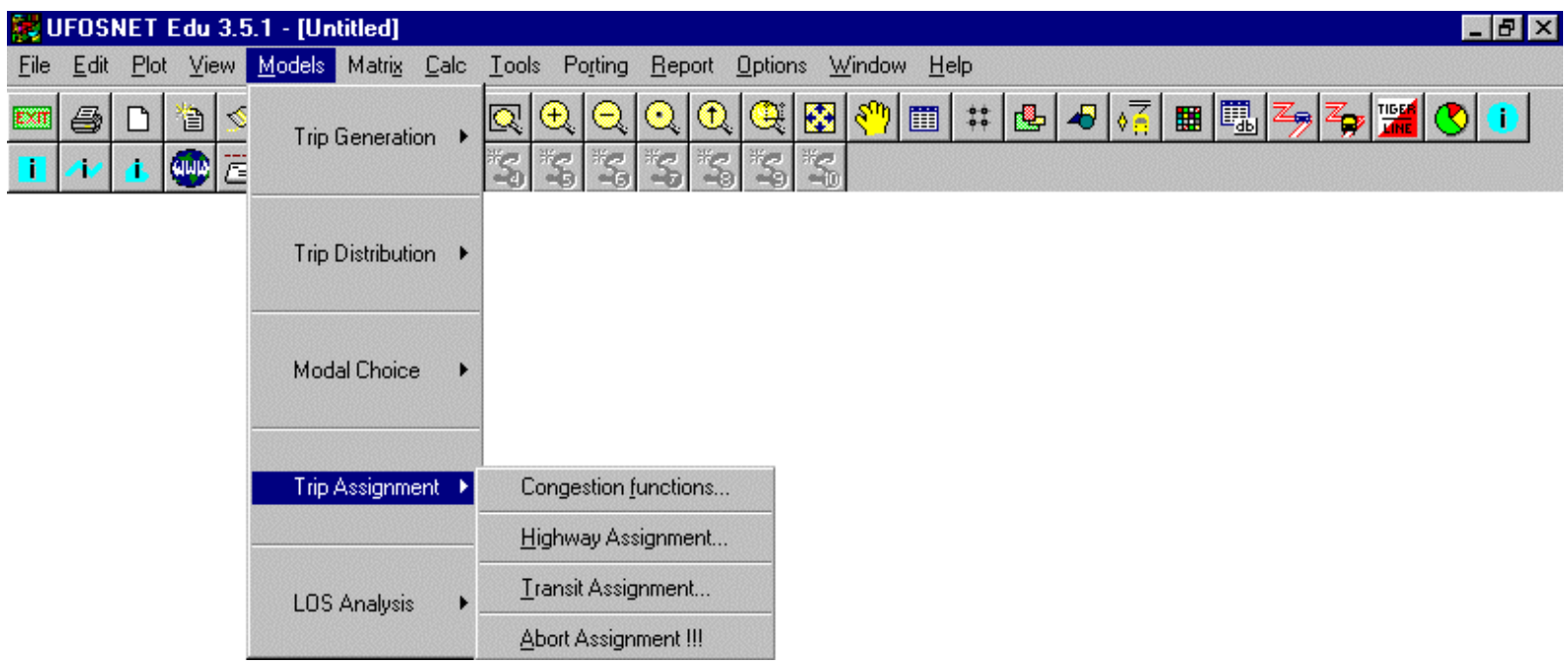

Figura 4.83 - Opção TRIP AssignMENT do menu Models do menu principal do UfosNet

Na etapa de alocação de tráfego estima-se o fluxo de tráfego sobre uma rede. As opções disponíveis para alocação de tráfego, verificadas na figura 4.83, opção TRIP ASSIGNMENT do menu Models, são as seguintes:

- Congestion functions: as funções de congestionamento representam as relações entre os atrasos (tempo gasto) e as razões volume/capacidade, para links e nós; 
- Highway Assignment: nesta opção obtém-se a alocação do tráfego de automóveis em uma rede com base em algoritmo de caminho mínimo, utilizando-se dos métodos do tudo-ou-nada, incremental ou do equilíbrio;

- Transit Assignment: opção utilizada para alocação do tráfego de passageiros de transporte público urbano em uma rede de TPU;

- Abort Assignment: opção utilizada para cancelar uma operação de alocação de tráfego.

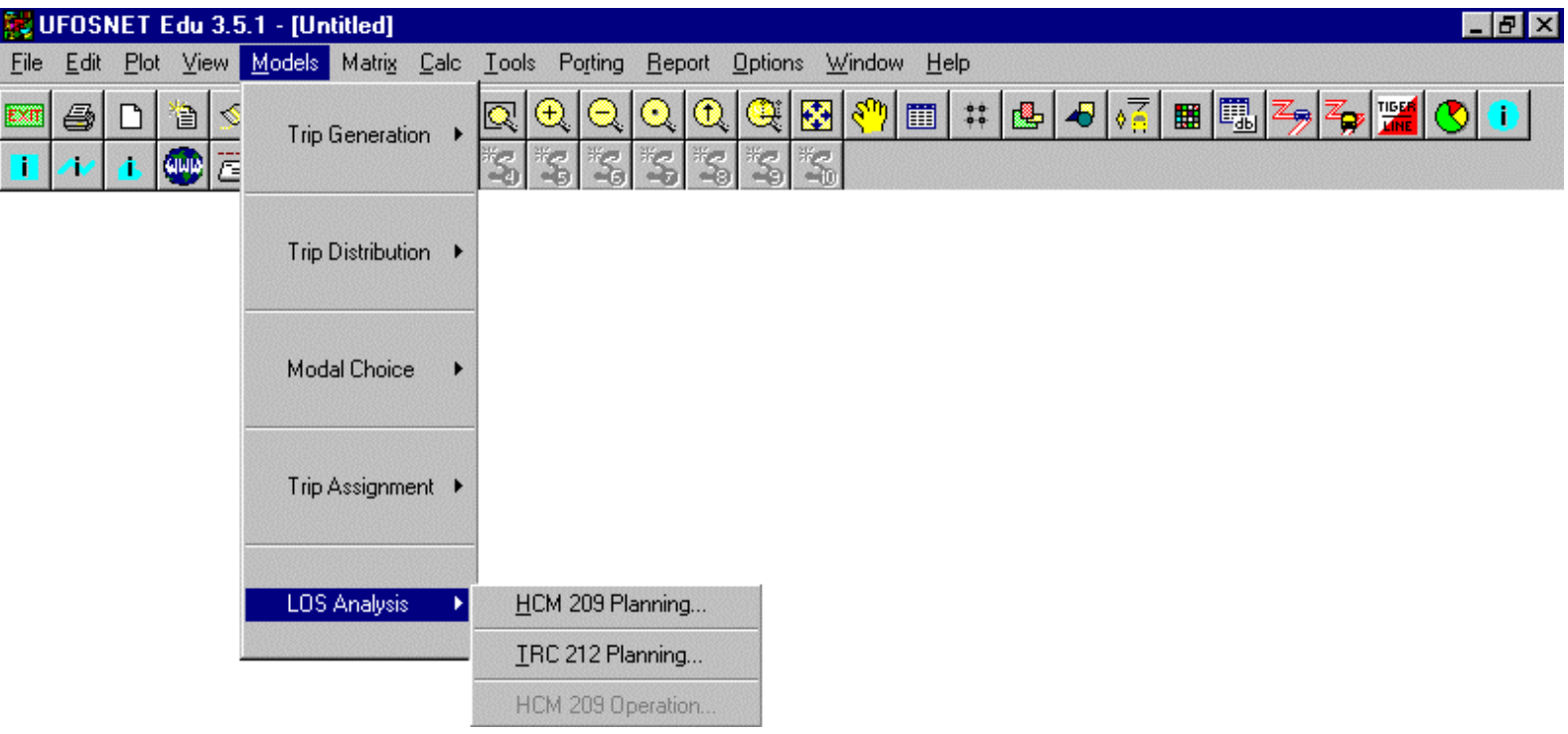

Figura 4.84 - Opção LOS ANALYSIS do menu Models do menu principal do UfosNet

As opções disponíveis no item LOS ANALYSIS do menu Models, figura 4.84, são destinadas à análise de capacidade de interseções. Suas siglas têm os seguintes significados:

- HCM 209 Planning: Highway Capacity Manual's planning method;

- TRC 212 Planning: Transportation Research Circular 212's planning method;

- HCM 209 Operation. 


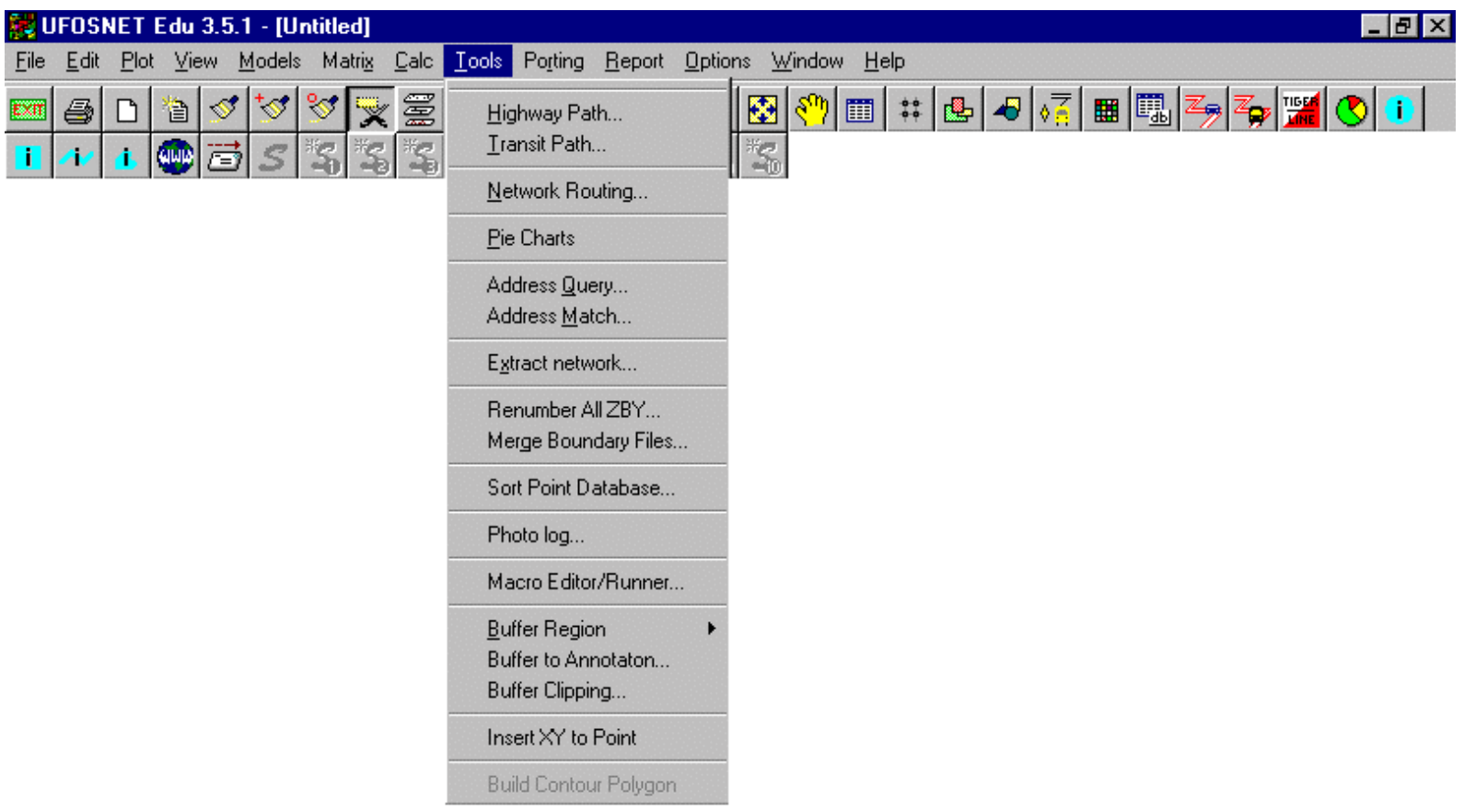

Figura 4.85 - Opção TRANSiT PATH do menu Tools do menu principal do UfosNet

A opção TRANSIT PATH do menu Tools, figura 4.85, é utilizada para encontrar o caminho mínimo entre dois pontos de TPU. É uma excelente ferramenta para verificar a conectividade de uma rede de TPU. 


\subsection{Software ArcView (Versão 3.1)}

\subsubsection{Comandos Básicos e Rotinas Avançadas de SIG}

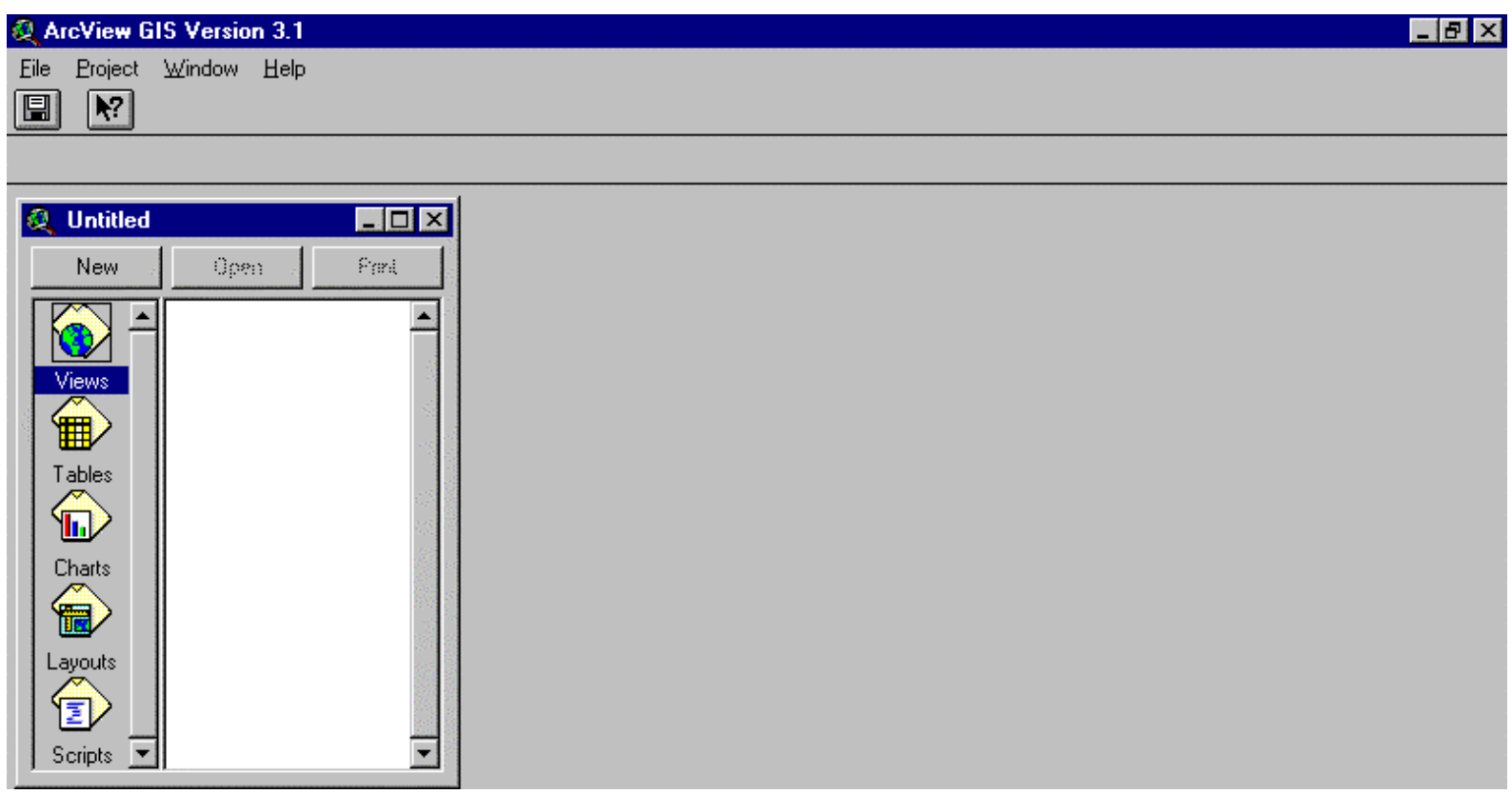

Figura 4.86 - Menu inicial e janela do projeto do ArcView

A tela inicial do ArcView, figura 4.86, apresenta uma janela através da qual pode-se criar, abrir, imprimir ou visualizar vistas, tabelas, gráficos, leiautes e scripts pertencentes a determinado projeto, que pode ser ativado e configurado através das opções disponíveis nos menus File e Project, figuras 4.87 e 4.88. A opção Scripts disponível apresenta uma janela destinada à edição, manipulação e criação de scripts (macros escritas pelo usuário), e não será abordada neste documento.

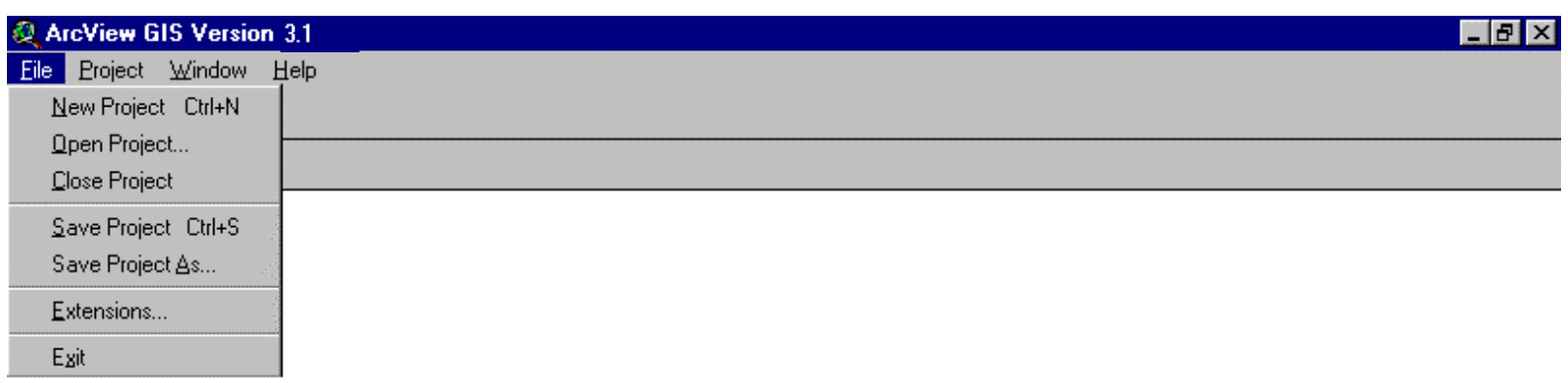

Figura 4.87 - Opção File do menu inicial do ArcView

As opções New Project, Open Project e Close Project do menu File, figura 4.87, realizam as seguintes funções: criar um novo projeto, abrir um projeto existente e fechar o projeto ativo, respectivamente. As opções SAVE Project e SAVE Project As realizam o salvamento do projeto ativo, a primeira conservando o nome atual e a segunda com um novo nome. Através da opção EXTENSIONS pode-se tornar ativas ou desativar as extensões e módulos adicionais disponíveis no ArcView (descritos no capítulo 2 - Programas Estudados). A opção EXIT finaliza o programa. 


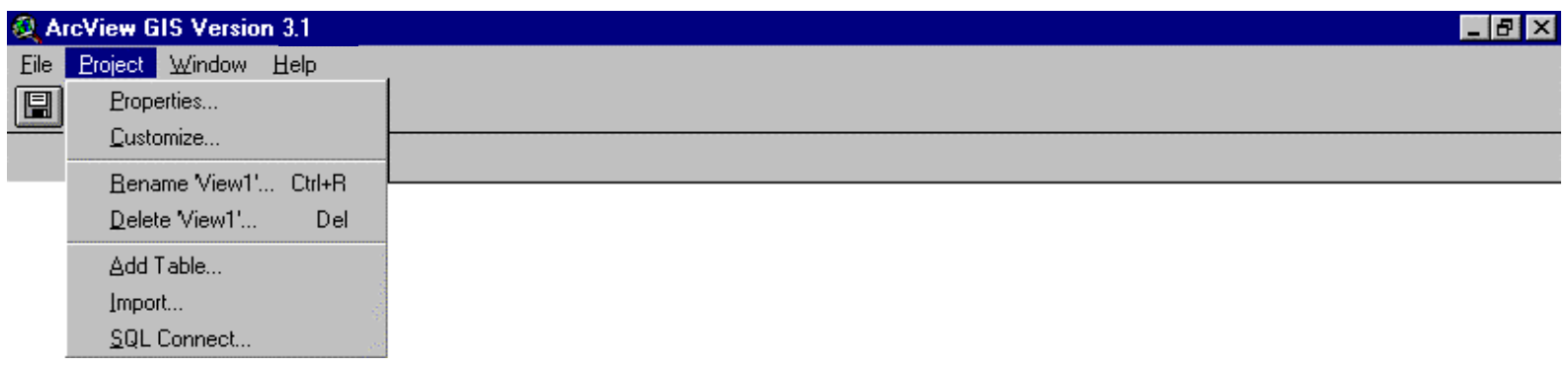

Figura 4.88 - Opção Project do menu inicial do ArcView

A opção Properties do menu Project, figura 4.88, ativa uma caixa de diálogos onde podem ser definidos e verificados os seguintes itens relativos ao projeto: o nome de uma script a ser executada no momento da abertura do projeto, o nome de uma script a ser executada quando o projeto for fechado, o diretório a ser utilizado pelo ArcView para salvar os arquivos do projeto atual, o nome do criador do projeto, a data em que foi criada a primeira vista (campo preenchido automaticamente e não editável), a cor a ser utilizada na seleção de objetos e um comentário relativo ao projeto. As opções disponíveis na caixa de diálogos ativada pelo comando CUSTOMIZE permitem a definição dos tipos (coleção de controles utilizados para interagir com os documentos) de documentos presentes na janela do projeto, figura 4.86. Os tipos disponíveis na janela de projeto default do ArcView são: vistas, tabelas, gráficos, leiautes e scripts, mas o software disponibiliza também os tipos projetos e "appl" (quando o arquivo de projeto é fechado). Pode-se, ainda, através do comando de personalização dos tipos de documentos, remover tipos da lista, alterar seus nomes e ícones, alterar a ordem de aparência dos mesmos na janela de projeto e criar novos tipos. Os menus, botões, ferramentas e barras de rolagem presentes nas janelas de cada um desses tipos, quando da abertura de algum documento, podem ser alterados e customizados pelo usuário.

As opções RENAME e DELETE permitem renomear e excluir o documento selecionado na janela de projetos. A opção ADD TABLE permite adicionar uma tabela, extensão *.dbf, INFO ou *.txt, ao projeto. Através da opção IMPORT pode-se importar para dentro do projeto ativo um outro projeto (*.apr) e/ou uma vista (*.av), sendo ambos os tipos de arquivos gerados pelo ArcView.

A opção SQL CONNECT permite estabelecer uma conexão com servidores de bancos de dados e realizar consultas para extrair registros, os quais serão importados sob a forma de uma tabela. Na caixa de diálogos ativada por esta opção deve-se determinar o tipo de banco de dados que será conectado (arquivos dBASE, FoxPro, texto, Excel e bancos de dados MS Access 97), selecionar o ícone Connect e escolher o arquivo desejado. Realizados estes comandos aparecerá uma listagem das tabelas encontradas no banco de dados ativado e as colunas pertencentes a cada tabela. Os demais campos disponíveis referem-se à seleção de colunas a serem extraídas (Select), às planilhas que contém tais colunas (from), os registros que serão extraídos (neste campo pode-se determinar uma condição do tipo "se $x>y$ " para a extração de registros específicos, isto é, especificar uma consulta) (where) e ao nome da tabela criada pelo ArcView para mostrar os resultados da consulta (Output Table). O ícone 
Clear limpa todos os campos preenchidos pelo usuário e o ícone Query realiza a operação especificada.

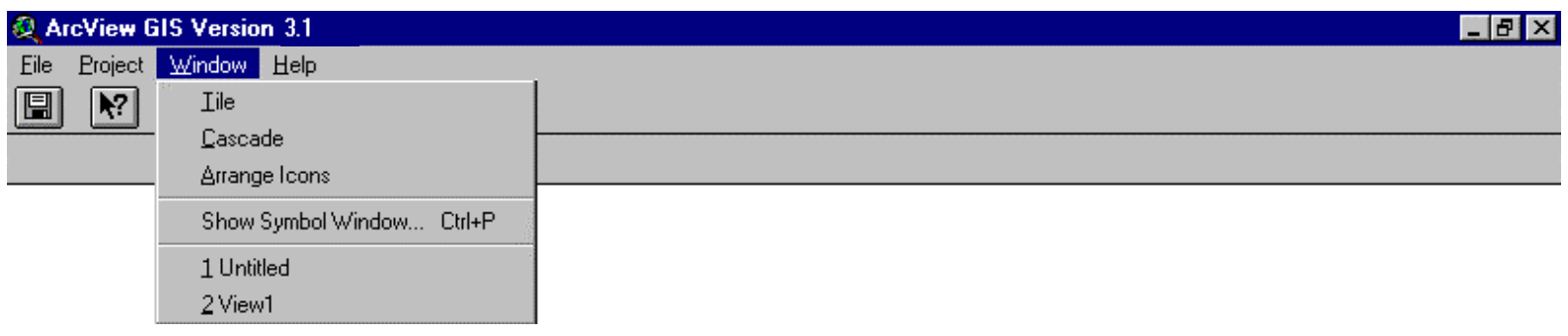

Figura 4.89 - Opção Window do menu inicial do ArcView

As opções disponíveis no menu Window, figura 4.89, são semelhantes às ofertadas pelo mesmo item do menu do TransCAD e do UfosNet, e portanto já foram descritas.

Figura 4.90 - Menu de vistas do ArcView

Selecionando-se a opção de vistas (views), figura 4.86, pode-se visualizar todas as vistas existentes no projeto. O usuário poderá selecionar o documento desejado e visualizá-lo numa janela, a qual apresentará o menu de vistas mostrado na figura 4.90.

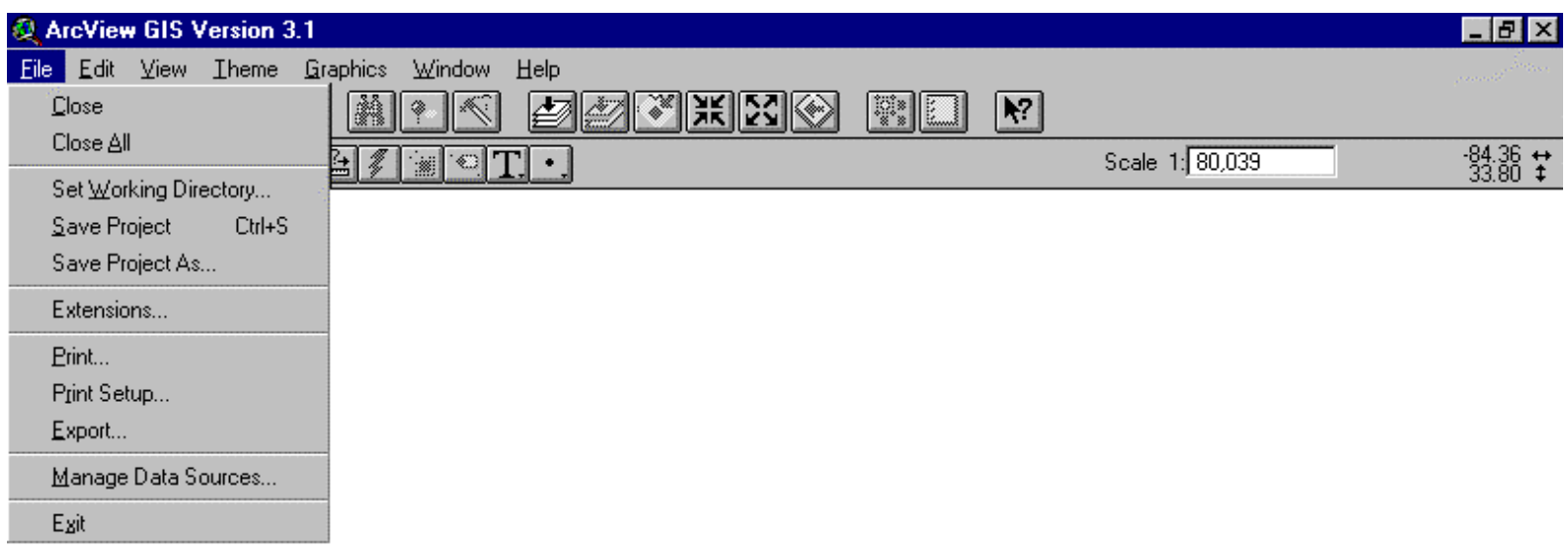

Figura 4.91 - Opção File do menu de vistas do ArcView

As opções Close e Close All disponíveis no menu File, figura 4.91, são utilizadas para fechar a vista ativa e fechar todas as vistas abertas, respectivamente. A opção SET WORKING DIRECTORY permite a alteração do diretório de trabalho, onde serão salvos todos os arquivos do projeto atual. As opções SAVE Project e SAVE ProjeCt As são utilizadas para salvar o projeto ativo. A opção EXTENSIONS é a mesma apresentada pelas opções File $\Rightarrow$ EXTEnsions da janela inicial do ArcView. A opção PrInT permite imprimir a vista ativa diretamente ou criar um arquivo de impressão com extensão *.prt e a opção PRINT SETUP 
ativa uma caixa de diálogos onde podem ser configurados os itens: tipo da impressora e suas propriedades; e tamanho, origem e posição do papel. Através da opção MANAGE DATA SOURCES pode-se excluir, copiar e renomear fontes de dados tais como shapefiles, grids e TINs. A opção EXIT finaliza o programa.

As opções dos menus File das demais janelas de trabalho do ArcView não apresentam inovações em relação a esta primeira, já descrita, e portanto não serão detalhadas novamente.

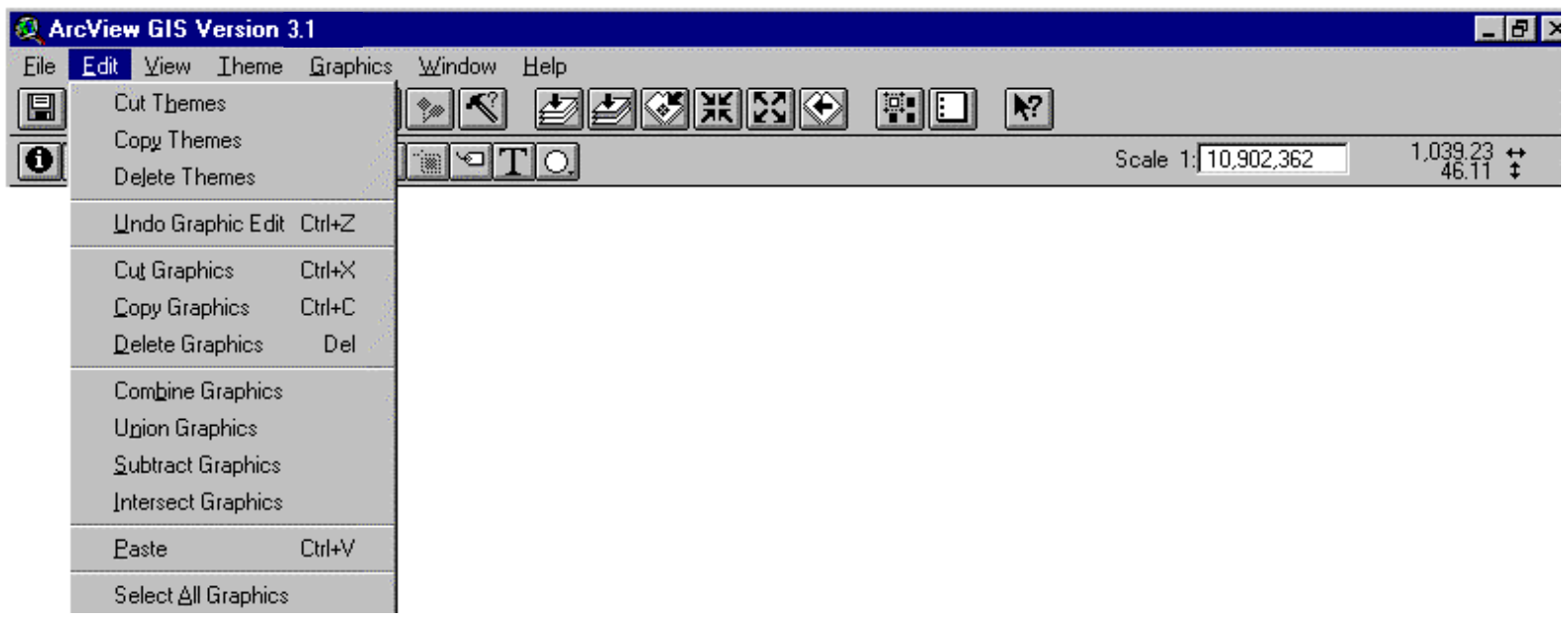

Figura 4.92 - Opção Edit do menu de vistas do ArcView

No ArcView as camadas de um mapa são denominadas Themes (temas). Pode-se cortar, copiar ou excluir temas existentes no mapa utilizando-se das opções CUT THEMES, Copy THEMES e Delete THEMES disponíveis no menu Edit, figura 4.92. Objetos gráficos são entidades inseridas no mapa (desenhos, textos), pelo usuário, através de ícones disponíveis na barra de ferramentas da janela de vistas do Arcview, figura 4.93. Os três últimos ícones apresentados na linha de ícones de desenho (draw line to...) são utilizados na edição de temas de linhas e áreas do mapa. São considerados também como objetos gráficos, as ferramentas denominadas "frame tools", que englobam: legenda, barra de escala, indicação de norte, etc., as quais estão disponíveis apenas na janela de leiautes, mostrada posteriormente.

A opção UNDO GRAPHIC EDIT desfaz o último comando de edição realizado em algum objeto gráfico do mapa e as opções CUT Graphics, Copy Graphics e DeleTE GRAPHICS realizam as funções: cortar, copiar e excluir objetos gráficos. A opção COMBINE GRAPHICS permite combinar objetos gráficos tornando-os um só. A opção UNION GRAPHICS une objetos gráficos de forma que suas linhas não mais se cruzem e sim formem um único objeto. A opção SUBTRACT GRAPHICS subtrai do primeiro objeto selecionado a porção do mesmo interceptada por outro objeto. A opção INTERSECT GRAPHICS apresenta a área de interseção comum a dois ou mais objetos. A opção PASTE cola algum objeto ou tema que tenha sido copiado ou recortado. A opção SELECT AlL GRAPHICS realiza a seleção de todos os objetos gráficos existentes no mapa. 


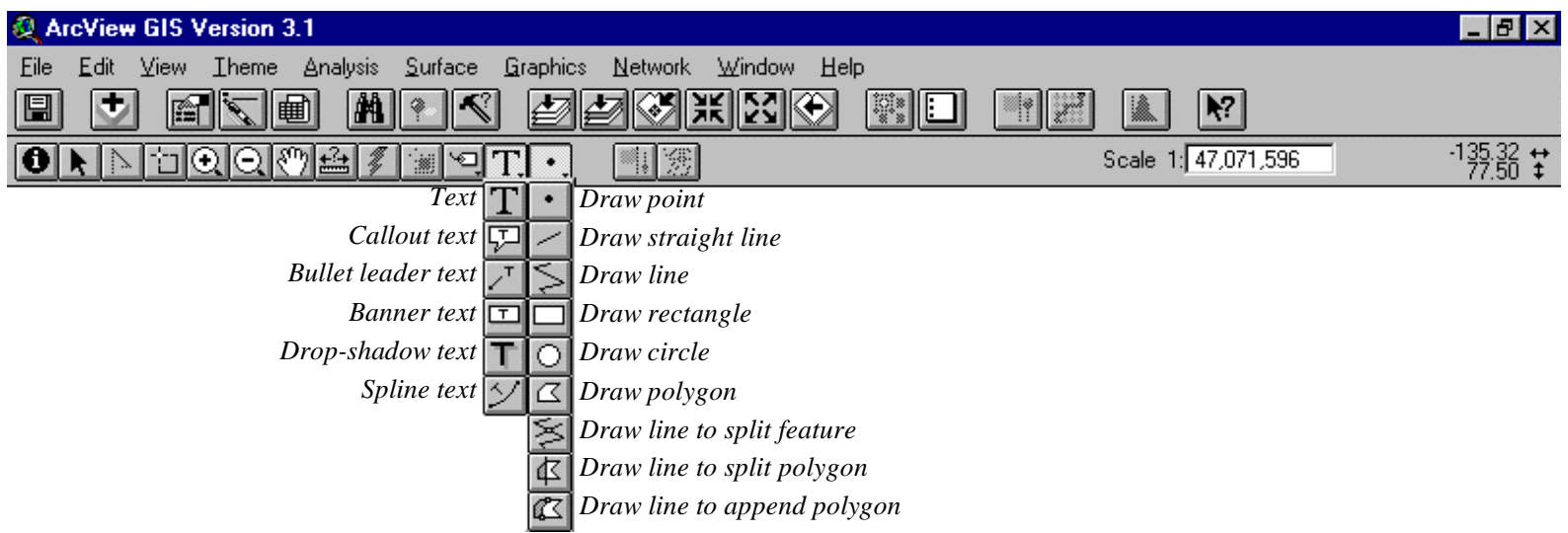

Figura 4.93 - Ícones utilizados para inserir textos e desenhos ao mapa

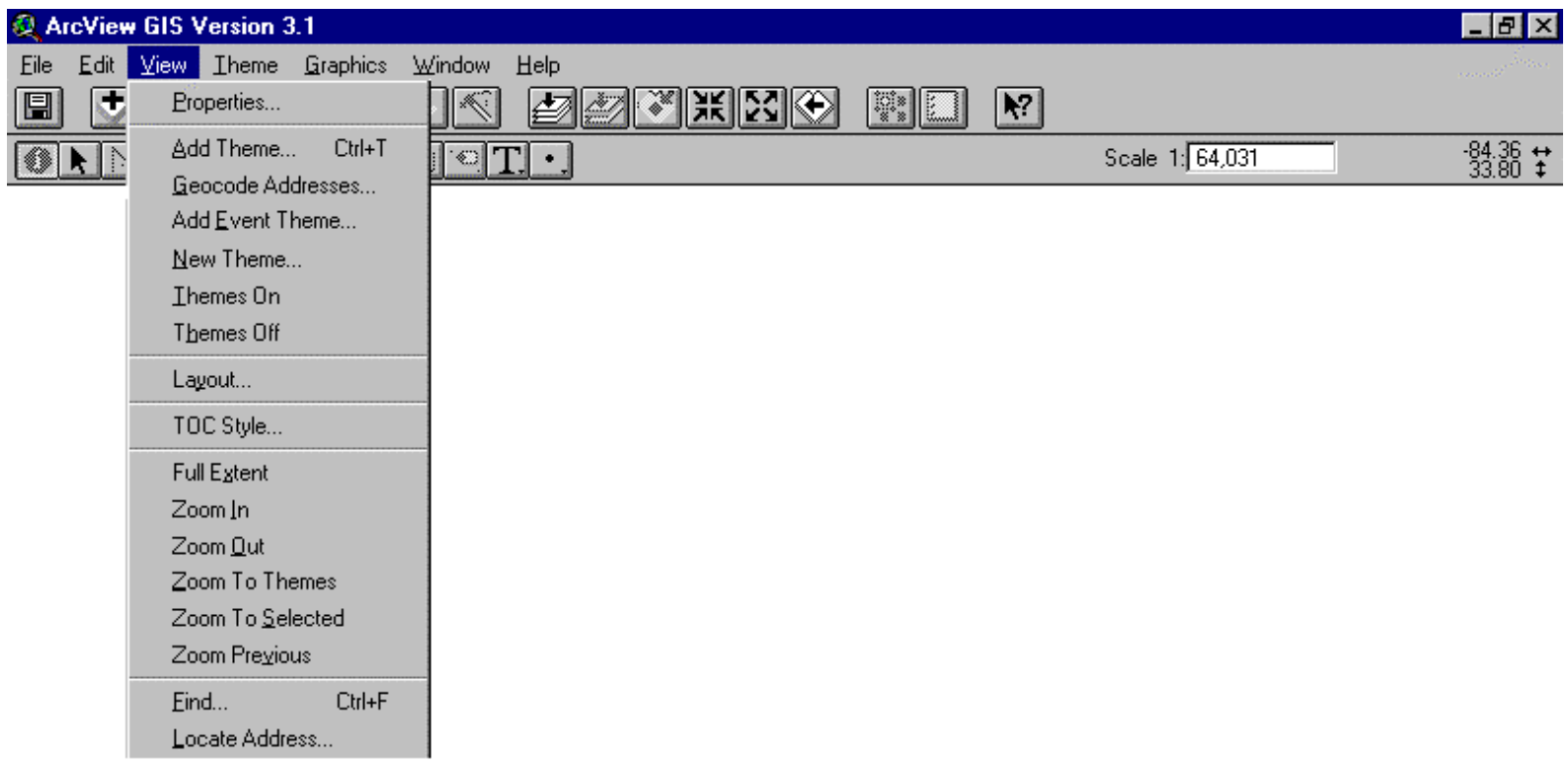

Figura 4.94 - Opção View do menu de vistas do ArcView

A opção PROPERTIES, disponível no menu View ilustrado na figura 4.94, apresenta as seguintes informações relativas à vista ativa: nome; data de criação; nome do criador; unidade do mapa (não conhecida, graus decimais, polegadas, pés, jardas, milhas, milímetros, centímetros ou metros); unidade de distância (não conhecida, polegadas, pés, jardas, milhas, milhas náuticas, milímetros ou centímetros); a projeção da vista, onde são definidas a categoria e o tipo da projeção; a área de interesse, onde o usuário define a dimensão da tela, em coordenadas, utilizada para visualizar temas da vista; a cor do plano de fundo; e uma caixa com comentários. Todas as opções descritas podem ser editadas ou alteradas pelo usuário. A opção ADD THEME permite adicionar um tema ao mapa, cada tema ou conjunto de temas podem ser provenientes de arquivos com extensão *.shp (shapefiles do ArcView); arquivos de imagens nos seguintes formatos: BSQ, BIL, BIP, ERDAS LAN, ERDAS IMAGINE, JPEG, BMP e TIFF; arquivos de desenhos gerados pelo AutoCAD até a versão 13 (*.dwg), Microstation até a versão 5.5 (*.dgn) e arquivos com extensão *.dxf; arquivos de texto (*.txt), dBase e no formato INFO (formato de banco de dados utilizado pelo software ArcInfo) e arquivos no formato MIF (MapInfo Interchange Format). 
Através da opção GEOCODE ADDRESSES pode-se identificar a localização de uma lista de pontos com base em alguma informação concernente ao seu endereço. Este processo é semelhante ao descrito na seqüência de comandos do TransCAD, denominado pin mapping. É uma operação computacional equivalente a fixar um mapa na parede e marcar os locais especificados com alfinetes. Na caixa de diálogos ativada por esta opção deve-se definir: o tema a ser usado como referência para combinar com os endereços procurados; o campo da tabela de atributos do tema de referência que será unido ao novo tema adicionado ao mapa, resultante do processo de geocodificação; o estilo do endereço a ser aplicado no tema de referência (os estilos disponíveis e suas definições serão descritas posteriormente); a tabela que contém os endereços a serem geocodificados; o campo desta tabela que contém os endereços, interseções entre ruas ou o nome dos lugares a serem encontrados; o campo da tabela que contém as informações referentes às zonas (só será necessário preencher este campo no caso de o estilo de endereço conter um campo de zona a ser utilizado na pesquisa); um campo adicional da tabela para conter informações adicionais referentes aos endereços encontrados que o usuário julgue importantes; uma distância de offset a partir do segmento da rua onde será posicionado o ponto relativo ao endereço encontrado; uma tabela (opcional) contendo nomes alternativos para endereços e interseções entre ruas ou endereços associados; um novo nome e localização de arquivo para o novo tema (o ArcView fornece um nome padrão para o novo tema contendo os resultados do processo de geocodificação).

Pode-se, acionando-se o ícone Geocoding Preferences, definir alguns itens relativos ao processo de geocodificação, tais como a sensibilidade da ortografia, o escore mínimo de coincidência de endereços, o escore mínimo para que o endereço seja considerado um candidato, rever candidatos quando mais de um candidato obtiver o maior escore, quando múltiplos candidatos apresentarem escores maiores que o mínimo especificado e quando nenhum candidato coincidir com o endereço procurado. O processo de geocodificação pode ser realizado de duas maneiras, a opção Batch Match realizará o comando automaticamente e ativará a opção Re-match Addresses, que possibilita que o usuário realize nova procura em todos os registros ou em apenas uma seleção, através do processo automático ou através de um processo interativo onde o usuário pode acompanhar a procura endereço por endereço. Este mesmo processo pode ser utilizado optando-se pelo ícone Interactive Match disponível na caixa de diálogos do comando Geocode Addresses em questão.

A opção ADD EvEnT THEME permite adicionar um novo tema ao mapa utilizando uma tabela de eventos do projeto como fonte de dados. Pode-se adicionar dois tipos de eventos: $X Y$, sendo que cada registro da tabela representa um ponto associado a uma coordenada XY; e Routes, onde cada registro representa um ponto ou uma linha localizada em uma posição sobre um sistema de rotas. Através da opção NEW THEME pode-se adicionar um tema de pontos, linhas ou polígonos ao mapa, sendo necessário definir o arquivo (*.shp) que contém os dados a serem importados para o novo tema. As opções THEMES ON e THEMES OfF tornam todos os temas do mapa visíveis e não-visíveis, respectivamente.

A opção LAYOUT permite criar um leiaute, para impressão, da porção visível do mapa. Através da opção TOC STYLE (Table of Contents Style) pode-se definir o estilo de linhas, símbolos e fontes da tabela de conteúdos do mapa. Esta tabela apresenta todos os temas presentes no mapa. As opções Full Extent, Zoom In, Zoom Out, Zoom to Themes, ZOOM TO SELECTED e ZOOM PREVIOUS são utilizadas para alterar a janela de visualização do mapa. A opção FIND localiza um determinado campo dentro dos temas selecionados no mapa 
e ajusta a vista posicionando o campo encontrado no centro dela e visualizando-o por inteiro. A opção LOCATE ADDRESS realiza a procura por um endereço específico dentro do tema ativo e indica sua posição na vista com um ponto.

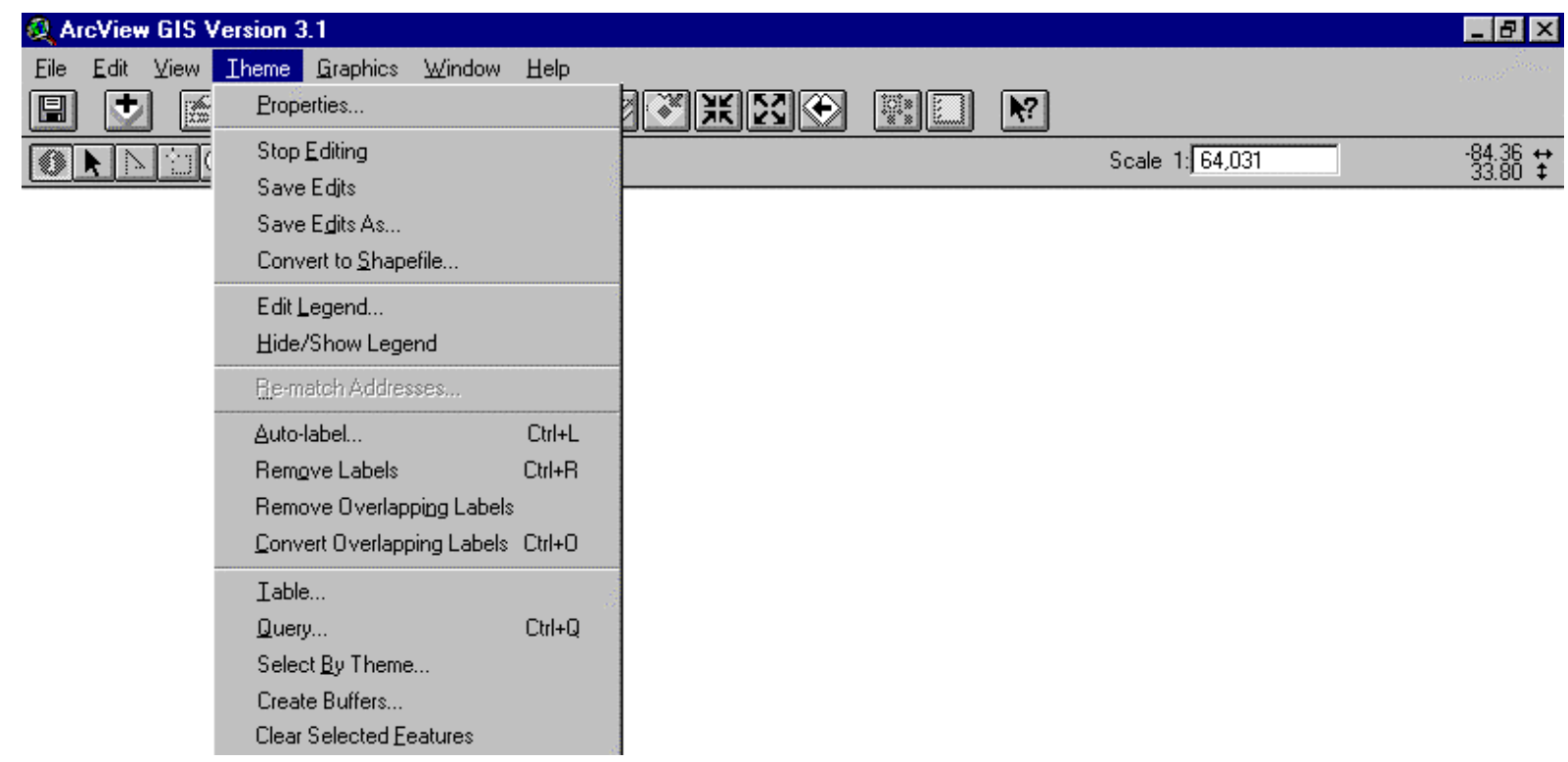

Figura 4.95 - Opção Theme do menu de vistas do ArcView

A opção PROPERTIES do menu Theme, figura 4.95, ativa uma caixa de diálogos onde podem ser verificadas e alteradas as propriedades do tema ativo com relação a:

- Definição (definition): pode-se visualizar o nome e localização do arquivo do tema e o tipo do tema (pontos, linhas ou polígonos), filtrar os dados definindo-se uma condição de consulta e resultando numa seleção de dados, e inserir um comentário;

- Rótulos (text labels): pode-se verificar o campo da tabela de dados do tema a ser utilizado na rotulação dos elementos e a posição do texto relativa ao ponto de rotulação;

- Geocodificação (geocoding): nesta opção pode-se definir o estilo do endereço, os componentes utilizados na geocodificação e uma tabela de nomes alternativos para os endereços (opcional);

- Edição (editing): pode ser definido o modo de atualização dos dados quando são utilizadas as ferramentas de edição para dividir linhas ou polígonos e de união de campos, e pode-se definir tolerâncias para a função de "snapping", sendo ele geral e/ou interativo;

- Visualização (display): pode-se especificar as escala mínimas e máximas de visualização;

- Hot link: pode-se definir hot links para acessar qualquer dado ou aplicação diretamente da vista, para isso deve-se especificar o campo que contém o nome do arquivo a ser ativado e a ação que será realizada, por exemplo abrir um documento de texto ou uma imagem, ou ainda executar uma macro;

- Opção de bloqueio ou proteção (locked): pode-se definir uma senha de acesso às propriedades do tema. 
A opção START EDITING é utilizada para se especificar o início da edição de um tema. Após o seu acionamento ela será substituída pela opção STOP EDITING de acordo com a figura 4.95, que quando selecionada finaliza a ação de edição do tema, apresentando ao usuário a alternativa de salvar ou não as edições realizadas, o que pode ser feito, também, através das opções SAVE EDITS e SAVE EDITS As. A opção CONVERT TO SHAPEFILE converte o tema ativo para um shapefile do ArcView, arquivo com extensão *.shp.

A opção Edit LEgEnd ativa uma caixa de diálogos possibilitando a edição da legenda do tema. Pode ser definido o tipo da legenda como um único símbolo, definindo-se as características deste símbolo e um rótulo; graduação de cores, onde é definido o campo a ser utilizado para a classificação, o tipo da classificação (áreas iguais, intervalos iguais, quebras naturais, quantitativo ou desvio padrão), o número de classes e a precisão dos valores, o campo a ser utilizado para normalizar os valores e as cores a serem utilizadas; único valor, onde define-se o campo que contém os valores a serem utilizados. São utilizados pontos para representar os dados do campo selecionado como campo de densidade, pode ser especificado também um campo de dados para normalizar os demais e definida ou calculada automaticamente a legenda de pontos (valor numérico que cada ponto representa). Na opção de gráfico pode-se definir os campos a serem representados graficamente por círculos ou barras. Ainda na caixa de diálogos de edição da legenda do tema pode-se, selecionando o ícone Statistics, obter as seguintes informações estatísticas de cada campo da tabela: valores mínimo e máximo, número total de valores, somatório, média e desvio padrão dos valores. As legendas dos temas podem ser salvas em arquivos com extensão *avl e posteriormente serem carregadas e utilizadas para outros temas e projetos. A opção HidE/SHOW LEGEND mostra ou esconde a legenda dos temas do mapa.

A opção RE-MATCH ADDRESSES, que só apresenta-se ativa quando foi efetuada uma operação de procura de endereços, é utilizada para realizar uma nova procura com as mesmas especificações da primeira. A opção AUTO-LABEL realiza a rotulação de todos os elementos do tema ativo no mapa. Neste item devem ser definidos: o campo da tabela que contém a definição dos rótulos, as opções de $\checkmark$ utilizar a propriedade de posicionamento de rótulos do tema ou $\checkmark$ encontrar a melhor posição para o rótulo (neste item estão disponíveis as opções de permitir que os rótulos se sobreponham, remover rótulos duplicados e posicionar o rótulo acima, abaixo ou em cima da linha), $\checkmark$ adaptar o tamanho dos rótulos à vista e $\checkmark$ rotular apenas os campos visíveis na janela do mapa. A opção REMOVE LABELS remove os rótulos do tema ativo e a opção REMOVE OVERLAPPING LABELS remove apenas os rótulos que estejam se sobrepondo. Através da opção CONVERT OVERLAPPING LABELS pode-se converter todos os rótulos que se sobrepõem para rótulos não sobrepostos, pois os rótulos que sobrepõem os demais aparecem na tela em cor diferenciada.

Através da opção TABLE pode-se abrir a tabela de dados do tema selecionado. A opção QUERY permite selecionar campos baseado numa consulta aos dados especificando-se uma fórmula. Para isso o ArcView fornece uma lista de todos os campos do tema ativo e seus valores, operadores matemáticos $(=,\langle\rangle,,\langle>,\langle=\rangle=,,())$ e operadores lógicos (e, ou, não). A opção SELECT BY THEME possibilita a seleção de campos do tema ativo que contém completamente, interceptam ou estão a uma determinada distância dos temas selecionados de outro campo. Nas opções utilizadas para seleção dos dados, QUERY e SELECT BY THEME, pode-se criar uma nova seleção, adicionar à uma seleção existente ou gerar uma seleção dentro de uma outra seleção. A opção CREATE BUFFERS permite gerar áreas de buffer em 
torno dos gráficos apresentados na vista ou nos campos de um determinado tema com a opção de se utilizar apenas os elementos selecionados. Pode-se criar áreas de abrangência a um valor de distância específico, a uma distância a partir de um campo de atributos ou como anéis múltiplos, sendo definidos o número de anéis e a distância entre eles. Deve-se especificar a unidade de distância: milhas, graus decimais, milhas náuticas, quilômetros, metros ou pés. Na criação de buffers também estão disponíveis as opções de dissolver ou não as barreiras entre buffers, criar buffers (dentro e fora, apenas fora ou apenas dentro dos polígonos) e salvar as áreas criadas (como gráficos na vista, dentro de uma tema existente ou em um novo tema). A opção Clear SElECted FeATURES exclui as seleções de campos do mapa.

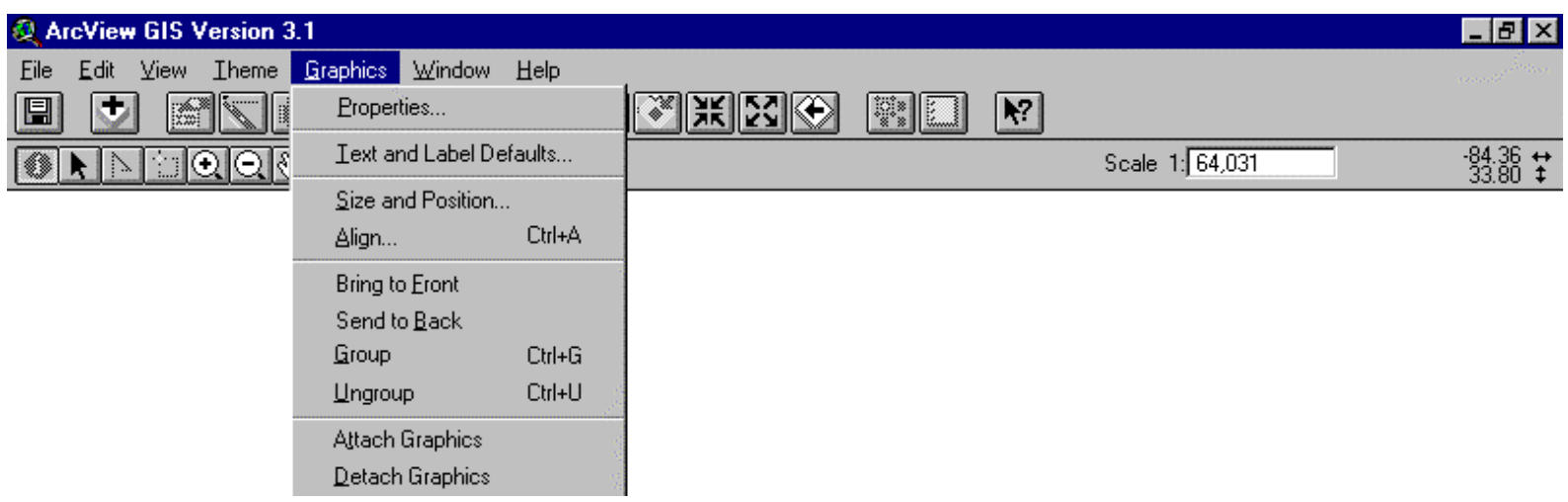

Figura 4.96 - Opção Graphics do menu de vistas do ArcView

Através da opção PROPERTIES do menu Graphics, figura 4.96, pode-se configurar as seguintes propriedades dos objetos gráficos adicionados ao mapa: cor e padrão de preenchimento; tipo e espessura de linhas; tipo, tamanho e inclinação de símbolos; tipo, tamanho e estilo da fonte. A opção TEXT AND LABEL DEFAULTS permite configurar o padrão a ser utilizado para representação dos rótulos dos campos do tema e as propriedades dos textos inseridos através da ferramenta de texto e dos textos apresentados na rotulação dos dados. A opção SIZE AND POSITION permite o ajuste do tamanho e da posição do objeto gráfico selecionado através da determinação dos valores de altura e largura e das coordenadas $\mathrm{X}$ e $\mathrm{Y}$. Através da opção ALIGN pode-se especificar o alinhamento vertical e horizontal dos objetos selecionados. As opções BRING TO FRONT e SEND TO BACK são utilizadas para definir a ordem de redesenho dos objetos ou a posição dos mesmos em relação a outros objetos, isto é trazer os objetos selecionados para frente ou para trás dos demais. A opção GroUP permite agrupar os objetos selecionados e a opção UNGROUP desagrupá-los. As opções ATTACH GRAPHICS e DETACH GRAPHICS realizam as seguintes operações respectivamente: adiciona os objetos gráficos selecionados ao tema selecionado e os exclui do tema.

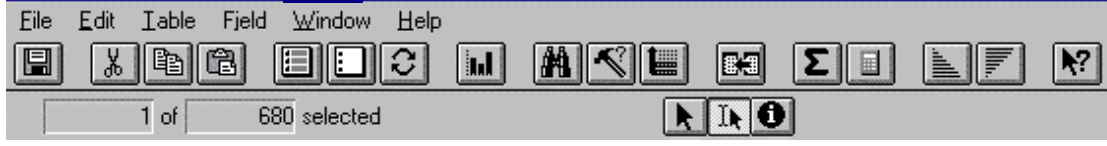

Figura 4.97 - Menu de tabelas do ArcView 
Selecionando-se a opção de tabelas (tables), figura 4.86, pode-se visualizar todas as tabelas existentes no projeto. O usuário poderá selecionar o documento desejado e visualizá-lo numa janela, a qual apresentará o menu de tabelas mostrado na figura 4.97.

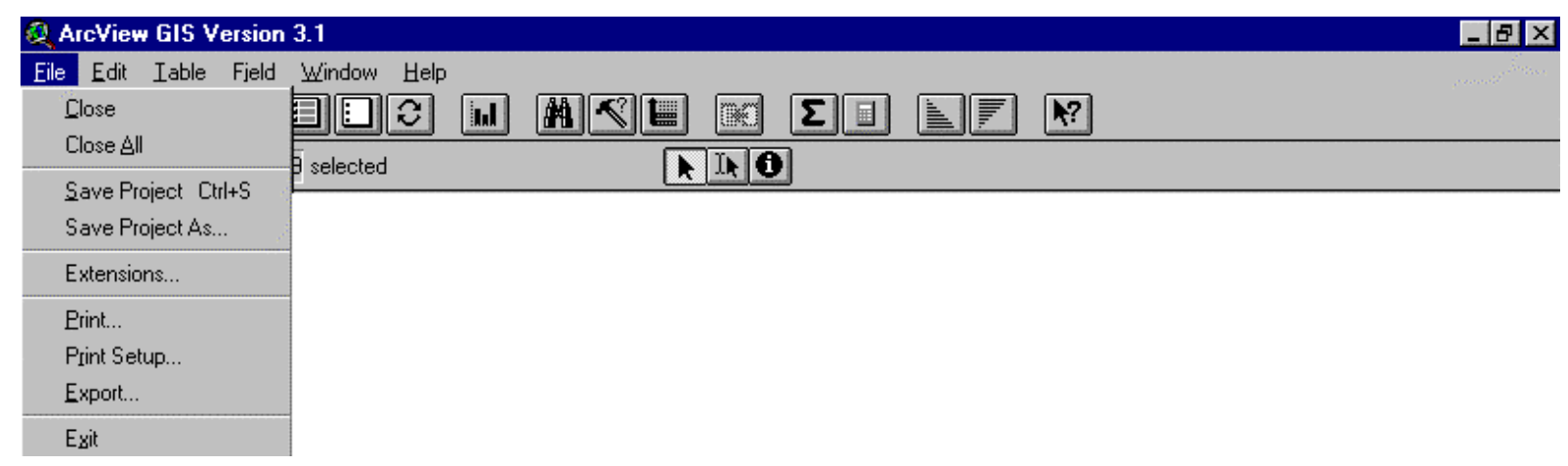

Figura 4.98 - Opção File do menu de tabelas do ArcView

As opções apresentadas na figura 4.98 não apresentam nenhuma novidade funcional em relação ao que já foi mencionado em outros parágrafos, a única diferença é que os comandos se referem aos arquivos de tabelas.

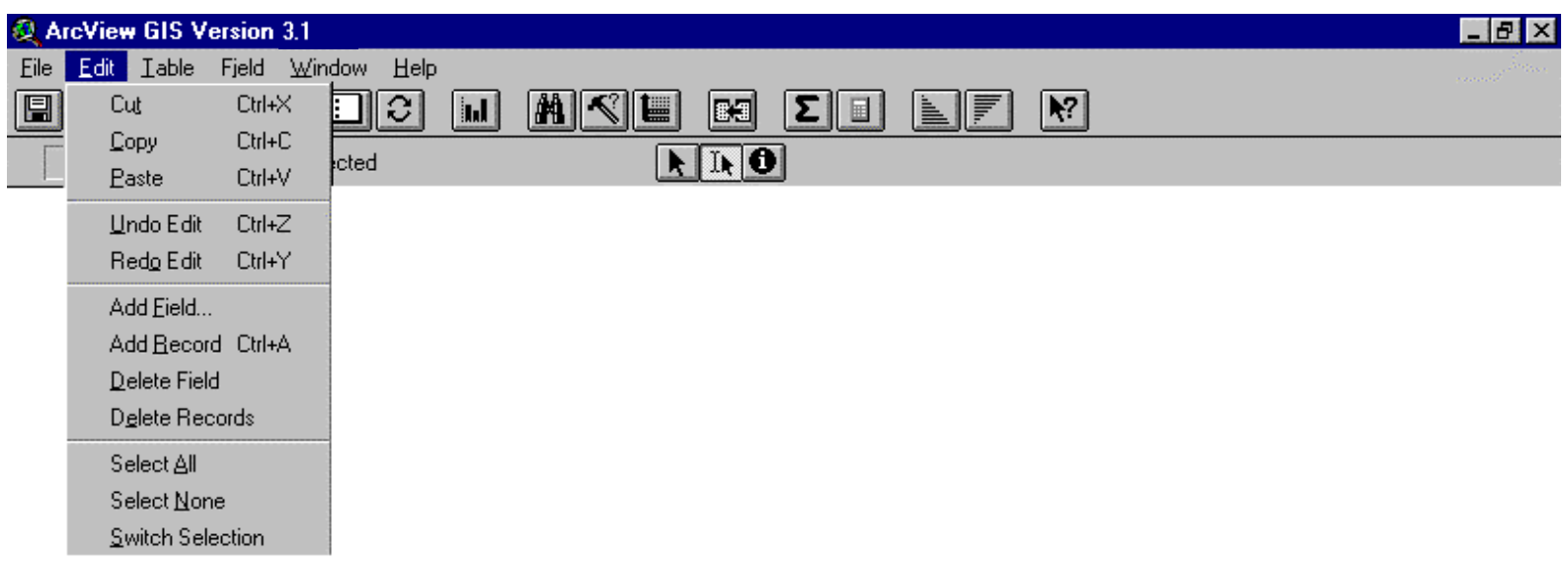

Figura 4.99 - Opção Edit do menu de tabelas do ArcView

As opções Cut (cortar), COPY (copiar) e PASTE (colar), figura 4.99, são utilizadas para cortar e copiar valores ou textos das células de uma tabela e colá-los em outra célula especificada. A opção UNDO EDIT desfaz o último comando de edição realizado e a opção REDO EDIT refaz o comando de edição desfeito. Através da opção ADD FIELD pode-se adicionar um novo campo à tabela, definindo-se os seguintes itens: o nome do novo campo, o tipo (numérico, de caracteres, de critérios lógicos de busca ou data), o tamanho e o número de casa decimais. A opção ADD RECORD adiciona um registro à tabela, sendo que cada registro possui um conjunto de valores, um para cada campo existente. As opções DELETE FIELD e DELETE RECORDS excluem o campo selecionado e o conjunto de registros selecionados, respectivamente. As opções Select All, Select None e Switch Selection realizam as seguintes operações: selecionar todos os registros, limpar todas as seleções existentes e trocar a seleção ativa por outra não ativa. 


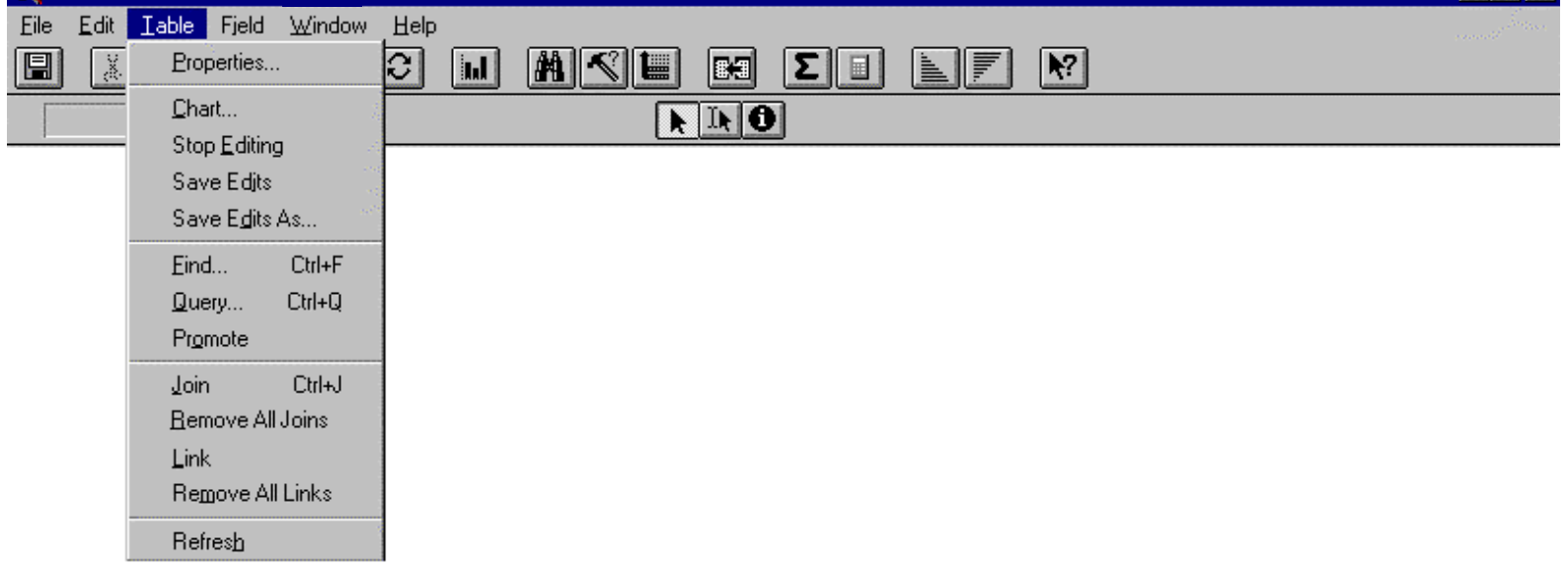

Figura 4.100 - Opção Table do menu de tabelas do ArcView

Através da opção PROPERTIES do menu Table, figura 4.100, pode-se verificar as seguintes características da tabela: título, nome do criador, data de criação, comentários, os campos existentes na tabela, se estes se apresentam visíveis e se possuem mais alguma denominação. A opção CHART permite construir um gráfico de representação dos dados, sendo necessária a definição dos itens: o nome do gráfico, os campos a serem utilizados e o campo a ser utilizado como rótulo das séries do gráfico (legenda do gráfico). A opção START EDITING, substituída pela opção STOP EDITING quando selecionada, ativa o modo de edição da tabela. As opções SAVE EDITS e SAVE EDITS As salvam as alterações efetuadas na tabela.

Através da opção FIND pode-se encontrar um determinado valor de registro na tabela. A opção QUERY permite selecionar registros especificando-se uma fórmula para efetuar-se a consulta aos dados a partir de: uma lista de todos os campos da tabela e seus valores, operadores matemáticos $(=,\langle\rangle,,\langle>,<=\rangle=,,())$ e operadores lógicos (e, ou, não). A consulta pode ser mostrada como uma nova seleção, adicionada à uma seleção existente ou gerada a partir de uma seleção já existente. A opção PROMOTE posiciona os registos selecionados no topo (início) da tabela. Através da opção JoIN pode-se unir duas tabelas com base nos valores de um campo comum encontrado em ambas. A opção REMOVE ALL JOINS remove todas as uniões de tabelas realizadas, isto é, exclui da tabela os campos, pertencentes à outra tabela, adicionados a ela. Através da opção LINK pode-se vincular uma tabela à outra especificando-se um campo em comum. A opção REMOVE ALL LiNKS remove todos os links definidos. O comando REFRESH é utilizado para redesenhar a tabela, atualizando-a.

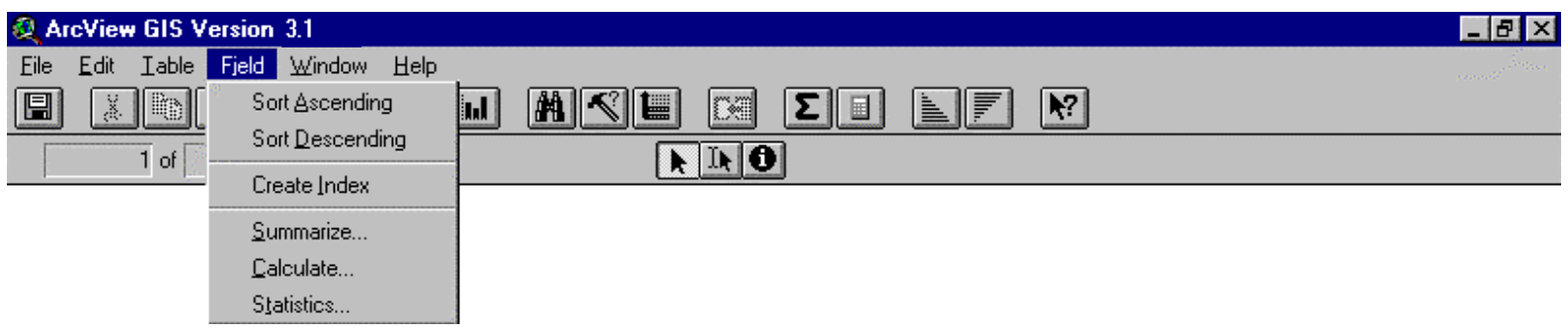

Figura 4.101 - Opção Field do menu de tabelas do ArcView 
As opções Sort Ascending e Sort Descending, do menu Field ilustradas na figura 4.101, colocam os dados em ordem ascendente e descendente, respectivamente, com base nos valores ou textos do campo selecionado. A opção CREATE INDEX cria um índice no campo da tabela selecionado. Através da opção SUMMARIZE pode-se obter um resumo de uma seleção de registros da tabela. Para realizar esta operação deve-se definir o nome para a nova tabela que será gerada e os campos a serem utilizados; de acordo com o tipo de dados do campo, as opções de resumo para dados numéricos são: utilizar a média ou somatório dos valores, valor máximo ou mínimo, desvio padrão, variância, primeiro ou último valor ou a contagem de valores; e para dados alfanuméricos: utilizar o primeiro ou o último registro. A opção CALCulate permite realizar cálculos entre os dados dos campos da tabela. A opção STATISTICS apresenta as seguintes informações estatísticas do campo numérico selecionado: somatório, contagem dos valores, média, valor máximo e mínimo, intervalo, variância e desvio padrão.

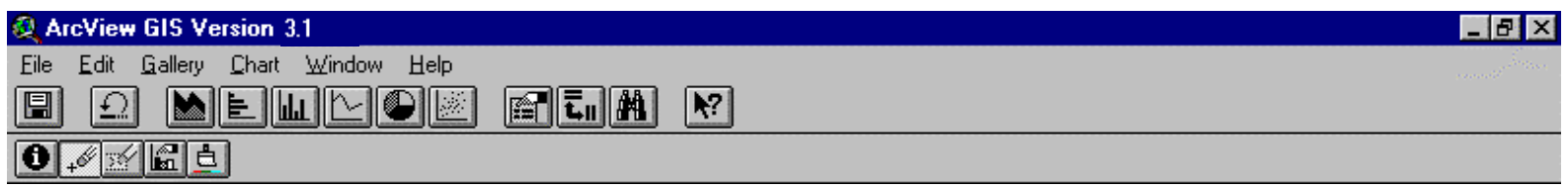

Figura 4.102 - Menu de gráficos do ArcView

Selecionando-se a opção de gráficos (charts), figura 4.86, pode-se visualizar todos os gráficos existentes no projeto. O usuário poderá selecionar o documento desejado e visualizálo numa janela, a qual apresentará o menu de gráficos mostrado na figura 4.102.

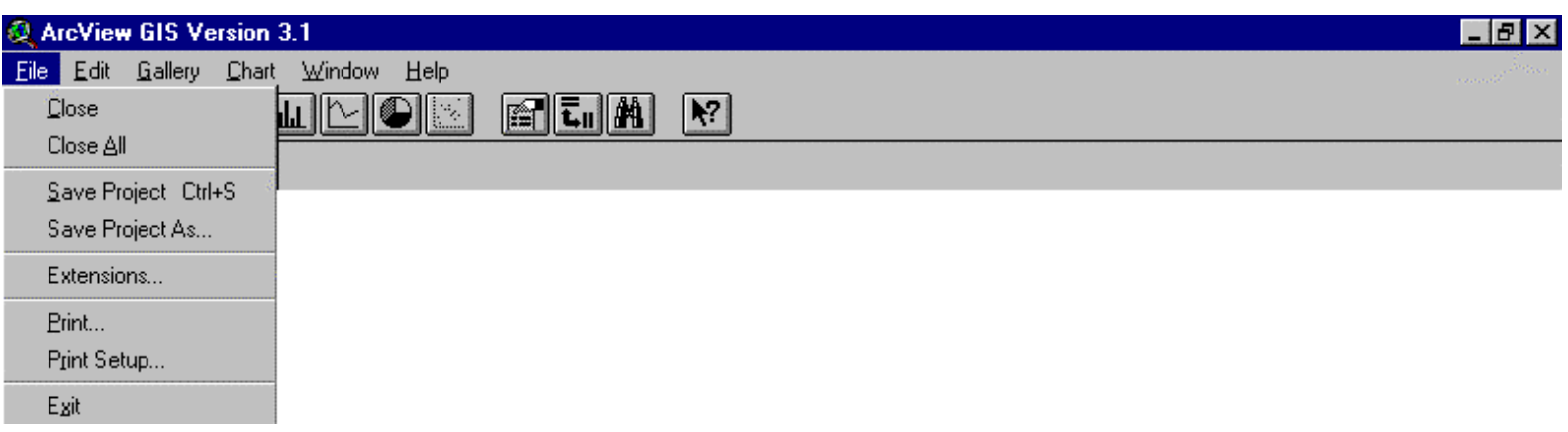

Figura 4.103 - Opção File do menu de gráficos do ArcView

A figura 4.103 apresenta as opções do menu File, as quais já foram comentadas.

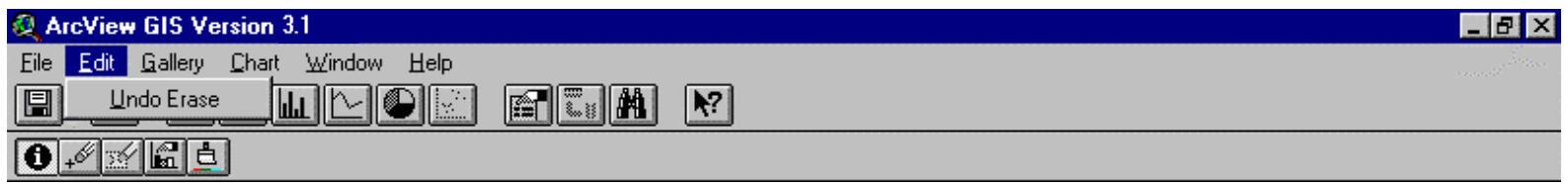

Figura 4.104 - Opção Edit do menu de gráficos do ArcView

A única opção disponível no menu Edit da figura 4.104, UNDO ERASE, desfaz o último comando de exclusão de algum elemento do gráfico. As demais ferramentas de edição estão disponíveis na forma de ícones e serão identificadas posteriormente. 


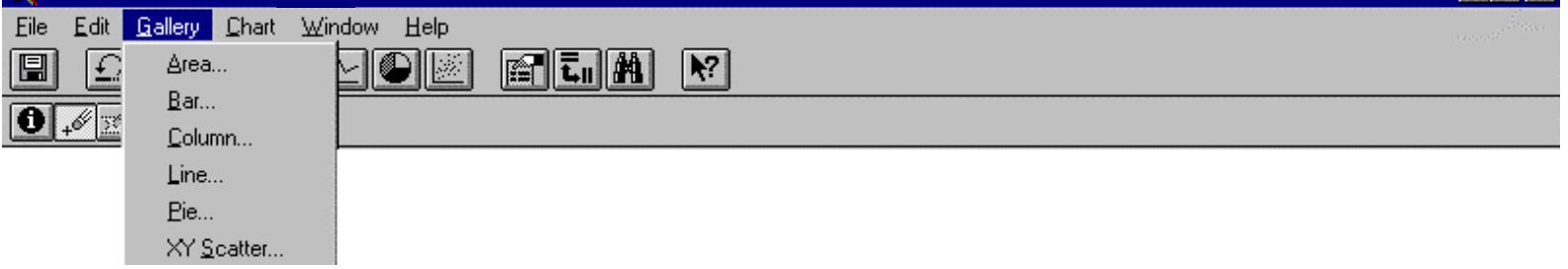

Figura 4.105 - Opção Gallery do menu de gráficos do ArcView

As opções disponíveis no menu Gallery, figura 4.105, são utilizadas para formatar o gráfico ativo como um gráfico de áreas, barras, colunas, linhas, "pizza" ou dispersão XY.

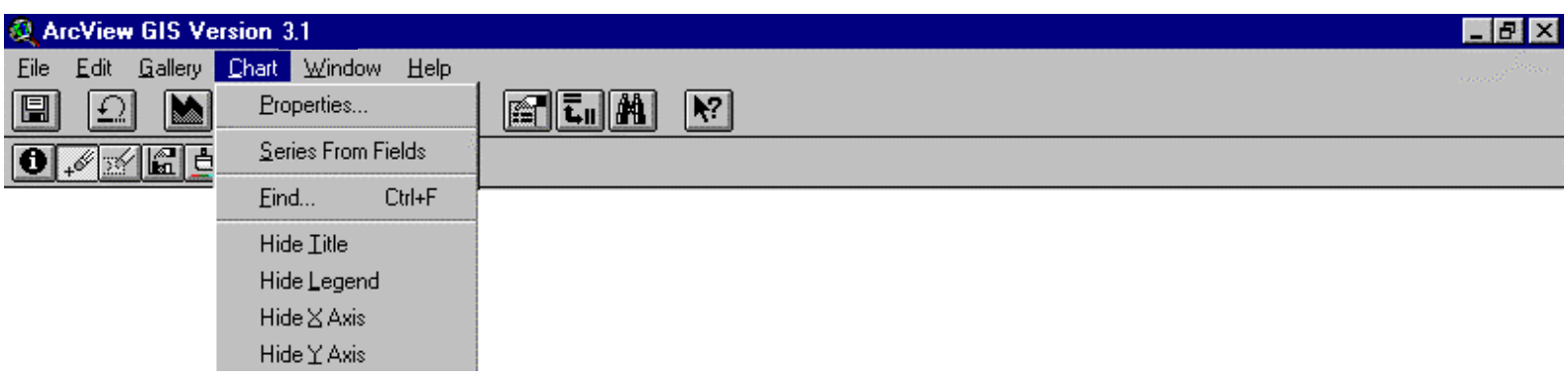

Figura 4.106 - Opção Chart do menu de gráficos do ArcView

A opção PROPERTIES do menu Chart, figura 4.106, permite visualizar e alterar as seguintes propriedades do gráfico ativo: nome do gráfico, a tabela cujos dados estão sendo representados, os campos numéricos da tabela que podem ser adicionados ou excluídos da lista de grupos que são efetivamente representados no gráfico. Pode-se ainda definir um campo a ser utilizado como rótulo dos dados e pode-se adicionar comentários relativos ao gráfico em questão. A opção SERIES FROM FIELDS altera a representação dos dados de séries para registros e vice-versa. Através da opção FIND pode-se, em um gráfico, localizar o campo que possui o valor procurado. As opções Hide Title, Hide Legend, Hide X AXIS e Hide Y AXIS são utilizadas para ocultar do gráfico, o título, a legenda e os eixos de valores $\mathrm{X}$ e $\mathrm{Y}$. Após a utilização de alguma dessas opções a palavra HidE é substituída por SHOw e, conseqüentemente, passará a executar a função contrária, mostrando os respectivos itens.

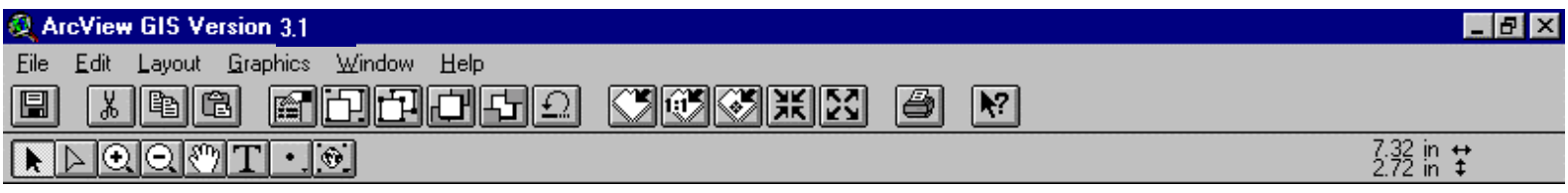

Figura 4.107 - Menu de leiautes do ArcView

Selecionando-se a opção de leiautes (layouts), figura 4.86, pode-se visualizar todos os leiautes existentes no projeto. $\mathrm{O}$ usuário poderá selecionar o documento desejado e visualizá-lo numa janela, a qual apresentará o menu de leiautes mostrado na figura 4.107. 


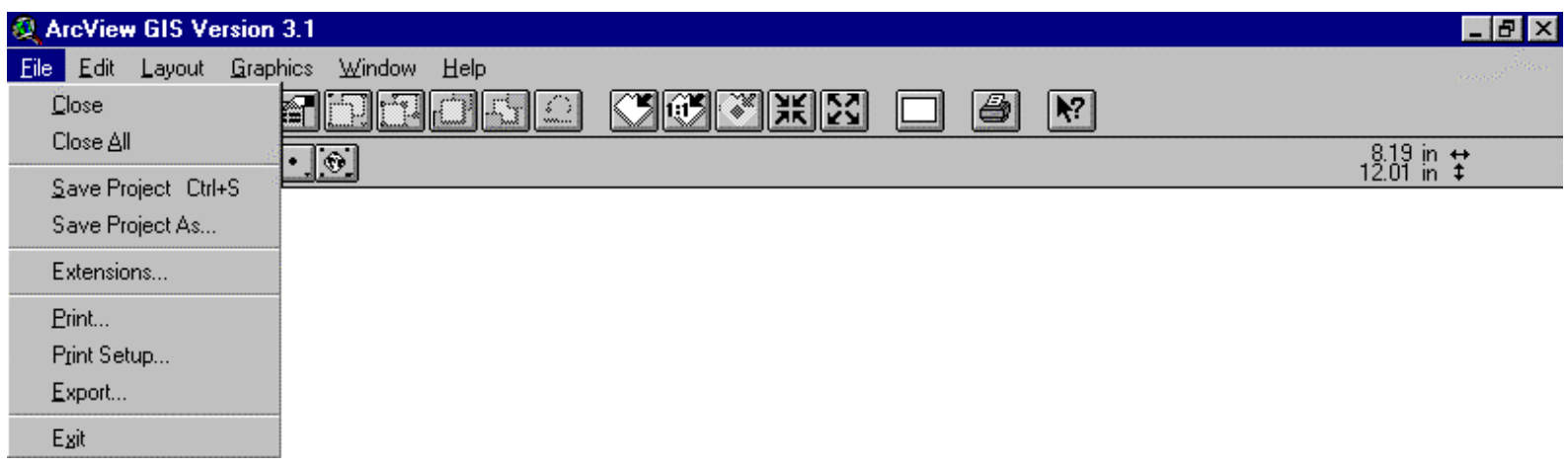

Figura 4.108 - Opção File do menu de leiautes do ArcView

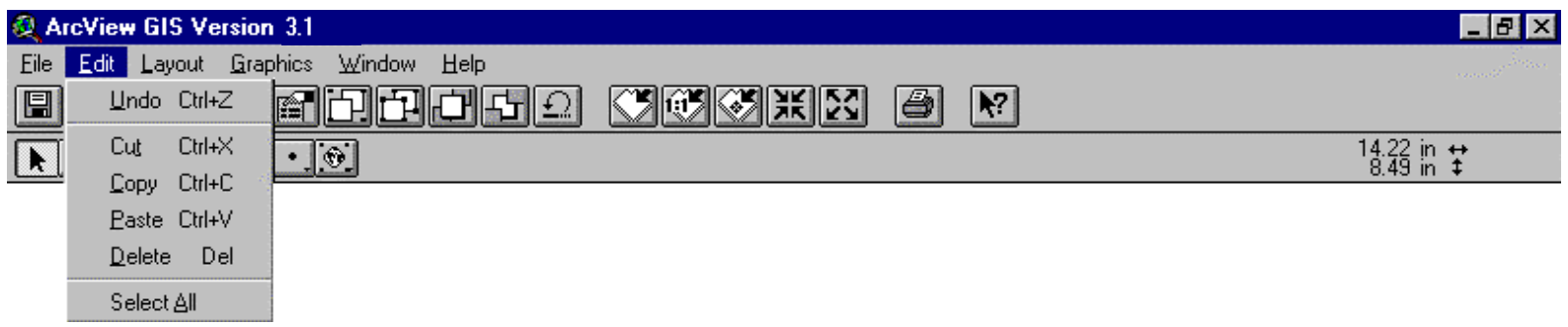

Figura 4.109 - Opção Edit do menu de leiautes do ArcView

A opção UNDO do menu Edit, figura 4.109, desfaz o último comando de edição realizado no leiaute. As opções CUT, COPY, PASTE e DELETE são utilizadas para cortar, copiar, colar ou excluir um objeto do leiaute. A opção SELECT All realiza a seleção de todos os objetos do leiaute.

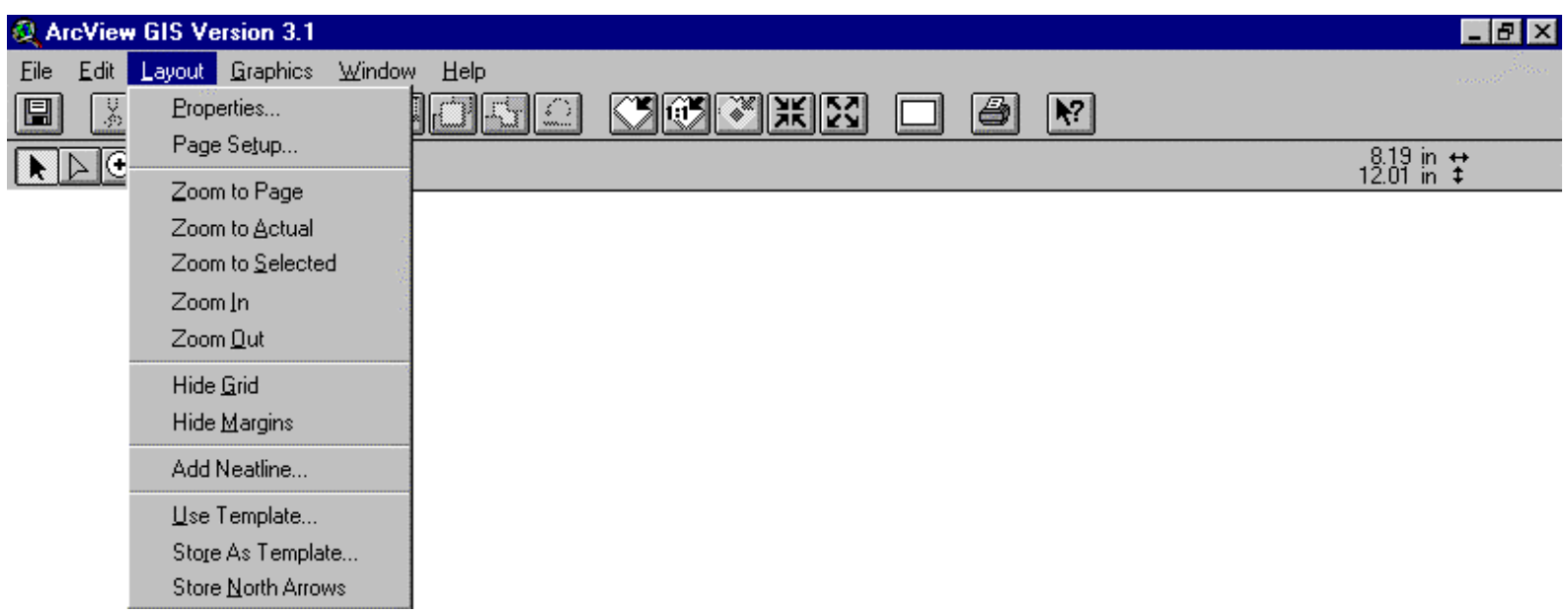

Figura 4.110 - Opção Layout do menu de leiautes do ArcView

Através da opção PROPERTIES, disponível no menu Layout da figura 4.110, pode-se visualizar e editar as seguintes propriedades do leiaute ativo: nome, espaçamento horizontal e vertical da grade (numérico em polegadas) e optar por "ajustar" os objetos à grade. Na opção PAGE SETUP pode-se definir o tamanho da página da lista de formatos disponíveis ou especificando-se uma largura e altura e a unidade a ser utilizada, a orientação do papel (retrato 
ou paisagem), as margens (acima, abaixo, esquerda e direita) e a resolução a ser utilizada na impressão (baixa, normal ou alta). As opções de ZoOM... são utilizadas para alterar a área de visualização da tela. As opções HidE GRID e HidE MARGINS escondem a grade e as margens visíveis no leiaute e serão substituídas por SHOW... após sua utilização. A opção ADD NEATLINE permite adicionar uma linha (borda) em torno dos objetos gráficos selecionados ou em torno de todos os objetos, ou ainda próxima à margem da folha. Os demais itens que podem ser definidos nesta opção são: $\checkmark$ agrupar a linha com os gráficos, especificar a distância da mesma a partir de cada lado dos objetos, especificar o estilo, espessura, cor e sombreamento da linha e a $\checkmark$ utilização de bordas arredondadas.

Através da opção UsE TEMPLATE pode-se utilizar o gerenciador de padrões para se especificar a posição da folha. Pode-se, utilizando-se a opção StORE As TEMPLATE, armazenar as configurações de página do leiaute ativo como um "padrão", o qual pode ser utilizado na configuração de outros leiautes. Através da opção STORE NORTH ARROWS podese adicionar o elemento selecionado ao banco de símbolos que podem ser utilizados como indicação de norte.

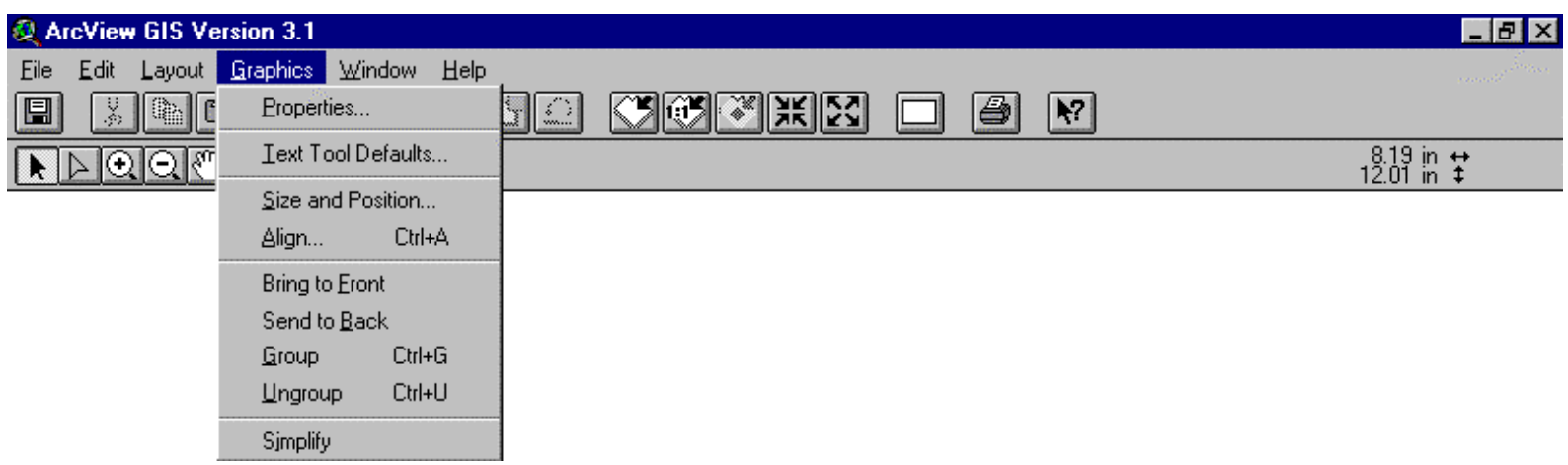

Figura 4.111 - Opção Graphics do menu de leiautes do ArcView

Através da opção PROPERTIES, disponível no menu Graphics da figura 4.111, podese visualizar e editar as propriedades de cada objeto selecionado do leiaute. Os objetos gráficos que podem ser adicionados a um leiaute englobam desenhos, textos, legendas, barra de escala, indicação de norte, gráficos, tabelas, figuras e vistas e poderão ser inseridos através de ícones. Os ícones para a adição de desenhos e textos são ilustrados na figura 4.93 os demais, denominados "frame tools", são demonstrados na figura 4.112.

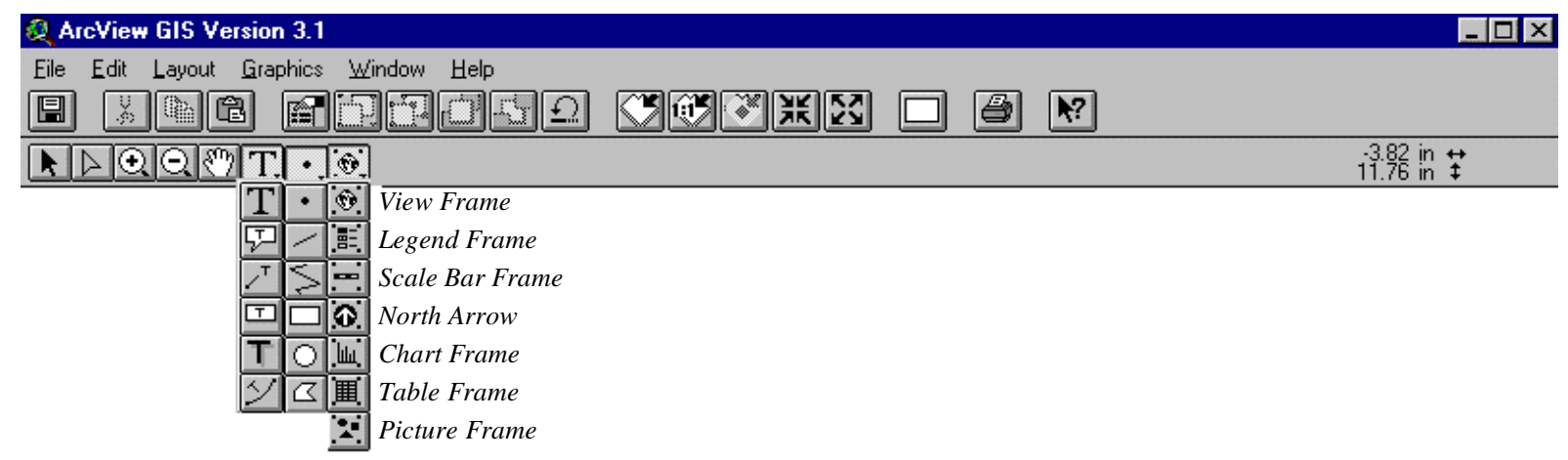

Figura 4.112 - Ícones utilizados para inserir objetos à vista 
As opções Text Tools Defaults, Size And Position, Align, Bring To Front, SEND To BACK, GROUP e UnGROUP são idênticas às opções intituladas com o mesmo nome do menu Graphics na barra de comandos da janela de vistas. A opção SIMPLIFY converte um elemento do leiaute, por exemplo a barra de escala ou a indicação de norte, em elementos gráficos simples, permitindo que cada "pedaço" da figura possa ser reposicionado e editado. Dependendo do tipo da figura, se ela possuir muitos elementos, este procedimento pode se tornar extremamente lento e exigir um hardware mais eficiente.

Como no TransCAD, muitos dos comandos do ArcView descritos acima podem ser executados através de ícones, os quais variam de acordo com o tipo de tela em que se está trabalhando. Estes ícones serão ilustrados a seguir, figuras 4.113 a 4.124, acompanhados da indicação da função a que são destinados.

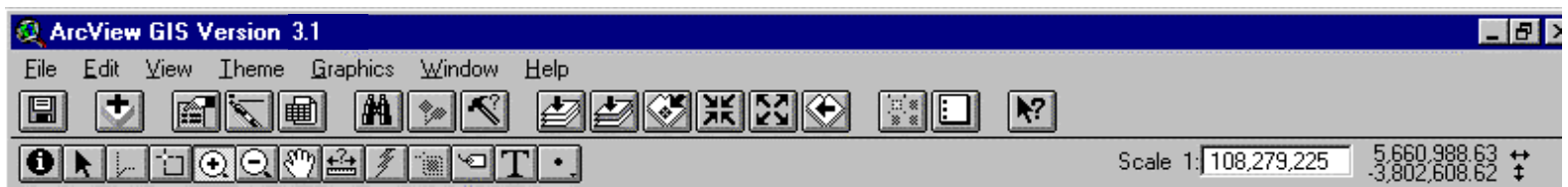

Figura 4.113 - Ícones disponíveis na barra de menu da janela de vistas do ArcView

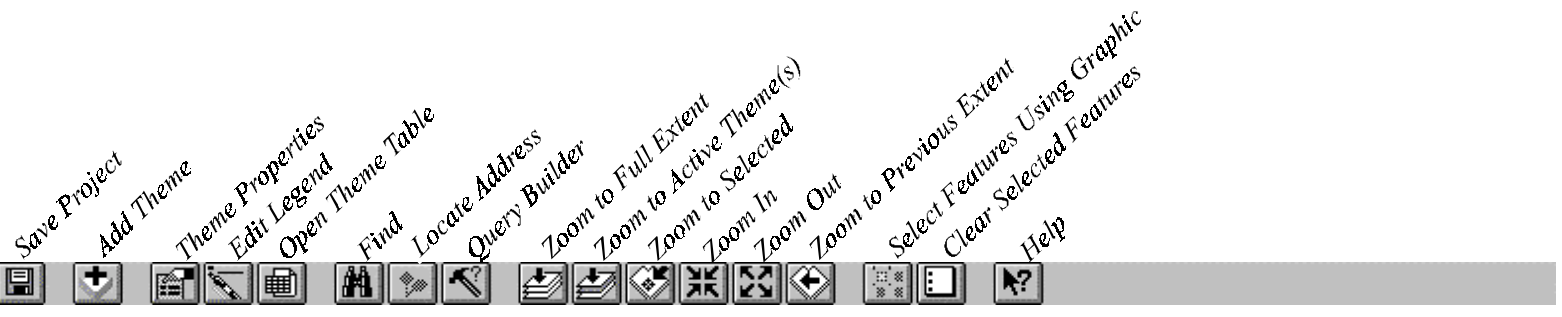

Figura 4.114 - Primeira linha de ícones disponíveis na barra de menu da janela de vistas do ArcView
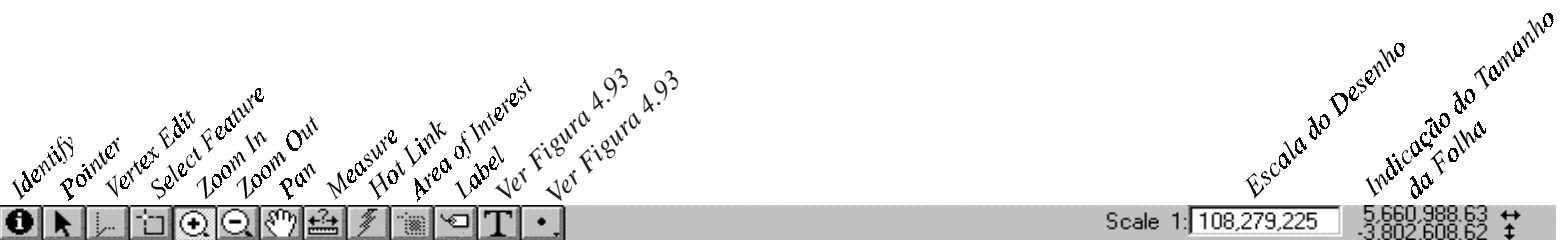

Figura 4.115 - Segunda linha de ícones disponíveis na barra de menu da janela de vistas do ArcView

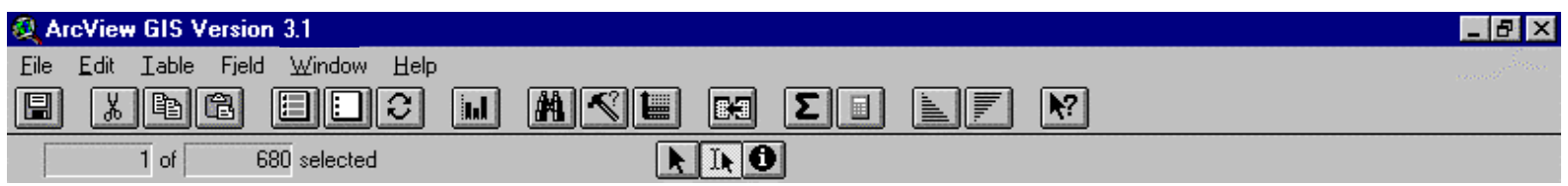

Figura 4.116 - Ícones disponíveis na barra de menu da janela de tabelas do ArcView 


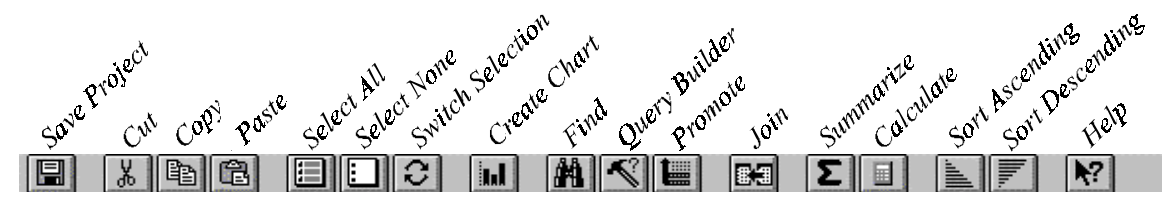

Figura 4.117 - Primeira linha de ícones disponíveis na barra de menu da janela de tabelas do ArcView

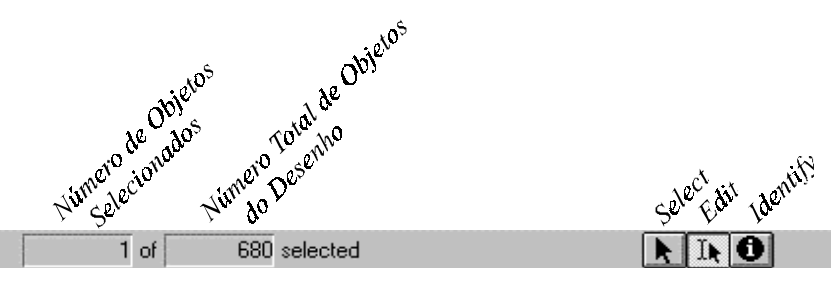

Figura 4.118 - Segunda linha de ícones disponíveis na barra de menu da janela de tabelas do ArcView

Figura 4.119 - Ícones disponíveis na barra de menu da janela de gráficos do ArcView

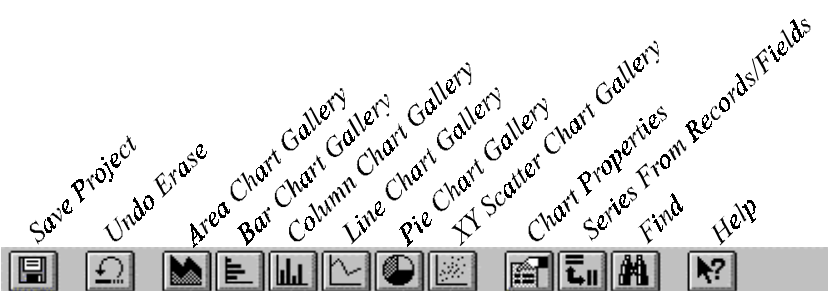

Figura 4.120 - Primeira linha de ícones disponíveis na barra de menu da janela de gráficos do ArcView

(1)+四圆圆

Figura 4.121 - Segunda linha de ícones disponíveis na barra de menu da janela de gráficos do ArcView

\section{ArcView GIS Version 3.1}

Eile Edit Layout Graphics Window Help

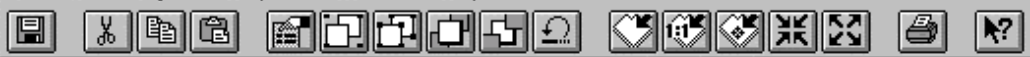

$\Delta[\Delta] Q[\mathrm{sm}] \cdot[\cdot[\cdot]$

Figura 4.122 - Ícones disponíveis na barra de menu da janela de leiautes do ArcView 


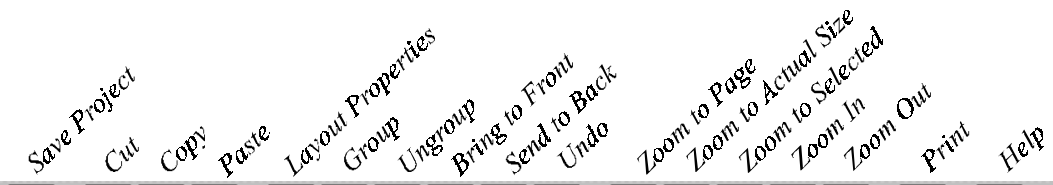

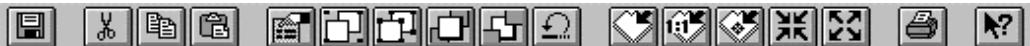

Figura 4.123 - Primeira linha de ícones disponíveis na barra de menu da janela de leiautes do ArcView

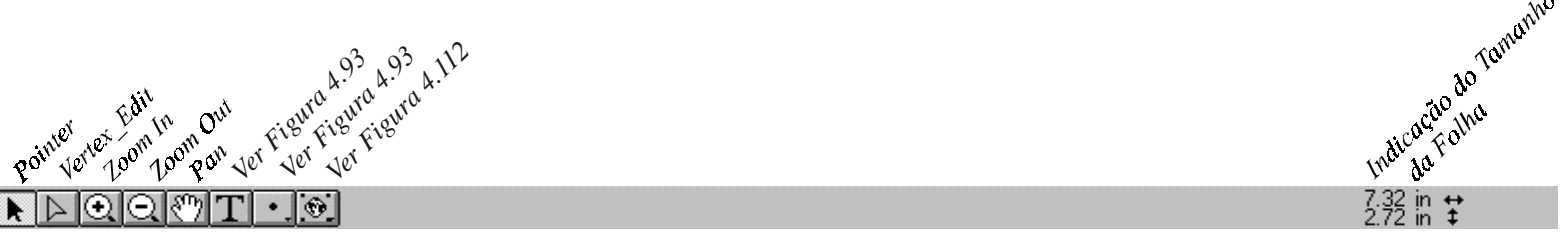

Figura 4.124 - Segunda linha de ícones disponíveis na barra de menu da janela de leiautes do ArcView

\subsubsection{Spatial Analyst e Network Analyst}

Como o ArcView, por si só, não apresenta ferramentas específicas de transportes e os comandos ofertados pelos módulos adicionais (Spatial Analyst e Network Analyst) mesclam ferramentas específicas de transportes e comandos avançados de SIG, optou-se por não denominar este item como rotinas específicas de transportes pois desta forma este não retrataria a realidade. Vale ressaltar que muitos dos comandos disponíveis no módulo Spatial Analyst possibilitam a realização de análises em imagens, através da unidade de distância calculada pelo número de pixels ou células presentes em determinada área.

Os módulos adicionais apresentados são instalados através de seus respectivos CDs e transferem as informações de seus hardlocks para o hardlock principal do ArcView, o que possibilita que o usuário utilize apenas uma chave de acesso e não três. Estes módulos devem ser ativados no ArcView através da opção EXTENSIONS do menu inicial ou através das opções File $\Rightarrow$ EXTENSIONS disponíveis nas demais janelas do ArcView (item 4.3.1). Após a sua adição os seguintes itens de menu, mostrados na figura 4.125, estarão disponíveis: Analysis e Surface, referentes ao módulo Spatial Analyst e Network, referente ao módulo Network Analyst.

2 ArcView GIS Version 3.1

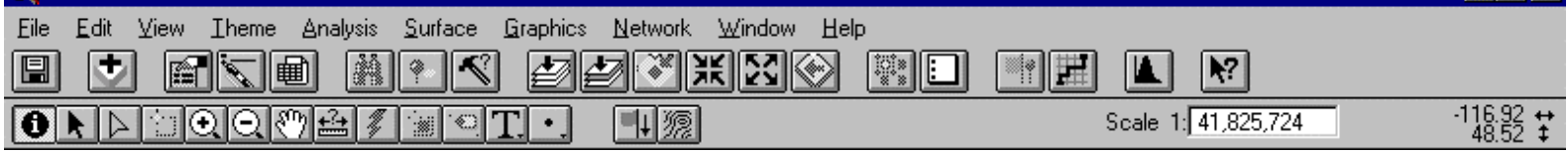

Figura 4.125 - Menu inicial de vistas do ArcView com os módulos adicionais Spatial Analyst e Network Analyst 


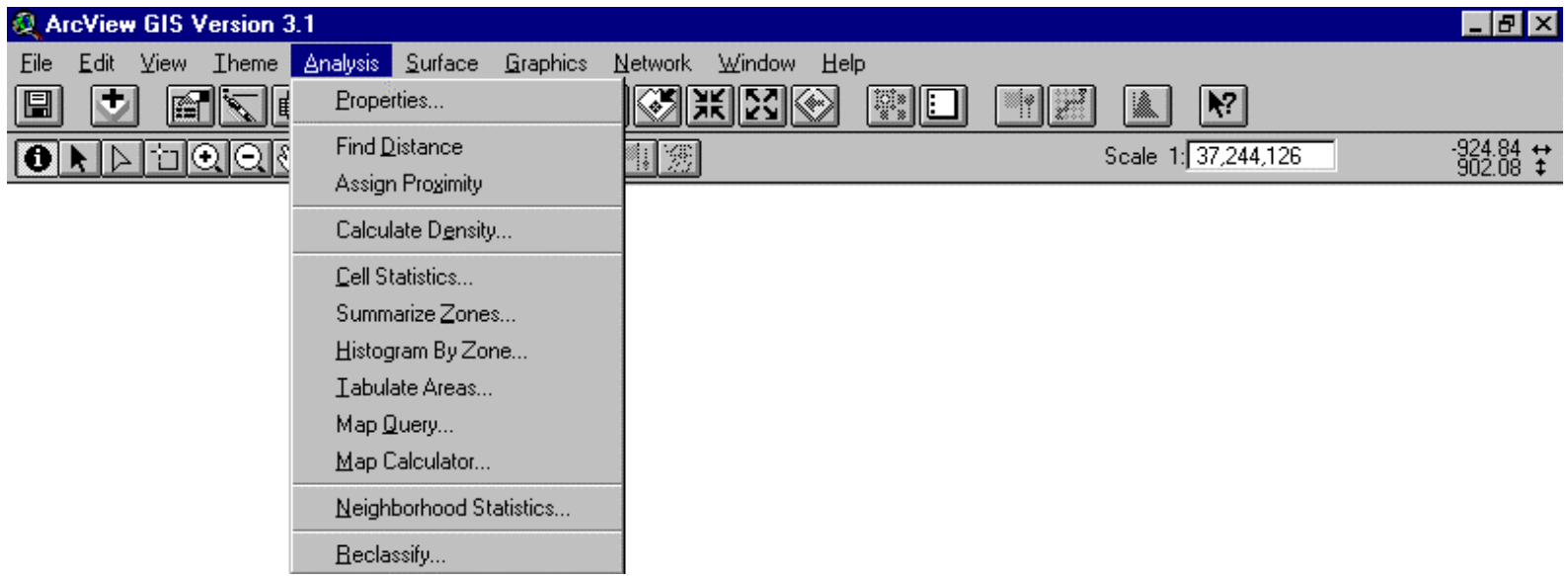

Figura 4.126 - Opção Analysis, pertencente ao módulo Spatial Analyst, do menu de vistas do ArcView

A opção Properties... do menu Analysis, figura 4.126, permite definir as dimensões da tela de zoom espacial e sua resolução para a apresentação dos resultados das operações de análises descritas a seguir. A opção FIND DISTANCE encontra a menor distância ao campo desejado no tema ativo, criando um tema contendo uma grade como saída. Cada célula na grade contém a distância a partir daquela localização até o campo mais próximo. A opção ASSIGN PROXIMITY designa áreas de proximidade aos campos encontrados no tema ativo criando uma grade. Através da opção CALCULATE DENSITY... pode-se calcular a densidade de pontos presentes em uma determinada área.

A opção Cell STATISTICS... realiza um cálculo estatístico baseado nos valores das localizações entre os temas de grades utilizados na análise. As opções disponíveis para este cálculo são: a maioria, máximo valor, média, valor médio (mediana), valor mínimo, minoria, intervalo, desvio padrão, somatório e valor único. A opção SUMMARIZE ZONES... calcula um resumo estatístico para cada zona em uma grade ou tema (de zonas) baseada nos valores das células de um outro tema (grade) que coincidem com cada zona. A opção HistogRAM BY ZONE... cria um gráfico com uma distribuição em forma de histograma separada de um tema de grade para cada área do mesmo atributo (zona) em outro tema. A opção TABULATE AREAS... realiza uma tabulação cruzada das zonas entre dois temas. A opção MAP QUERY... permite a elaboração de consultas em vários temas de grades e a opção MAP CALCULATOR... realiza análises em temas de grades utilizando expressões matemáticas definidas pelo usuário.

A opção NeIGHBORHOOD STATiSTiCS... realiza um cálculo estatístico para os valores encontrados em uma região específica utilizando um tema de pontos ou grade. Esta região pode ser determinada pelo usuário como um retângulo, círculo ou a área compreendida entre dois círculos (como um "biscoito") e pode-se determinar a unidade a ser utilizada como unidade de distância ou número de células. A opção RECLASSIFY... permite alterar os valores dos campos de um tema de grade especificando-se novos valores. 


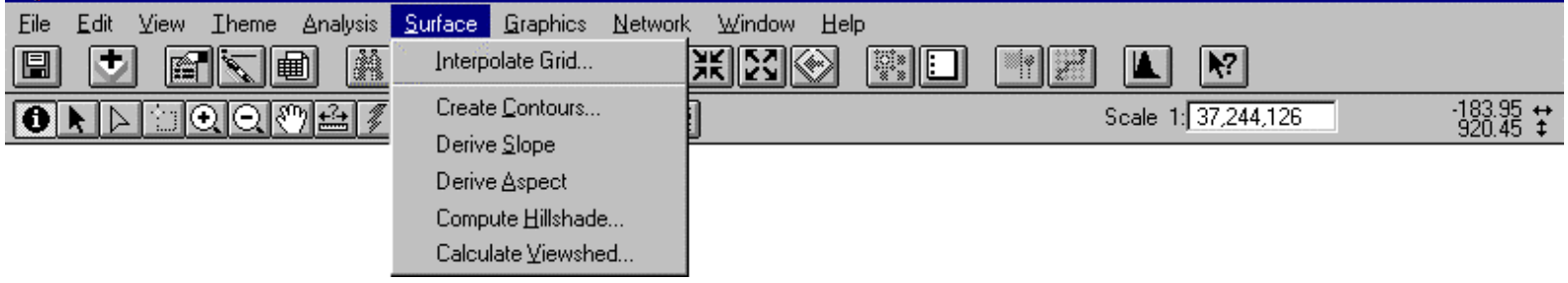

Figura 4.127 - Opção Surface, pertencente ao módulo Spatial Analyst, do menu de vistas do ArcView

A opção INTERPOLADE GRID..., figura 4.127, realiza a interpolação dos pontos de um tema analisando os pontos ao redor de cada localização com o objetivo de preencher os espaços vazios e criar uma superfície contínua. A opção CREATE CONTOURS... desenha as curvas de nível, ligando os pontos que possuem valores constantes, em um tema de pontos, grade ou TIN utilizando um intervalo especificado pelo usuário. Na caixa de diálogos ativada por esta opção devem ser determinados os seguintes itens: o método a ser utilizado (IDW ou spline), o campo do tema que contém os valores de altura " $Z$ " e optar por utilizar $\checkmark$ o vizinho mais próximo ou $\checkmark$ um raio fixo, a intensidade e o tema a ser utilizado como um obstáculo. As opções DERIVE SloPE e DERIVE ASPECT realizam as seguintes funções, respectivamente: calcular o intervalo de mudança máximo para localizações em temas de grade ou TIN e calcular o aspecto para cada célula de um tema de grade ou para cada triângulo de um tema TIN. A opção COMPUTE HiLlSHADE... calcula os valores de iluminação para uma superfície baseada em uma grade ou TIN. A opção CALCULATE VIEWSHED... permite calcular as áreas, em uma superfície, que são visíveis a partir de um ou mais pontos de observação.

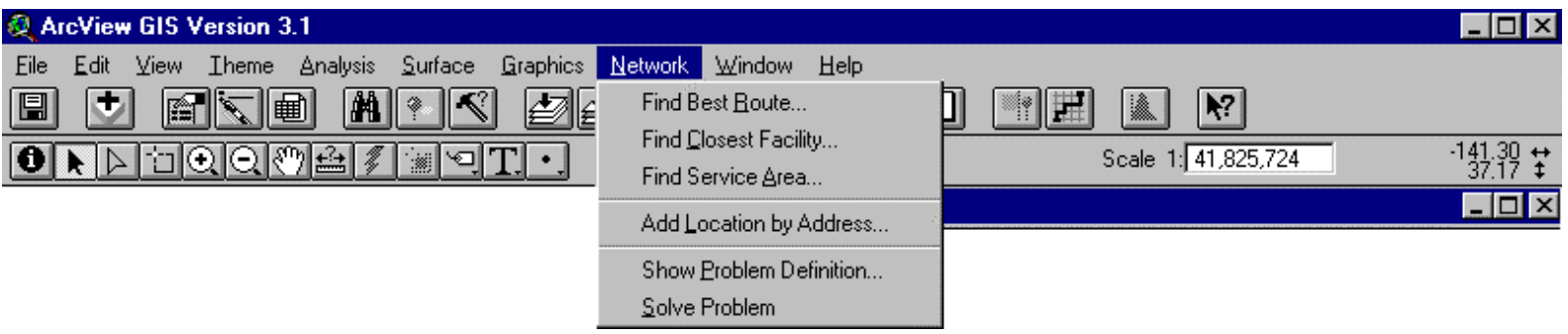

Figura 4.128 - Opção Network, pertencente ao módulo Network Analyst, do menu de vistas do ArcView

A opção FIND BEST RouTE..., figura 4.128, permite encontrar a melhor rota em um tema de linhas, visualizá-la e gerar instruções de viagem. Na caixa de diálogos ativada por esta opção pode-se visualizar os pontos de parada, alterar a sua ordem de apresentação e excluí-los; optar pelos itens $\checkmark$ encontrar a melhor ordem e $\checkmark$ retornar à origem. Os ícones disponíveis são: Directions, onde visualiza-se as instruções de viagens a serem seguidas para se proceder à viagem; Load Stops, para carregar pontos de parada a partir de uma tabela ou tema; Save Stops, para salvar este pontos como um tema (*.shp) e Properties, onde pode-se visualizar e definir os seguintes itens: nome do tema de linhas que está sendo utilizado, o campo que define o custo de viagem, a unidade deste custo, a unidade para os demais campos numéricos, o número de casas decimais para se proceder ao arredondamento e a opção de manter as definições executadas como padrão. Este comando é executado através do ícone 
e os resultados são apresentados nesta mesma caixa de diálogos, indicando os pontos de parada utilizados e o comprimento da viagem.

A opção FIND CLOSEST FACILITY... permite localizar as infra-estruturas pontuais mais próximas de determinado ponto em um tema de linhas, mostra a melhor rota a partir/para a localização e gera as instruções de viagem. Para a realização deste comando devem ser definidos, na caixa de diálogos ativada: o tema de pontos que contém as infra-estruturas a serem analisadas; definir o número de infra-estruturas que entrarão na análise; o custo máximo de viagem que não pode ser ultrapassado; o evento a partir do qual deseja-se encontrar a infra-estrutura mais próxima e definir se a direção da viagem será do evento para a infra-estrutura ou vice-versa. Os ícones disponíveis nesta opção são: Directions, onde podese visualizar as direções a serem seguidas no decorrer da viagem de um ponto ao outro; Load Events, para carregar os eventos a serem analisados; Save Events, para salvar os eventos que estão sendo utilizados como um tema do mapa (*.shp); e Properties, já descrito na função FIND BEST RouTE... anterior. O comando em questão é executado através do ícone $F^{\nexists}$ e os resultados são apresentados nesta mesma caixa de diálogos, indicando a infra-estrutura encontrada e o comprimento da viagem.

Através da opção FIND SERVICE AREA... pode-se localizar uma área de serviços ou uma rede de serviços em torno de uma localização em um tema de linhas. Na caixa de diálogos ativada por esta opção devem ser definidos os seguintes itens: os nomes das localizações a partir das quais deseja-se encontrar uma área de serviço, o que pode ser feito através do ícone Load Sites; selecionar o item Compact Area para criar uma área de serviços compacta e definir o sentido da viagem: a partir da localização ou para a localização. Os demais ícones disponíveis são Save Sites e Properties, já descritos anteriormente. Para a realização desta operação utiliza-se o ícone e os resultados são apresentados nesta mesma caixa de diálogos, indicando a localização utilizada e o comprimento da viagem.

Nas três opções Find Best Route..., Find Closest Facility... e Find Service AREA... descritas anteriormente pode-se definir os pontos a serem analisados através das opções: Add Location, disponível apenas no ícone $\square_{\downarrow}$ e ADD LOCATION BY ADDRESS..., figura 5.128, que permite definir uma localização através de seu endereço. Nesta última opção devese definir o endereço a ser encontrado e a zona em que este se localiza. No ícone Preferences pode-se definir o grau de coincidência dos valores e a necessidade de verificar algum resultado obtido. A opção Show PROBlem Definition... mostra as definições feitas para a execução dos comandos FIND..., isto é, mostra as suas respectivas caixas de diálogos. A opção SOlVE PROBlem soluciona os problemas de análise da rede do tema ativo definidos e mostra os resultados na tela. 


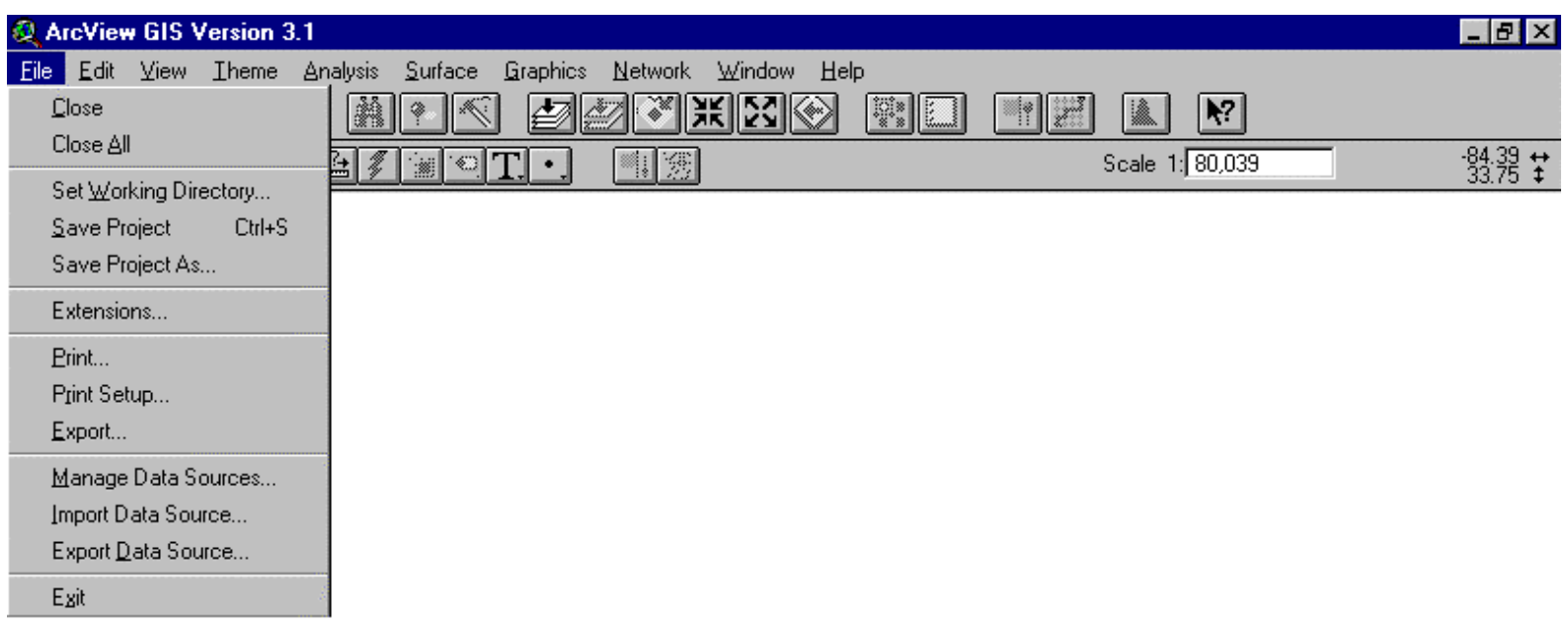

Figura 4.129 - Opção File do menu inicial de vistas do ArcView com os módulos adicionais Spatial Analyst e Network Analyst

A opção File, figura 4.129 apresenta os seguintes itens adicionais: MANAGE DATA Sources, Import Data Sources e Export Data Sources que realizam as funções de manipulação, importação e exportação de fontes de dados.

Após a instalação dos módulos descritos pode-se observar a presença de alguns ícones adicionais que realizam funções específicas, figura 4.130, já apresentadas ao longo do item 4.3.2.

\section{ArcView GIS Version 3.1}

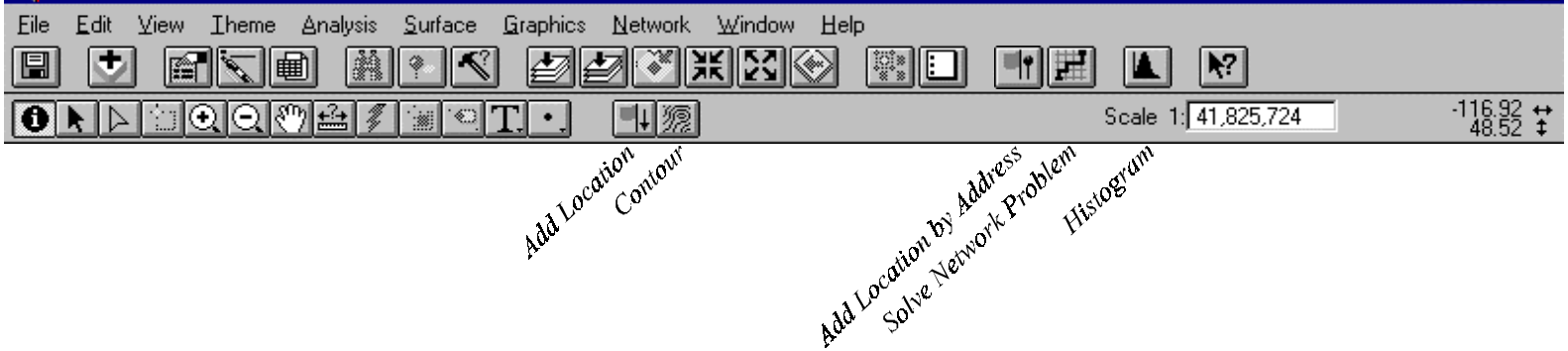

Figura 4.130 - Ícones adicionais disponíveis na barra de menu da janela de vistas do ArcView com os módulos Spatial Analyst e Network Analyst 


\section{Avaliação Comparativa dos Programas}

Neste capítulo foram, primeiramente, abordados alguns tópicos gerais, considerados importantes para os usuários de qualquer SIG, tais como: tempo de aprendizado, possibilidade de customização, atualizações, etc. A avaliação de alguns destes itens reflete direta e tão somente a visão pessoal da autora do trabalho. Posteriormente foram avaliados, sob a forma de checagem, os pontos descritos como características operacionais (item 3.1.2, capítulo 3). Estes dois conjuntos de avaliação se enquadram nas características básicas de SIG.

Com relação às rotinas avançadas de SIG, foi avaliada a existência das funções de manipulação dos dados em cada um dos software e especificada a localização dos comandos utilizados para realizá-las. Esta localização foi indicada como uma seqüência de comandos, a partir das barras de menu dos programas, os quais já foram descritos detalhadamente no capítulo 4 deste documento. Para analisar, preliminarmente, as rotinas de transportes fez-se uma checagem da existência de cada comando nos software estudados, avaliação complementada posteriormente com o emprego dos programas para a solução de um problema de transporte envolvendo redes e matrizes, conforme já descrito na metodologia.

\subsection{Características Básicas de SIG}

\subsubsection{Aspectos Descritivos}

a) Versão estudada

TransCAD: 3.2, plataforma Windows;

UfosNet: 3.5.1, plataforma Windows;

ArcView: 3.1, plataforma Windows;

b) Versão mais atual

TransCAD: 4.0 ;

UfosNet: 4.2 .0 ;

ArcView: 8.1;

c) Configurações mínimas de hardware exigidas pelos programas

TransCAD: $14 \mathrm{MB}$ de espaço disponível em disco rígido e exigências semelhantes às do Windows;

UfosNet: computador com no mínimo16 MB de memória RAM e 20 MB de espaço disponível em disco rígido; 
ArcView: não fornecida pelo fabricante;

d) Tipo de dados processados pelo programa

TransCAD: vetoriais;

UfosNet: vetoriais;

ArcView: vetoriais;

Os três programas aceitam a importação de imagens, embora estas não se constituam na realidade em estruturas de representação geométrica de dados, os chamados dados matriciais (ou raster). A única exceção a este caso é o software ArcView, desde que se disponha do módulo adicional denominado Spatial Analyst;

e) Material de apoio

TransCAD: possui quatro manuais: guia do usuário (TransCAD User's Guide), guia de programação (GISDK Programmer's Guide), modelagem de demanda de viagens (Travel Demand Modeling with TransCAD) e roteamento e logística (Routing and Logistics with TransCAD);

UfosNet: possui um guia do usuário (UfosNet User's Guide) e um manual de funções de programação denominado Uscript. O guia do usuário contempla todos os comandos do programa;

ArcView: possui um manual denominado "Using ArcView GIS", relativo ao programa básico e um manual para cada módulo adicional, no caso estudado: "Using the ArcView Network Analyst" e "Using the ArcView Spatial Analyst";

f) Tempo aproximado de aprendizado (baseado na experiência pessoal da autora)

TransCAD: 100 horas;

UfosNet: 150 horas;

ArcView: 100 horas;

g) Suporte técnico (baseado na experiência pessoal da autora)

TransCAD: via internet, email, fax ou telefone. Eficiente;

UfosNet: via internet, email, fax ou telefone. Muito eficiente;

ArcView: via internet, email, fax ou telefone. Não consultado;

h) Última atualização

TransCAD: $1^{\circ}$ semestre de 2001;

UfosNet: $2^{\circ}$ semestre de 2000 ;

ArcView: $1^{\circ}$ semestre de 2001 ;

i) Linguagem de programação

TransCAD: linguagem própria $(G I S D K)$;

UfosNet: $\mathrm{C} / \mathrm{C}^{++}$;

ArcView: Avenue e, na versão mais atual, Visual Basic;

j) Possibilidade de customização

TransCAD: sim, arquitetura modular, aberta;

UfosNet: sim, linguagem de programação usual;

ArcView: sim, apesar de possuir linguagem de programação diferenciada. 
k) Custos

TransCAD: Standard TransCAD 4.0 License - US\$9.995,00;

Base TransCAD License - US\$2.995,00;

Academic - fornecido apenas via fax ou telefone;

UfosNet: Pro Version - US\$9.500,00 ( $1^{\mathrm{a}}$ cópia), US\$5.000,00 (2 a 5 cópias) e US $\$ 3.000,00$ (mais de 6 cópias);

Lite Version - US\$3.500,00;

Edu Version - US\$995,00;

ArcView: Área educacional - US\$440,00;

Área comercial - US\$1.890,00.

\subsubsection{Características Operacionais}

\begin{tabular}{|c|c|c|c|c|}
\hline \multicolumn{5}{|c|}{ Quanto à modelagem dos dados } \\
\hline & & TransCAD & UfosNet & ArcView \\
\hline \multicolumn{2}{|c|}{$\begin{array}{l}\text { Aceita dados descritos em termos de feições com } \\
\text { atributos }\end{array}$} & $\checkmark$ & $\checkmark$ & $\checkmark$ \\
\hline \multicolumn{2}{|c|}{ Suporta complexas modelagens de feições } & $\checkmark$ & $\checkmark$ & $\checkmark$ \\
\hline \multicolumn{2}{|c|}{ Permite codificação de redes } & $\bar{\checkmark}$ & $\bar{\checkmark}$ & $\bar{\checkmark}$ \\
\hline \multicolumn{2}{|c|}{ Suporta interface com bancos de dados relacionais } & $\sqrt{ }$ & $\checkmark$ & 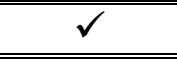 \\
\hline \multicolumn{2}{|c|}{ Permite estruturação topológica dos dados } & 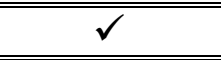 & $\checkmark$ & $\checkmark \checkmark$ \\
\hline \multicolumn{2}{|c|}{ Distingue a representação gráfica da geométrica } & $\bar{V}$ & $\bar{\checkmark}$ & $\checkmark$ \\
\hline \multicolumn{2}{|c|}{ Suporta séries temporais de dados } & $\checkmark$ & $\checkmark$ & $\checkmark$ \\
\hline \multirow{3}{*}{$\begin{array}{l}\text { Acesso aos dados } \\
\text { através de }\end{array}$} & linguagem de alto nível & $\checkmark$ & $\checkmark$ & $\checkmark$ \\
\hline & estrutura de menus e ícones & 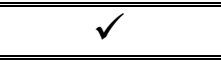 & $\bar{\checkmark}$ & 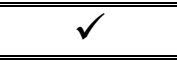 \\
\hline & linguagem SQL & $\checkmark$ & $\sqrt{ }$ & 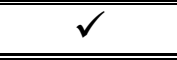 \\
\hline
\end{tabular}

Tabela 5.1 - Características Operacionais Básicas de SIG quanto à modelagem dos dados

\begin{tabular}{||l|c|c|c|}
\hline \multicolumn{4}{|c|}{ Quanto à linguagem de consulta } \\
\hline \hline \multicolumn{1}{|l|}{} & TransCAD & UfosNet & ArcView \\
\hline Dispõe de interface amigável & $\checkmark$ & $\checkmark$ & $\checkmark$ \\
\hline Permite gerar e manipular comandos SQL & $\checkmark$ & $\checkmark$ & $\checkmark$ \\
\hline $\begin{array}{l}\text { Permite a integração de extensões de operadores } \\
\text { SQL lógicos e aritméticos }\end{array}$ & $\checkmark$ & $\checkmark$ & $\checkmark$ \\
\hline $\begin{array}{l}\text { Permite o agrupamento lógico de campos de várias } \\
\text { tabelas }\end{array}$ & $\checkmark$ & $\checkmark$ & $\checkmark$ \\
\hline \begin{tabular}{l} 
Gerencia conjuntos selecionados de dados \\
\hline Permite a ordenação de registros
\end{tabular} & $\checkmark$ & $\checkmark$ & $\checkmark$ \\
\hline Suporta a apresentação de dados alfanuméricos & $\checkmark$ & $\checkmark$ & $\checkmark$ \\
\hline
\end{tabular}

Tabela 5.2 - Características Operacionais Básicas de SIG quanto à linguagem de consulta 
Quanto à geração de relatórios, importação e exportação de arquivos

Permite a definição do conteúdo e formato dos relatórios

Apresenta os relatórios na forma WYSIWYG Facilita a importação de vários tipos de arquivos

Facilita a exportação de vários tipos de arquivos

Tabela 5.3 - Características Operacionais Básicas de SIG quanto à geração de relatórios, importação e exportação de arquivos

\begin{tabular}{|c|c|c|c|c|}
\hline \multicolumn{5}{|c|}{ Quanto à entrada de dados } \\
\hline & & TransCAD & UfosNet & ArcView \\
\hline \multicolumn{2}{|c|}{$\begin{array}{l}\text { Permite a associação de códigos de feição a pontos, } \\
\text { linhas e áreas }\end{array}$} & $\checkmark$ & $\checkmark$ & $\checkmark$ \\
\hline \multirow{3}{*}{$\begin{array}{l}\text { Suporta o usuário } \\
\text { nos processos de }\end{array}$} & atribuição de códigos & $\bar{\checkmark}$ & $\bar{\checkmark}$ & $\bar{\square}$ \\
\hline & fechamento de polígonos & 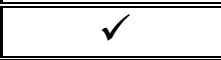 & 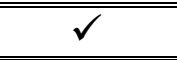 & \\
\hline & reconhecimento de proximidade & $\checkmark$ & $\checkmark$ & \\
\hline \multicolumn{2}{|c|}{ Suporta o usuário na criação da topologia } & $\checkmark \checkmark$ & $\checkmark$ & 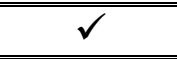 \\
\hline \multicolumn{2}{|c|}{ Oferece recursos de ajuste de bordas } & $\bar{\checkmark}$ & & \\
\hline \multicolumn{2}{|c|}{ Suporta a transferências entre bases de dados } & $\bar{\checkmark} \checkmark$ & $\bar{\checkmark} \checkmark$ & $\bar{\checkmark}$ \\
\hline
\end{tabular}

Tabela 5.4 - Características Operacionais Básicas de SIG quanto à entrada de dados

\begin{tabular}{||l|c|c|c||}
\hline \multicolumn{4}{|c|}{ Quanto à edição de dados } \\
\hline \hline \multicolumn{2}{|c|}{} \\
\hline $\begin{array}{l}\text { Identifica quaisquer feições a partir de códigos, } \\
\text { coordenadas ou coordenadas de cursor }\end{array}$ & $\checkmark$ & $\checkmark$ & ArcView \\
\hline Permite a manipulação de feições & $\checkmark$ & $\checkmark$ & $\checkmark$ \\
\hline Permite a junção de pontos, inserção de nódulos, etc & $\checkmark$ & $\checkmark$ & \\
\hline Posiciona automaticamente textos e símbolos & $\checkmark$ & $\checkmark$ & $\checkmark$ \\
\hline $\begin{array}{l}\text { Permite que o usuário defina o posicionamento de } \\
\text { símbolos e textos }\end{array}$ & $\checkmark$ & $\checkmark$ & $\checkmark$ \\
\hline Permite a definição de limites de tolerância & $\checkmark$ & & \\
\hline $\begin{array}{l}\text { Permite a inserção automática, configuração e } \\
\text { edição de indicação de escala }\end{array}$ & $\checkmark$ & & $\checkmark$ \\
\hline Permite a inserção de indicativos de norte & $\checkmark$ & & $\checkmark$ \\
\hline Permite a geração de mapas temáticos & $\checkmark$ & $\checkmark$ & $\checkmark$ \\
\hline
\end{tabular}

Tabela 5.5 - Características Operacionais Básicas de SIG quanto à edição de dados 


\subsection{Rotinas Avançadas de SIG}

Na tabela a seguir são abordados os itens relacionados à manipulação de dados:

\begin{tabular}{|c|c|}
\hline \multicolumn{2}{|c|}{\begin{tabular}{|c|} 
Extração de dados por código, atributo ou critério não combinados \\
\end{tabular}} \\
\hline TransCAD & Tools $\Rightarrow$ Locate By Value \\
\hline UfosNet & Edit $\Rightarrow$ Toolbox-Network $\Rightarrow$ Find Nodes; \\
\hline ArcView & Theme $\Rightarrow$ Properties; \\
\hline \multicolumn{2}{|c|}{ "Realização de operações geométricas (cálculo de distâncias, perímetros, áreas, etc.) } \\
\hline TransCAD & Í́cones: Measure Distance e Measure Size \\
\hline UfosNet & $\begin{array}{l}\text { Edit } \Rightarrow \text { Toolbox-Network } \Rightarrow \text { Calculate Distance } \\
\text { Edit } \Rightarrow \text { Toolbox-Boundary } \Rightarrow \text { Calculate Boundary } \\
\text { Area/Perimeter }\end{array}$ \\
\hline ArcView & Analysis $\Rightarrow$ Find Distance \\
\hline \multicolumn{2}{|r|}{ Banco de fórmulas para filtragem dos dados, geração de novas colunas } \\
\hline TransCAD & $\begin{array}{l}\text { Edit } \Rightarrow \text { Fill } \Rightarrow \text { Formula } ; \quad \text { Dataview } \Rightarrow \text { Formula Fields; } \\
\text { Dataview } \Rightarrow \text { Select By Condition }\end{array}$ \\
\hline UfosNet & Calc $\Rightarrow$ Zone/Node/Link/Point/F-Factor/Transit \\
\hline ArcView & $\begin{array}{l}\text { Table } \Rightarrow \text { Query; } \quad \text { Analysis } \Rightarrow \text { Map Query/Map Calculator } \\
\text { Obs: Não apresenta funções para geração de novas colunas }\end{array}$ \\
\hline \multicolumn{2}{|r|}{ Geração de buffers } \\
\hline TransCAD & Tools $\Rightarrow$ Bands \\
\hline UfosNet & $\begin{array}{l}\text { Edit } \Rightarrow \text { Toolbox-Boundary } \Rightarrow \text { Create Boundary Polygon Buffer Region } \\
\text { Tools } \Rightarrow \text { Buffer Region/to Annotation }\end{array}$ \\
\hline ArcView & Theme $\Rightarrow$ Create Buffers \\
\hline \multicolumn{2}{|r|}{ Manipulação e criação de redes } \\
\hline TransCAD & Procedures $\Rightarrow$ Networks/Paths \\
\hline UfosNet & Tools $\Rightarrow$ Extract Network; \\
\hline ArcView & Não Disponível \\
\hline \multicolumn{2}{|r|}{ Realização de agrupamentos, particionamentos e locação de facilidades } \\
\hline TransCAD & $\begin{array}{l}\text { Procedures } \Rightarrow \text { Networks/Paths } \Rightarrow \text { Network Partitioning; } \\
\text { Procedures } \Rightarrow \text { Routing/Logistics } \Rightarrow \text { Regional Partitioning/Clustering/Facility } \\
\text { Location }\end{array}$ \\
\hline UfosNet & Não Disponível \\
\hline ArcView & Network $\Rightarrow$ Find Closest Facility/Find Service Area \\
\hline \multicolumn{2}{|r|}{ Obtenção de caminhos mínimos e custos de deslocamento } \\
\hline TransCAD & Procedure $\Rightarrow$ Networks/Paths $\Rightarrow$ Shortest Path \\
\hline UfosNet & Tools $\Rightarrow$ Highway Path \\
\hline ArcView & Network $\Rightarrow$ Find Best Route \\
\hline \multicolumn{2}{|r|}{ Realização de overlay } \\
\hline TransCAD & Tools $\Rightarrow$ Overlay \\
\hline UfosNet & Tools $\Rightarrow$ Buffer Clipping \\
\hline ArcView & Analysis $\Rightarrow$ Calculate Density \\
\hline
\end{tabular}




\begin{tabular}{|c|c|}
\hline \multicolumn{2}{|r|}{ Geração de áreas de busca } \\
\hline TransCAD & Procedure $\Rightarrow$ Networks/Paths $\Rightarrow$ Network Bands \\
\hline UfosNet & Tools $\Rightarrow$ Highway Path \\
\hline ArcView & Analysis $\Rightarrow$ Assign Proximity \\
\hline \multicolumn{2}{|r|}{ Geração de modelo digital do terreno } \\
\hline TransCAD & Tools $\Rightarrow$ TINS \\
\hline UfosNet & Não Disponível \\
\hline ArcView & Surface $\Rightarrow$ Interpolate Grid \\
\hline \multicolumn{2}{|r|}{ Geração de curvas de nível } \\
\hline TransCAD & Tools $\Rightarrow$ TINS $\Rightarrow$ Generate Contours \\
\hline UfosNet & Não Disponível \\
\hline ArcView & Surface $\Rightarrow$ Create Contours \\
\hline \multicolumn{2}{|r|}{ Geração de desenhos de perspectiva de MDT } \\
\hline TransCAD & Não Disponível \\
\hline UfosNet & View $\Rightarrow 3-D$ View \\
\hline ArcView & Não Disponível \\
\hline \multicolumn{2}{|r|}{ Extração de informações estatísticas } \\
\hline TransCAD & Dataview $\Rightarrow$ Statistics; \\
\hline UfosNet & Calc $\Rightarrow$ Regression/Histogram \\
\hline ArcView & $\begin{array}{l}\text { Theme } \Rightarrow \text { Edit Legend } \Rightarrow \text { Statistics; } \quad \text { Field } \Rightarrow \text { Statistics/Summarize } \\
\text { Analysis } \Rightarrow \text { Summarize Statistics/Cell Statistics/Tabulate Areas/Neighborhood } \\
\text { Statistics }\end{array}$ \\
\hline \multicolumn{2}{|r|}{ Geração de gráficos de representação dos dados } \\
\hline TransCAD & Map $\Rightarrow$ Chart Theme \\
\hline UfosNet & Regression $\Rightarrow$ Scattergram; \\
\hline ArcView & Chart $\Rightarrow$ Gallery \\
\hline \multicolumn{2}{|r|}{ Realização de procura e identificação de endereços } \\
\hline TransCAD & Tools $\Rightarrow$ Locate By Address/Locate By ZIP Code \\
\hline UfosNet & Tools $\Rightarrow$ Address Query/Address Match \\
\hline ArcView & View $\Rightarrow$ Geocode Addresses/Locate Address \\
\hline
\end{tabular}

Tabela 5.6 - Rotinas Avançadas de SIG 


\subsection{Rotinas Específicas de Transportes}

\subsubsection{Avaliação geral}

\begin{tabular}{|c|c|c|c|c|}
\hline \multicolumn{2}{|c|}{\begin{tabular}{|ll} 
Comandos & Software \\
\end{tabular}} & TransCAD & UfosNet & ArcView \\
\hline \multicolumn{2}{|c|}{ Desenvolvimento de matrizes } & $\bar{\checkmark}$ & $\bar{\checkmark}$ & \\
\hline \multirow{3}{*}{$\begin{array}{l}\text { Geração de } \\
\text { Viagens }\end{array}$} & produção & $\checkmark$ & $\checkmark$ & \\
\hline & atração & $\checkmark$ & $\checkmark$ & \\
\hline & balanceamento & $\bar{~} \bar{\checkmark}$ & 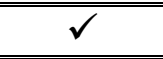 & \\
\hline \multirow{4}{*}{$\begin{array}{l}\text { Distribuição de } \\
\text { Viagens } \\
\text { (modelos) }\end{array}$} & método do fator de crescimento & $\bar{~} \checkmark$ & $\bar{~} \checkmark$ & \\
\hline & Fratar & $\bar{~} \checkmark$ & 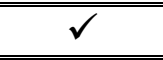 & \\
\hline & gravitacional & $\checkmark$ & $\checkmark$ & \\
\hline & entrópicos & $\checkmark \checkmark$ & & \\
\hline \multicolumn{2}{|l|}{ Divisão modal } & $\bar{\checkmark}$ & $\checkmark$ & \\
\hline \multirow{5}{*}{$\begin{array}{l}\text { Alocação de } \\
\text { Tráfego } \\
\text { (métodos) }\end{array}$} & tudo-ou-nada & $\checkmark \checkmark$ & $\checkmark \checkmark$ & \\
\hline & incremental & $\sqrt{ }$ & $\checkmark$ & \\
\hline & do equilíbrio & 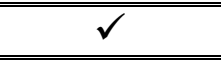 & 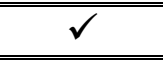 & \\
\hline & da restrição da capacidade & $\bar{~} \checkmark$ & & \\
\hline & sistema ótimo & $\checkmark \checkmark$ & & \\
\hline \multicolumn{2}{|l|}{ Sistemas de rotas } & $\bar{\checkmark} \checkmark$ & $\bar{\checkmark}$ & \\
\hline \multicolumn{2}{|l|}{ Roteirização } & $\checkmark \checkmark$ & 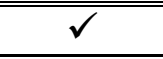 & $\sqrt{ } \checkmark$ \\
\hline
\end{tabular}

Tabela 5.7 - Rotinas Específicas de Transportes - Avaliação Geral

\subsubsection{Avaliação de Recursos Básicos de Transportes}

Neste item foram analisadas as ferramentas necessárias à solução de um problema de transportes que envolve a manipulação de redes e matrizes: o cálculo de uma das mais simples e diretas medidas de acessibilidade encontradas na literatura de planejamento de transportes, a que mede a separação média entre pontos de uma rede, conforme especificado no capítulo 3 deste trabalho.

\subsubsection{Considerações Gerais}

Foram apresentados os comandos básicos e avançados necessários à realização do problema proposto por software, obedecendo a ordem de apresentação dos mesmos nos demais capítulos deste trabalho; primeiramente o TransCAD, posteriormente o UfosNet e por fim o ArcView.

O computador utilizado na análise apresentava a seguinte configuração básica: Pentium III 700MHz, com 128MB de memória RAM. Pode-se afirmar, a princípio, que a eficiência do software varia de acordo com o equipamento utilizado e o número de dados a serem processados. Assim, quanto maiores forem os bancos de dados, mais lenta ficará a realização de qualquer procedimento. O tempo de processamento só foi mencionado nos 
procedimentos em que ultrapassou um limite a partir do qual passou a ser considerado relevante para a análise.

De acordo com Silva (1998a), a medida de acessibilidade aqui considerada (descrita em Allen et al., 1993) leva em consideração os menores caminhos entre os pontos. Logo, os nós com menores valores absolutos, geralmente na área central da cidade, são aqueles que têm melhores níveis de acessibilidade. $\mathrm{O}$ valor da acessibilidade tende a diminuir na medida em que os pontos estão situados mais para a periferia da cidade. Assim sendo, segundo Raia Jr. e Silva (1998), se a rede apresentar falhas de conectividade deverá ser observada uma distorção nos valores de acessibilidade, o que pode ser facilmente identificado através de um simples mapa temático.

Os procedimentos descritos a seguir foram realizados a partir de um arquivo da rede viária da cidade de São Carlos já existente que, obrigatoriamente, continha dois tipos de camadas (layers ou themes): de linhas (segmentos de vias) e nós (cruzamentos) e seus respectivos bancos de dados.

\subsubsection{Cálculo da Medida de Acessibilidade no Software TransCAD}

- Abrir o arquivo da rede viária; comandos utilizados: File $\Rightarrow$ OPEN

- Abrir a camada de pontos; comandos utilizados: Map $\Rightarrow$ LAYERS $\Rightarrow$ Show Layer

- Criar a rede; comandos utilizados: Networks/Paths $\Rightarrow$ CREATE

opções: Create Links from (Entire line layer)

Read length from (Length)

Save network as (dar nome à rede, *net)

- Criar a matriz de caminhos mínimos entre todos os pontos; comandos utilizados: Networks/Paths $\Rightarrow$ MultiPle PATHS

opções: Minimize (Length)

From (All features)

To (All features)

$\checkmark$ Matrix File

Save Output Matrix As (dar nome à matriz, *mtx)

- Somar as colunas da matriz: é necessário fazer-se a somatória de todas as distâncias, para utilização na equação da medida de acessibilidade de Allen et al. (1993); comandos utilizados: Matrix $\Rightarrow$ SETTINGS

opções: Marginals (Sum)

resultado: Matriz com 4958 linhas por 4958 colunas

tempo gasto: 3 minutos

- Exportar a coluna marginal (SUM), criando novo arquivo (de tabela, com extensão

*dbf), identificado pelo software como Shortest Path; comandos utilizados: Matrix $\Rightarrow$ EXPORT ROws OR COLUMNS

opções: Export $\checkmark$ Column Marginals

File Name (dar nome à nova tabela, *dbf)

- Criar nova coluna no arquivo dbf; comandos utilizados: Dataview $\Rightarrow$ ModIFY TABLE 


\section{opções: Add Field \\ Name (dar nome à nova coluna) \\ Type (Real Number ou Integer) \\ Decimals (2, na opção Real Number)}

- Preenchê-la com uma fórmula: para o cálculo da medida de acessibilidade considerada deve-se dividir a somatória das colunas (SUM) pelo número de pontos (nós da rede) menos um (N-1); comandos utilizados: Edit $\Rightarrow$ FILL

\section{opções: Fill Method $\checkmark$ Fórmula \\ Fórmula (SUM/(4958-1))}

- Juntar os dados de ID dos nós e suas acessibilidades (deixando-se a camada de nós do mapa ativa);

comandos utilizados: Dataview $\Rightarrow$ JoIN

$$
\text { opções: Name (Endpoints+Shortest Path Table) }
$$

- Construção do mapa temático de acessibilidade (deixando-se a camada de nós do mapa ativa); comandos utilizados: Map $\Rightarrow$ COLOR THEME

opções: Field (nome da coluna com os valores SUM/(4958-1))

Method (Equal Number of Features)

Class (número de classes desejado)

\subsubsection{Cálculo da Medida de Acessibilidade no Software UfosNet}

Como o mapa de São Carlos utilizado estava originalmente nos padrões/formatos utilizados pelo software TransCAD, para utilização deste no UfosNet foi necessária a conversão dos arquivos, o que foi feito pelo próprio autor do programa, Robert S. Tung. A partir daí todos os procedimentos descritos neste item foram feitos seguindo diretamente as suas orientações, transmitidas através de correio eletrônico. Na conversão de arquivos o número de nós foi reduzido de 4958 para 4485.

- Abrir o arquivo do projeto; comandos utilizados: File $\Rightarrow$ LOAD PROJECT

- Alterar a camada de linhas, incluindo os campos distance, capacity, vdf, volume e time, que é a configuração mínima necessária para se efetuar o procedimento utilizado para criar a matriz de caminhos mínimos (Highway Assigment); comandos utilizados: Edit $\Rightarrow$ DATABASE DEFINITION $\Rightarrow$ Link

opções: Append

$$
\begin{aligned}
& \text { Name (distance), (capacity), (vdf), (volume), (time) } \\
& \text { Type }(\mathrm{N}, \text { Num }) \\
& \text { Update }
\end{aligned}
$$

- Preencher os campos capacity com o valor 1000 e $v d f$ com o valor 1 ; comandos utilizados: Calc $\Rightarrow$ LINK

$$
\begin{aligned}
& \text { opções: Then (1000), (1) } \\
& \text { Output Field (capacity), (vdf) } \\
& \text { Calculate }
\end{aligned}
$$

- Adicionar uma camada de nós, para armazenar os dados finais de acessibilidade; comandos utilizados: Edit $\Rightarrow$ DATABASE DEFINITION $\Rightarrow$ Node opções: Append 


\section{Name (access) \\ Type (N, Num) \\ Update}

- Criar uma matriz de origens e destinos;

comandos utilizados: Matrix $\Rightarrow$ DEFINE/SELECT

opções: Name (OD)

Type (MODTT)

Dimension: Rows (4485), Cols (4485)

New

resultado: Matriz com 4485 linhas por 4485 colunas

tempo gasto: 3 minutos

- Criar uma matriz de distâncias;

comandos utilizados: Matrix $\Rightarrow$ DEFINE/SELECT

opções: Name (Distance)

Type (MDIST)

Dimension: Rows (4485), Cols (4485)

New

resultado: Matriz com 4485 linhas por 4485 colunas

- Rodar o procedimento Highway Assigment;

comandos utilizados: Model $\Rightarrow$ TRIP Assigment $\Rightarrow$ HighwAY ASSIGMENT

opções: Method $\checkmark$ All or Nothing

Input Link Fields: Lenght (Lenght), Capacity (Capacity), VDF

(VDF), Lenght (Lenght)

Output Link Fields: Volume (Volume), Time (Time)

Primary OD table (OD)

$\checkmark$ Distance Matrix: Travel Distance Matrix (Distance)

Start Highway Assigment

tempo gasto: 14 minutos

- Salvar o somatório das colunas da matriz de distâncias em uma matriz do tipo COLSUM;

comandos utilizados: Matrix $\Rightarrow$ DEFINE/SELECT

opções: Name (Colsum)

Type (MCOLS)

Dimension: Rows (1), Cols (4485)

New

resultado: Matriz com 1 linha por 4485 colunas

comandos utilizados: Matrix $\Rightarrow$ CALC

opções: Then (COLSUM(matriz distance))

Output Matrix (Colsum)

tempo gasto: 5 minutos

- Rodar o programa/script MATNODE, desenvolvido por Robert S. Tung especialmente para este caso, para copiar os valores de somatório das colunas (matriz Colsum) para o campo access criado na camada de nós; comandos utilizados: Quick Macro $\Rightarrow$ MATNODE

- Inserir mais um campo na camada de nós e preenchê-lo com a fórmula (SUM/(44851)); comandos utilizados: Edit $\Rightarrow$ DATABASE DEFINITION $\Rightarrow$ Node opções: Append 
Name (access2)

Type (N, Num)

Update

comandos utilizados: Calc $\Rightarrow$ NODE

opções: Then (access/(4485-1))

Output Field (access2)

Calculate

- Construção do mapa temático de acessibilidade;

comandos utilizados: Plot $\Rightarrow$ Define Default StYle $\Rightarrow$ Node

opções: Thematic Mapping: Node Field (access)

Redraw

\subsubsection{Cálculo da Medida de Acessibilidade no Software ArcView}

Para adequação dos arquivos da rede viária de São Carlos nos formatos aceitos pelo ArcView, foi necessária a exportação dos mesmos através dos seguintes comandos do software TransCAD:

Tools $\Rightarrow$ EXPORT (com a camada de linhas ativa)

opções: Export (All Records)

To (ArcView Shape)

Tools $\Rightarrow$ EXPORT (com a camada de pontos ativa)

opções: Export (All Records)

To (ArcView Shape)

- Importação dos arquivos para compor as camadas (layers ou themes) do mapa; comandos utilizados: View $\Rightarrow$ ADD THEME

opções: selecionar o arquivo desejado (*.shp)

- Disponibilizar as extensões Network Analyst e Spatial Analyst;

comandos utilizados: File $\Rightarrow$ EXTENSIONS

opções: $\checkmark$ Network Analyst

$\checkmark$ Spatial Analyst

- Obter e disponibilizar a macro FastSNP10.avx, utilizada para a obtenção dos caminhos mínimos entre todos os nós da rede. Esta script foi escrita por um usuário do ArcView e está disponível no site da ESRI na Internet (www.esri.com); comandos utilizados: File $\Rightarrow$ EXTENSIONS

opções: $\checkmark$ Fast Shortest Network Paths v1.0

- Rodar a rotina para encontrar os caminhos mínimos. Para tanto é necessário que o mapa possua pelos menos uma camada de pontos e uma camada de linhas;

comandos utilizados: ícone: Fast SNP v1.0

opções: Please select the point theme representing the origins and destinations (pontos.shp)

Please select the Point ID Field (ID)

Please select the Point Label-Field (optional) (cancel)

Please select the origin( $(s)$

Please select the destination(s)

Please select the Network Theme (vias.shp) 
Please enter the search tolerance (points $<->$ network), Select 'Cancel' for the default value (fornecido pelo programa)

Please enter the directory and filename for the resulting shapefile

Do you want to exclude 'A-A' paths - identical origin/destination? (yes)

Add new theme to view? (yes)

tempo gasto: $\sim 3$ horas

Para rodar a rotina de caminhos mínimos descrita foi utilizada uma rede de transportes com apenas 500 nós. O equipamento utilizado não comportava, em tamanho, os arquivos resultantes de redes maiores do que este limite. Utilizando-se uma rede como a dos exemplos anteriores, com aproximadamente 5000 nós, pode-se estimar que a rotina necessitaria de pelo menos 35 GB de espaço livre em disco rígido. Considerando-se ainda que o acréscimo de tempo seja proporcional ao tamanho da rede, seriam necessários sete dias de processamento para rodar a rede toda, o que certamente é inviável para fins práticos e, no caso desta avaliação em particular, a sua execução na íntegra sequer é necessária para se cumprir os objetivos da análise.

A rotina FastSNP10.avx adiciona um tema de linhas ao mapa e seu respectivo banco de dados, o qual representa todos os possíveis caminhos mínimos encontrados a partir de todos os pontos de origens para todos os pontos de destinos. O banco de dados resultante contém seis campos, sendo eles: shape (polilinha), ID da origem, ID do destino, rótulo de dados da origem, rótulo de dados do destino e custo (no caso, caminho mínimo). Nos outros dois programas, TransCAD e UfosNet, o resultado é apresentado sob a forma de uma matriz com igual número de linhas e colunas; no caso do ArcView, para uma rede com 500 nós, obteve-se uma tabela com 249.500 linhas.

De acordo com as análises já apresentadas o ArcView não trabalha com matrizes e não permite a geração de novas colunas em tabelas com aplicação de fórmulas, portanto foi necessária a exportação e manipulação dos dados obtidos em uma planilha eletrônica, no caso o programa MS Excel. Como a versão empregada do mesmo possuía um limite de linhas igual a 65.536, a exportação dos dados teve que ser realizada em partes, através de diversos arquivos.

- Exportação da tabela de caminhos mínimos para o formato *.txt; comandos utilizados: File $\Rightarrow$ EXPORT

opções: Export Format (Delimited Text)

Os procedimentos realizados no Excel foram resumidamente os seguintes:

- somatório das distâncias obtidas a partir de cada origem para todos os destinos;

- aplicação da fórmula para o cálculo da medida de acessibilidade (SUM/(N-1))

- importação da tabela obtida no Excel para o ArcView; comandos utilizados: no menu principal, opção Tables $\Rightarrow$ ADD

- união da tabela de atributos da camada de pontos de origem do mapa e a tabela obtida no Excel, com base na coluna de ID’s dos nós;

comandos utilizados: Table $\Rightarrow$ JoIN (mantendo selecionadas as colunas de ID's em ambas as tabelas) 
- construção do mapa temático de acessibilidade;

comandos utilizados: duplo clique no tema de pontos de origem para ativar a janela de editor de legenda (Legend Editor)

opções: Legend Type (Graduated Color)

Classification Field (Allen)

$\checkmark$ Classify

Type (Equal Interval)

Number of Classes (5)

$\checkmark$ Apply

\subsection{Síntese da Comparação das Características dos Programas}

Os três programas estudados apresentam-se muito semelhantes com relação aos itens avaliados como aspectos descritivos. Todos apresentam versões padrão Windows, com interface gráfica amigável, manuais de apoio e suporte ao usuário, atualizações constantes e possibilidade de customização.

O tempo de aprendizado inicial dos software TransCAD e UfosNet foi muito reduzido com a utilização dos tutoriais desenvolvidos por Silva et al. (1997), Silva e Waerden (1997) e Silva (org.) (1998). De forma semelhante, o manual ArcView GIS, The Geographic Information System for Everyone, Using ArcView GIS, fornecido pela ESRI (1996) é um excelente guia para o aprendizado do ArcView. Mais recentemente foi também produzido pela empresa um Tutorial, em CD-ROM, que embora não tenha sido aqui empregado, constatou-se que é ainda mais eficiente que o manual para o aprendizado inicial do ArcView. Apesar da relativa facilidade para o aprendizado básico, a descrição detalhada de todas as ferramentas disponíveis nos programas estudados requereu uma consulta minuciosa de todos os manuais fornecidos pelos respectivos fabricantes, o que consumiu um tempo considerável.

O check list das características operacionais básicas de SIG confirma a observação de que estas ferramentas devem estar presentes em qualquer software com o propósito de atuação como um SIG. Apenas alguns itens não foram encontrados nos programas, o que pode ser verificado na tabela 5.8, que sintetiza, em termos quantitativos, as tabelas 5.1, 5.2, 5.3, $5.4 \mathrm{e}$ 5.5 apresentadas anteriormente.

\begin{tabular}{||l|c|c|c|}
\hline Disponibilidade das Opções & TransCAD & UfosNet & ArcView \\
\hline \hline \multicolumn{3}{|c|}{ Quanto à modelagem dos dados } \\
\hline Opções disponíveis & 10 & 10 & 10 \\
\hline Opções não disponíveis & 0 & 0 & 0 \\
\hline \hline \multicolumn{4}{|c|}{ Quanto à linguagem de consulta } \\
\hline Opções disponíveis & 7 & 7 & 7 \\
\hline Opções não disponíveis & 0 & 0 & 0 \\
\hline \hline \multicolumn{2}{|c|}{ Quanto à geração de relatórios, importação e exportação de arquivos } \\
\hline \hline Opções disponíveis & 3 & 4 & 3 \\
\hline \hline Opções não disponíveis & 1 & 0 & 1 \\
\hline \hline
\end{tabular}




\begin{tabular}{|c|c|c|c|}
\hline \multicolumn{4}{|c|}{ Quanto à entrada de dados } \\
\hline Opções disponíveis & 7 & 6 & 4 \\
\hline Opções não disponíveis & 0 & 1 & 3 \\
\hline \multicolumn{4}{|c|}{ Quanto à edição de dados } \\
\hline Opções disponíveis & 9 & 6 & 6 \\
\hline Opções não disponíveis & 0 & 3 & 3 \\
\hline \multicolumn{4}{|c|}{ SÍNTESE } \\
\hline Opções disponíveis & 36 & 33 & 30 \\
\hline Opções não disponíveis & 1 & 4 & 7 \\
\hline
\end{tabular}

Tabela 5.8 - Avaliação quantitativa das características operacionais básicas de SIG disponíveis e não disponíveis nos programas avaliados

Com relação às rotinas avançadas de SIG, pode-se afirmar que os três software apresentam ferramentas para a solução da maioria dos itens listados. $\mathrm{Na}$ análise das rotinas específicas de transportes o ArcView deixa a desejar quando comparado com os demais, TransCAD e UfosNet. A seguir é apresentada uma tabela onde pode-se avaliar quantitativamente estas análises:

\begin{tabular}{||l|c|c|c|}
\hline Disponibilidade das Opções & TransCAD & UfosNet & ArcView \\
\hline \hline \multicolumn{5}{|c|}{ Rotinas Avançadas de SIG } \\
\hline Opções disponíveis & 14 & 12 & 13 \\
\hline \hline Opções não disponíveis & 1 & 3 & 2 \\
\hline \hline \multicolumn{5}{|c|}{ Rotinas Específicas de Transportes } \\
\hline Opções disponíveis & 16 & 13 & 1 \\
\hline Opções não disponíveis & 0 & 3 & 15 \\
\hline
\end{tabular}

Tabela 5.9 - Avaliação quantitativa das rotinas avançadas de SIG e específicas de transportes disponíveis e não disponíveis nos programas avaliados

A análise do problema proposto, envolvendo rotinas específicas para o cálculo de redes e matrizes com um grande número de dados, demonstrou que a obtenção de resultados satisfatórios e em tempo hábil depende diretamente da configuração do equipamento/computador que está sendo utilizado. Reforçando o que já foi mencionado no item 5.3.2.1 deste capítulo, quanto melhor a configuração do computador, mais rápido será o processamento dos dados. A seguir serão apresentadas as dificuldades e facilidades encontradas pela autora para a realização do cálculo da medida de acessibilidade nos programas estudados:

\begin{tabular}{||l|l|}
\hline \multicolumn{2}{|c|}{ Importação do mapa contendo a rede viária de São Carlos } \\
\hline TransCAD & Sem dificuldades, pois o mapa obtido foi criado no próprio TransCAD \\
\hline UfosNet & Foi necessária a ajuda do fabricante do software \\
\hline ArcView & Sem dificuldades, foi feita a importação direta através do TransCAD \\
\hline
\end{tabular}




\section{Identificação de ferramentas}

TransCAD $\quad$ Fácil e direta, os menus possuem ordem de apresentação lógica. Não necessitou de programação

\begin{tabular}{l|l}
\hline UfosNet & A identificação das ferramentas e inserção dos parâmetros e variáveis
\end{tabular}
necessárias exigem conhecimento prévio. Necessidade de programação

\begin{tabular}{|l|l|l|l}
\hline ArcView & Fácil identificação das ferramentas disponíveis, menor número de menus em
\end{tabular} relação aos demais, ausência de ferramentas necessárias a execução do problema. Necessidade de programação

\section{Facilidades de operação}

\begin{tabular}{|l|l|}
\hline TransCAD & Rápida regeneração de telas, atualização de dados e manipulação de arquivos. \\
\hline
\end{tabular} Permite aplicação de fómulas e edição dos bancos de dados

\begin{tabular}{l|l}
\hline UfosNet & A manipulação de matrizes é lenta, rápida regeneração do mapa. Permite
\end{tabular} atualização de dados através da aplicação de fórmulas e edição de dados

\begin{tabular}{l|l}
\hline ArcView & Edição e atualização do mapa extremamente lenta. Não permite a utilização
\end{tabular} de fórmulas na edição de bancos de dados

Tempo de processamento, espaço em disco rígido

\begin{tabular}{l|l}
\hline TransCAD & Rápido e coerente, necessidade de 1GB disponível
\end{tabular}

\begin{tabular}{|l|l|}
\hline UfosNet & Mais lento que o TransCAD, porém viável, necessidade de 1GB disponível \\
\hline A
\end{tabular}

\begin{tabular}{l|l}
\hline ArcView & Inviável para a rede em questão. Considerando-se uma evolução exponencial
\end{tabular} em relação ao número de dados processados, haveria a necessidade de pelo menos 35GB disponível

\begin{tabular}{|l|l|}
\hline \multicolumn{2}{|c|}{ Produto final } \\
\hline TransCAD & Satisfatório \\
\hline UfosNet & Satisfatório \\
\hline ArcView & Não satisfatório \\
\hline
\end{tabular}

Tabela 5.10 - Avaliação de dificuldades e facilidades na solução de um problema proposto

A seguir são apresentadas, para avaliação do resultado final, as telas resultantes dos mapas temáticos, os quais representam o resultado da medida de acessibilidade utilizada. 

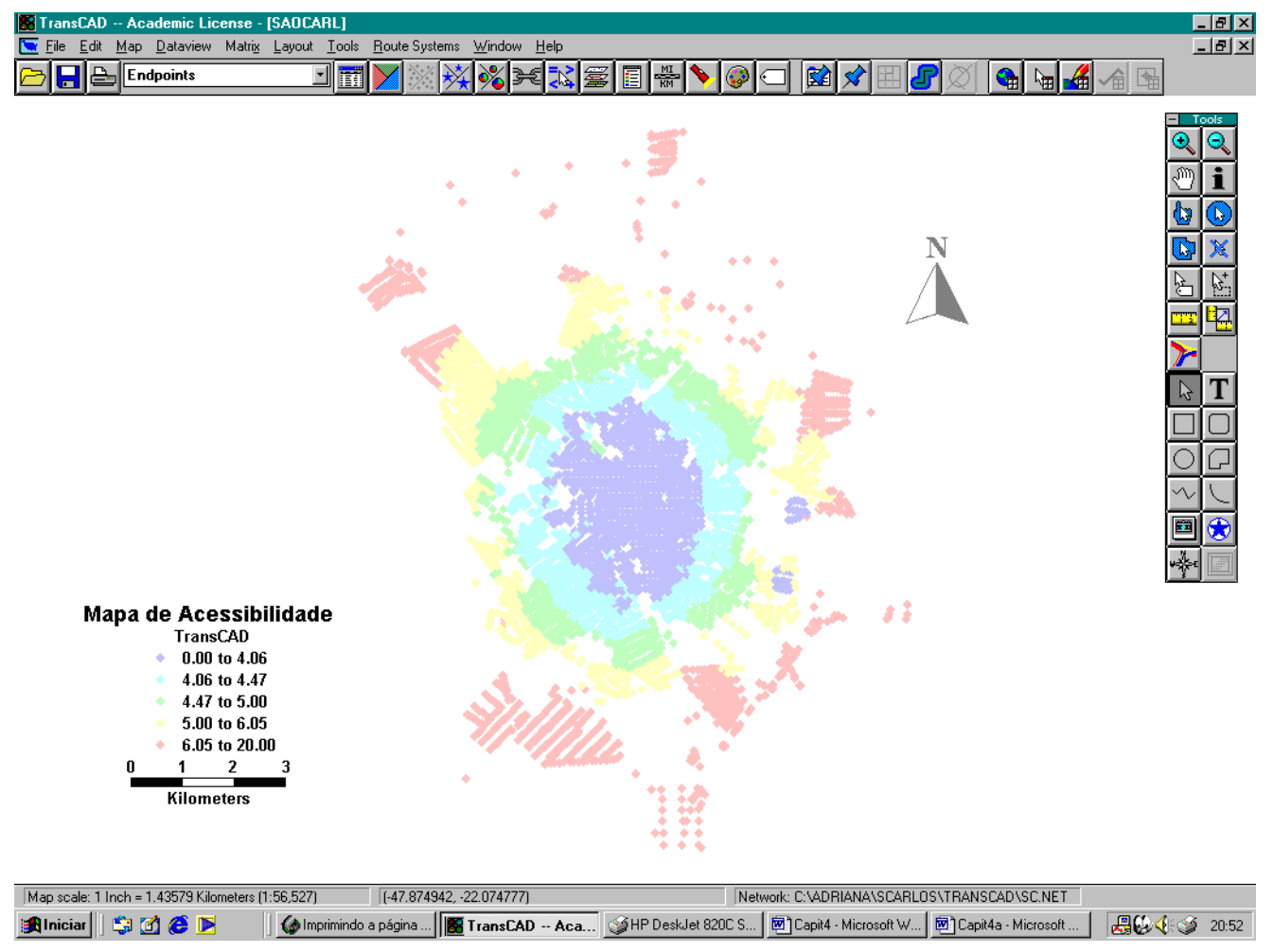

Figura 5.1 - Mapa Temático de Acessibilidade no TransCAD

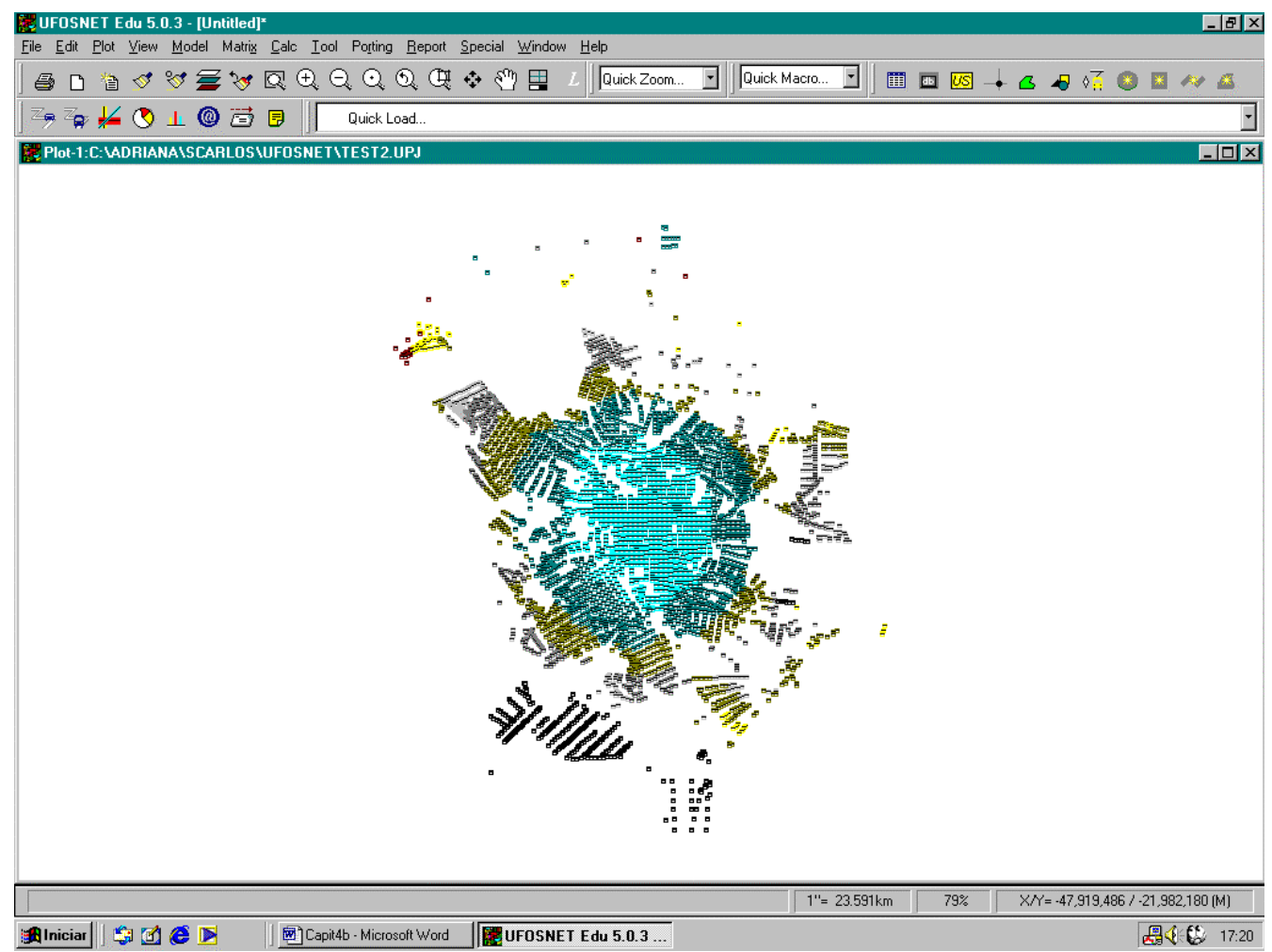

Figura 5.2 - Mapa Temático de Acessibilidade no UfosNet 

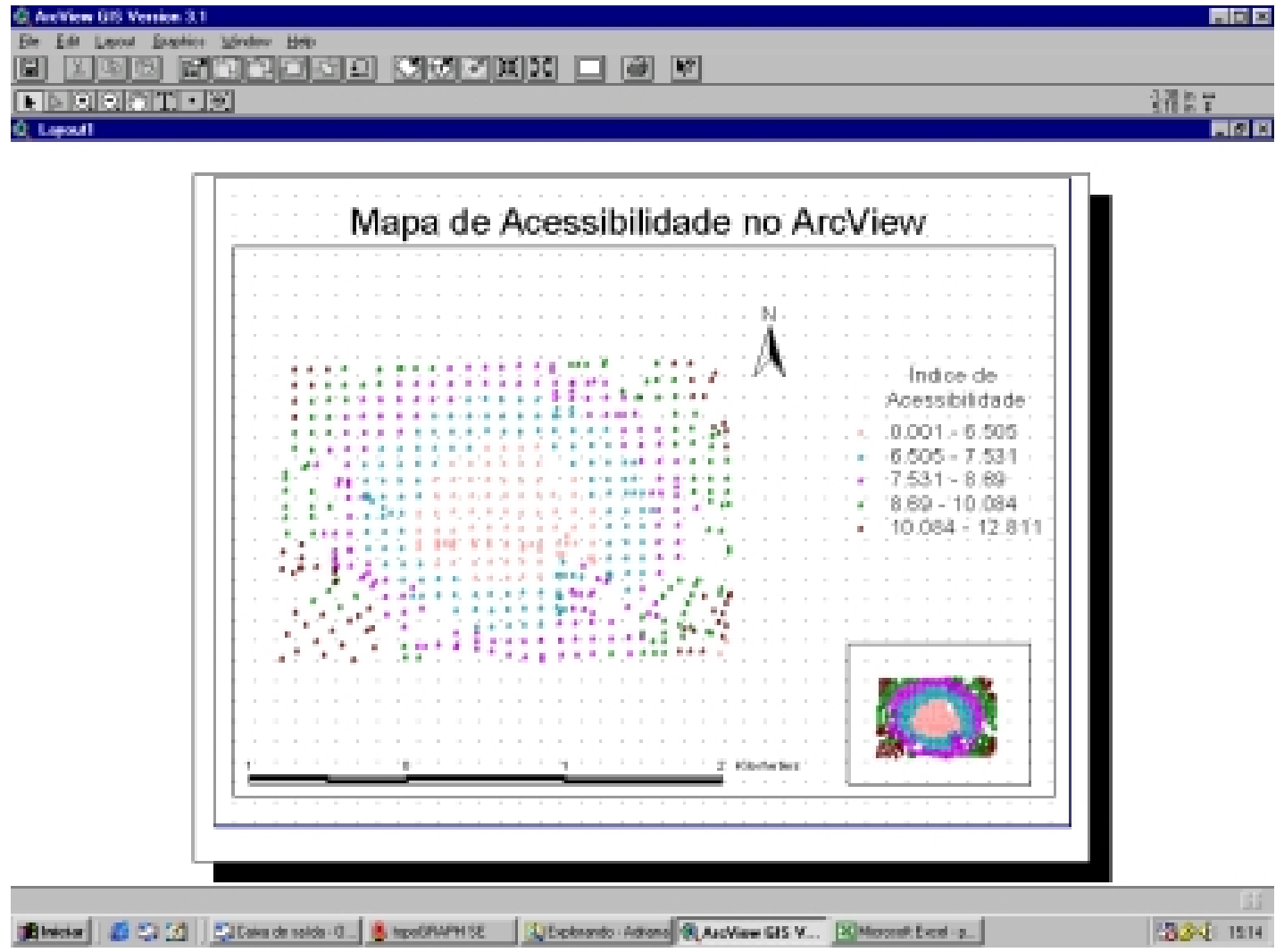

Figura 5.3 - Mapa Temático de Acessibilidade no ArcView

As poucas opções avançadas disponíveis no módulo básico e as dificuldades encontradas para a utilização do ArcView na solução do problema proposto apontavam claramente para uma série de limitações do uso do mesmo, de forma direta, como ferramenta para planejamento de transportes. Este quadro, no entanto, parece ter sido de alguma forma observado pelo fabricante, que promoveu uma alteração significativa do software na versão mais recente, inclusive com mudanças conceituais. A tabela 5.11, reproduzida de ESRI (2001), ilustra a dimensão das alterações introduzidas, através de uma comparação entre as ferramentas e conceitos antigos e os da atual versão: 


\begin{tabular}{|c|c|}
\hline SIS 3 & iew 8.1 \\
\hline \multicolumn{2}{|c|}{ ELEMENTOS CHAVE } \\
\hline terface com múltiplos documentos & Interface com um \\
\hline Project - Projeto (.c & Map Document - Documento do Map \\
\hline \begin{tabular}{|l}
$\rightarrow$ Organiza e armazena as informações de \\
vistas, tabelas, gráficos, leiautes e scripts
\end{tabular} & $\begin{array}{l}\rightarrow \text { Arquivo de representação de uma mapa que } \\
\text { armazena seus mapas, gráficos, tabelas e } \\
\text { macros }\end{array}$ \\
\hline View - Vista: & Data Frame - Estrutura dos dados: \\
\hline $\begin{array}{l}\rightarrow \text { Grupo de elementos (temas) que são } \\
\text { visualizados juntos. Têm sua própria tabela } \\
\text { de conteúdos (informações) e área de } \\
\text { visualização. }\end{array}$ & $\begin{array}{l}\rightarrow \text { Grupo de elementos (camadas) que são } \\
\text { visualizados juntos. Listados na tabela principal } \\
\text { de conteúdos e visualizados na área principal } \\
\text { de visualização. }\end{array}$ \\
\hline Table of Contents - Tabela de conteúdos: & Table of Contents - Tabela de conteúdos: \\
\hline$\rightarrow$ Lista os temas em uma vista individual. & $\begin{array}{l}\rightarrow \text { Lista a estrutura de dados com seus } \\
\text { respectivos níveis. }\end{array}$ \\
\hline Theme - Tema: & Layer-Camada: \\
\hline $\begin{array}{l}\rightarrow \text { Representa um conjunto de elementos do } \\
\text { mesmo tipo, tais como lagos ou rodovias. } \\
\text { Existem apenas dentro do projeto principal. }\end{array}$ & $\begin{array}{l}\rightarrow \text { Representa um conjunto de elementos do } \\
\text { mesmo tipo, tais como lagos ou rodovias. } \\
\text { Persiste independentemente da estrutura de } \\
\text { dados e pode ser compartilhado com outros } \\
\text { usuários. }\end{array}$ \\
\hline Chart-Gráfico: & Graph-Gráfico: \\
\hline $\begin{array}{l}\rightarrow \text { Representação gráfica da informação dos } \\
\text { elementos do mapa e as relações entre eles. } \\
\text { Os tipos mais comuns são: gráficos de } \\
\text { linhas, barras e pizza. }\end{array}$ & $\begin{array}{l}\rightarrow \text { Representação gráfica da informação dos } \\
\text { elementos do mapa e as relações entre eles. Os } \\
\text { tipos mais comuns são: gráficos de linhas, } \\
\text { barras e pizza. }\end{array}$ \\
\hline Layout - Leiaute: & Map in Layout View - Mapa em uma vista de \\
\hline $\begin{array}{l}\rightarrow \text { Arranjo de vistas e elementos do mapa } \\
\text { em uma página. As ferramentas de análises } \\
\text { geográficas não podem ser utilizadas em } \\
\text { leiautes, pois os elementos do mapa não } \\
\text { estão "vivos". São aceitos múltiplos leiautes. }\end{array}$ & $\begin{array}{l}\text { leiaute: } \\
\rightarrow \text { Arranjo da estrutura de dados e elementos } \\
\text { do mapa em uma página. As ferramentas de } \\
\text { análises geográficas podem ser utilizadas, pois } \\
\text { os elementos do mapa estão "vivos". Os } \\
\text { leiautes podem ser alterados dinamicamente } \\
\text { utilizando-se padrões do mapa. É aceito apenas } \\
\text { um leiaute. }\end{array}$ \\
\hline Avenue Script: & VBA Macro: \\
\hline $\begin{array}{l}\rightarrow \text { Macros escritas na linguagem de } \\
\text { programação Avenue. }\end{array}$ & $\begin{array}{l}\rightarrow \text { Macros escritas na linguagem de } \\
\text { programação Visual Basic for Applications. }\end{array}$ \\
\hline \multicolumn{2}{|c|}{ AÇÕES TÍPICAS } \\
\hline Select by Theme - Seleção por tema: & Select by Location - Seleção por lo \\
\hline $\begin{array}{l}\rightarrow \text { Seleciona elementos com base em sua } \\
\text { localização em relação a elementos de } \\
\text { outros temas. }\end{array}$ & $\begin{array}{l}\rightarrow \text { Seleciona elementos com base em } \\
\text { localização em relação a elementos de ol } \\
\text { camadas. }\end{array}$ \\
\hline
\end{tabular}




\begin{tabular}{|c|c|}
\hline ArcView GIS 3 & ArcView 8.1 \\
\hline \multicolumn{2}{|c|}{ ELEMENTOS CHAVE } \\
\hline SQL Select - Seleção SQL: & Select by Attribute - Seleção por atributo: \\
\hline $\begin{array}{l}\rightarrow \text { Seleciona elementos com base em seus } \\
\text { atributos. }\end{array}$ & $\begin{array}{l}\rightarrow \text { Seleciona elementos com base em seus } \\
\text { atributos. }\end{array}$ \\
\hline Convert to Shapefile - Converter em um & Data $>$ Export- Exportação de dados: \\
\hline $\begin{array}{l}\text { Shapefile: } \\
\rightarrow \text { Exporta os elementos selecionados como } \\
\text { um novo shapefile. }\end{array}$ & $\begin{array}{l}\rightarrow \text { Exporta os elementos selecionados como } \\
\text { uma nova camada. }\end{array}$ \\
\hline Add Theme - Adicionar um tema: & Add Data - Adicionar dados: \\
\hline$\rightarrow$ Adiciona um novo tema à vista ativa. & $\begin{array}{l}\rightarrow \text { Adiciona uma nova camada de dados à } \\
\text { estrutura de dados ativa. }\end{array}$ \\
\hline Promote - Promover: & Show Selected-Mostrar seleção: \\
\hline $\begin{array}{l}\rightarrow \text { Move registros selecionados para o topo } \\
\text { da tabela. }\end{array}$ & $\begin{array}{l}\rightarrow \text { Mostra apenas os registros selecionados em } \\
\text { uma tabela. }\end{array}$ \\
\hline
\end{tabular}

Tabela 5.11 - Alterações conceituais importantes introduzidas na versão mais recente do software ArcView 


\section{Conclusões}

Neste estudo foram desenvolvidas diversas análises comparativas envolvendo três Sistemas de Informação Geográfica aplicados aos transportes, TransCAD, ArcView e UfosNet. A primeira conclusão importante é que os três software atendem plenamente as condições necessárias para atuarem como um SIG. No entanto, analisando-se a particularidade do problema que o próprio título do trabalho exprime, comparação de SIG-T, observou-se que o ArcView não possui ferramentas adequadas e/ou suficientes para esta finalidade.

A metodologia aqui aplicada, que envolveu um levantamento minucioso de todas as ferramentas presentes nos programas estudados, demonstrou que, com relação aos aspectos descritivos analisados e às características operacionais básicas de SIG, TransCAD, UfosNet e ArcView, praticamente não diferem. Uma análise mais específica das rotinas avançadas de SIG envolveu a identificação das ferramentas necessárias à execução de algumas tarefas, tais como: realização de operações geométricas, aplicação de fórmulas, obtenção de caminhos mínimos, geração de curvas de nível, etc. Esta análise demonstrou que o UfosNet não permite a geração de modelos digitais do terreno e curvas de nível, em contrapartida gera desenhos de perspectivas envolvendo modelos 3D (três dimensões). O TransCAD e o ArcView-Spatial Analyst permitem a geração dos dois primeiros itens citados, mas não fazem desenhos de "perspectiva". Ainda, com referência às rotinas avançadas, observou-se que o ArcView não permite a edição e manipulação de bancos de dados, como os demais. Pode-se apenas alterar dados um a um e fazer consultas com aplicação de fórmulas simples para obtenção de conjuntos de seleção de dados. Em resumo, o ArcView realiza a maioria das tarefas presentes nos outros dois programas de uma forma mais simplificada.

O levantamento das rotinas específicas de transportes, sob a forma de check-list, evidenciou a afirmação do primeiro parágrafo deste texto. É importante observar que apesar do ArcView só apresentar ferramentas para análises de roteirização (módulo adicional Network Analyst) ele é um sofware comercialmente bem mais barato do que os demais, portanto mais acessível ao usuário. Vale lembrar, também, que todos os procedimentos necessários à análises de transportes, tais como execução das etapas de geração e distribuição de viagens, divisão modal, alocação de tráfego e sistemas de rotas, são extremamente complexos para quem os desenvolve, exigem um conhecimento específico do problema, técnicos especializados e muita pesquisa.

A solução do problema proposto, que consistia no cálculo de uma medida de acessibilidade, facilitou a análise direta de algumas ferramentas consideradas básicas na solução da maioria dos problemas de transportes, as redes e matrizes. Este proporcionou 
adicionalmente a possibilidade de avaliação das dificuldades encontradas na utilização e manipulação dos comandos básicos disponíveis em cada software, tais como: importação e exportação de arquivos, manipulação de bancos de dados, mapas e seus diversos layers. Como já foi comentado, o ArcView e o TransCAD apresentam maior facilidade de manipulação e identificação das ferramentas a serem utilizadas. $O$ UfosNet exigiu maior tempo de estudo, auxílio externo (por parte do autor do programa) e mais consultas ao capítulo 4 deste trabalho. Vale aqui abrir um parêntese para registrar a importância do capítulo 4 para melhor visualização das ferramentas presentes em cada programa, bem como para facilitar a identificação da sua localização nas telas de menus disponíveis. Este pode ser largamente utilizado por usuários dos software como auxílio na sua manipulação e rápida identificação do comando que se deseja utilizar e dos resultados através dele obtidos, tendo sido constantemente empregado para este fim durante a realização deste trabalho.

A utilização dos comandos de geração e manipulação de redes, matrizes, bancos de dados e visualização de dados em mapas temáticos foi plenamente satisfatória nos programas TransCAD e UfosNet, resultando no produto final esperado. Por outro lado, devido às restrições do ArcView não foi possível a análise completa dos dados. Mesmo trabalhando-se com apenas uma amostra destes, o produto final exigiu uma boa dose de criatividade e versatilidade para a solução do problema proposto. Importante constatação deu-se com relação aos itens tempo de processamento e tamanho dos arquivos gerados, o que acabou por inviabilizar a análise. Possivelmente a rotina FastSNP utilizada no ArcView não apresenta a mesma lógica de programação utilizada pelo TransCAD e UfosNet. Pode-se verificar que o objetivo da macro citada certamente não é o de trabalhar com um número tão elevado de nós, o que possivelmente levaria a uma solução através da utilização de matrizes, recurso que o software não possui .

Apenas para reforçar o conceito de SIG-T, vale observar o que afirmam Verma e Dhingra (2001) a respeito. Para eles, um SIG-T deve, em resumo, indispensavelmente realizar algumas funções, tais como: manipular atributos de links e nós para produzir novos atributos com aplicações em planejamento de transportes, editar dados espacialmente, importar dados raster (imagens) para visualização, realizar procedimentos de buffer e overlay, combinar buscas espaciais e questionamentos (queries), geocodificar endereços, criar e manipular matrizes, conduzir diferentes análises de caminhos mínimos e de roteirização de veículos e, por fim, realizar os passos necessários à modelagem do transporte urbano, o que envolve a geração/atração de viagens, distribuição de viagens, escolha modal e alocação de tráfego.

Baseando-se no exposto acima e nas inúmeras análises apresentadas no decorrer deste trabalho conclui-se que não podemos definir o software ArcView como um SIG-T, embora seja inegável que se trata de um excelente SIG, com ótima relação custo/benefício. Já o TransCAD e o UfosNet enquadram-se perfeitamente na configuração exigida para atuar com um SIG-T, embora isto represente um custo de aquisição muito maior.

Os programas computacionais aqui analisados tendem a ficar obsoletos em um curto espaço de tempo. Mas a análise aqui apresentada é de suma importância para trabalhos futuros e serve de referência aos usuários, tanto para identificação do programa mais adequado às suas necessidades como para auxílio na manipulação do mesmo. Em análises futuras, este trabalho poderia acompanhar as atualizações dos programas, podendo então ser constantemente consultado por usuários, potenciais usuários e, até mesmo, revendedores. 


\section{Referências Bibliográficas}

Alencar, V. C. e Aquino, M. S. (1994). Um sistema de informações geográficas para o planejamento de rotas de ônibus. In: $1^{\circ}$ GIS Brasil 94 - Congresso e Feira para Usuários de Geoprocessamento. Anais, Sagres Editora/Revista FATOR GIS, Curitiba, p. $1-9$.

Allen, W. B.; Liu, D.; Singer, S. (1993). Acessibility measures of U.S. Metropolitan Areas. Transportation Research. Part B, Methodological, 27(6): 439-50.

Antenucci, J. C. et al. (1991). Geographic Information System: a guide to the technology. New York, Van Nostrand Reinhold. 301p.

Bravo, F. e Cerda, J. (1995). Tecnologia SIG aplicada a sistemas de transporte. In: VII Congresso Chileno de Ingeniería de Transporte. Santiago, Chile. Actas del Séptimo Congreso Chileno de Ingeniería de Transporte, pp. 547-562.

Calijuri, M. L. e Röhm, S. A. (1993). Sistemas de Informações Geográficas. Universidade Federal de Viçosa - Imprensa Universitária, Minas Gerais.

Caliper (1996). TransCAD-Transportation GIS Software-User's Guide, Version 3.0 for Windows. Newton, Ma, Caliper Corporation.

Câmara, G. (1994). Anatomia de um SIG. Revista Fator GIS - A Revista do Geoprocessamento, 1(4): 11-15.

Dantas, A. S.; Taco, P. W. G.; Yamashita, Y. (1996). Sistemas de Informação Geográfica em Transportes. O Estudo do Estado da Arte. In: X Congresso de Pesquisa e Ensino em Transportes. Anais, Volume 1. Associação Nacional de Pesquisa e Ensino em Transportes - ANPET, Brasília, pp. 211-219.

Davis, C. (1998). Critérios para escolha de um GIS. Revisa InfoGEO, 1(1): 17-17.

ESRI (1996). ArcView GIS, The Geographic Information System for Everyone, Using ArcView GIS. United States of America, Environmental Systems Research Institute, Inc. Ferrari, R. (1997). Viagem ao SIG. Curitiba, Sagres. 
HCM 209 (1985). Highway Capacity Manual's planning method - Chapter 9.

Heikkila, E. J. (1998). GIS is Dead. Long Live GIS! APA Journal, summer 1998, pp. 350360.

Hsiao, S. e Sterling, J. (1992). Use of Geographic Information System for Transportation Data Analysis. In: Chow, J.; Litvin, D. M.; Opiela, K. S. (eds) (1992) American Society of Civil Engineers, New York. Microcomputers in Transportation, pp. 94-102.

Jong, T. e Ritsema van Eck, J. (1991). Funcionality of Geographical Information Systems with regard to Transportation Networks, Interaction and Location/Allocation: An Evaluation of 4 GIS-packages (em holandês). Universidade de Utrecht.

Kagan, H.; Rossetto, C. F.; Custódio, P. S.; Martins, W. C. (1992). Uso de Sistemas de Informação Geográfica no Planejamento de Transportes. In: VI Congresso de Pesquisa e Ensino em Transportes. Anais, Volume 1. Associação Nacional de Pesquisa e Ensino em Transportes - ANPET, Rio de Janeiro, pp. 892-909.

Kemp, Steven (1994). Introducing a Geographical Information System (GIS) in a Rapidly Changing Business Environment. The $22^{\text {nd }}$ European Transport Forum (The PTRC Summer Annual Meeting), Geographic Information System, 12-16 Setembro 1994, pp. 29-35.

Korte, G. B. (1997). The GIS Book, Fourth Edition. United States of America, OnWord Press.

Levine, J. e Landis, J. (1989). Geographic Information System for Local Planning. Journal of the American Planning Association 55,2: 209-20.

Lewis, S. (1990). Use of Geographical Information Systems in Transportation Modeling. ITE Journal, Março 1990, pp. 34-38.

Nazário, P. (1998). GIS: Definições e aplicações na logística. Revista Tecnologística, Outubro/98, pp. 16-21.

Paredes, E. A. (1994). Sistema de Informação Geográfica (SIG) - Princípios e Aplicações (Geoprocessamento). São Paulo, Érica.

Rosseto, C. F. e Cunha, C. B. (1994). A aplicação do geoprocessamento na roteirização de veículos. In: $1^{o}$ GIS Brasil 94 - Congresso e Feira para Usuários de Geoprocessamento. Anais, Sagres Editora/Revista FATOR GIS, Curitiba, p. 35-44.

RST (1997). Ufosnet 3.3 User's Guide. Washington, U.S.A., RST International, Inc. 
Silva, A. N. R. (1998). Sistemas de Informação Geográfica para Planejamento de Transportes. Trabalho apresentado para obtenção do título de Livre-Docente. Escola de Engenharia de São Carlos, Universidade de São Paulo, São Carlos.

Silva, A. N. R. (org.) (1998). Ferramentas Específicas de um Sistema de Informações Geográficas para Transportes. São Carlos, EESC-USP.

Silva, A. N. R.; Melo, J. J. O.; Brondino, N. C. M. (1997). Uma Introdução ao Planejamento de Transportes com Sistemas de Informação Geográfica. São Carlos, EESC-USP.

Silva, A. N. R e Waerden, P. V. D. (1997). First Steps with a Geographic Information System for Transportation. Ribeirão Preto, São Paulo.

Siqueira, C. A. B. e Cassundé, M. I. V. (1994). O geoprocessamento como instrumento de gestão de transporte coletivo na EMTU/Recife. In: $8^{\circ}$ Congresso de Pesquisa e Ensino em Transportes, ANPET. Anais, Vol. 1, Recife, pp. 551-556.

SOSSLAU, Arthur B. et al. Quick-response urban travel estimation techniques and transferable parameters - User's guide. Transportation Research Board, Washington, D.C., NCHRP Report 187, 1978, 229 p.

TRB 187 (1978). Quick Response Method - National Cooperative Highway Research Program Report 187, Transportation Research Board, National Research Council. Washington DC.

TRC 212. Transportation Research Circular 212's planning method.

Viviani, E.; Sória, M. H. A.; Silva, A. N. R. (1994). Gerenciamento de vias não pavimentadas e a utilização de sistemas de informação geográfica. In: $1^{o}$ Congresso Brasileiro de Cadastro Técnico Multifinalitário. Anais, Florianópolis, pp. 118-126.

Viviani, E. (1998). A Utilização de um Sistema de Informação Geográfica como Auxílio à Gerência de Manutenção de Estradas Rurais não-pavimentadas. Tese de Doutorado. Escola de Engenharia de São Carlos, Universidade de São Paulo, São Carlos.

Verma, A. e Dhingra, S. L. (2001). Study of GIS Applications to Transportation: A Compreensive Review.

Vonderohe, A. P; Travis, L.; Smith, R.; Tsai, V. (1994). Adapting Geographic Information Systems for Transportation. TR News 171, Março-Abril 1994, pp. 7-9.

Vonderohe, A. P., Fisher, S. S.; Krohn, D. K. (1990). A positional comparison of the results of two digital cadastral mapping methods. Surveying and Land Information Systems, v. 50, n. 1, pp. 11-24. 
Vonderohe, A. P. et al. (1993). Adaptation of Geographic Information Systems for Transportation. Washington: National Academy Press. 70p. (Report 359).

Waerden, P. van der; Timmermans, H. (1996). Transportation planning and the use of Transcad. Revista Transportes, pp. 25-37.

Waerden, P. van der; Timmermans, H. (1994). Parking Simulation Using a Geographical Information System. Paper presented at the $2^{\text {nd }}$ Design \& Decision Support Systems in Architecture \& Urban Planning Conference, Agosto 15-19 1994, Vaals, The Netherlands. 